ORNL-3679

Contrac No. W-7405-eng-26

\title{
CHEMISTRY DIVISION ANNUAL PROGRESS REPORT \\ for Period Ending June 20, 1964
}

E. H. Taylor, Director

M. A. Bredig, Associate Director

B. H. Ketelle, Assistant Director

\section{SEPTEMBER 1964}

\footnotetext{
OAK RIDGE NATIONAL LABORATORY

Oak Ridge, Tennessee

operated by

UNION CARBIDE CORPORATION

for the

U. S. ATOMIC ENERGY COMMISSION
} 


\section{DISCLAIMER}

This report was prepared as an account of work sponsored by an agency of the United States Government. Neither the United States Government nor any agency Thereof, nor any of their employees, makes any warranty, express or implied, or assumes any legal liability or responsibility for the accuracy, completeness, or usefulness of any information, apparatus, product, or process disclosed, or represents that its use would not infringe privately owned rights. Reference herein to any specific commercial product, process, or service by trade name, trademark, manufacturer, or otherwise does not necessarily constitute or imply its endorsement, recommendation, or favoring by the United States Government or any agency thereof. The views and opinions of authors expressed herein do not necessarily state or reflect those of the United States Government or any agency thereof. 


\section{DISCLAIMER}

Portions of this document may be illegible in electronic image products. Images are produced from the best available original document. 



\section{Summary}

\section{NUCLEAR CHEMISTRY}

A rare-earth isotope with a half-life of $13.5 \mathrm{~min}$ was discovered and identified as ${ }^{136} \mathrm{Pr}$. The ${ }^{136} \mathrm{Ce}$ energy levels populated by the decay of ${ }^{13}{ }^{6} \mathrm{Pr}$ were consistent with those expected for a 58-proton-78-neutron nucleus on the basis of the energy level systematics for even-even nuclei.

The energies (and relative intensities) of the two intense gamma rays from $38-\mathrm{min}{ }^{38} \mathrm{Cl}$ were measured as $1598 \pm 5 \mathrm{kev}(0.85 \pm 0.03)$ and $2166 \pm$ $5 \mathrm{kev}(1.00)$. The intensity of the $3760-\mathrm{kev}$ crossover transition in ${ }^{38} \mathrm{Ar}$ was found to be $(4.9 \pm 0.7) \times$ $10^{-4}$ relative to that of the $2166-\mathrm{kev}$ gamma ray.

The decay properties of $2.91-\mathrm{min}{ }^{90} \mathrm{Rb}$ were investigated by scintillation techniques. From single-crystal and gamma-gamma coincidence measurements, 23 gamma-ray transitions can be attributed to the depopulation of 11 excited states in ${ }^{90} \mathrm{Sr}$.

Some properties of even-even nuclei in the medium-weight region were surveyed. Distinct subshell effects were seen in the trends of such states as the first $2+$ vibrational level.

A three-crystal scintillation pair spectrometer was used to determine the following energies in Mev (and relative intensities) of gamma rays emitted in the decay of $8.8-\mathrm{min}{ }^{49} \mathrm{Ca}: 2.22 \pm 0.02$ $(0.40 \pm 0.08), 2.36 \pm 0.02(0.57 \pm 0.11), 3.10 \pm$ $0.02(100), 4.085 \pm 0.025(8.7 \pm 0.6)$, and $4.74 \pm$ $0.03(0.34 \pm 0.05)$. Each of these gamma rays depopulates a level in ${ }^{49} \mathrm{Sc}$ excited through beta decay from ${ }^{49} \mathrm{Ca}$.

Osmium-194 was observed to decay via a $52-k e v$ beta ray to a level in ${ }^{194} \mathrm{Ir}$ at $43.0 \pm 0.4 \mathrm{kev}$. The half-life of this nuclide was measured as $6.0 \pm$ 0.2 years.

The thermal-neutron activation cross section and resonance integral of stable ${ }^{106} \mathrm{Pd}, \sigma_{\text {th }}=0.29$ barn and $I_{0}=5.7$ barns, were obtained with an error of $\pm 10 \%$. A more precise determination than previously reported yielded for ${ }^{104} \mathrm{Ru}$ values of $\sigma_{0}=0.47, \sigma_{\text {th }}=0.48$, and $I_{0}=4.6$ barns.

A thermal-neutron capture cross section of ${ }^{105} \mathrm{Rh}$ of $\sim 2 \times 10^{4}$ and a resonance integral of $\cong 1.65 \times 10^{5}$ barns are reported. Irradiations of the calutron-enriched isotopes ${ }^{98} \mathrm{Ru},{ }^{99} \mathrm{Ru}$, ${ }^{100} \mathrm{Ru}$, and ${ }^{101} \mathrm{Ru}$ and subsequent mass analysis by means of the two-stage mass spectrometer yielded cross-section estimates for these nuclides.

By measuring the amount of ${ }^{243} \mathrm{Pu}$ formed in irradiations of ${ }^{242} \mathrm{Pu}$, a thermal-neutron capture cross section of $25 \pm 4$ and a resonance integral of $1280 \pm 60$ barns were determined for ${ }^{242} \mathrm{Pu}$. Very pure submicrogram samples of ${ }^{232} \mathrm{U}$ produced from ${ }^{23{ }^{1}} \mathrm{~Pa}$ were irradiated and mass spectrographically analyzed. A thermal (or subcadmium) neutron cross section of $78 \pm 4$ and a resonance integral of $280 \pm 15$ barns were measured for ${ }^{23} \mathrm{U}$.

By determining the amount of $21-\mathrm{min}{ }^{107} \mathrm{Rh}$ produced in irradiations of the 1.0 -year ${ }^{106} \mathrm{Ru}$ a thermal-neutron capture cross section of 0.35 and a resonance integral of 1.1 barns were found for ${ }^{106} \mathrm{Ru}$. These values are sufficiently low to signify a negligible neutron loss through poisoning in a nuclear reactor.

A measurement was made of the thermal-neutron capture cross section and resonance integral of the 9.0 -hour isomer of ${ }^{58} \mathrm{Co}$.

The alpha-to-beta emission branching ratio for ${ }^{249} \mathrm{Bk}$ was determined by alpha-particle spectroscopy to be $1.41 \pm 0.03 \times 10^{-5}$. The new value differs by almost $50 \%$ from an earlier one obtained by a less direct method.

The use of $2 \%$ acetylene in argon as a counting gas resulted in an improvement in resolution of gridded ion chambers used for alpha-particle spectroscopy. Resolutions of $0.28 \%$ (16 kev full width at half maximum) were obtained at counting geometries approaching $2 \pi$. 


\section{NUCLEAR AND INORGANIC CHEMISTRY OF SPECIAL ELEMENTS}

Work was undertaken to develop methods for determining protactinium species in HF solutions. The $\mathrm{TaF}_{6}{ }^{-}$and $\mathrm{TaF}_{7}{ }^{2-}$ ions formed by tantalum in $\mathrm{HF}$ solutions were identified by comparing the Raman spectra of crystalline $\mathrm{CsTaF}_{6}$ and $\mathrm{K}_{2} \mathrm{TaF}_{7}$ with spectra of the solutions. The Raman spectra of crystalline $\mathrm{Na}_{3} \mathrm{TaF}_{8}$ and $\left(\mathrm{NH}_{4}\right)_{3} \mathrm{TaOF}_{6}$ were also recorded. At low $\mathrm{HF}$ concentrations two unidentified tantalum species appear, one with a Raman line in the tantalum-oxygen stretch region and the other with a line in the tantalum-fluoride stretch region.

The specific activity and half-life of ${ }^{99} \mathrm{Tc}$ were redetermined by a liquid scintillation counting technique and found to be $3.75 \times 10^{4} \mathrm{dis} \mathrm{min}^{-1}$ $\mu \mathrm{g}^{-1}$ and $2.14 \times 10^{5}$ years, respectively, in good agreement with previous results using $4 \pi$ beta counting techniques.

A crystal-field analysis of the visible spectrum of rhenium trichloride in hydrochloric acid showed that the observed absorption bands are consistent with the trivalent rhenium being in tetrahedral coordination. A prediction of the visible spectrum of the corresponding technetium complex is given.

\section{ISOTOPE CHEMISTRY}

Selectivity and diffusion coefficients were determined for $\mathrm{Li}^{+}$and $\mathrm{Na}^{+}$in anhydrous solution with Dowex 50-X1, -X8, and -X16 ion exchange resins, and with ethylenediamine as the solvent.

Lithium isotopic separation factors were determined as a function of eluant concentration in ion exchangers Zeo-Karb and Dowex 50 with $\mathrm{HCl}$ as the eluant, and in Dowex 50 with ammonium acetate as the eluant. In each case the separation factors decreased as the concentration increased.

Studies were made of the exchange of boron between $\mathrm{BF}_{3}$ (gas) and the liquid $\mathrm{BF}_{3}$ coordination complexes of $\mathrm{Et}_{2} \mathrm{O}, \mathrm{Et}{ }_{2} \mathrm{~S}, \mathrm{Et}{ }_{3} \mathrm{~N}$, and $\mathrm{THF}^{3}$. Isotopic equilibrium constants and thermodynamic functions characterizing these reactions were obtained.

New adducts useful in the separation of boron isotopes were sought. Boron trifluoride and $\mathrm{BCl}_{3}$ were added to thiophenol, diphenyl sulfide, diphenyl methyl amine, $N N$-dimethyl aniline, and methyl isocyanide. The resulting molecular addition compounds are described.
The single-stage separation factors for ${ }^{13} \mathrm{C} /{ }^{12} \mathrm{C}$ and ${ }^{18} \mathrm{O} /{ }^{16} \mathrm{O}$ were determined for diethylamine carbamate and n-propylamine carbamate in equilibrium with an excess of $\mathrm{CO}_{2}$ at the boiling point of the respective carbamates. It was shown that the carbon isotope separation factors for these systems are strongly temperature dependent but relatively insensitive to the molecular weight or degree of branching of the constituent amine.

Operation of the Oxygen-17 Facility continued without major interruptions during this report period. Currently, peak concentrations of ${ }^{17} \mathrm{O}$ and ${ }^{18} \mathrm{O}$ are $4.3 \%$ and $99.6 \%$ respectively. Isotopically enriched water valued at more than $\$ 70,000$ has been placed in inventory.

The nitrogen isotope effect in the decomposition of aryl diazonium ion, $\operatorname{ArNN}^{+}$, to $\mathrm{N}_{2}$ is 1.0531 at $6.9,1.0451$ at 40.5 , and 1.0426 at $68.5^{\circ} \mathrm{C}$.

The fundamental frequencies for the ${ }^{14} \mathrm{~N}$ and ${ }^{15} \mathrm{~N}$ species of $\mathrm{C}_{6} \mathrm{H}_{5} \mathrm{NNBF}_{4}$ are $455 / 451,533 / 526$, and $1152 / 1139 \mathrm{~cm}^{-1}$. The predicted isotope effects for decomposition of diazo salts are 1.0389 at $6.9^{\circ} \mathrm{C}, 1.0352$ at $40.5^{\circ} \mathrm{C}$, and 1.0327 at $68.5^{\circ} \mathrm{C}$.

The single-stage separation factor for potassium isotopes in the system aqueous metal hydroxidemetal amalgam was determined to be $1.0006 \pm$ 0.0004 for ${ }^{39} \mathrm{~K}$ and ${ }^{41} \mathrm{~K}$. The heavy isotope concentrates in the aqueous phase.

A CsF pellet pressed at 55 tons/in. ${ }^{2}$ was found to transmit in the infrared with no cutoff evident out to $250 \mathrm{~cm}^{-1}$.

The rate of exchange of $\mathrm{BF}_{3}$ between $\left(\mathrm{C}_{2} \mathrm{H}_{5}\right)_{2} \mathrm{O}$. $\mathrm{BF}_{3}$ and $\mathrm{C}_{6} \mathrm{H}_{5} \mathrm{OCH}_{3} \cdot \mathrm{BF}_{3}$ in a mixture of $\left(\mathrm{C}_{2}^{2} \mathrm{H}_{5}^{5}\right)_{2}^{2} \mathrm{O}$, $\mathrm{C}_{6} \mathrm{H}_{5} \mathrm{OCH}_{3}$, and $\mathrm{BF}_{3}$ was found to follow the rate law

$$
\begin{aligned}
R=k_{1}\left[\left(\mathrm{C}_{2} \mathrm{H}_{5}\right)_{2} \mathrm{O} \cdot \mathrm{BF}_{3}\right]\left[\mathrm{C}_{6} \mathrm{H}_{5} \mathrm{OCH}_{3} \cdot \mathrm{BF}_{3}\right] \\
+k_{2}\left[\left(\mathrm{C}_{2} \mathrm{H}_{5}\right)_{2} \mathrm{O} \cdot \mathrm{BF}_{3}\right]\left[\mathrm{C}_{6} \mathrm{H}_{5} \mathrm{OCH}_{3}\right] .
\end{aligned}
$$

In a mixture containing $\left(\mathrm{C}_{2} \mathrm{H}_{5}\right)_{2} \mathrm{O}$, tetrahydrofuran, and $\mathrm{BF}_{3}$, a similar expression plus a third term, $k_{3}\left[\left(\mathrm{C}_{2} \mathrm{H}_{5}^{3}\right)_{2} \mathrm{O}\right] /\left[\left(\mathrm{C}_{2} \mathrm{H}_{5}\right)_{2} \mathrm{O} \cdot \mathrm{BF}_{3}\right]$, is needed to fit the experimental data. In completely complexed mixtures of $\mathrm{BF}_{3},\left(\mathrm{C}_{2} \mathrm{H}_{5}\right)_{2} \mathrm{O}$, and a second ether or thioether, the stronger the second $\mathrm{BF}_{3}$ complex, the slower is the $\mathrm{BF}_{3}$ exchange between the two addition compounds.

Nuclear magnetic resonance data are given for $\mathrm{ClF}_{5}$ and $\mathrm{FClO}_{2}$. 
All the fundamental vibrational frequencies of the chloryl fluoride $\left(\mathrm{ClO}_{2} \mathrm{~F}\right)$ molecule were observed in the Raman spectra. The chlorine and oxygen isotopic structures of many of the fundamental, overtone, and combination bands were resolved. Valence force constants were calculated which closely reproduce the observed fundamental frequencies and their isotopic shifts. The infrared and Raman spectra of the square pyramidal molecules $\mathrm{XeOF}_{4}, \mathrm{IF}_{5}, \mathrm{BrF}_{5}$, and $\mathrm{ClF}_{5}$ were recorded, and valence force constants were calculated. The remarkable resemblance between the xenon compound and the interhalogen compounds is pointed out.

Thermodynamic functions were computed for the isotopic reaction occurring when light and heavy water are mixed. Excess functions for liquid mixtures of the isotopic forms of water were also derived.

\section{RADIATION CHEMISTRY}

A series of reactions to explain the role of $\mathrm{CO}$ as a sensitizing agent in the radiation-induced synthesis of water was postulated. The same scheme (omitting the reactions involving $\mathrm{CO}_{2}$ ) is applicable to the nonsensitized reaction. Rate equations were derived from these mechanisms, and rate constants were calculated. The constants for both reactions are 7.3 curie $^{-1}$. Carbon dioxide appears to enter into the mechanism even though no $\mathrm{CO}_{2}$ is consumed in the overall reaction.

An induction period in methane radiolysis due to the presence of oxygen in the methane is described. Yields ( $G$ values) for oxygen consumption were measured and ethylene production was observed. After the induction dose, or in its absence, $G\left(\mathrm{C}_{2} \mathrm{H}_{6}\right)=2.36 \pm 0.12$ and $\mathrm{G}\left(\mathrm{C}_{3} \mathrm{H}_{8}\right)=0.54 \pm 0.03$ molecule/100 ev. The role of ethylene in methane radiolysis was studied by irradiation of methane containing added $\mathrm{O}_{2}, \mathrm{C}_{2} \mathrm{H}_{4}$, or $\mathrm{C}_{2} \mathrm{H}_{2}$, With added oxygen, the ethylene yield in methane radiolysis was $\mathrm{G}\left(\mathrm{C}_{2} \mathrm{H}_{4}\right)=0.83 \pm 0.01$ molecule $/ 100$ ev. With added acetylene, about $40 \%$ of the acetylene consumption leads to ethylene formation and the much higher ethylene yields are not indicative of the ethylene yield from methane itself.

The radiolysis of condensed methane at 77 and $90^{\circ} \mathrm{K}$ was studied. Yields of ethane, hydrogen, propane, and butane were much less than in gas- phase radiolysis. Methane containing added ethylene or acetylene was irradiated to determine $G$ values for their consumption at $90^{\circ} \mathrm{K}$ and their effect on product yields. From the polymer yield determined by others, the $G$ value for methane disappearance at $77^{\circ} \mathrm{K}$ is estimated to be only 5.4 molecules $/ 100$ ev compared with gas-phase values of 8 to 9 at room temperature.

In the radiolysis of water, experimental evidence was obtained for reaction, in the spur, of solute with electronically excited water molecules. A new diffusion model is proposed.

The effect of formic acid on the photochemical reduction of ceric ion yielded further evidence for the $\mathrm{OH}$ radical as an intermediate and for reaction of $\mathrm{OH}$ radical with sulfuric acid.

Study of the radiolysis of aqueous sulfuric acid solutions consisted of three parts: (1) the determination of the reasons why ceric ion solutions purged with helium during irradiation give lower cerous ion yields than solutions simply saturated with helium, (2) the development of an analytical procedure for the analysis of micromolar concentrations of cerous ions, and (3) some aspects of the cerium-thallium system.

The effects of LET (linear energy transfer), or track effects, on the radiolysis of several solids were studied. Yields were compared for irradiation by gamma rays and alpha particles in the production of $\mathrm{ClO}^{-}, \mathrm{ClO}_{2}{ }^{-}$, and $\mathrm{ClO}_{2}$ from sodium chlorate and of $\mathrm{NO}_{2}{ }^{-}$from ammonium nitrate and in the production of color in polystyrene and polymethylmethacrylate. The annealing behavior was also studied.

The radiolytic decomposition of anhydrous calcium and barium bromates by ${ }^{60} \mathrm{Co}$ gamma rays was investigated. The bromate decomposition in the calcium salt increased nonlinearly with radiation dose up to ca. $7 \times 10^{23} \mathrm{ev} / \mathrm{mole}$. Bromine oxidation states intermediate between bromate and bromide were produced; the yield of these also was nonlinear with increasing dose. The production of bromide ion showed that following an initial increase, the rate of formation appeared to become and remain approximately constant. Initial 100-ev radiolytic yields were estimated to be: $G_{0}\left(-\mathrm{BrO}_{3}^{-}\right)=2.24, G_{0}\left(\mathrm{Br}^{-}\right)=0.44$, and $G_{0}($ (Ox") $=1.80$. The average oxidation number of the oxidizing fragments decreased from an initial value of 3.5 to a constant value of 2.05 after approximately 0.5 mole \% decomposition. 
The extent of the radiolysis of $\mathrm{BrO}_{3}-$ ion in $\mathrm{Ba}\left(\mathrm{BrO}_{3}\right)_{2}$ was observed to increase with the temperature at which the salt was dried in a vacuum prior to irradiation. This effect is thought to be due to a phase transition as indicated by DTA studies.

The initial $G$ value for the decomposition of $\mathrm{BrO}_{3}{ }^{-}$ion by ${ }^{6} \mathrm{Li}$ fission recoil particles was found to be 1.48 , and the corresponding value for oxidizing fragment production $\left(\mathrm{BrO}_{2}^{-}+\mathrm{BrO}^{-}\right)$ 1.1 molecules $/ 100 \mathrm{ev}$. These values are five times larger than those of ${ }^{60} \mathrm{Co}$ gamma rays indicating a large LET effect, but no change in the radiolytic mechanism. The yields remained unchanged for a tenfold increase in the dose rate.

Irradiations in the Bulk Shielding Reactor of molten lithium nitrate containing 1.0 at. $\%{ }^{6} \mathrm{Li}$ for periods varying up to $2 \mathrm{hr}$ showed that: (1) nitrite and oxygen are the primary decomposition products and these are produced in a stoichiometric ratio of approximately 2 to 1 ; (2) the initial $G$ values for the production of nitrite and oxygen are 5.4 and 2.3 , respectively, or about 25 times greater than for solid-state irradiations at $40^{\circ} \mathrm{C}$; (3) the decomposition vs dose curves are nonlinear and give lower $G$ values at higher doses; and (4) greater than $99.9 \%$ of the gaseous decomposition products are released from the molten salt. A maximum fission dose of $7 \times 10^{23} \mathrm{ev} /$ mole was absorbed in the $2-$ hr irradiation period.

\section{ORGANIC CHEMISTRY}

No isotope effect was observed in the reaction between o-tolualdehyde, labeled in the methyl group with ${ }^{14} \mathrm{C}$, and 2,4-dinitrophenylhydrazine.

The chemical shifts of the hydroxylic protons, recorded in the nuclear magnetic resonance spectra of-several pairs of diastereoisomeric 1,2-glycols, were correlated with the configurations of the compounds.

Carbon-14 labeling was used to study the mechanism of the thermal decarboxylation of the iron salts of fatty acids and of mixed fatty acids and iron benzoate. The data are consistent with a mechanism that involves a six-membered cyclic intermediate. The reaction affords a convenient route for the synthesis of labeled alkyl phenyl ketones.

Irradiation, with unfiltered ultraviolet light, of aroyl cyanides was found to produce benzils. The study was extended to determine the generality of the reaction. Aroyl chlorides were shown to inhibit benzil formation and to promote the formation of an unstable addition compound, which may be an intermediate in the formation of benzil during the normal irradiation procedure.

3-endo-Amino-2-endo-phenylnorborneol and 3endo-amino-2-exo-phenylnorborneol were prepared and subjected to deaminating conditions. Several products are formed from both reactants, and five of these from the latter aminoalcohol were isolated and purified. One compound, 3-cyclohexenyl phenyl ketone, was identified as a reaction product from the deamination of both aminoalcohols studied.

The 2,4-dinitrobenzenesulfenate esters of erythro and threo-3-phenyl-2-butanol-1- ${ }^{14} \mathrm{C}$ were subjected to chlorinolysis both in acetic acid and in chloroform solutions. Optically active as well as racemic samples were studied. The products were identified, and in certain cases the distributions of the ${ }^{14} \mathrm{C}$ labels were determined. Whenever possible the degree of optical purity of each product was observed. From these data a mechanism for the chlorinolyses was established, which includes ion-pair intermediates.

The rearrangement of 2-phenylnorbornane-2,3-cisexo-diol (VI) in concentrated sulfuric acid at $0^{\circ} \mathrm{C}$ was found to take place with intramolecular migration of hydrogen from $\mathrm{C}-3$ to $\mathrm{C}-2$. Rearrangement of the norbornane carbon skeleton also occurs, with an accompanying 6,1-shift of hydrogen. The configuration of the product, 3-endo-phenyl-2norbornanone (VII), is inverted with respect to the configuration of reactant (VI). The results, attained with tritium, ${ }^{14} \mathrm{C}$, and stereochemical studies, can best be accommodated by assuming nonclassical carbonium ion intermediates.

A series of amides was prepared and tested for the solvent extraction of uranium and thorium. Dramatic differences in the selectivity of uranium over thorium were detected in those $N, N$-dialkyl amides that contained three groups on the alpha carbon atom. The distribution coefficients for uranium varied inversely with the size of the alkyl groups on the nitrogen atom.

Dibutyl dimethylphosphoramidate was hydrolyzed with scission of the $\mathrm{P}-\mathrm{N}$ bond in heterogeneous systems when a solution was passed over a cation exchange resin in the hydrogen form or when a hexane solution of the amidate was equilibrated with aqueous hydrochloric acid. The hexane solution of the amidate was not hydrolyzed when equilibrated with distilled water. 
Triallyl phosphate, an ester of an unsaturated alcohol, when tested as the stationary liquid phase for the separation of alkanes and alkenes, was found to perform like triethyl phosphate which gave better resolution of butene-1, cis- and transbutene-2, and 1,3-butadiene than did tributyl phosphate.

\section{CHEMISTRY OF AQUEOUS SYSTEMS}

Measurements of the emf of the cell

$$
\mathrm{Pt}-\mathrm{D}_{2}(p)|\mathrm{DCl}(m)| \mathrm{AgCl}, \mathrm{Ag}
$$

were used to determine the thermodynamic properties of $\mathrm{DCl}$ solutions in $\mathrm{D}_{2} \mathrm{O}$ as well as the standard potential of the cell to $225^{\circ} \mathrm{C}$. The standard potential was found to be lower in the deuterated system than in the corresponding protonated system and the difference became greater the higher the temperature. Activity coefficient behavior in the two systems is consistent with a lower value of the dielectric constant of $\mathrm{D}_{2} \mathrm{O}$ at all temperatures. As judged from the variation of activity coefficients with temperature and concentration the difference in the dielectric constant values appears to go through a minimum at about $100^{\circ} \mathrm{C}$.

Four methods for inverting large symmetric positive definite matrices were compared. These are the Gauss-Jordan, Choleski, congruent transformation, and rank annihilation methods. An attempt has been made to consider the effects of both condition and order of the matrix to be inverted on the closeness of the computed inverse to the exact inverse. Each method was programmed in IBM 7090 FORTRAN II (version 2) using only single-precision arithmetic. Then the error indicators were computed using double-precision arithmetic so that the latter calculation was not a limiting factor. It was found that any one of the methods is satisfactory for a well-conditioned least-squares matrix of order 10-30. However, when the matrix becomes ill-conditioned then the Gauss-Jordan method appears to be clearly superior (at least for the matrices studied).

An improved cell assembly for the standard Cary model 14 spectrophotometer provides for routine measurements of fluid and frozen samples from -80 to $280^{\circ} \mathrm{C}$ and 0 to 2000 psia. It operated flexibly and trouble-free for more than 100 runs in studies with a number of pure solvents.
Seven of nine principal bands which occur in $\mathrm{CO}_{2}$ in the condensed states between 1.19 and $1.66 \mu$ were identified. The effects of temperature were measured in a frozen sample from $-80^{\circ} \mathrm{C}$ and 13 psia to the freezing point $\left(-56.6^{\circ} \mathrm{C}\right.$ and 75 psia), in the liquid from the freezing point to the critical point $\left(31.1^{\circ} \mathrm{C}\right.$ and $\left.1072 \mathrm{psia}\right)$, and in the gas from the critical point up to $65^{\circ} \mathrm{C}$ and about 2000 psia.

From equilibrium ultracentrifugation, acidity measurements, and comparison of Raman spectra of solutions and solids of known structure, it is concluded that the main polyanionic species formed on addition of acid to tungstate solutions (up to 1.5 moles of acid per mole of $\mathrm{WO}_{4}{ }^{2-}$ ) are $\mathrm{HW}_{6} \mathrm{O}_{21}{ }^{5-}, \mathrm{W}_{12} \mathrm{O}_{41}{ }^{10-}$, and $\mathrm{W}_{12} \mathrm{O}_{39}{ }^{6-}$. Equilibrium ultracentrifugation and comparison of Raman spectra indicate that the species $\mathrm{Ta}_{6} \mathrm{O}_{19}{ }^{8-}$ predominates in basic $\mathrm{Ta}(\mathrm{V})$ solution. Evaluation of equilibrium ultracentrifugation for determination of activity coefficients in three-component aqueous solutions was completed; it appears that the technique may be of value in some of such cases.

A general treatment for the electrostatic potential of a water molecule led to the result that, energetically at least, hydrogen-bonded structures in liquid water can be compatible with the hydration requirement for small positive ions. Possible consequences and experimental investigations are suggested.

Apparatus for the rapid high-precision measurement of the densities of aqueous solutions was completed. Preliminary measurements on $\mathrm{NaCl}$ solutions gave excellent agreement with previous work.

The osmotic coefficients of the pure lithium, sodium, potassium, and cesium salts of p-ethylbenzene sulfonic acid ( $p$-EBS) were measured as a function of concentration at $25^{\circ} \mathrm{C}$ by the isopiestic vapor pressure method. $p$-Ethylbenzene sulfonic acid is the monomer unit of the Dowex 50 cation exchange resins and, as such, is expected to be a useful model compound.

At any given concentration in the range studied, the osmotic coefficients of the alkali-metal salts of $p$-EBS follow the order $\mathrm{Li}>\mathrm{Na}>\mathrm{K}>\mathrm{Cs}$, which is the usual sequence for most alkali-metal salts. The ionic selectivities observed with polystyrene sulfonic acid cation exchangers (i.e., Dowex 50) also follow this trend (e.g., cesium is preferred over sodium, etc.). 
Selectivity coefficients and heats of exchange were measured for the exchange of $\mathrm{Li}^{+}$and $\mathrm{Cs}^{+}$on a lightly cross-linked polymethacrylic acid type cation exchanger. The thermodynamic quantities calculated at $25^{\circ} \mathrm{C}$ for the uptake of the preferred ion $\left(\mathrm{Li}^{+}\right)$are $\Delta F^{\circ}=-107 \mathrm{cal}, \Delta H^{\circ}=+374 \mathrm{cal}$, and $\Delta S^{\circ}=+1.6 \mathrm{eu}$.

Spectrophotometric measurements made on a liquid cation exchanger, prepared by dissolving dinonyl naphthalene sulfonic acid in toluene, and on a cross-linked polystyrene sulfonate exchanger after equilibration with solutions of $\mathrm{Fe}$ (III) in concentrated $\mathrm{LiBr}$ or $\mathrm{HBr}$ solutions showed the presence of the tetrahedral anion $\mathrm{FeBr}_{4}{ }^{-}$.

The heats of dilution of polystyrene sulfonic acid and of its lithium, sodium, potassium, and cesium salts were measured. Initial concentrations ranged from 0.04 equivalent per kilogram of $\mathrm{H}_{2} \mathrm{O}$ to 12 equivalents $/ \mathrm{kg}$ with the final concentration about $1 \times 10^{-3}$ equivalent $/ \mathrm{kg}$.

Ion exchange studies in both dilute and concentrated $\mathrm{HCl}$ and $\mathrm{HClO}_{4}$ solutions were continued. Cation exchange behavior was summarized in two "periodic tables" which were published. Distribution coefficients for cation exchange in $9 \mathrm{M} \mathrm{HCl}-\mathrm{HClO}_{4}$ mixtures are given as a function of the $\mathrm{HCl}$ fraction for a large number of elements showing an enormous variability in adsorbability which can form the basis of numerous separations. Activity coefficient ratios $\Gamma=\gamma_{ \pm(r)} / \gamma_{ \pm}$of $\mathrm{HCl}$ and $\mathrm{HClO}_{4}$ were found to be approximately unity in the acid concentration region of 1 to $16 \mathrm{M}$. A large difference in adsorbability of $\mathrm{In}$ (III) in $\mathrm{HBr}$ from that in $\mathrm{HCl}$ is discussed.

Work continued on the development of a general separations scheme for the elements based principally on ion exchange. Several examples of cation and anion exchange methods are mentioned, which include separation of trace amounts of neptunium and niobium from macroamounts of zirconium, separation of uranium, neptunium, and plutonium from each other and from many nonadsorbable elements, the recovery of $\mathrm{UX}_{1}\left({ }^{234} \mathrm{Th}\right)$ from uranyl nitrate solution, and others.

\section{ELECTROCHEMICAL KINETICS AND ITS APPLICATION TO CORROSION}

The kinetics of the exchange of various anions for ${ }^{51} \mathrm{Cr}(\mathrm{VI})$ in the film on passive iron, chromium, and stainless steel was studied. The exchange process was found to be complex in all cases investigated.

Iron dissolution in noninhibiting media was interpreted in terms of a mechanism which takes formal account of the simultaneous adsorption of water molecules, hydroxyl ions, and a reaction intermediate, and which provides a basis for the interpretation of the effects of adsorbed inhibitors on iron dissolution kinetics.

The anodic dissolution of crystal-bar zirconium in aqueous solutions containing $\mathrm{HF}$ and $\mathrm{H}_{2} \mathrm{SO}_{4}$ or $\mathrm{HNO}_{3}$ was investigated with a rotating-disk electrode system. Reaction orders and rate constants were evaluated by measuring the current at constant potential as a function of concentration and rotational velocity of the disk. On the assumption that the reaction mechanism involves adsorption of $\mathrm{HF}$ and $\mathrm{SO}_{4}{ }^{2-}$, a kinetic equation was derived which describes the results.

\section{NONAQUEOUS SYSTEMS AT HIGH T EMPERATURES}

In pursuance of the study of mixtures of metals with molten salts, the electrical conductivity and cryoscopic behavior of the solutions of the alkaline-earth metals strontium and barium in their respective chlorides, bromides, and iodides were determined. Strontium was shown to behave similarly to calcium and to sodium. The decrease in metal solute conductivity with increasing metal concentration indicates the trapping of mobile electrons in pairs in the form of alkaline-earth molecule ions, $\mathrm{M}_{2}{ }^{2+}$, analogous in electronic structure to the diatomic sodium molecules, $\mathrm{Na}_{2}$. Barium metal solutions, however, resemble the potassium systems with less stable $\mathrm{K}_{2}\left(\mathrm{Ba}_{2}{ }^{2+}\right)$ in showing high metal solubility and an increase in solute conductivity with solute concentration. Correlation of electronic conductivity with the product of electron and metal ion concentrations is discussed.

The phase diagrams of the systems barium bromide (or iodide)-barium metal were determined. Miscibility of salt and metal is much greater than in calcium systems. It increases in going from the chloride via the bromide to the iodide system in correspondence with the decrease in the interionic binding force with increasing size of the halide ion. The critical solution temperature drops from 1018 to $960^{\circ} \mathrm{C}$ and to $914^{\circ} \mathrm{C}$ respec- 
tively. The solubility of the metal in the salt at the consolute temperatures increases from 54 to 62 and 70 mole \%, as expected from the increase in the molar volume of the salt.

The solubility of calcium metal in solid calcium fluoride was found to increase to slightly more than 2 mole $\%$ metal on reaching the monotectic temperature of $1290^{\circ} \mathrm{C}$. These data allow an interpretation of the $\mathrm{CaF}_{2}-\mathrm{Ca}$ liquidus in terms of an equilibrium between mobile electrons and diatomic calcium molecule ions in the molten solution similar to that in other calcium metal-calcium halide melts, as well as to the equilibrium $\mathrm{Na}{ }_{2} \rightleftharpoons 2 \mathrm{Na}^{+}+2 \mathrm{e}^{-}$in sodium metal-sodium halide melts.

\section{CHEMICAL PHYSICS}

Paramagnetic resonance measurements on single crystals of hydrogen peroxide photolyzed with ultraviolet continued. The most prominent spectrum results from a triplet-state species. Single crystals of $\mathrm{D}_{2} \mathrm{O}_{2}$ were also studied, and they show the same triplet plus another triplet species not found in $\mathrm{H}_{2} \mathrm{O}_{2}$. Other less intense spectra are also present.

The paramagnetic resonance spectra of rather simple, short-lived organic free radicals were observed in liquids at room temperature during intense uv photolysis. The systems thus far studied are alcohols containing a small amount of hydrogen peroxide. Radicals that were identified are $\mathrm{CH}_{2} \mathrm{OH}, \mathrm{CH}_{3} \mathrm{CHOH}, \mathrm{CH}_{3} \mathrm{COHCH}_{3}$, and $\mathrm{CHOHCH}_{2} \mathrm{OH}$.

Parameters of the spin Hamiltonian for a tripletstate species in gamma-irradiated dimethylglyoxime were ascertained from electron spin resonance measurements of single crystals. These parameters show that the triplet-state species is a pair of coupled doublet-state radicals which had been studied previously. The doubletstate radicals are believed to be formed by the removal of one of the $\mathrm{N}-\mathrm{O}-\mathrm{H}$ hydrogen atoms of dimethylglyoxime by the radiation. The tripletstate species is formed when the removed hydrogen atom abstracts an $\mathrm{N}-\mathrm{O}-\mathrm{H}$ hydrogen atom from a neighboring molecule one unit cell distance away in the direction of the crystal a axis.

A semiautomatic machine is described which prepares an integrated recording from an existing chart recording. An accuracy of about $2 \%$ can be achieved routinely.

Apparent molar enthalpies of mixing in the molten $\mathrm{LiF}-\mathrm{NaF}$ system at $1278^{\circ} \mathrm{K}$, observed by high-precision drop calorimetry, show evidence of the presence of solid solutions in the quenched sample mixtures and are therefore in need of correction by using aqueous solution calorimetry.

The unusual behavior of the heat capacity of $\mathrm{ReCl}_{3}(\mathrm{c})$ below $50^{\circ} \mathrm{K}$ was confirmed by additional heat capacity measurements. The behavior is believed to arise from vibrational energy states of the $\mathrm{Re}_{3} \mathrm{Cl}_{9}$ clusters present in $\mathrm{ReCl}_{3}$ (c) rather than from magnetic or electronic excitation phenomena. The thermodynamic properties of $\mathrm{ReCl}_{3}$ from 0 to $300^{\circ} \mathrm{K}$ are tabulated.

The anisotropic temperature factor coefficients derived during refinement of three-dimensional neutron or $x$-ray Bragg-reflection intensity data define a trivariate normal probability density function for the thermal motion of each atom. The most convenient graphic representation is the "thermal-motion probability ellipsoid" where the ellipsoid is a surface of constant probability density centered about the atomic site. This tedious drafting problem was automated by using a computer and digital $X-Y$ plotter. The illustrations produced are suitable for journal publication. Stereoscopic pairs of illustrations can also be plotted to aid in the visualization of complex thermal-motion patterns.

Preliminary plans are presented for a relatively inexpensive computer-controlled $\mathrm{x}$-ray or neutron diffractometer.

A refinement of the crystal structure of $a \times D$ glucose $\left(\mathrm{C}_{6} \mathrm{H}_{12} \mathrm{O}_{6}\right)$ from three-dimensional neutron data was nearly finished. The standard errors of the coordinates are about 0.001 to $0.002 \mathrm{~A}$ for the carbon and oxygen atoms and 0.002 to $0.005 \mathrm{~A}$ for the hydrogen atoms. The molecular parameters of the molecule are, in general, quite close to those of the glucose moiety in sucrose, but there are some significant differences in $\mathrm{C}-\mathrm{O}$ bond lengths.

The structure of monoclinic $\mathrm{K}_{2} \mathrm{NbF}_{7}$ was redetermined from three-dimensional neutron diffraction data. The basic correctness of Hoard's structure of 1939 was confirmed. The structural parameters, including anisotropic thermal parameters, are now known to high precision. The niobium-fluorine bond lengths, after correction for thermal motion, range from 1.939 to $1.977 \mathrm{~A}$. 
The crystal structure of potassium hydrogen chloromaleate was determined from three-dimensional neutron diffraction data. The anion is nearly planar with an internal hydrogen bond of length $2.403 \mathrm{~A}$. The hydrogen atom is apparently situated in the center of this bond.

Analysis of three-dimensional x-ray precession data of a crystalline material grown from xenon hexafluoride preparations yielded the monoclinic space group $P 2, / m$, with eight xenon atoms per unit cell. A Patterson synthesis placed these into two regular tetrahedral groups, related by a center of symmetry. A length of $4.19 \pm 0.02 \mathrm{~A}$ for the edges of the xenon tetrahedra was obtained.

Molecular beam scattering techniques were used to study intermolecular potentials and chemical reactions in a number of systems. "Rainbow" scattering was observed in the potassium-xenon system, and the depth of the interatomic potential well was found to be $200 \mathrm{cal}$. Measurement of the relative total cross section of scattering of potassium by $I_{2}$ and by atomic iodine indicated that the contribution of electronic exchange to the potential was observable in the total scattering cross section. Work was begun on the measurement of the relative scattering cross sections of $\mathrm{H}_{2}$ and $\mathrm{D}_{2}$ in helium.

Crossed molecular beam techniques were used to study the reaction of potassium and cesium with $\mathrm{Br}_{2}$. The angular distribution of the alkali bromide molecules showed that the reaction involved a "stripping" mechanism (i.e., no activated complex) in which the second bromine atom acted only as a "spectator" particle.

A new molecular beam scattering apparatus which utilizes a rotatable four-pole mass filter was designed and constructed. A part of this apparatus was used to study the differential elastic scattering of $\mathrm{Cs}^{+}$( 2 to $20 \mathrm{ev)}$ from argon. Good agreement was found with the repulsive part of the theoretical potential.

Measurement of the phase shift of a modulated helium beam reflected from a heated platinum surface indicated that the surface was covered with a low-molecular-weight contaminant. Treatment of the platinum with low pressures of $\mathrm{O}_{2}$ appeared to remove this contaminant and the reflection patterns observed were sharper than any reported heretofore. Fine structure was observed in these patterns and may be due to diffraction from the surface grating.
A comprehensive program for studying atomic readjustment to inner-shell vacancies is centered around the measurement of the relative abundances of ions produced from $\mathrm{x}$ irradiation of rare gases. The results have been interpreted in terms of Auger cascades and electron shake-off. Molecular gases are also currently being investigated for the consequences of the "explosion" of highly charged ions.

\section{WATER RESEARCH PROGRAM}

Work on this program continued under the sponsorship of the Office of Saline Water (OSW) and an agreement between the Department of the Interior and the U.S. Atomic Energy Commission, a substantial portion of it being carried out in the Chemistry Division.

Hyperfiltration by membranes was studied, especially the behavior of a cellophane-g-polyacrylic-acid membrane. Equipment was developed for rapidly evaluating membranes. A mathematical analysis was carried out for a model membrane to elucidate the influence of differences in diffusion rates of solute and solvent in the membrane and of differences in the distribution of the two components between solution and membrane phases. The effect of the dielectric constant difference on hyperfiltration was investigated. Equipment for determination of self-diffusion and tracer diffusion coefficients in solution was assembled, and results for several typical cases are reported.

Activity coefficients of salts in water mixtures of glycol, glycerol, and their acetates were studied. In an investigation of the effect of salts on the miscibility gap in the glycerol triacetate-water system, a large "salting-in" effect was observed which can lead to complete miscibility on addition of certain salts, for example, perchlorates, thiocyanates, iodides, and salicylates. Other water-organic solvent mixtures were studied.

Special glass electrodes were evaluated for use in the determination of free energies of salts in aqueous and mixed aqueous-organic solvent systems.

Calculation of vapor pressures of sea salt solutions based on $\mathrm{NaCl}$ osmotic coefficient data and comparison with experimental measurements is discussed. 
Studies of the adsorption and ion exchange behavior of a variety of inorganic materials were continued, with emphasis on $\mathrm{MgO}, \mathrm{La}_{2} \mathrm{O}_{3}, \mathrm{Bi}_{2} \mathrm{O}_{3}$, and sulfides, and also on adsorption properties of oxides with respect to sulfides.
The calculation of polarization in porous electrodes is discussed, as are differential capacity measurements on such electrodes, which are of interest for various applications. 


\section{Contents}

SUMMARY

1. NUCLEAR CHEMISTRY

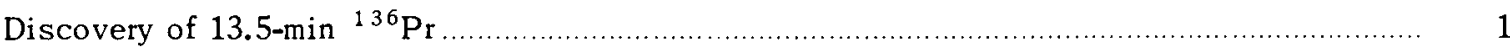

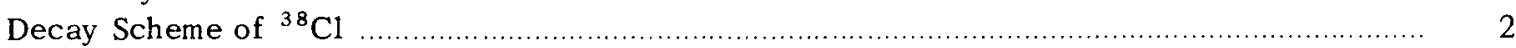

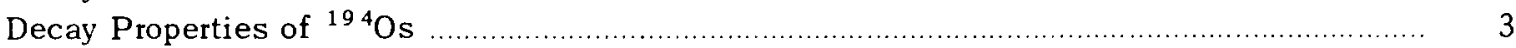

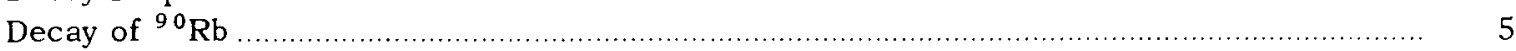

A Survey of Some Properties of Even-Even Nuclei …............................................................. 6

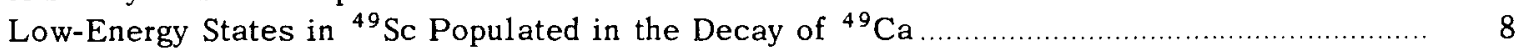

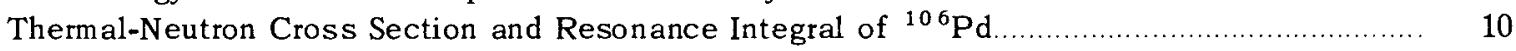

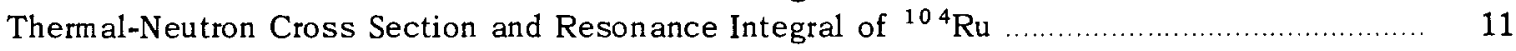

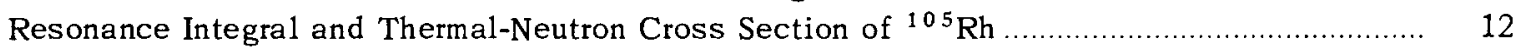

The Neutron Capture Cross Sections of Ruthenium Nuclides, Mass Number 98

Through 101

The Thermal-Neutron Capture Cross Section and Resonance Integral of ${ }^{242} \mathrm{Pu} \ldots \ldots \ldots \ldots \ldots \ldots . . . . . . . . . .13$

The Thermal-Neutron Capture Cross Section and Resonance Integral of ${ }^{232} \mathrm{U} \ldots \ldots \ldots \ldots \ldots \ldots \ldots . . . \ldots 14$

The Thermal-Neutron Capture Cross Section and Resonance Integral of ${ }^{106} \mathrm{Ru} \ldots \ldots \ldots \ldots \ldots \ldots . . . \ldots . \ldots 15$

The Thermal-Neutron Capture Cross Section and Resonance Integral of ${ }^{58}$ Co .................... 16

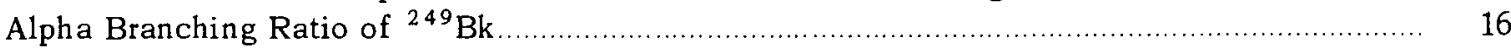

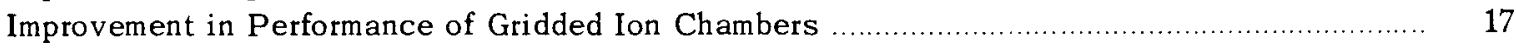

2. NUCLEAR AND INORGANIC CHEMISTRY OF SPECIAL ELEMENTS .......................................... 19

A Study by Raman Spectroscopy of Complex Ions Formed by $\mathrm{Ta}(\mathrm{V})$ in the System

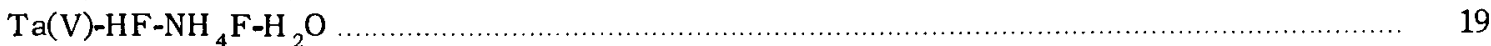

Specific Activity of ${ }^{2}{ }^{9} \mathrm{Tc}$ by Liquid Scintillation Counting .................................................... 19

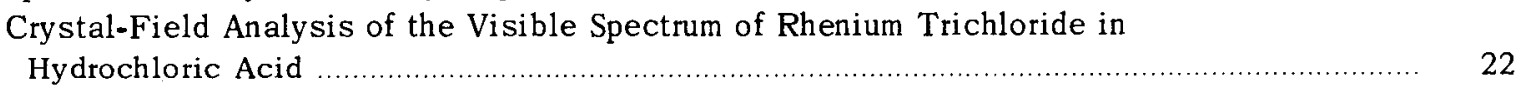

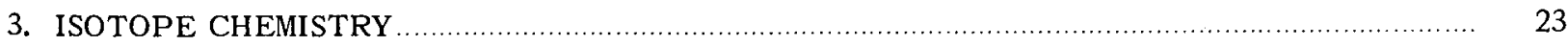

Ion Exchange Studies in Ethylenediamine.......................................................................... 23

The Effect of Eluent Concentration on the Separation Factor for Lithium Isotopes

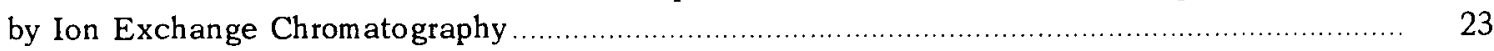

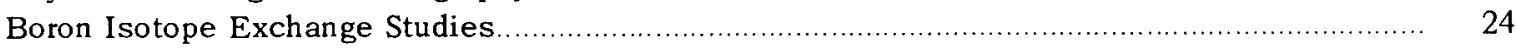

Coordination Compounds of Boron Halides ........................................................................ 24

The Fractionation of Carbon and Oxygen Isotopes in the $\mathrm{CO}_{2}$-Carbamate System ................. 25

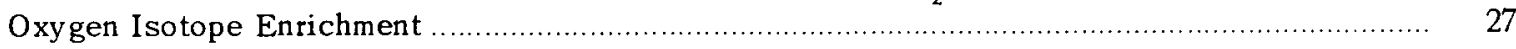

The Nitrogen Isotope Effect in the Decomposition of Diazo Salts ................................. 27

Infrared Spectra and Predicted Isotope Effect for Diazonium Salts ................................ 28

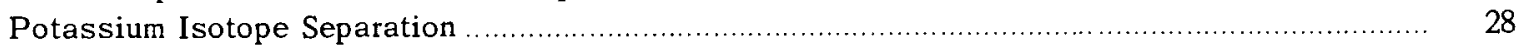

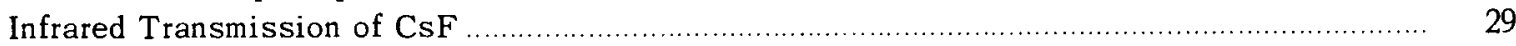


Isotopic Mass Spectra..

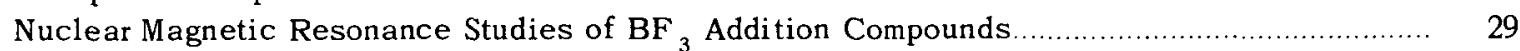

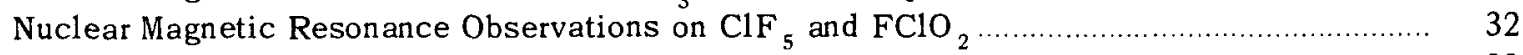

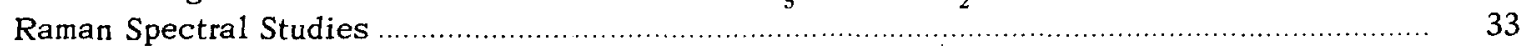

Thermodynamic Effects of Mixing Light and Heavy Water ............................................... 38

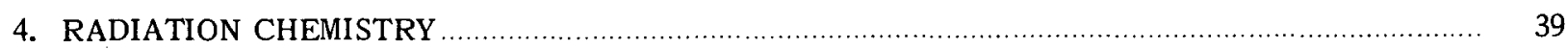

Energy Transfer from Carbon Dioxide in the Radiation-Induced Synthesis of Water................. 39

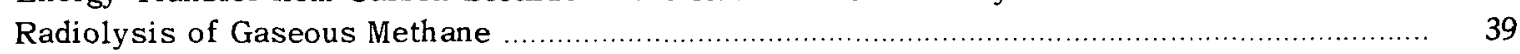

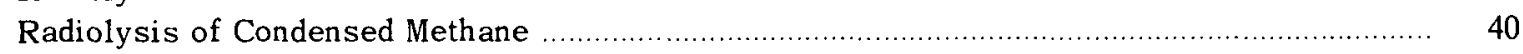

A New Postulate in the Diffusion Model for the Radiolysis of Water ................................. 41

Photochemical and Radiation Chemical Reduction of Ceric Ion in Aqueous Sulfuric

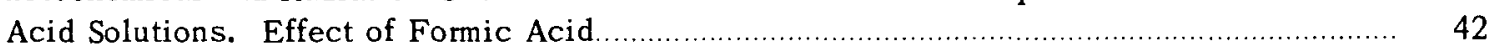

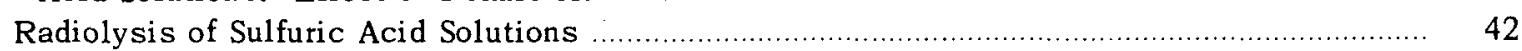

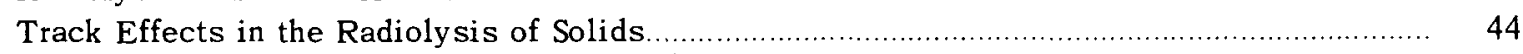

Radiolysis of Alkaline-Earth Bromates by ${ }^{60} \mathrm{Co}$ Gamma Rays.......................................... 45

The Radiolysis of Crystalline $\mathrm{LiBrO}_{3}$ by ${ }^{6} \mathrm{Li}$ Fission Recoil Particles ............................. 46

Radiolysis of Molten $\mathrm{LiNO}_{3}$ by ${ }^{6} \mathrm{Li}$ Fission Product Recoils ...................................... 47

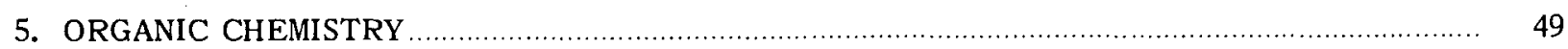

Primary and Secondary Carbon-14 and Deuterium Isotope Effects.................................. 49

Determination of the Stereochemistry of 1,2-Glycols by Nuclear Magnetic

Resonance Spectroscopy

Mechanism of Pyrolysis of Iron Salts of Carboxylic Acids .............................................

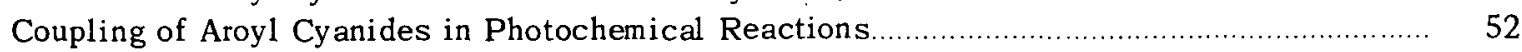

The Pinacol Rearrangement of 2-Phenylnorbornane-2,3-cis-exo-diol ................................. 52

The Deamination of 3-endo-amino-2-endo-phenyl-norborneol (I) and of

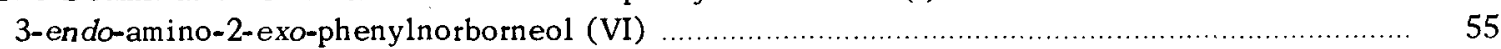

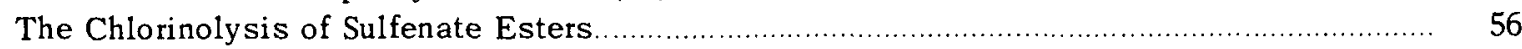

Amides of Carboxylic Acids as Solvents for the Extraction of Electrolytes ....................... 56

Acid-Catalyzed Hydrolysis of Dibutyl Dimethylphosphoramidate .................................... 58

Triallyl Phosphate as the Stationary Liquid Phase in the Gas Chromatographic

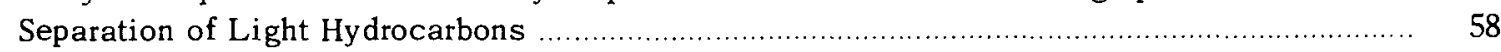

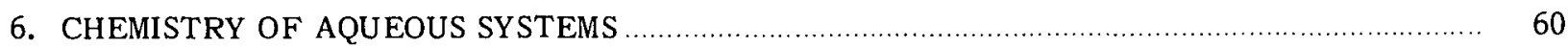

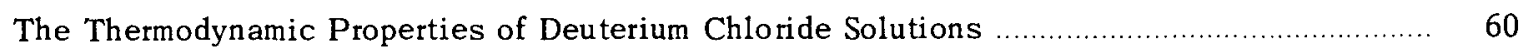

A Comparison of Several Methods for Inverting Large Symmetric Positive

Definite Matrices

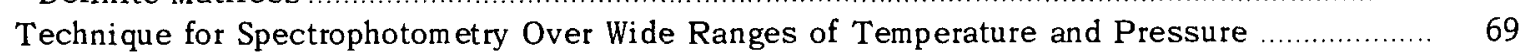

The Absorption Spectrum of $\mathrm{CO}_{2}$ in the Near-Infrared Region as a Function of

Temperature from Below the Freezing Point to Above the Critical Point .......................... 69

Hydrolysis of Metal Ions; Activity Coefficients in Three-Component Solutions ..................... 71

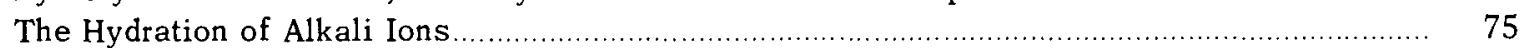

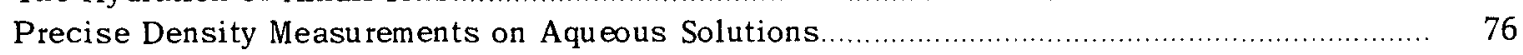

Physical Chemistry of Ion Exchangers: Isopiestic Vapor Pressure Measurements

on Alkali-Metal Cation Salts of para-ethylbenzene Sulfonic Acid..................................... 77

Physical Chemistry of Ion Exchangers: Heat and Entropy Changes in the

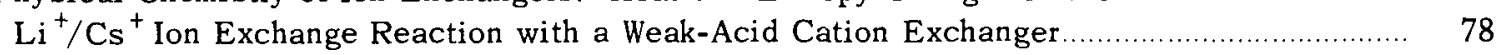

Physical Chemistry of Ion Exchangers: Identity of the $\mathrm{Fe}$ (III) Ion Taken Up from

Concentrated Aqueous Halide Solutions by Strong-Acid Cation Exchangers.

The Heats of Dilution of Polystyrene Sulfonic Acid and the Li, $\mathrm{Na}, \mathrm{K}$, and

Cs Salts 


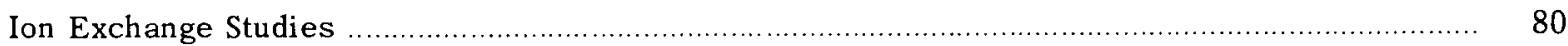

Ion Exchange in Concentrated $\mathrm{HCl}$ and $\mathrm{HClO}_{4}$ Solutions .................................................. 80

Adsorption of the Elements from $\mathrm{HCl}-\mathrm{HClO}_{4}$ Mixtures ……................................................... 81

Activity Coefficients of $\mathrm{HCl}$ and $\mathrm{HClO}_{4}$ in a Cation Exchanger ......................................... 82

Adsorption of In(III) by a Cation Exchanger from HBr Solutions ............................................. 82

Development of an Ion Exchange Separations Scheme

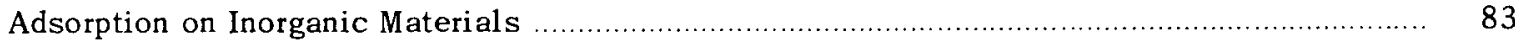

7. ELECTROCHEMICAL KINETICS AND ITS APPLICATION TO CORROSION ….......................... 84

Ion Exchange at the Surface of Passive Metals …................................................................... 84

Adsorption Effects in Iron Dissolution Kinetics ................................................................. 84

Rotating-Disk Studies of the Dissolution of Zirconium in Aqueous Solutions of

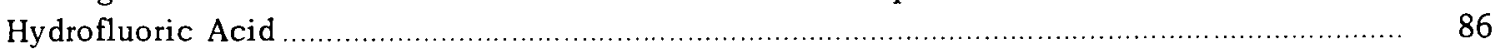

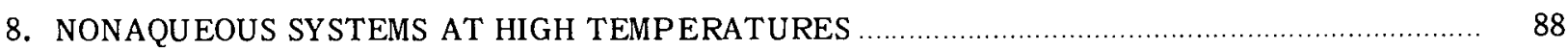

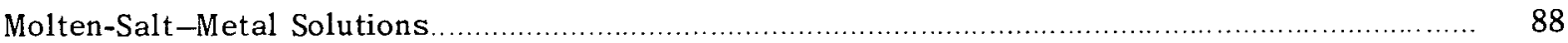

Electrical Conductivity and Cryoscopy in Solutions of Alkaline-Earth Metals in

Their Molten Chlorides, Bromides, and Iodides.................................................................... 88

Miscibility of Barium Metal with Its Molten Halides ......................................................... 91

Solid Solutions of Calcium in Calcium Fluoride ................................................................. 93

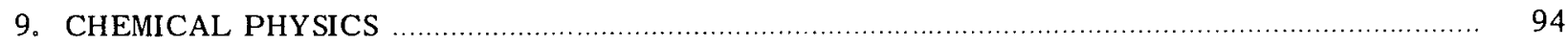

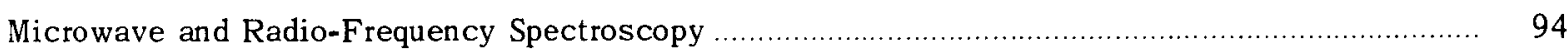

Paramagnetic Resonance Study of Photolyzed Hydrogen Peroxide ........................................ 94

Paramagnetic Resonance Study of Free Radicals Formed in Liquids During

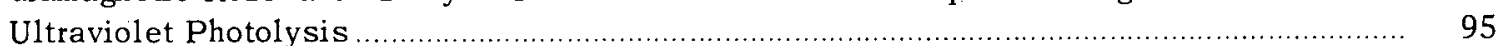

Paramagnetic Resonance Study of Irradiated Dimethylglyoxime ......................................... 95

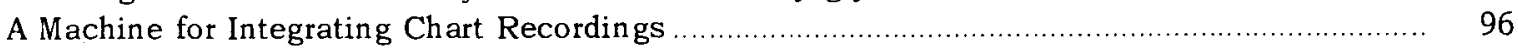

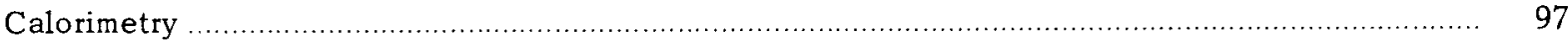

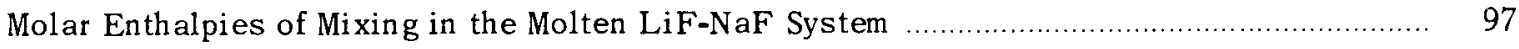

Thermodynamic Properties of Rhenium Trichloride ................................................................ 98

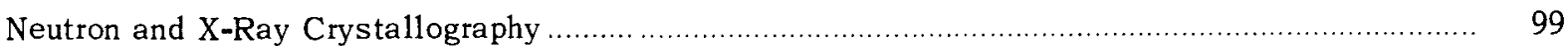

Machine-Plotted Crystal Structure Diagrams with Thermal-Motion

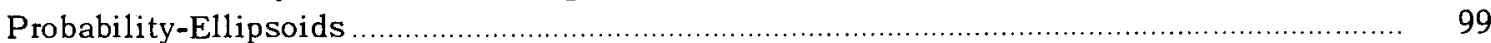

The Design of a Relatively Inexpensive Computer-Controlled Diffractometer........................... 100

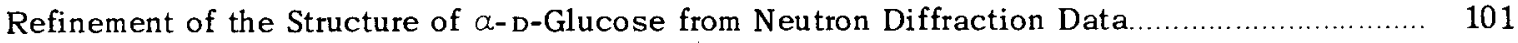

Refinement of the Structure of $\mathrm{K}_{2} \mathrm{NbF}_{7}$ from Neutron Diffraction Data ................................. 104

A Neutron Diffraction Study of the Structure of Potassium Hydrogen Chloromaleate ................ 106

An X-Ray Diffraction Study of a Crystalline Material Obtained from Xenon

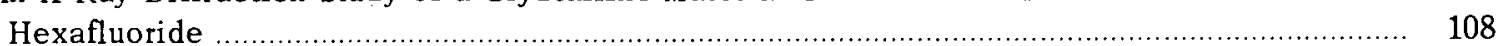

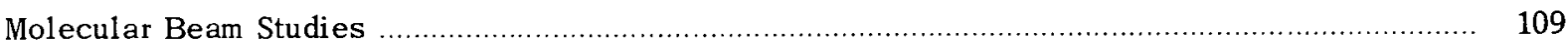

"Rainbow" Scattering in the Potassium-Xenon System ........................................................ 109

Relative Total Scattering Cross Section of Potassium in Molecular and Atomic Iodine ........... 110

A Study of the Reactions of Cesium and Potassium with Bromine in Crossed
Molecular Beams

A New Molecular Beam Scattering Apparatus .................................................................... 112

Differential Elastic Scattering of Low-Energy Cs ${ }^{\dagger}$ Ions (2 to $20 \mathrm{ev}$ ) from Noble Gases ........... 113

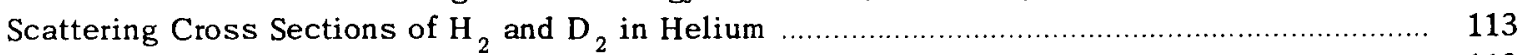

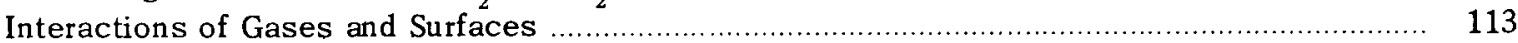

Mass Spectrometry and Related Techniques .................................................................... 115

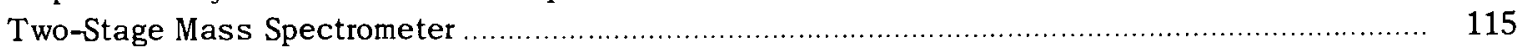




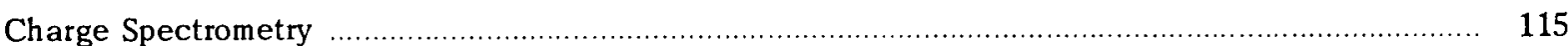

The Consequences of Inner-Shell Vacancies to Atoms and Molecules ................................ 115

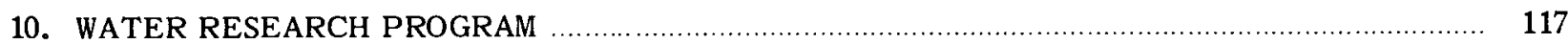

Hyperfiltration Studies of Membranes.................................................................... 117

Properties of a Cellophane-g-Polyacrylic-Acid Membrane .............................................. 117

Development of Equipment for Rapidly Evaluating Membranes .................................... 118

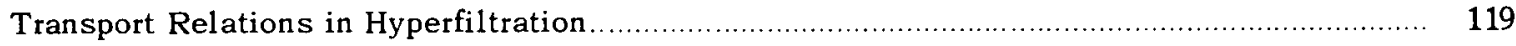

The Effect of Dielectric Constant Difference on Hyperfiltration of Salt Solutions................. 120

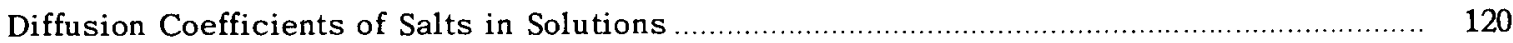

Activity Coefficients of Salts in Water Mixtures of Glycol, Glycerol, and Their

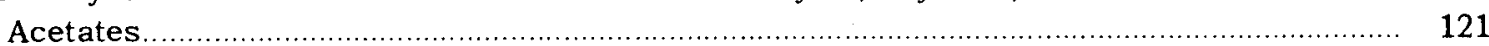

Effect of Salts on the Miscibility Gap in the Glycerol Triacetate-Water System ................. 121

Other Studies of Water-Organic Mixtures .................................................................... 121

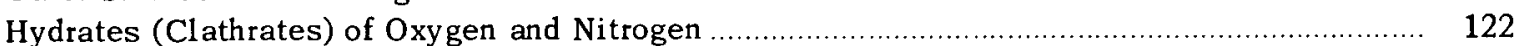

Activity Coefficients of Salts by EMF Methods ........................................................ 122

Calculation of Vapor Pressures of Sea Salt Solutions.................................................... 123

Ion Exchange; Adsorption on Inorganic Materials ..................................................... 124

Methods for the Calculation of Polarization in Porous Electrodes ................................. 125

Differential Capacity Measurements on Porous Electrodes ........................................... 126

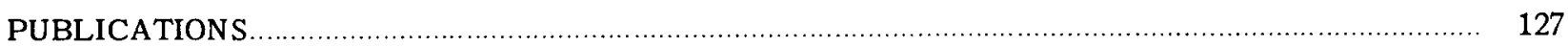

PAPERS PRESENTED AT SCIENTIFIC AND TECHNICAL MEETINGS ................................... 133

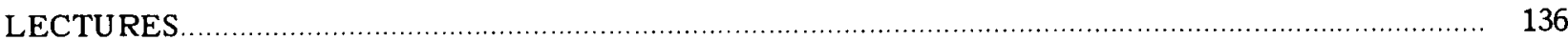




\section{Nuclear Chemistry}

\section{Discovery of $13.5-\min { }^{136} \mathrm{Pr}$}

\author{
B. H. Ketelle A. R. Brosi \\ J. R. Van Hise
}

A study of the ${ }^{135} \operatorname{Pr}$ decay scheme was initiated to make definite spin assignments to the levels populated by the decay of the $20-\mathrm{sec}{ }^{135} \mathrm{Ce}$ isomer reported last year. Praseodymium-135 has been reported to have a half-life of $22 \mathrm{~min}$. Measurements with a semiconductor detector of the activity produced by 22-Mev protons on cerium enriched in ${ }^{136} \mathrm{Ce}$ showed that the conversion electron peaks decayed with a half-life of $27 \mathrm{~min}$, while the positrons decayed with a half-life which varied with energy. The high-energy end of the positron spectrum had a half-life of about $13.5 \mathrm{~min}$. The work done to identify the isotope with a $13.5-\mathrm{min}$ half-life is described below.

When cerium enriched in ${ }^{136} \mathrm{Ce}$ was bombarded with $14-\mathrm{Mev}$ protons, the $13.5-\mathrm{min}$ activity was produced along with some $19.2 \mathrm{hr}{ }^{142} \mathrm{Pr}$ and $4.6-\mathrm{hr}$ ${ }^{139} \mathrm{Pr}$, but the $27 \cdot \mathrm{min}{ }^{135} \mathrm{Pr}$ was absent. A NaI scintillation spectrometer showed that $x$ rays and gamma rays with energies of $\sim 500, \sim 1000, \sim 1500$, $\sim 2000$, and $\sim 2500 \mathrm{kev}$ decayed with the $13.5 \mathrm{~min}$ half-life. A lithiumadrifted germanium detector resolved the $500 \mathrm{kev}$ peak into 460-, 511-, 540-, and 552-kev peaks. The $\sim 1000$-kev peak was resolved into 1000- and 1092-kev peaks.

The $x$ rays of the $13.5-\mathrm{min}$ activity were counted with a xenon proportional spectrometer. Since the $x$ rays of rare-earth elements of adjacent atomic number are easily resolved by this counter, it was possible to show that the $13.5-\mathrm{min}$ activity emitted cerium $x$ rays.

In order to assign the isotope with the 13.5-min decay period to a definite mass number, cerium samples with two different isotopic compositions were bombarded in the same target with $14-\mathrm{Mev}$ protons. The yields of the $13.5-\mathrm{min}$ activity relative to the yields of $19.2-\mathrm{hr}{ }^{142} \mathrm{Pr}$ and 140 -day ${ }^{1}{ }^{9} \mathrm{Ce}$ showed that it was produced by a reaction on ${ }^{136} \mathrm{Ce}$. The cross section for production of the 13.5-min activity was of the order of a barn. This is about the magnitude expected for $p, n$ and $p, 2 n$ reactions but several orders of magnitude larger than expected for $p, \gamma$ reactions. A $p, p, n$ reaction can be ruled out because the well-known transitions in ${ }^{135} \mathrm{La}$ and ${ }^{135} \mathrm{Ba}$ are not observed.

Since $27-\mathrm{min}{ }^{135} \mathrm{Pr}$ is produced by $22-\mathrm{Mev}$ protons but not by 14-Mev protons, and the 13.5-min activity is produced by both but in higher yield by 14-Mev protons, it is concluded that the $13.5-\mathrm{min}$ activity is produced by a $p, n$ reaction on ${ }^{136} \mathrm{Ce}$ and is therefore ${ }^{136} \mathrm{Pr}$. This assignment is consistent with the decay by positron emission and electron capture with the emission of cerium $x$ rays. No definite evidence has been found in this work for the 70-min activity which previously was assigned to ${ }^{136} \mathrm{Pr}$.

Measurements of the intensities of the $x$ rays and gamma rays relative to the annihilation radiation have been made. On the basis of the intensity measurements and the precise gamma-ray energies measured with a germanium detector, the incomplete energy level scheme for ${ }^{136} \mathrm{Ce}$ shown in Fig. 1.1 is proposed. The energies of the first two excited states are consistent with the energy levels of the other even-even nuclei in the 58proton-78-neutron region. The systematics of even-even nuclei indicates that the first two excited levels probably have spins of $2+$. An attempt will be made to fit the low-intensity transitions into an energy level scheme and to get experimental evidence for the spin assignments. 
UNCLASSIFIED

ORNL-DWG. 64-5708

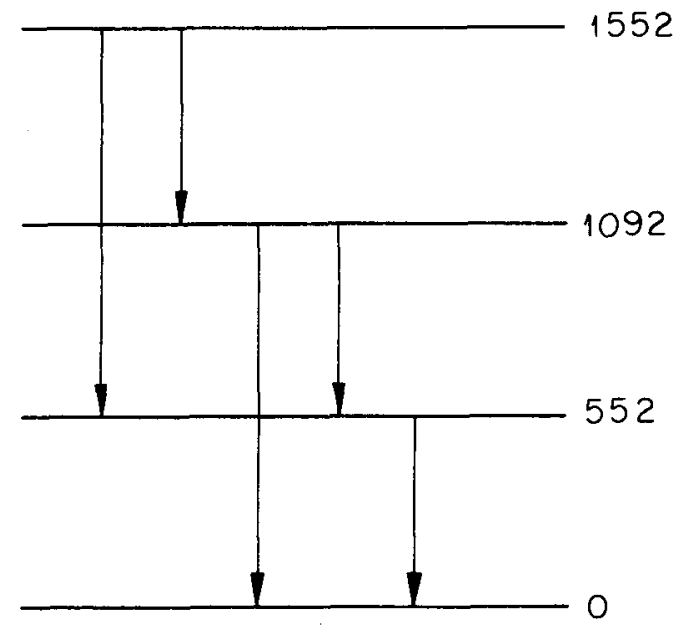

Fig. 1.1. Tentative Level Scheme of ${ }^{136} \mathrm{Ce}$.

\section{Decay Scheme of ${ }^{38} \mathrm{Cl}$}

B. L. Robinson ${ }^{1}$

Beta-ray spectroscopy and gamma-gamma angular and polarization correlation studies have established ${ }^{2}$ that ${ }^{38} \mathrm{Cl}$ decays by beta emission to the $0^{+}$ground state of ${ }^{38} \mathrm{Ar}$ and to excited states at $2.16 \mathrm{Mev}\left(2^{+}\right)$and $3.75 \mathrm{Mev}\left(3^{-}\right)$. The relative level spacings in ${ }^{38} \mathrm{Ar}$ and the spins and parities of the levels are analogous to those of ${ }^{88} \mathrm{Sr}$, and the two nuclides are further similar in that each lacks two protons of having a doubly "magic" configuration. The $E 3 / E 1$ branching ratio from the $3^{-}$state of ${ }^{88} \mathrm{Sr}$ was determined ${ }^{3}$ as $6.0 \times$ $10^{-3}$, while only an upper limit was set for ${ }^{38} \mathrm{Ar}$. In view of the great similarity between ${ }^{88} \mathrm{Sr}$ and ${ }^{38} \mathrm{Ar}$, an experiment was undertaken to observe the $E 3$ transition in ${ }^{38} \mathrm{Ar}$ from the decay of ${ }^{38} \mathrm{Cl}$.

For its simplicity, straightforward interpretation of the experimental data, and especially for its strong discrimination in favor of high-energy

\footnotetext{
${ }^{1}$ ORINS Research Participant, 1960. Permanent address: Western Reserve University, Cleveland, Ohio.

${ }^{2}$ Nucleat Data Sheets, National Academy of SciencesNational Research Council, Washington, D.C.

${ }^{3}$ R. W. Peelle, Neutron Phys. Div. Ann. Progr. Rept. Sept. 1, 1960, ORNL-3016, pp. 110-15.
}

gamma rays, the scintillation pair spectrometer seemed the appropriate instrument for this investigation. Accordingly, a pair spectrometer was assembled, using a central crystal of $\mathrm{NaI}, 1$ in. in diameter and $2 \mathrm{in}$. long. The positrons, formed by pair production in the central crystal, were detected by observing their annihilation radiation in a pair of $3 \times 3$ in. NaI detectors. A triple coincidence between the detectors announced a pair event in the central crystal. Single-channel "windows" on the amplifiers for the $3 \times 3$ in. side crystals were set to accept only the fullenergy peak of the annihilation radiation (0.511 Mev), and the coincidence bias for the central detector was adjusted to accept all pulses $>50$ or $100 \mathrm{kev}$. Coincidence resolving time was about 80 nsec.

The threefold coincidence signal opened a linear gate ${ }^{4}$ to pass the signal from the central detector to a multichannel analyzer. The linearity of the amplifier + linear gate + multichannel analyzer was confirmed with a precision pulse generator. Since the triple coincidence scheme utilized crossover point timing, it constituted a pulse-shape discriminator system, ${ }^{5}$ thus making possible the toleration of high counting rates (to 50,000 counts/sec) with minimum distortion of the pulse-height spectrum due to pileup.

A typical scintillation pair spectrum of ${ }^{38} \mathrm{Cl}$ is shown in Fig. 1.2. By intercomparison of pair spectra of ${ }^{38} \mathrm{Cl}$ and those of ${ }^{140} \mathrm{La}$ and ${ }^{144} \mathrm{Pr}$, the low-energy line in ${ }^{38} \mathrm{Cl}$ was found to be $2 \pm 5$ kev higher in energy than the ${ }^{140} \mathrm{La}$ line at $1596 \pm$ $2 \mathrm{kev}$; and the high-energy line was found to be $20 \pm 5 \mathrm{kev}$ lower in energy than the ${ }^{144} \mathrm{Pr}$ line at $2186 \pm 2$ kev. Thus, the ${ }^{38} \mathrm{Cl}$ gamma-ray energies are $1598 \pm 5 \mathrm{kev}$ and $2166 \pm 5 \mathrm{kev}$.

The crossover transition appears in the pair spectrum of Fig. 1.2 centered at channel 180 . The small peak at channel 215 is an artifact, for its relative intensity was doubled when the counting rate in the central crystal was doubled. The continuum between the 2166-kev line and the

\footnotetext{
${ }^{4}$ Model 801 linear gate, Sturrup, Inc., Middletown, Conn.

${ }^{5}$ R. E. Segel, Bull. Am. Phys. Soc. 7, 542 (1962). In a private communication, W. Zobel, Neutron Physics Division, pointed out that in a pair spectrometer with crossover timing, the detection of the two annihilation photons serves as the time reference rather than the leading edge of the signal, as described by Segel for a single-crystal s pectrometer.
} 


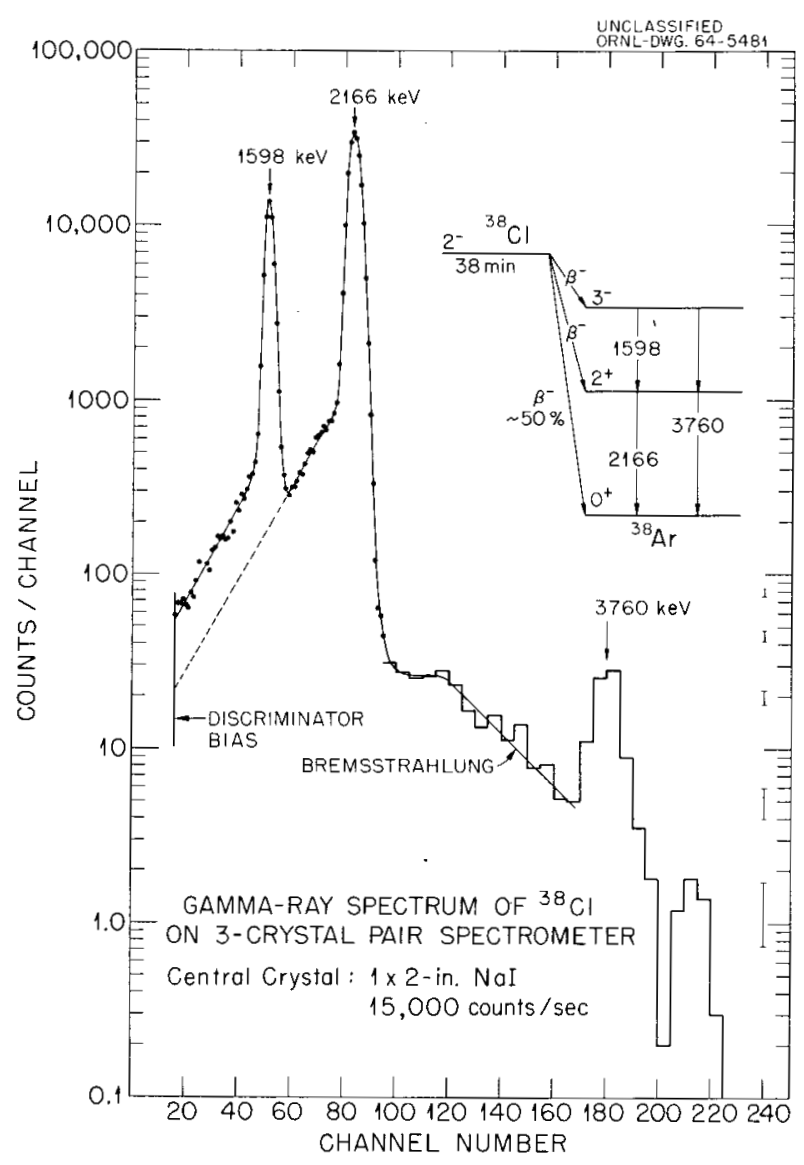

Fig. 1.2. Gamma-Ray Spectrum of ${ }^{38} \mathrm{Cl}$ on a ThreeCrystal Scintillation Pair Spectrometer. Energies ore given in kev. A decay scheme for ${ }^{38} \mathrm{Cl}$ is shown in the inset. The statistical spread is indicated on the right-hand side for several count values.

crossover is nearly independent of counting rate; it is probably the bremsstrahlung from the intense ground-state beta branch, which obscured the crossover in a previous attempt to observe it by the detection of photoneutrons. ${ }^{6}$

The area of the peak due to the crossover transition was corrected for a contribution of $3 \%$ due to true coincident summing. A correction for random coincidence summing was calculated and then checked by measuring ${ }^{38} \mathrm{Cl}$ pair spectra at integral counting rates of 30,000 counts/sec and at 15,000 counts/sec.

${ }^{6}$ V. Myers and A. Wattenberg, Phys. Rev. 75, 992 (1949).
The relative intensities of the gamma rays were obtained from the areas in the pulse-height distributions by means of a calculation which involved only the crystal length and the pair cross section for NaI. The measurement of relative intensities with this spectrometer was checked by measuring the relative intensities of the prominent, highenergy gamma rays of ${ }^{24} \mathrm{Na}$ and ${ }^{144} \mathrm{Pr}$; agreement was obtained within $5 \%$ of literature values. The relative intensities of the ${ }^{38} \mathrm{Cl}$ gamma rays were found to be: $\left(I_{1598} / I_{2166}\right)=0.85 \pm 0.03$ and $\left(I_{3760} / I_{2166}\right)=(4.9 \pm 0.7) \times 10^{-4}$. The quantity which is of concern is the branching ratio $E 3 / E 1$ from the $3^{-}$state, that is, $\left(I_{3760} / I_{1598}\right)=(5.8 \pm$ $0.8) \times 10^{-4}$. The observed branching ratio may be compared with the single-particle estimate of $2.5 \times 10^{-7}$. In the case of ${ }^{88} \mathrm{Sr}$, a pair spectrum recorded with a source of ${ }^{88} \mathrm{Y}$ gave $(E 3 / E 1)=$ $\left(I_{2740} / I_{899}\right)=(5.6 \pm 0.4) \times 10^{-3}$, in good agreement with Peelle's value of $(5.95 \pm 0.25) \times 10^{-3}$. The single-particle estimate for this ratio in ${ }^{88} \mathrm{Sr}$ is $4 \times 10^{-7}$.

\section{Decay Properties of ${ }^{194} \mathrm{Os}_{\mathrm{s}}$}
N. R. Johnson
W. N. Bishop ${ }^{7}$

To produce ${ }^{194} \mathrm{Os}$, about $2 \mathrm{~g}$ of metallic osmium was irradiated for six weeks in the Oak Ridge LITR. Four years later, after most of the ${ }^{185} \mathrm{Os}$ had decayed, the source was chemically purified by a series of distillation and solvent extraction steps. A purified ${ }^{194} \mathrm{Os}$ source has since been counted periodically on an end-window proportional counter for over five years. When analyzed with a computer least-squares program, these data show a single exponential decay with a halflife of $6.0 \pm 0.2$ years. This value differs considerably from that of 700 days first reported by Lindner, ${ }^{8}$ but agrees with the recent measurement of $5.8 \pm 0.4$ years by Williams and Naumann. ${ }^{9}$

$\mathrm{An} \mathrm{NaI}$ single-crystal gamma-ray spectrum of ${ }^{194} \mathrm{Os}$, freshly separated from its daughter ${ }^{194} \mathrm{Ir}$,

\footnotetext{
${ }^{7}$ ORINS Graduate Fellow. Present address: Brookhaven National Laboratory, Yaphank, N.Y.

${ }^{8}$ Manfred Lindner, Phys. Rev. 84, 240 (1951).

${ }^{9}$ D. C. Williams and R. A. Naumann, Bull. Am. Phys. Soc. 9, 18 (1964); private communication.
} 
is shown in Fig. 1.3. The small contribution of ${ }^{194}$ Ir which was present in the gross spectrum as a result of growth has been subtracted. A prominent peak is observed at $43.0 \mathrm{kev}$ along with its characteristic iodine x-ray "escape" peak. Much weaker peaks are also analyzed at 63.5 and $77 \mathrm{kev}$. The 43.0-kev energy was carefully determined by counting simultaneously the ${ }^{194} \mathrm{Os}$ and standard sources.

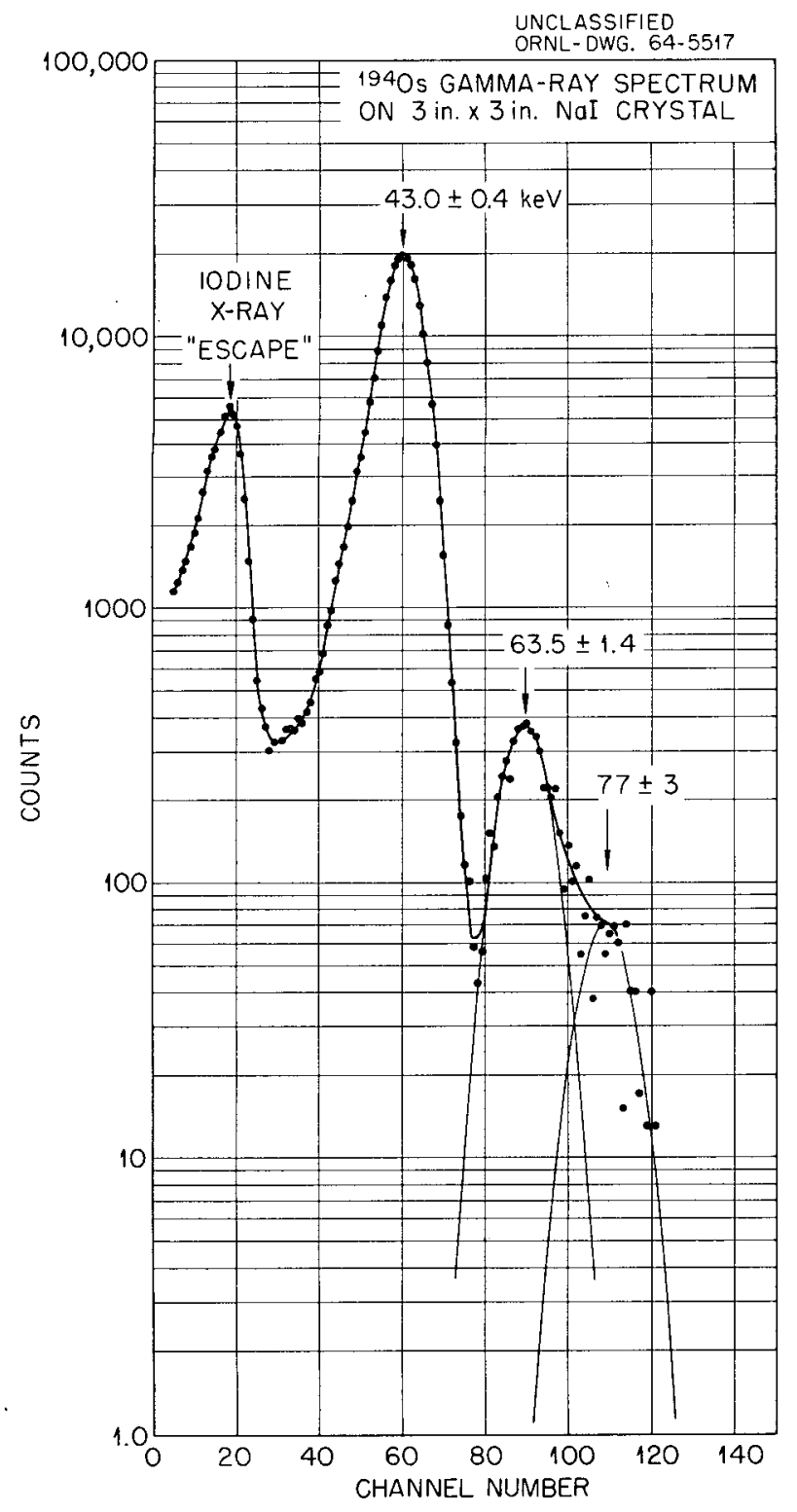

Fig. 1.3. Gamma-Ray Spectrum of ${ }^{194}$ Os Freshly Separated from ${ }^{194}$ Ir. The spectrum has been corrected for the growth of a small amount of ${ }^{194} \mathrm{Ir}$.
An investigation of any possible gamma-gamma coincidence relationships has been made using two very thin Nal crystals and a Victoreen multiparameter coincidence analyzer. The results showed that there are no true gamma-gamma coincidence events in the decay of ${ }^{194} \mathrm{Os}$.

Attempts to measure the single-crystal beta-ray spectrum with an anthracene detector were unsuccessful. However, by gating on the 43-kev gamma rays, it was possible to measure the beta rays in coincidence. As shown in Fig. 1.4, this revealed a very-low-energy beta group with an end point at $52 \mathrm{kev}$.

These measurements indicate a very simple decay scheme for ${ }^{194}$ Os. It appears that the first excited state in ${ }^{194} \mathrm{Ir}$ is at $43 \mathrm{kev}$ and that the total energy separation between the ${ }^{194}$ Os and ${ }^{194} \mathrm{Ir}$ ground states is $95 \mathrm{kev}$, that is, the energy of this level plus that of the coincident beta ray. This conclusion is in agreement with the recent work of Williams and Naumann. ${ }^{9}$

The present measurements show that the 63.5and 77-kev peaks are not in coincidence. It is not possible, however, from these experiments to determine (1) if both of these represent gamma-ray transitions depopulating excited states in ${ }^{194} \mathrm{Ir}$ at the respective energies, or (2) if the $63.5 \mathrm{kev}$

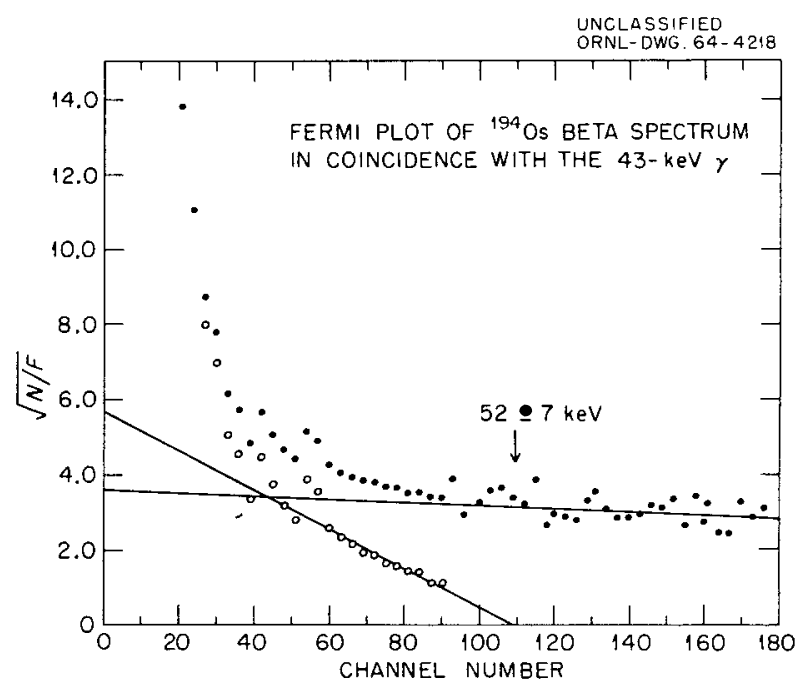

Fig. 1.4. Fermi Plot of ${ }^{194}$ Os Beta-Ray Spectrum in Coincidence with the $43-\mathrm{kev}$ Gamma Ray. The highenergy background, which is assumed to result from $194 \mathrm{Ir}$, has been subtracted as if it were a single betaray group. 
peak is an $\mathrm{x}$ ray following the internal conversion of a 77 -kev gamma ray. Williams and Naumann ${ }^{9}$ chose the latter possibility (they report the gammaray energy as $82 \mathrm{kev}$ ) and get $\alpha_{K}=9.4 \pm 0.5$, whereas the present data would yield a considerably lower value $\alpha_{K}=5.3 \pm 1.2$.

\section{Decay of ${ }^{90} \mathrm{Rb}(\operatorname{Ref} 10)$}
N. R. Johnson
G. D. O'Kelley
E. Eichler

Following the neutron irradiation of uranyl stearate, ${ }^{90} \mathrm{Rb}$ sources were prepared by "milking" from the emanated ${ }^{90} \mathrm{Kr}$. The decay properties of ${ }^{90} \mathrm{Rb}$ were then investigated with scintillation techniques. The single-crystal gamma-ray spectrum shown in Fig. 1.5 illustrates the complexity of this problem. From the single-crystal

\footnotetext{
${ }^{10}$ Accepted for publication in the Physical Review.
}

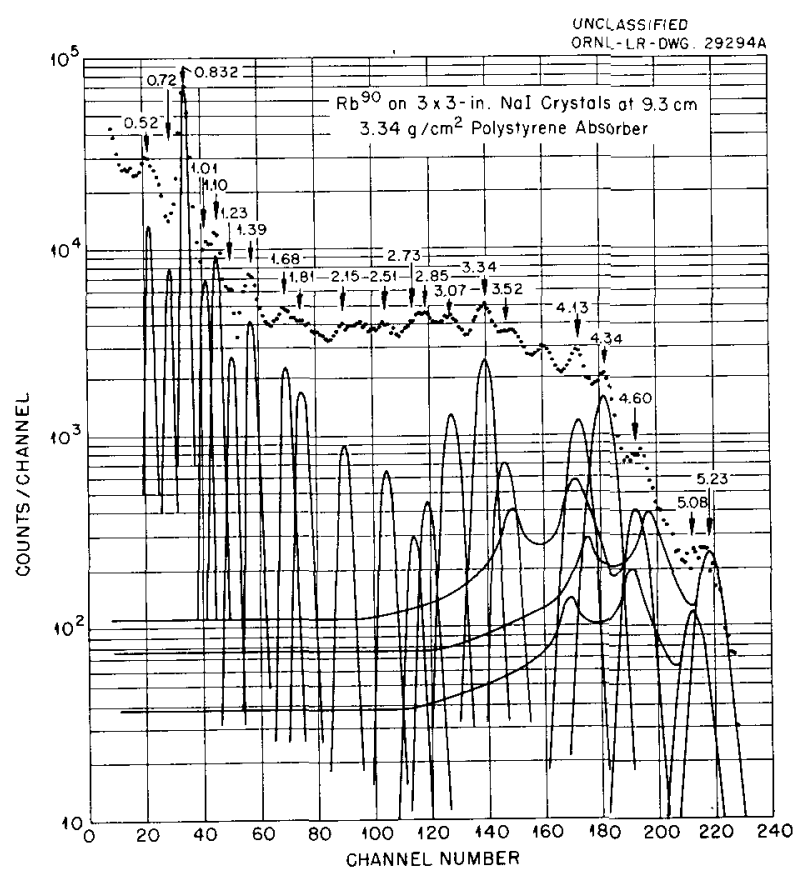

Fig. 1.5. Single-Crystal Gamma-Ray Spectrum of ${ }^{90} \mathrm{Rb}$. The dato have been corrected for the contribution from $14.9-\min { }^{89} \mathrm{Rb}$. and gamma-gamma coincidence spectra, the best energy values (and intensities) of the gamma rays were found to be $0.53(6.6), 0.72(6.5), 0.832$ (90), $0.86(10), 1.03(6.0), 1.11$ (13), $1.24(4.3), 1.40$ (8.3), $1.70(6.1), 1.82(4.8), 2.20(3.6), 2.51(5.6)$, $2.72(1.8), 2.84(3.0), 3.07(9.7), 3.34(28), 3.54$ (12), $4.13(20), 4.34(24), 4.37(7.8), 4.60(8.4)$, 5.08 (3.0), and 5.23 (6.7) Mev. Also, from singlecrystal and beta-gamma coincidence spectra, betaray groups were observed with energies of 1.31 , $2.0,2.2$ (complex), 4.37, 5.81, and $6.60 \mathrm{Mev}$, where the last energy represents the separation between the ${ }^{90} \mathrm{Rb}$ and ${ }^{90} \mathrm{Sr}$ ground states.

From these measurements, a decay scheme is proposed for ${ }^{90} \mathrm{Rb}$, which involves 12 states in the daughter nucleus ${ }^{90} \mathrm{Sr}$. This scheme is shown in Fig. 1.6.

During the course of these experiments, the half-lives of ${ }^{90} \mathrm{Rb}$ and ${ }^{91} \mathrm{Rb}$ were remeasured as $2.91 \pm 0.05 \mathrm{~min}$ and $1.17 \pm 0.10 \mathrm{~min}$ respectively.

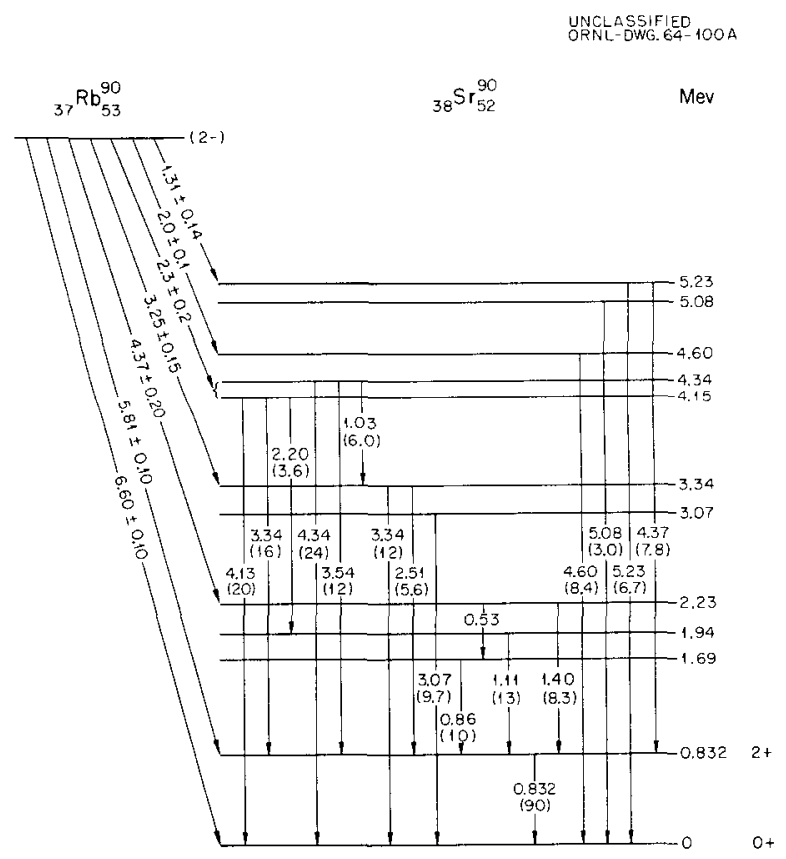

Fig. 1.6. Partial Decay Scheme Proposed for ${ }^{90} \mathrm{Rb}$. All energies are in Mev. Relative intensities based on the single crystal and coincidence data are given in parentheses beneath the gamma-ray energies. 


\section{A Survey of Some Properties of Even-Even Nuclei}

Eugene Eichler

Ten years have passed since the last comprehensive surveys of the properties of even-even nuclei. ${ }^{11}$ These explorations proved most valuable in establishing two regions of homogeneous behavior: the rotational region and the vibrational region. Properties of the nuclei in the former region are now quite accurately described by the collective model of Bohr and Mottelson ${ }^{12}$ with its numerous extensions. However, as yet no single model describes completely the vibrational nuclei.

The vibrational nuclei are found in the mediumweight region $(50<A<150)$. This designation arises from several systematic characteristics of these nuclei:

1. They all possess low-lying first excited states with spin and parity $2+$ (except for ${ }^{90} \mathrm{Zr}$ and ${ }^{72} \mathrm{Ge}$, which have $0+$ first excited states).

2. The second excited states appear at approximately twice the energy of the first and have the character $2+, 4+$, or $0+$.

3. These states are strongly excited in electric quadrupole processes such as Coulomb excitation; conversely, their decay rates are far in excess of the single-particle estimates.

Such level spectra are suggestive of a simple quadrupole vibrator. The $2+$ character of the first excited state and the energy ratio of the second to first state of about 2 are consistent with experimental observations. In the pure vibrational picture, the two- and three-phonon states are degenerate multiplets. However, with real nuclei the degeneracy of the upper phonon levels is lifted, and the second excited states have unique spins and parities. The most frequently observed character for the second state is $2+$, with $4+$ much less usual, and $0+$ only rarely observed. A number of $2+, 4+$ doublets have been seen, but in only a few instances has the full triplet been identified. In the hope that the considerable body of new data may aid in further interpretation, I have sur-

\footnotetext{
${ }^{11}$ G. Scharff-Goldhaber, Phys. Rev. 90, 587 (1953); also P. Preiswerk and P. Stahelin, Helv. Phys. Acta 24, 623 (1952).

${ }^{12}$ A. Bohr and B. Mottels on, Kgl. Danske Videnskab. Selskab, Mat.-Fys. Medd. 26(16) (1953).
}

veyed some of the nuclear properties of even-even nuclei in the medium-weight region. The energies of the one-phonon states will be considered in this report. The complete survey has been published in the open literature. ${ }^{13}$

In this investigation, the source of most of the data was the Nuclear Data Sheets. ${ }^{14}$ In order to gather the recent information, the "Recent References - August, 1962" from the Nuclear Data Group and the indexes of Nuclear Science $A b$ stracts were used as guides. ("Recent References - July, 1963" was not available at the time this survey was completed.) Unfortunately, space limitations preclude referencing each entry in the illustrations shown below.

Figures 1.7 and 1.8 show the first $2+$ excited state energies vs both $N$, neutron number, and $Z$, proton number. A similar plot was prepared by Nakasima and issued with the Nuclear Data Sheets. ${ }^{15}$ Looking first at the neutron number plot, Fig. 1.7, we are struck by the rapid increase at the major shell closures with a decrease in between to a rather low valley. Beyond the 82 she11, there is a precipitous drop to the rareearth deformed region. The valley between the shells also descends to a new deformed region.

The valleys between the shells are peppered with fine structure. Starting at the high end of the $Z$ plot (Fig. 1.8), we see a small peak at 64 protons in the 84- and 86-neutron chains. This corresponds to the filling of both the $1 g_{7 / 2}$ and $2 d_{5 / 2}$ orbitals. This " 64 " effect is seen also for neutrons in the 50-proton nuclei. At lower $Z$ values, the $g_{7 / 2}$ filling at 58 protons produces a peaking which is seen not only in the 78-, 80-, and 84-neutron chains, but also in magic series of $N=$ 82. There is no 58 -neutron peak, but there is one at 56 in the 40- and 42-proton families. This is to be expected since the $g_{7 / 2}, d_{5 / 2}$ order is inverted for neutrons. Similar subshell effects have been seen by Cohen et al. ${ }^{16}$ in their measurement of neutron-separation energies at 56 and 64 neutrons.

\footnotetext{
${ }^{13} \mathrm{E}$. Eichler, to be published in Reviews of Modern Physics.

${ }^{14}$ Nuclear Data Sheets, National Academy of Sciences, National Research Council, Washington, D.C.

${ }^{15}$ R. Nakasima, Nuclear Data Sheets, NRC 61-4-127.

${ }^{16}$ B. L. Cohen et al., Bull. Am. Phys. Soc. 9, 461 (1964).
} 


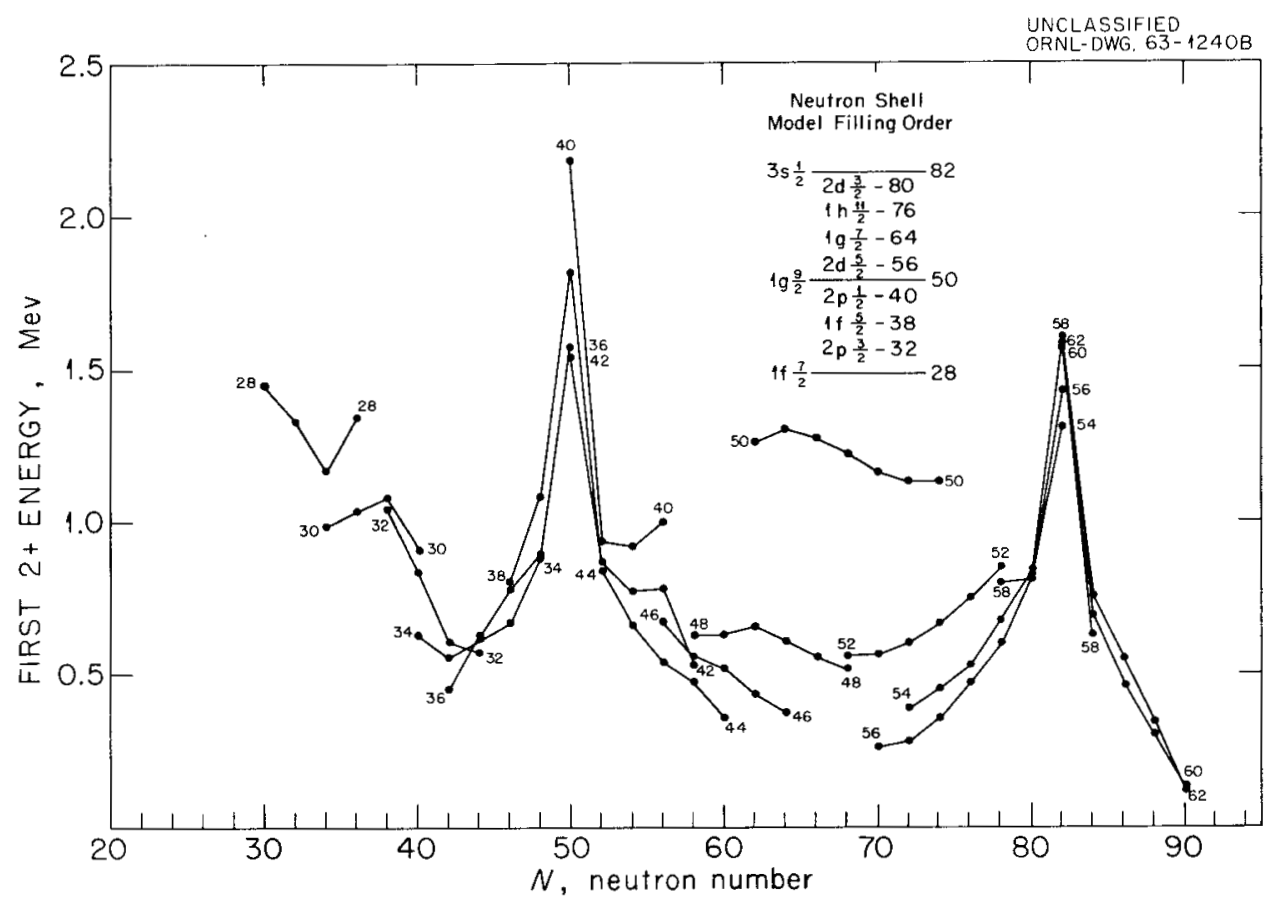

Fig. 1.7. Plot of the Energies of the First 2+ Excited States of Even-Even Nuclei vs Neutron Number. Lines join isotopic chains and are marked with proton numbers.

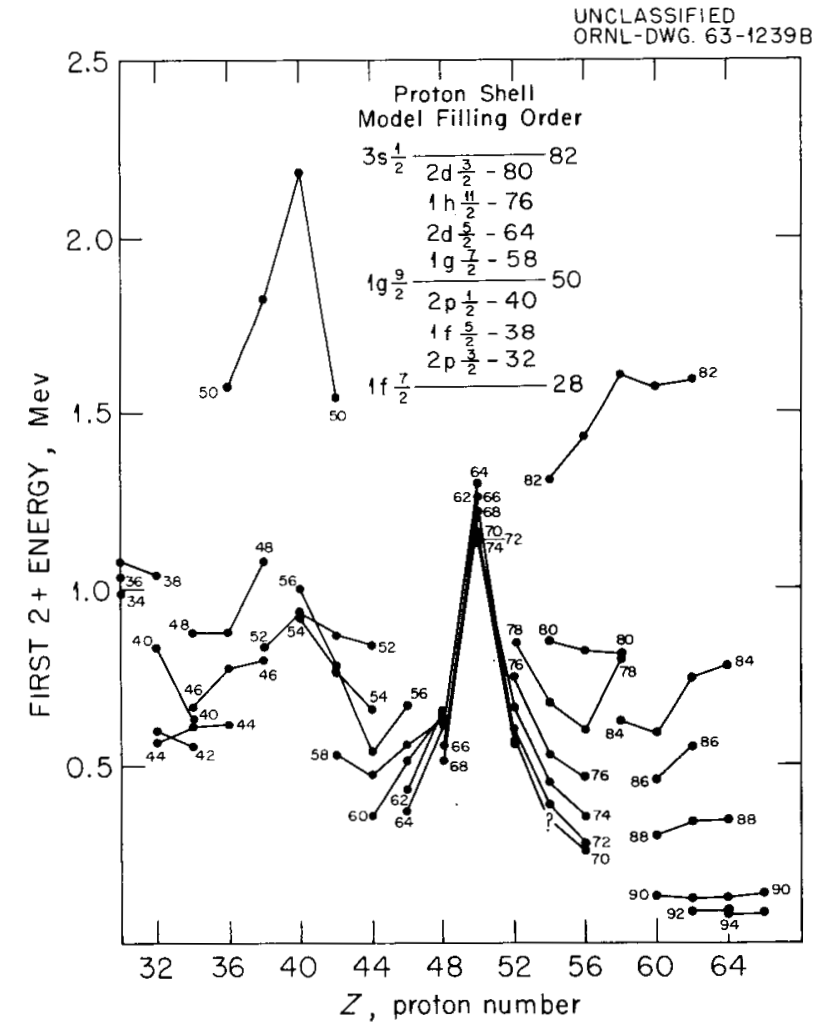

Fig. 1.8. Plot of the Energies of the First 2+ Excited States of Even-Even Nuclei vs Proton Number. Lines join isotonic choins and are marked with neutron numbers. 
The effect of the 38 and 40 subshells is interesting. First of all, there is a distinct peak at $N=$ 38 seen in the zinc $(Z=30)$ and germanium $(Z=$ 32) families. However, there seems to be none for $N=40$ unless the 34-proton upswing can be called a peak. On the other hand, at $Z=40$ there is a distinct peaking. In fact, ${ }^{9} \mathrm{Zr}$ with 40 'protons and 50 neutrons behaves like a doubly magic nuclide having a $0+$ first excited state and first $2+$ excited state of $2.18 \mathrm{Mev}$, the highest above the lightelement region. There is also a peak in the $N=52, N=54$, and $N=56$ chains at 40 protons. But there is no $f_{5 / 2}$ filling effect at 38 protons.

To recapitulate briefly, there is definite evidence of shell-model fine structure at certain points between the major shell closures for many isotopic and isotonic families. The presence of these effects in some chains and their absence in others suggests several thoughts about even-even nuclei and their vibrational motion.

First, the great sensitivity of the phonon energy to subshell closure supports the view that vibrational motion involves principally the particles beyond the major closed shells. Further, the normal shell-model ground-state filling scheme must be altered in even-even nuclei by the pairing force. Some subshell splittings become large, resulting in the discontinuities cited above.

However, note that these peaks in the $2+$ energy values occur for those isotopes whose proton numbers are not too far removed from closed-shell numbers (or conversely for those isotones whose neutron numbers are near magic values). For example, subshell effects are present in the isotopic chains with proton number 50 and 48 , but not 44 and 46. Thus, it appears that for nuclei fairly distant from closed shells the fine structure is washed out.

\section{Low-Energy States in ${ }^{49} \mathrm{Sc}$ Populated in the Decay of ${ }^{49} \mathrm{Ca}$}

\author{
G. G. Chilosi ${ }^{17}$ G. D. O'Kelley
}

\section{E. Eichler}

Early investigations of the decay properties of $8.8-\min { }^{49} \mathrm{Ca}$ at this Laboratory ${ }^{18}$ and elsewhere ${ }^{19}$ established three energy levels in ${ }^{49} \mathrm{Sc}$ at about 3.1, 4.1, and 4.7 Mev (see decay scheme, Fig.
1.10). The ground state of ${ }^{49} \mathrm{Ca}$ has been identified as $32^{-}$, in agreement with the shell-model prediction of $p_{3 / 2}$. The values of $\log f t$ for the beta transitions from ${ }^{49} \mathrm{Ca}$ to the excited states indicated that the transitions were all allowed. On the basis of this information and the absence of intense cascade gamma rays between the excited levels, the 3.1- and 4.1-Mev states were assigned spins and parities $3 / 2-$ and $5 / 2-$ respectively. These states were identified as the $p_{3 / 2}$ and $f_{5 / 2}$ single-particle states. However, gamma-ray transition probability arguments militated against the expected assignment of $p_{1 / 2}$ to the $4.7-$ Mev state. ${ }^{18}$

Recently, new low-lying energy levels of ${ }^{49} \mathrm{Sc}$ were discovered in studies of the reaction ${ }^{48} \mathrm{Ca}(p, \gamma){ }^{49} \mathrm{Sc}$. Vingiani and Endt ${ }^{20}$ reported levels in ${ }^{49} \mathrm{Sc}$ at $2.21,2.35,3.09$, and possibly 3.90 Mev. Similar results were obtained by Dubois and Maripuu, ${ }^{21}$ who found evidence for levels at $2.22,2.34,3.10,3.50$, and probably 3.93 Mev. All of these levels except the one at $3.50 \mathrm{Mev}$ decayed by direct gamma-ray emission to the $7 / 2$ - ground state of ${ }^{49} \mathrm{Sc}$.

When the early results of Vingiani and Endt became available, we decided to reinvestigate the decay of ${ }^{49} \mathrm{Ca}$, in the hope that the gamma rays from the two ${ }^{49} \mathrm{Sc}$ levels near $2 \mathrm{Mev}$ could be seen. It seemed possible that these low-energy levels might be the expected $d_{3 / 2}$ and $s_{1 / 2}$ hole states; if so, then the expected gamma-ray intensity would only be a few tenths of a percent of the 3.10-Mev gamma-ray intensity. In the earlier experiments on ${ }^{49} \mathrm{Ca}$, which used $3 \times 3$ in. NaI detectors, such weak gamma peaks were presumed to have been submerged in the Compton electron distribution and annihilation radiation escape peaks from the intense 3.10-Mev gamma ray. For this reason, the new investigation employed a

\footnotetext{
${ }^{17}$ NATO Fellow on leave of absence from I.N.F.N. and Istituto di Fisica Superiore, Universita di Napoli, Naples, Italy.

${ }^{18}$ G. D. O'Kelley, N. H. Lazar, and E. Eichler, Phys. Rev. 101, 1059 (1956).

${ }^{19}$ D. W. Martin, J. M. Cork, and S. B. Burson, Phys. Rev. 102, 457 (1956).

${ }^{20} \mathrm{G}$. B. Vingiani and P. M. Endt, abstract of a paper presented at XLIL Congresso della Società Italiana di Fisica, Bari, Italy, November 6-13, 1963; to be published in Nuovo Cimento, Supplemento.

21 J. Duobis and S. Maripuu, Phys. Letters 8, 349 (1964).
} 
three-crystal scintillation pair spectrometer, ${ }^{22}$ whose response to high-energy gamma rays exhibits a very small low-energy "tail."

The low-energy portion of a pair spectrum of ${ }^{49} \mathrm{Ca}$ is shown in Fig. 1.9. Two weak gamma-ray peaks were successfully resolved at $2.22 \pm 0.02$ and $2.36 \pm 0.02 \mathrm{Mev}$, and their intensities were measured relative to the intensity of the gamma ray at $3.10 \mathrm{Mev}$. The gamma ray from the reported $^{20.21}$ level at $3.9 \mathrm{Mev}$ was not seen; its intensity must be less than 0.001 that of the 3.10-Mev gamma ray.

The results are summarized in the decay scheme of Fig. 1.10. After the completion of our experiments on ${ }^{49} \mathrm{Ca}$, Yntema and Satch ler ${ }^{23}$ published

\footnotetext{
${ }^{22}$ A general description of the instrument is given in "Decay Scheme of ${ }^{38} \mathrm{Cl}$," sect. 1 , this report.
}

information on the low-energy levels of several scandium isotopes studied by means of the $\left(d,{ }^{3} \mathrm{He}\right)$ reaction on titanium. They found that the angular distribution of the ${ }^{3} \mathrm{He}$ group from the $2.36 \mathrm{Mev}$ state of ${ }^{49} \mathrm{Sc}$ possessed a considerable $1=2$ component which approximately exhausted the $d_{3 / 2}$ hole strength. From angular correlation measurements, Dubois and Maripuu ${ }^{21}$ proposed a spin of either $\frac{3}{2}$ or $\frac{5}{2}$ for this level. The high $\log f t$ for the beta transition suggests positive parity for the 2.36-Mev level, which further confirms its identification as a $d_{3 / 2}$ hole state.

The $\log f t$ value (7.9) for the beta transition to the 2.22-Mev level suggests positive parity for this state also. It appears unlikely that this level can be the $s_{1 / 2}$ hole state, since the systematic

${ }^{23}$ J. L. Yntema and G. R. Satchler, Phys. Rev. 134, B976 (1964).

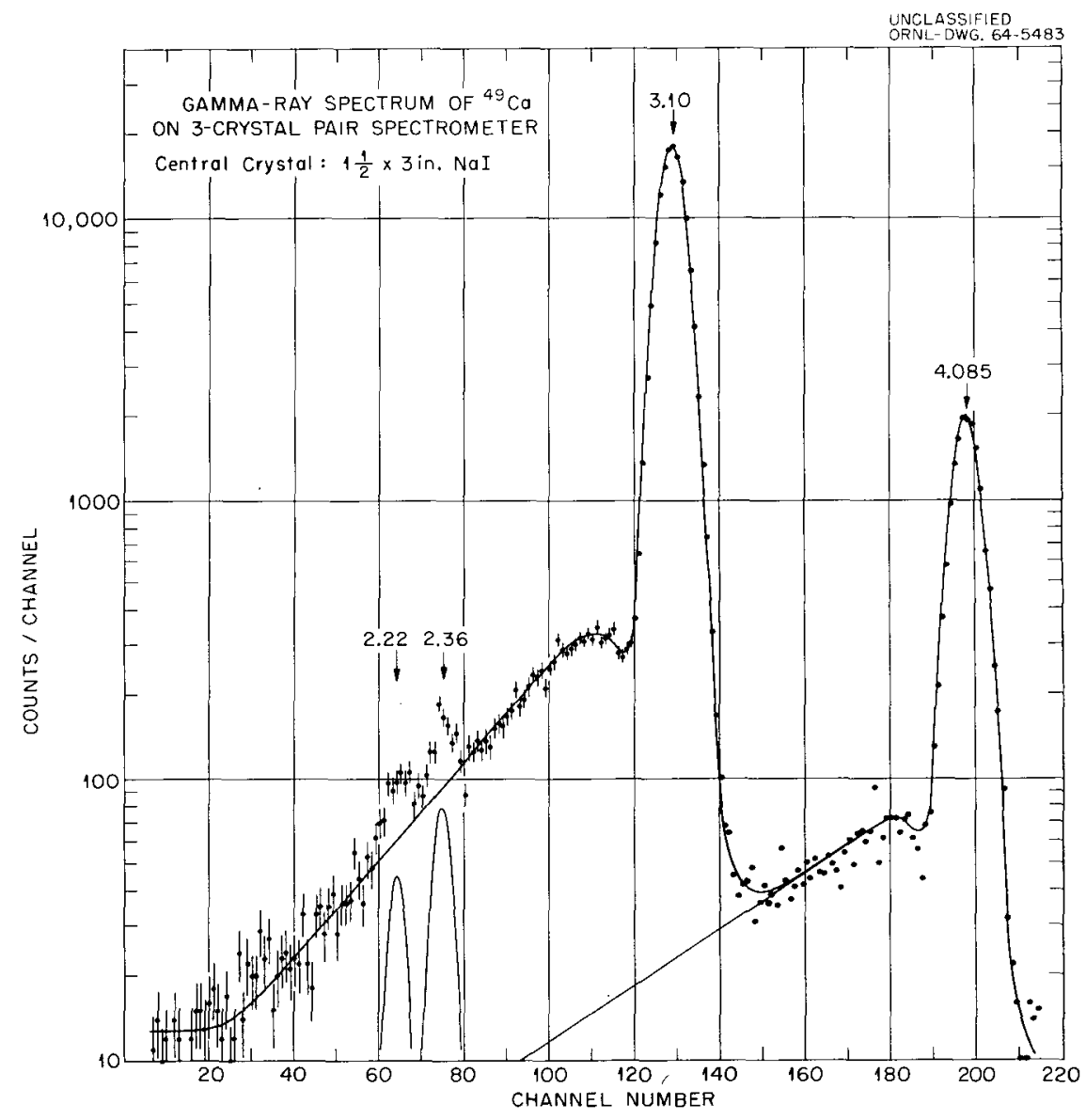

Fig. 1.9. Pair Spectrum of 8.8-min ${ }^{49} \mathrm{Ca}$, Low-Energy Portion. Energies are in Mev. 


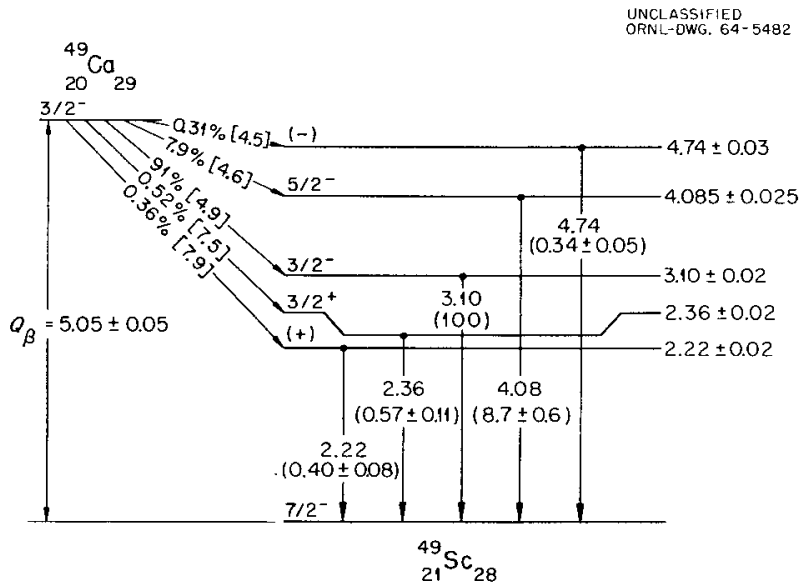

Fig. 1.10. Decay Scheme Proposed for ${ }^{49} \mathrm{Ca}$. The pair of numbers with each gamma ray gives its energy in Mev and in parentheses its intensity relative to that of the 3.10-Mev gamma ray as 100 units. The pairs of numbers for the beta transitions give the branching in percent and the log $f t$ value in brackets.

trend in the excitation energy of the $s_{1 / 2}$ hole state in the scandium isotopes ${ }^{23}$ indicates that this level must be rather high in ${ }^{49} \mathrm{Sc}$, probably $>3$ Mev. It is possible that the $3.50-$ Mev state observed by Dubois and Maripuu may be the expected $s_{1 / 2}$ level, since it is not populated strongly in beta decay, and its gamma decay to the $7 / 2$ ground ștate of ${ }^{49} \mathrm{Sc}$ has not been observed.

It should be noted that the $\log \mathrm{ft}$ values for beta transitions to the 2.22- and 2.36-Mev states of ${ }^{49} \mathrm{Sc}$ are lower limits, since the calculated beta branching would be lowered if there were weak cascade gamma rays decaying to these levels. However, previous investigations ${ }^{18,19}$ failed to disclose any such low-energy cascade transitions.

\section{Thermal-Neutron Cross Section and Resonance Integral of ${ }^{106} \mathrm{Pd}$}

\author{
P. M. Lantz \\ C. R. Baldock
}

L. E. Idom

The cross section of stable ${ }^{106} \mathrm{Pd}$ formed in fission has taken on a new significance since the cross section of another source, ${ }^{105} \mathrm{Rh}$, reported in this chapter has been found to be very large. The direct measurement of the ${ }^{106} \mathrm{Pd}$ activation cross section was possible since the available source material contained less than one part of mass 107 in $5 \times 10^{5}$ parts of mass 106 .

A sample of calutron-concentrated (82.36\%) ${ }^{106} \mathrm{Pd}$ metal was divided into three parts and sealed in quartz ampuls. The bare and the two cadmium-wrapped ampuls were irradiated with dilute cobalt monitors in an appropriate container in a high-flux position in the ORR. They were irradiated to $4.02 \times 10^{20} \mathrm{nvt}$ in a region where the $\Phi_{t h} / \Phi_{r}=14.9$.

After the irradiation the palladium was dissolved out of the quart $z$ container with aqua regia and adjusted to a weak nitrate solution. The ${ }^{107} \mathrm{Pd}$ content of each of the samples relative to ${ }^{106} \mathrm{Pd}$ was determined using a two-stage mass spectrometer. ${ }^{24}$ The palladium was reduced with hydrazine hydrate on a thenium filament and $\mathrm{Pd}^{+}$ metal ions were produced by a surface ionization technique; the ions were detected with a multistage electron multiplier tube. The data are summarized in Table 1.1.

The mass spectrographic ratios ${ }^{107} \mathrm{Pd} /{ }^{106} \mathrm{Pd}$ (accurate to $\sim 1 \%$ ) are shown in the fourth column. The fifth column gives the effective cross section

\footnotetext{
${ }^{24}$ See “Two-Stage Mass Spectrometer," Chemical Physics, sect. 9, this report.
}

Table 1.1. Neutron Cross Section Determination of ${ }^{106} \mathrm{Pd}$

\begin{tabular}{ccccccc}
\hline Sample & $\begin{array}{c}\Phi_{\mathrm{th}} \\
\text { (neutrons } \mathrm{cm}^{-2} \mathrm{sec}^{-1} \text { ) }\end{array}$ & $\begin{array}{c}\Phi_{\mathrm{r}} \\
\text { (neutrons } \mathrm{cm}^{-2} \mathrm{sec}^{-1} \text { ) }\end{array}$ & $\frac{{ }^{107} \mathrm{Pd}}{106 \mathrm{Pd}}$ & $\begin{array}{c}\sigma_{\text {eff }} \\
\text { (barns) }\end{array}$ & $\begin{array}{c}\sigma_{\mathrm{th}} \\
\text { (barns) }\end{array}$ & $\begin{array}{c}I_{0} \\
\text { (barns) }\end{array}$ \\
\hline & $\times 10^{13}$ & $\times 10^{12}$ & $\times 10^{-4}$ & & & \\
1 & & 5.94 & 1.41 & & & 5.50 \\
3 & 9.32 & & 2.72 & 0.676 & 0.292 & \\
\hline
\end{tabular}


for the bare sample, where the ratio $\Phi_{t h} / \Phi_{r}$ was 14.9. In columns six and seven are given the single thermal-neutron cross section, $\sigma_{t h}$, measurement of 0.29 barn and the two resonance integral, $I_{0}$, determinations, whose average is 5.73 barns. The error in these determinations, due largely to the uncertainties in the flux measurements, is estimated to be less than $10 \%$.

These ratios will be reexamined in the course of mass spectrographic measurements of mass shift in samples of enriched ${ }^{104} \mathrm{Pd}$ and ${ }^{105} \mathrm{Pd}$, as well as natural palladium, which were irradiated with the above ${ }^{106} \mathrm{Pd}$ material.

\section{Thermal-Neutron Cross Section and Resonance Integral of ${ }^{104} \mathrm{Ru}$}

\section{P. M. Lantz}

The neutron activation cross section of ${ }^{104} \mathrm{Ru}$ has been reported in the literature by Seren et al. ${ }^{25}$ as $0.7 \pm 0.2$ barn. To determine accurately the neutron cross section of ${ }^{105} \mathrm{Rh}$, produced by activation of ${ }^{104} \mathrm{Ru}$, it was necessary to measure the thermal-neutron cross section, $\sigma_{\text {th }}$, and resonance integral, $I_{0}$, of ${ }^{104} \mathrm{Ru}$.

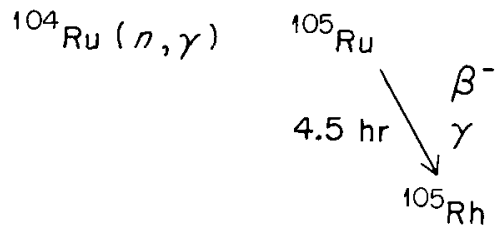

The activation cross section for this reaction can be determined by measuring the activity of ${ }^{105} \mathrm{Ru}$ formed in the irradiation of ${ }^{104} \mathrm{Ru}$.

Ruthenium-105 emits a simple beta spectrum with an end-point energy of $1.15 \mathrm{Mev}$, followed by a $0.726-\mathrm{Mev}$ gamma ray to a metastable level in ${ }^{105} \mathrm{Rh}$. The counting efficiency for the $0.726-\mathrm{Mev}$ gamma ray in a 3-in. NaI crystal-Du Mont 6363 phototube assembly and multichannel analyzer was established by determining the absolute counting rate of a pure $(>99 \%){ }^{105} \mathrm{Ru}$ source by the $4 \pi$ beta-gamma coincidence method. The specific activity of the $0.726 \mathrm{Mev}$ energy peak was measured with the same geometry and energy-to-channel relationship. Since no interference was expected from induced activity in other ruthenium isotopes of natural ruthenium, this was considered a satisfactory method. The samples were irradiated in sealed quartz ampuls according to the cadmium ratio technique using dilute cobalt and gold monitors for $\sim 2.2 \times 10^{17} n v t$ in the LITR.

Following the irradiation, the quartz ampuls were crushed and the weighed ruthenium metal dissolved by fusing with $\mathrm{NaOH}-\mathrm{NaNO}_{3}$ and dissolving the cake in water. Appropriate aliquots of these solutions were counted in the crystal counter for one to two ${ }^{105} \mathrm{Ru}$ half-lives.

The data from several of these measurements are summarized in Table 1.2. The $15 \%$ spread between the extreme cross section values can

\footnotetext{
${ }^{25}$ Leo Seren, H. N. Friedlander, and S. H. Turkel, Phys. Rev. 72, 888 (1947).
}

Table 1.2. Measurement of Neutron Cross Section of ${ }^{104} R_{u}$

\begin{tabular}{|c|c|c|c|c|c|c|c|c|}
\hline Sample & $\frac{\Phi_{\mathrm{th}}}{\Phi_{\mathrm{r}}}$ & $\begin{array}{c}\Phi_{\mathrm{th}} \\
\text { (neutrons } \mathrm{cm}^{-2} \mathrm{sec}^{-1} \text { ) }\end{array}$ & $\begin{array}{l}\text { Mass Ratio } \\
\qquad \begin{array}{c}\frac{105}{104} \\
\text { (Bare) }\end{array}\end{array}$ & $\begin{array}{l}\text { Mass Ratio } \\
\frac{105}{104} \\
\text { (Cadmium } \\
\text { Wrapped) }\end{array}$ & $\begin{array}{c}\sigma_{0} \\
\text { (barns) }\end{array}$ & $\begin{array}{c}\sigma_{\text {th }} \\
\text { (barns) }\end{array}$ & $\begin{array}{c}I_{0} \\
\text { (barns) }\end{array}$ & $\begin{array}{c}\sigma_{\text {eff }} \\
\text { (barns) }\end{array}$ \\
\hline & & $\times 10^{-12}$ & $\times 10^{-8}$ & $\times 10^{-8}$ & & & & \\
\hline 1 & 19.0 & 8.62 & 8.7 & 3.2 & 0.45 & 0.46 & 5.0 & 0.72 \\
\hline 2 & 15.3 & 9.61 & 10.9 & 3.9 & 0.51 & 0.52 & 4.4 & 0.81 \\
\hline 3 & 15.9 & 9.51 & 10.1 & 3.5 & 0.49 & 0.50 & 4.3 & 0.77 \\
\hline \multirow[t]{2}{*}{4} & 15.3 & 8.41 & 8.8 & 3.7 & 0.43 & 0.44 & 4.7 & 0.75 \\
\hline & & & & & 0.47 & 0.48 & 4.6 & \\
\hline
\end{tabular}


be accounted for by the uncertainties inherent in the experiment; the principal one is the ease of oxidation of ruthenium to the highly volatile tetroxide. Further investigation is planned in an effort to eliminate some of this uncertainty. Subject to the above mentioned limitation, the activation cross section of ${ }^{104} \mathrm{Ru}$ can be reported as $\sigma_{0}=0.47$ barn, $\sigma_{\mathrm{th}}=0.48$ barn, and $I_{0}=4.6$ barns.

\section{Resonance Integral and Thermal-Neutron Cross Section of ${ }^{105} \mathrm{Rh}$}
P. M. Lantz
C. R. Baldock
R. W. Stoughton
L. E. Idom

The measurement of the effective cross section of ${ }^{105} \mathrm{Rh}$ previously reported ${ }^{26}$ has been extended to the determination of an upper limit for the thermal cross section and the resonance integral. The very large resonance integral was found to contribute at least $90 \%$ of the total neutron capture cross section.

Two batches of enriched ${ }^{104} \mathrm{Ru}$ metal (20 and $40 \mathrm{mg}$ ) were irradiated in the ORR $3-W-1$ stringer and No. 25 hydraulic tube under bare and cadmiumfiltered conditions for $7.52 \times 10^{20}$ and $3.94 \times 10^{20}$ $n v t$, respectively. After several weeks cooling time the ruthenium metal was dissolved and the palladium recovered according to methods ${ }^{26}$ previously described, for examination in a twostage mass spectrometer. The ratios ${ }^{106} \mathrm{Pd} /{ }^{105} \mathrm{Pd}$ relative to ${ }^{108} \mathrm{Pd}$, which was present in the enriched ${ }^{102} \mathrm{Pd}$ carrier, were determined by the isotope-dilution technique.

The desired cross sections were computed from the data on the IBM 7090 computer, with a program which took account of the actual schedule of irradiation instead of simply the total on-time of the reactor. Parameters used in the calculation were: $T_{1 / 2}{ }^{105} \mathrm{Ru}=4.5 \mathrm{hr},{ }^{27} T_{1 / 2}{ }^{105} \mathrm{Rh}=36.5$ hr, ${ }^{27} \sigma_{\text {th }}{ }^{104} \mathrm{Ru}=0.42$ barn, and $I_{0}{ }^{104} \mathrm{Ru}=4.1$ barns.

On the basis of these experiments a thermalneutron cross section of $\sim 2 \times 10^{4}$ barns and

\footnotetext{
${ }^{26}$ Chem. Div. Ann. Progr. Rept. June 20, 1963, ORNL3488 , p. 16 .

${ }^{27}$ W. H Sullivan, N. R. Sleight, and E. M. Gladrow, Nat1. Nucl. Energy Ser., Div. IV 9, 817-20 (1951).
}

a resonance integral approximately equal to $1.65 \times 10^{5}$ barns $^{28}$ can be reported for ${ }^{105} \mathrm{Rh}$. The effective cross sections measured were within the limits of those previously reported. Since the resonance integral exerts so large an influence on the effective cross section, it will be necessary to continue this investigation to establish a thermal-neutron cross section value with a higher confidence level. The magnitude of the resonance integral implies a significant neutron loss to ${ }^{105} \mathrm{Rh}$ in a fast-flux reactor system.

\section{The Neutron Capture Cross Sections of Ruthenium Nuclides, Mass Number 98 Through 101}

\section{J. Halperin \\ C. R. Baldock}

J. H. Oliver

Milligram quantities of calutron-enriched isotopes of metallic ${ }^{98} \mathrm{Ru},{ }^{99} \mathrm{Ru},{ }^{100} \mathrm{Ru}$, and ${ }^{101} \mathrm{Ru}$ have been irradiated in the lattice of the ORR for an integrated flux-time of $3.79 \times 10^{20}$ neutrons/ $\mathrm{cm}^{2}$. The thermal flux was measured as $0.88_{3} \times$ $10^{14}$ and the ratio of thermal to resonance flux was found to be $13.4_{4}$ using dilute cobalt alloys.

Mass analyses were performed on the unirradiated and irradiated ruthenium samples using the two-stage mass spectrometer. The ruthenium metal was deposited upon a rhenium filament, and singly charged ruthenium metal ions were produced by surface ionization and detected with a 14-stage electron multiplier tube. The mass data from these irradiations are summarized in Table 1.3.

Effective neutron capture cross sections and resonance integrals were estimated from the change in mass abundance using the expression

$$
\begin{array}{r}
\sigma_{i}=\frac{\left(N_{i+1} / N_{i}\right)_{f}-\left(N_{i+1} / N_{i}\right)_{o}}{\phi t\left[1-0.5 \phi t\left(\sigma_{i+1}-\sigma_{i}\right)\right]\left[1+\left(N_{i+1} / N_{i}\right)_{o}\right]} \\
+\frac{\left(N_{i+1} / N_{i}\right)_{o}}{1+\left(N_{i+1} / N_{i}\right)_{o}} \sigma_{i+1}
\end{array}
$$

Here the subscripts $i$ and $i+1$ refer to the abundant mass species being irradiated and the next higher mass number respectively; the subscripts

\footnotetext{
${ }^{28}$ The a uthors gratefully acknowledge the assistance of Joseph Halperin in making these measurements.
} 
Table 1.3. Neutron Capture Cross Sections of Ruthenium Isotopes

\begin{tabular}{|c|c|c|c|c|c|}
\hline \multirow{2}{*}{$\begin{array}{c}\text { Enriched } \\
\text { Nuclide }\end{array}$} & \multicolumn{3}{|c|}{ Mass Analys is } & \multirow{2}{*}{$\begin{array}{l}\sigma_{\text {eff }}^{a} \\
\text { (barns) }\end{array}$} & \multirow{2}{*}{$\begin{array}{c}I \\
\text { (barns) }\end{array}$} \\
\hline & $\begin{array}{c}\text { Nuclide } \\
\text { Ratio }\end{array}$ & Initial & Final & & \\
\hline${ }^{98} \mathrm{Ru}$ & $99 / 98$ & $0.3517 \pm 0.003$ & Unchanged & $<8$ & \\
\hline${ }^{99} \mathrm{Ru}$ & $100 / 99$ & $0.04508 \pm 0.0001$ & $0.04909 \pm 0.00005$ & $10.6 \pm 0.6$ & \\
\hline${ }^{99} \mathrm{Ru}^{b}$ & $100 / 99$ & $0.04508 \pm 0.0001$ & Unchanged & & $<4$ \\
\hline${ }^{100} \mathrm{Ru}$ & $101 / 100$ & $0.0456 \pm 0.0002$ & $0.0496 \pm 0.0001$ & $10.4 \pm 0.7$ & \\
\hline${ }^{101} \mathrm{Ru}$ & $102 / 101$ & $0.0543_{9} \pm 0.0003$ & $0.0555_{7} \pm 0.0002$ & $3.1 \pm 0.9$ & \\
\hline${ }^{101} \mathrm{Ru}^{b}$ & $102 / 101$ & $0.0543_{9} \pm 0.0003$ & Unchanged & & $<10$ \\
\hline
\end{tabular}

$f$ and $o$ refer to the ratio following irradiation and initially respectively. The effective cross section $\sigma\left(\sigma_{\text {eff }} \equiv\right.$ reaction rate per unit thermal flux ${ }^{29}$ ) may be replaced by the resonance integral $I$ when the thermal-flux-irradiation-time product is replaced by the resonance-flux-irradiation-time product.

No other measurements of the neutron capture cross sections of these ruthenium nuclides appear to have been reported. A summation of the partial cross sections of the seven stable nuclides of ruthenium leads to an elemental cross section of 3.8 barns, which is some $50 \%$ greater than the 2.5-barn pile oscillator measurement of Pomerance. $^{30}$ Ruthenium-101, which is made in fission with a yield of about $5 \%$, is found to have the relatively low cross section of $3.1 \pm 0.9$ barns. Ruthenium-100, which is formed from the neutron capture of the $2 \times 10^{5}$ year fission product ${ }^{9} \mathrm{Tc}$, is here found to have a cross section of $10.4 \pm$ 0.7 bams. The effective cross section of ${ }^{9}{ }^{9} \mathrm{Ru}$ is similarly found to be $10.6 \pm 0.6$ barns. No change was detected in the ${ }^{98} \mathrm{Ru}$ irradiation, leading to an upper limit of 8 barns. Similarly the cadmium-filtered irradiations of ${ }^{99} \mathrm{Ru}$ and ${ }^{101} \mathrm{Ru}$ showed no measurable change in mass ratio, yielding upper limits for the resonance integrals of 4 and 10 barns respectively.

${ }^{29} \mathrm{~J}$. Halperin and R. W. Stoughton, Nucl. Sci. Eng. 6, 100 (1959).

${ }^{30}$ H. Pomerance, Phys. Rev. 83, 641 (1951).

\section{The Thermal-Neutron Capture Cross Section and Resonance Integral of ${ }^{242} \mathrm{Pu}$}

J. Halperin J. H. Oliver

The neutron capture cross section of the $3.79 \times$ $10^{5}$ year ${ }^{242} \mathrm{Pu}$ is of some interest since it is an intermediate in the production of transplutonium elements in high-flux reactors. The buildup of the fissionable ${ }^{245} \mathrm{Cm}$ through neutron capture by ${ }^{242} \mathrm{Pu}$ can limit irradiation times because of the heat flux in target elements.

Samples of calutron-separated ${ }^{242} \mathrm{Pu}$ (99.91 at. \% or 98.25 alpha \%) were irradiated in the pneumatic tube facility of the LITR. Approximately $0.75-\mu \mathrm{g}$ samples were irradiated in a linear configuration of groups of three in which the outer two samples were cadmium-filtered to permit an unambiguous interpolation of the epithermal response to the interior position. Dilute aluminum alloys of $\mathrm{Mn}$ $(0.087 \%)$ served to monitor the irradiations. The ${ }^{242} \mathrm{Pu}$ content of the samples was determined by $2 \pi$ alpha counting. The 5.0-hr beta-emitting ${ }^{243} \mathrm{Pu}$ formed during the irradiation was assayed by measuring the $84-\mathrm{kev}$ gamma with a 3 -in. NaIphotomultiplier-tube-multichannel-analyzer assembly. The decay curve of the irradiated ${ }^{242} \mathrm{Pu}$ exhibited the appropriate half-life and showed less than $0.1 \%$ of long-lived impurities. The efficiency for measuring the ${ }^{243} \mathrm{Pu}$ was determined in a separate irradiation wherein the plutonium was purified by an $\mathrm{LaF}_{3}$ precipitation in dilute 
Table 1.4. Neutron Capture Cross Section of ${ }^{242} \mathrm{Pu}$

\begin{tabular}{ccccccc}
\hline Sample & ${ }^{242} \mathrm{Pu}(\mu \mathrm{g})$ & $\phi_{\mathrm{th}}$ & $\phi_{\mathrm{r}}$ & {$\left[\frac{243 \mathrm{Pu}(d / \mathrm{m})}{{ }^{242} \mathrm{Pu}(\mu \mathrm{g})}\right]_{0}$} & $I$ (barns) & $\sigma_{\text {eff }}$ (barns) \\
\hline & & $\times 10^{13}$ & $\times 10^{13}$ & $\times 10^{6}$ & $\times 10^{3}$ & \\
$1^{a}$ & 0.747 & & $0.048_{0}$ & $1.03_{9}$ & $1.27_{6}$ & \\
2 & 0.770 & $1.06_{9}$ & & $1.58_{4}$ & & $89.4_{0}$ \\
$3^{a}$ & 0.751 & & $0.059_{6}$ & $1.31_{2}$ & $1.29_{1}$ & \\
\hline
\end{tabular}

${ }^{a}$ Cadmium filtered.

$\mathrm{HNO}_{3}$ followed by a sorption and elution cycle on an anion exchanger. The purified plutonium was then assayed by a $4 \pi$ beta-gamma coincidence technique and then used to calibrate the counting arrangement.

The results are summarized in Table 1.4. The resonance integral of ${ }^{242} \mathrm{Pu}$ was measured as $1280 \pm 60$ barns. The effective cross section (i.e., based upon the thermal flux) in a position where the ratio of thermal to resonance flux is 19.87 was found to be $89.4 \pm 4.5$ barns. The thermal or subcadmium cross section is thus $24.9 \pm 4$ barns and the value of $\sigma_{0}$, the cross section for $2200-\mathrm{m} / \mathrm{sec}$ neutrons, is estimated as 24.4 barns assuming the usual $1 / v$ dependence in the thermal region.

\section{The Thermal-Neutron Capture Cross Section and Resonance Integral of ${ }^{232} \mathrm{U}$}

\section{J. Halperin C. R. Baldock}

J. H. Oliver

The 71.7-year ${ }^{232} \mathrm{U}$ is of interest in the ${ }^{233} \mathrm{Th}$ ${ }^{23} \mathrm{U}$ breeding cycle because it is formed as a by-product, primarily by the sequence of reactions shown in (1):

$$
\begin{gathered}
{ }^{2{ }^{2}} \mathrm{Th}(n, 2 n)^{231} \mathrm{Th} \underset{\beta^{-}}{\stackrel{25.6 \mathrm{hr}}{2}}{ }^{31} \mathrm{~Pa}(n, y)^{232} \mathrm{~Pa} \\
\stackrel{31.7 \mathrm{hr}}{\beta^{-}}{ }^{232} \mathrm{U} .
\end{gathered}
$$

Because of the relatively short half-life of ${ }^{232} \mathrm{U}$ and its daughters and the hard gammas in that decay chain, the presence of ${ }^{23}{ }^{2} U$ presents significant problems in the purification of ${ }^{233} \mathrm{U}$ and limits the decontamination factor that can be achieved.

Submicrogram samples of ${ }^{232} U$ (produced from irradiated ${ }^{231} \mathrm{~Pa}$ ) containing about $0.75 \%{ }^{233} \mathrm{U}$ were irradiated for times up to about a week in the hydraulic tube of the ORR. This facility provides a thermal flux of about $10^{14}$ neutrons $\mathrm{cm}^{-2} \mathrm{sec}^{-1}$ and a ratio $\phi_{\mathrm{th}} / \phi_{r}$ of approximately 10. Both cadmium-filtered and unfiltered samples were irradiated using dilute alloys of cobalt $(0.151 \%)$ in aluminum to monitor the irradiation. The irradiated samples of uranium were assayed using the two-stage mass spectrometer. Singly charged uranium metal ions were produced by surface ionization from rhenium filaments and measured with a 14-stage electron multiplier.

The data are summarized in Table 1.5 and yield a thermal-neutron capture cross section of $78 \pm 4$ barns and a resonance integral of $280 \pm 15$ barns. A $1 / v$ dependence of the capture cross section in the thermal region would give a value of 75 barns for $\sigma_{0}$, the capture cross section for 2200$\mathrm{m} / \mathrm{sec}$ neutrons. However this $1 / \mathrm{v}$ dependence appears not to be fulfilled in this case.

Uranium-232 is one of the relatively few eveneven nuclei that will undergo fission with thermal neutrons. The thermal fission cross section has been measured as 81 barns $^{31}$ (the reported value is corrected here for the more recent ${ }^{232} \mathrm{U}$ halflife of 71.7 years). The fission cross section of

\footnotetext{
${ }^{31}$ R. Elson et al., Phys. Rev. 89, 320 (1953).
} 
Table 1.5. Neutron Capture Cross Section of ${ }^{232} \mathrm{U}$

\begin{tabular}{|c|c|c|c|c|c|c|c|}
\hline Sample & $\begin{array}{l}\text { Irradiation } \\
\text { Time } \\
(\mathrm{sec})\end{array}$ & $\begin{array}{c}\phi_{\mathrm{th}} \\
\text { (neutrons } \\
\mathrm{cm}^{-2} \mathrm{sec}^{-1} \text { ) }\end{array}$ & $\begin{array}{c}\phi_{\mathrm{r}} \\
\text { (neutrons } \\
\mathrm{cm}^{-2} \mathrm{sec}^{-1} \text { ) }\end{array}$ & $\begin{array}{c}\text { Mass Analysis } \\
{ }^{a}{ }^{3} U /{ }^{232} U\end{array}$ & $\begin{array}{c}\sigma_{\text {eff }} \\
\text { (barns) }\end{array}$ & $\begin{array}{c}I \\
\text { (barns) }\end{array}$ & $\begin{array}{c}\sigma_{\text {th }} \\
\text { (barns) }\end{array}$ \\
\hline & $\times 10^{5}$ & $\times 10^{13}$ & $\times 10^{13}$ & $\times 10^{-2}$ & & & \\
\hline 1 & 2.77 & $11.2_{4}$ & $1.09_{7}$ & $\begin{array}{r}1.080 \pm 0.006 \\
0.838_{5}^{b} \pm 0.001\end{array}$ & $109 \pm 6$ & $285 \pm 30$ & $81 \pm 6$ \\
\hline \multirow[t]{2}{*}{2} & 5.36 & $11.5_{9}$ & $1.13_{6}$ & $\begin{array}{r}1.372 \pm 0.005 \\
0.920^{b} \pm 0.002\end{array}$ & $105 \pm 4$ & $279 \pm 15$ & $77 \pm 4$ \\
\hline & & & & & Weighted av & $280 \pm 15$ & $78 \pm 4$ \\
\hline
\end{tabular}

${ }^{a}$ Mass analysis of unirradiated sample $=0.752 \pm 0.005$.

${ }^{b}$ Mean of two samples.

${ }^{23} \mathrm{U}$ has been measured by James ${ }^{32}$ up to 400 ev. An analysis based upon the resonance parameters indicates that only about $1 / 4$ of the thermal fission cross section and $1 / 10$ of the thermal capture cross section can be accounted for from the known resonances. This indicates the presence of a negative-energy resonance, and a marked departure from a $1 / v$ dependence in the thermal region. The capture resonance integral estimated from the resonance parameters is 220 barns, compared to our directly measured value of 280 barns. However, the uncertainty in the resonance parameter computed value is probably of the order of $50 \%$.

\section{The Thermal-Neutron Capture Cross Section and Resonance Integral of ${ }^{106} \mathrm{Ru}$}
J. Halperin
R. E. Druschel

The neutron cross section of the fission product 1.0-year ${ }^{106} \mathrm{Ru}$ has been measured by irradiating and determining the amount of the $21-\mathrm{min}{ }^{107} \mathrm{Rh}$ formed. See diagram 1:

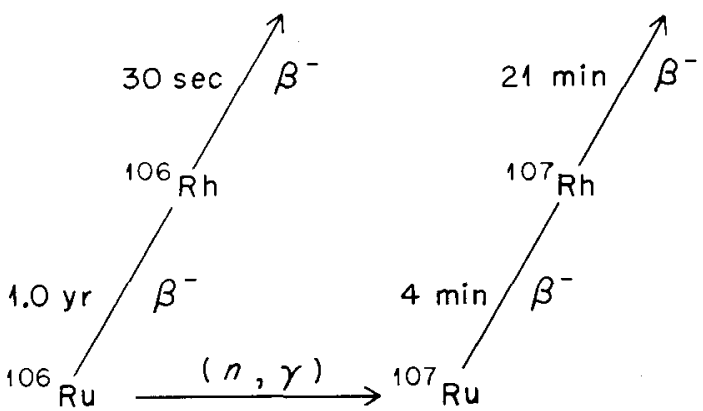

${ }^{32} \mathrm{G}$. D. James, private communication.
Irradiations of ${ }^{106} \mathrm{Ru}$ were carried out both in the pneumatic tube facility of the ORR with a thermal flux of $\sim 4 \times 10^{13}$ neutrons $\mathrm{cm}^{-2} \mathrm{sec}^{-1}$ and in the pneumatic tube of the LITR, where cadmium-filtered irradiations may be carried out at resonance fluxes of $\sim 5 \times 10^{11}$ neutrons $\mathrm{cm}^{-2}$ $\sec ^{-1}$ per unit $\ln E$. Dilute aluminum alloys of $\mathrm{Mn}(0.087 \%)$ were used to monitor the irradiations by measuring the $2.58-\mathrm{hr}{ }^{56} \mathrm{Mn}$.

Ruthenium-106 was deposited in $10-100 \mu \mathrm{c}$ quantities on small pieces of especially purified filter paper. These were enclosed in sealed polyethylene tubes and irradiated for times of from 10 to $30 \mathrm{~min}$. After the irradiation the filter paper was digested in an $\mathrm{H}_{2} \mathrm{SO}_{4}-\mathrm{HNO}_{3}-\mathrm{HClO}_{4}$ medium containing ruthenium and rhodium carriers. This was followed by an $\mathrm{RuO}_{4}$ distillation. In order to measure the ${ }^{107} \mathrm{Rh}$ it was necessary to achieve a decontamination factor of $10^{4}$ from ${ }^{106} \mathrm{Ru}$. The rhodium was then precipitated as the metal by reduction with Devarda's alloy. This latter step served to separate the rhodium from small amounts of other impurities invariably present in the mixture. Separately irradiated filter paper blanks demonstrated the freedom from radioactive contaminants.

Typically it was possible to begin measurements on the ${ }^{107} \mathrm{Rh}$ some two to three half-lives following the end of the irradiation. The 305- and 385kev gammas of ${ }^{107} \mathrm{Rh}$ were followed in an $\mathrm{NaI}$ scintillation well arrangement. They showed the characteristic $21-\mathrm{min}$ period. The $320-\mathrm{kev}$ gamma of ${ }^{51} \mathrm{Cr}$ served to calibrate the counter. The cross section may be estimated by means of Eq. 2:

$$
\sigma=\frac{\left(A_{57} / A_{46}\right)_{\mathcal{T}}}{\phi_{\mathrm{th}} F(t, \mathcal{T})},
$$




$$
\begin{gathered}
F(t, \tau)=\frac{e^{-\lambda_{57} \tau}}{\lambda_{46}\left(\lambda_{47}-\lambda_{57}\right)} \\
\quad\left[\lambda_{47}\left(1-e^{-\lambda_{57} t}\right)\right. \\
\left.-\lambda_{57} e^{-\left(\lambda_{47}-\lambda_{57}\right) \tau}\left(1-e^{-\lambda_{47} t}\right)\right],
\end{gathered}
$$

where $t$ is the irradiation time and $\tau$ is the interval from the end of the irradiation to the time of the ruthenium-rhodium separation. The subscripts 46,47 , and 57 refer to the nuclides ${ }_{44}^{106} \mathrm{Ru},{ }_{44}^{107} \mathrm{Ru}$, and ${ }^{107} \mathrm{Rh}$ respectively.

Preliminary measurements have yielded a thermal-neutron capture cross section of 0.065 barn and a resonance integral of 0.6 barn for ${ }^{106} \mathrm{Ru}$. These values are sufficiently low to signify a negligible effect of this nuclide as a neutron poison for the nuclear reactor system.

\section{The Thermal-Neutron Capture Cross Section and Resonance Integral of ${ }^{58} \mathrm{Co}$}
J. Halperin
J. C. Zukas ${ }^{33}$
R. W. Stoughton
J. H. Oliver

The very high neutron capture cross section and resonance integral of the $9.0-\mathrm{hr}$ isomer $58 \mathrm{~m}$ Co reported by Hogg and coworkers ${ }^{34}$ ( $\sigma=140,000$ barns) is of particular interest in the problem of measuring fast flux by the use of the ${ }^{58} \mathrm{Ni}(n, p){ }^{58} \mathrm{Co}$ reaction [see expression (1)]. Since the evaluation of the fast flux by the use of this reaction in high thermal fluxes depends critically upon the value of this cross section, we have undertaken to remeasure this value. An increased sensitivity over earlier experiments was obtained by measuring directly the 9.0 -hr ${ }^{58 m} \mathrm{Co}$, rather than observing the growth in the 71-day isomer.

\footnotetext{
${ }^{33}$ Metals and Ceramics Division.

${ }^{34}$ C. H. Hogg, L. D. Weber, and E. C. Yates, Thermal Neutron Cross Sections of the ${ }^{58} \mathrm{Co}$ Isomers and the Effect of Fast Flux Measurements Using Nickel, IDO-16744 (1962).
}

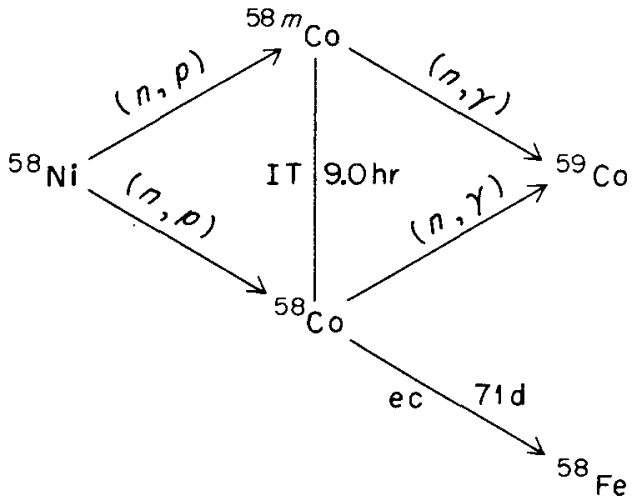

A series of irradiations of enriched samples of ${ }^{58} \mathrm{Ni}(>99 \%)$, both cadmium-filtered and bare, were carried out in the hydraulic tube facility of the ORR. The $9.0-\mathrm{hr}{ }^{58 \mathrm{~m}}$ Co was followed by means of its characteristic $6-\mathrm{kev} x$ ray using a krypton-filled proportional counter. Monitors of dilute ${ }^{59} \mathrm{Co}$ were used to monitor both the thermal and resonance flux. Samples of very pure iron were included to monitor the fast flux by means of the

$$
{ }^{54} \mathrm{Fe}(n, p){ }^{54} \mathrm{Mn} \underset{\mathrm{ec}}{\stackrel{314 \mathrm{~d}}{\longrightarrow}}
$$

reaction.

Preliminary values of 170,000 and 250,000 barns can be reported for the thermal-neutron capture cross section and resonance integral of ${ }^{58 m}$ Co. Similar irradiations and analyses are in progress for the 71-day isomer of ${ }^{58} \mathrm{Co}$.

\section{Alpha Branching Ratio of ${ }^{249} \mathrm{Bk}$}
A. Chetham-Strode
R. J. Silva

Berkelium-249 is the principal isotope of berkelium formed in the neutron irradiation of lighter transuranium isotopes. It decays by the emission of soft beta particles with a half-life of 314 days and also, to the extent of $\sim 10^{-3} \%$, by alphaparticle emission. Since absolute beta counting is a matter of some difficulty, and the berkelium is frequently contaminated by fission products, the alpha branch of the decay provides an important alternative for the identification and analysis 
of this isotope. To provide data of sufficient accuracy for this application, the alpha branching ratio of ${ }^{249} \mathrm{Bk}$ was determined by alpha spectroscopy of the ${ }^{249} \mathrm{Bk}$ and its beta-decay daughter ${ }^{24}{ }^{9} \mathrm{Cf}$.

A sample of approximately $0.1 \mu \mathrm{g}$ of ${ }^{249} \mathrm{Bk}$ was separated from all other radioactive isotopes by standard series of precipitation reactions and anion and cation exchange procedures. ${ }^{35}$ Small fractions of the resulting solution were electrodeposited over 1 -cm-diam areas in the center of platinum foils as invisible and essentially weightless sources.

Alpha-particle spectra of the sample were taken with a surface-barrier silicon detector and a newly developed low-noise pulse amplifier featuring double $R C$ pulse shaping and variable integrating and differentiating time constants. ${ }^{36}$ Double pulse shaping and operation at $0.4 \mu$ sec time constants enabled us to obtain alpha-particle resolution of about $20 \mathrm{kev}$ full width at half maximum even in the presence of $10^{5}$ times as many beta particles from the ${ }^{249} \mathrm{Bk}$ decay. Under these conditions the alpha groups from $24{ }^{9} \mathrm{Cf}$ could be cleanly separated from those of ${ }^{249} \mathrm{Bk}$ (Fig. 1.11) and their ratio accurately determined. Since the amount of ${ }^{249} \mathrm{Cf}$ grown into the separated berkelium measures the beta decay rate of its ${ }^{249} \mathrm{Bk}$ parent, a direct comparison of the alpha disintegration rate of parent and daughter gives the ${ }^{249} \mathrm{Bk}$ branching ratio independent of counting efficiency or chemical yields.

Sixteen determinations of the ${ }^{249} \mathrm{Bk}$ to ${ }^{249} \mathrm{Cf}$ alpha disintegration rates were made on two similar samples and at various times after final separation of the berkelium. The resulting alpha branching of ${ }^{249} \mathrm{Bk}$ was determined from these data to be $(1.41 \pm 0.03) \times 10^{-5}$, a value differing by almost $50 \%$ from a previous determination by a less direct method. The value quoted here depends linearly on the reciprocal of the half-life of ${ }^{249} \mathrm{Cf}$ (taken by us to be 360 years), ${ }^{37}$ and the quoted limits of error do not include uncertainties from this source.

\footnotetext{
${ }^{35}$ S. G. Thomps on et al., J. Am. Chem. Soc. 76, 6229 (1954).

${ }^{36}$ The authors are indebted to Edward Fairstein, Tennelec Instrument Co., for the use of his prototype TC-200 amplifier for this measurement.

${ }^{37}$ T. A. Eastwood et al., Phys. Rev. 107, 1635 (1957).
}

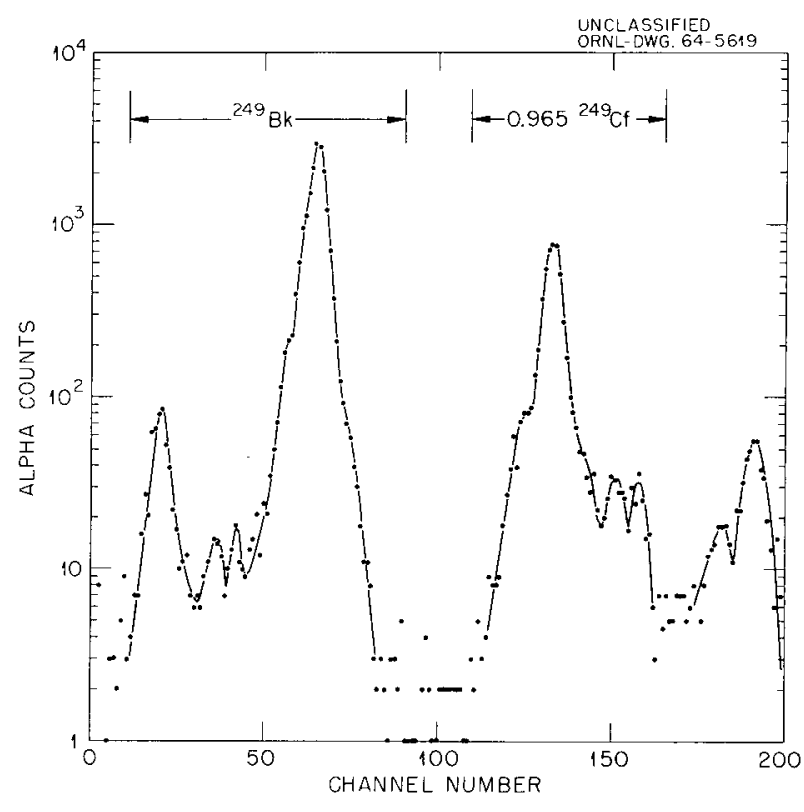

Fig. 1.11. Alpha Spectrum of Aged Berkelium-249 Source.

\section{Improvement in Performance of Gridded Ion Chambers}
A. Chetham-Strode
J. R. Tarrant

Recent work ${ }^{38-40}$ indicated that an improvement could be made in the resolution of gridded ionization chambers by substitution of approximately $2 \%$ acetylene for the usual $10 \%$ methane in the argon counting-gas mixture. This apparently occurs because the signal electrons normally lost due to excitation of metastable states in argon are regained by subsequent ionization of the acetylene by the excited argon atoms. The results are an increased output signal and a marked decrease in the variation in the number of electrons produced per alpha particle.

The gas mixture was made in an evacuated cylinder using twice-distilled acetylene, and argon which had been mass-spectroscopically

\footnotetext{
${ }^{38}$ A. A. Vorob'ev, A. P. Komar, and V. A. Korolev, Soviet Phys. JETP 16, 306 (1963).

${ }^{39}$ A. A. Vorob'ev, A. P. Komar, and V. A. Korolev, Soviet Phys. Doklady 6, 219 (1961).

${ }^{40}$ A. P. Komar, A. A. Vorob'ev, and V. A. Korolev, Soviet Phys. Doklady 6, 131 (1961).
} 
checked for purity. While in the counting chamber the gas was continuously circulated over sodium metal at $100^{\circ} \mathrm{C}$.

Difficulty was experienced with high-voltage corona and breakdown at about one-half the working potentials used in the normal argon-methane mixture. All feed-through and stand-off insulators were changed or enlarged and all arc points avoided in the wiring. Materials likely to outgas were also removed from the chamber.

Figure 1.12 is an example of the results obtained. Resolutions to $16 \mathrm{kev}$, full width at half maximum, have been observed under the best conditions for the $5.801-\mathrm{Mev}{ }^{244} \mathrm{Cm}$ alpha line. This includes the amplifier noise of $11 \mathrm{kev}(\sim 200 \mathrm{~ms}$ electrons). Computation ${ }^{4}$. gives a maximum resolution spread of approximately $8.5 \mathrm{kev}$ due to rise time variations ( 1 to $2 \mu \mathrm{sec}$ ). The remaining $8-\mathrm{kev}$ contribution to the resolution is in

${ }^{41}$ A. B. Gillespie, Signal, Noise and Resolution in Nuclear Counter Amplifiers, Macmillian, New York, 1953. agreement with the work previously cited. The energy required for ion pair production was found to be $22 \mathrm{ev}$. The resolution obtained approaches that of solid-state detectors but with a counting geometry of approximately $2 \pi$.

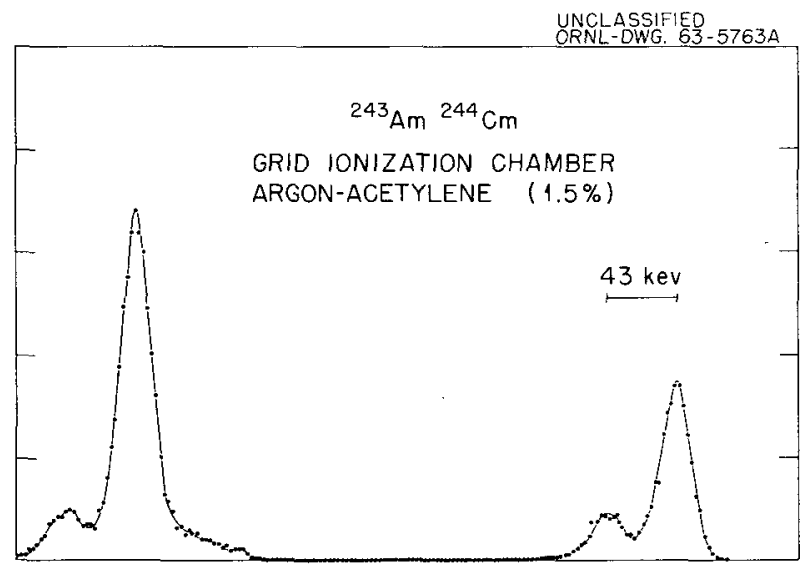

Fig. 1.12. Alpha Spectrum of ${ }^{243} \mathrm{Am}-{ }^{244} \mathrm{Cm}$. 


\section{Nuclear and Inorganic Chemistry of Special Elements}

\section{A Study by Raman Spectroscopy of Complex lons Formed by $\mathrm{Ta}(\mathrm{V})$ in the System $\mathrm{Ta}(\mathrm{V})$-HF-NH $\mathrm{H}_{4} \mathrm{~F} \cdot \mathrm{H}_{2} \mathrm{O}$}
o. L. Keller, Jr.
A. Chetham-Strode, Jr.

In a continuation of studies of elements related to protactinium, the $\mathrm{TaF}_{6}{ }^{-}$and $\mathrm{TaF}_{7}{ }^{2-}$ ions formed by tantalum in $\mathrm{HF}$ solutions were identified by comparing the Raman spectra of crystalline $\mathrm{CsTaF}_{6}$ and $\mathrm{K}_{2} \mathrm{TaF}_{7}$ with spectra of the solutions. In Fig. 2.1, for example, solution $12-\mathrm{C}$ is seen to contain the $\mathrm{TaF}_{7}{ }^{2-}$ ion, and solution 13-A contains the $\mathrm{TaF}_{6}{ }^{-}$and $\mathrm{TaF}_{7}{ }^{2-}$ ions. The Raman spectra of crystalline $\mathrm{Na}_{3} \mathrm{TaF}_{8}$ (Fig. 2.2) and $\left(\mathrm{NH}_{4}\right)_{3} \mathrm{TaOF}_{6}$ (Fig. 2.3) were al so recorded.

Tantalum metal was dissolved in $\mathrm{HF}$ to form solutions $\sim 1 M$ in tantalum. The HF concentrations of the solutions were about $23,12,3.5$, and $0.3 \mathrm{M}$. In $\sim 23 \mathrm{M} \mathrm{HF}$ the $\mathrm{TaF}_{6}{ }^{-}$ion was the predominant species, with the $\mathrm{TaF}_{7}{ }^{2-}$ ion barely detectable. In $\sim 12$ and $\sim 3.5 \mathrm{MHF}$, both $\mathrm{TaF}_{6}{ }^{-}$and $\mathrm{TaF}_{7}{ }^{2-}$ ions are present in large amounts. In $\sim 0.3 \mathrm{M} \mathrm{HF}$ the $\mathrm{TaF}_{6}{ }^{-}$and $\mathrm{TaF}_{7}{ }^{2-}$ ions are joined by a third unidentified species. which has a Raman line between those due to the symmetrical stretches of the two identified species.

Ammonium fluoride crystals were added to the solutions in increments, and the variation in the concentrations of the $\mathrm{TaF}_{6}{ }^{-}$and $\mathrm{TaF}_{7}{ }^{2-}$ ions

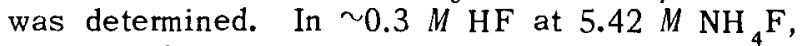
the $\mathrm{TaF}_{7}{ }^{2-}$ ion was found to be the predominant species, and $\mathrm{TaF}_{6}{ }^{-}$ion was not present. A new line appeared, however, in the tantalum-oxygen stretch region. Although this line is near the symmetrical stretch of $\mathrm{TaOF}_{6}{ }^{3-}$ (Fig. 2.3), it might equally well be due to the $\mathrm{TaOF}_{5}{ }^{2-}$ ion, which has never been prepared in a crystalline salt. The $\mathrm{TaF}_{8}{ }^{3-}$ ion was not detected in any of the solutions.

\author{
Specific Activity of ${ }^{99} \mathrm{Tc}$ by Liquid \\ Scintillation Counting
}

Gerald Goldstein ${ }^{1}$

The specific activity and the half-life of ${ }^{99} \mathrm{Tc}$, a pure beta emitter with a maximum energy of $300 \mathrm{kev}$, were redetermined by a liquid scintillation counting technique and were found to be $3.75 \times 10^{4}$ dis $\min ^{-1} \mu \mathrm{g}^{-1}$ and $2.14 \times 10^{5}$ years, respectively, in excellent agreement with previous results by Boyd, Larson, and Motta, ${ }^{2}$ and by Fried et al. ${ }^{3}$

For these determinations, two solutions of $\mathrm{NH}_{4} \mathrm{TcO}_{4}$ in water containing about 1 and $5 \mathrm{mg}$, respectively, of technetium per $\mathrm{ml}$ were prepared and were analyzed chemically by a coulometric method. ${ }^{4}$ The absolute counting rate of a known weight of technetium was then determined by transferring suitable aliquots of the solutions to a dioxanenaphthalene type of liquid scintillator and measuring the integral counting rate as a function of pulse-height discriminator setting with a Packard Tri-Carb liquid scintillation spectrometer. A plot of the log of the count rate vs discriminator setting is linear and can be extrapolated to an intercept (zero discriminator setting) which represents the absolute counting rate. ${ }^{5}$

It was found that the extrapolated intercept is, within reasonable limits, independent of instrumental conditions such as phototube voltage and amplifier gain setting (Fig. 2.4). By applying the same extrapolation technique with solutions

\footnotetext{
${ }^{1}$ Analytical Chemistry Division.

${ }^{2}$ G. E. Boyd, Q. V. Larson, and E. E. Motta, J. Am. Chem. Soc. 82, 809 (1960).

${ }^{3}$ S. Fried et al., Phys. Rev. 81, 741 (1951).

${ }^{4}$ A. A. Terry and H. E. Zittel, Anal. Chem. 35, 614 (1963).

${ }^{5}$ K. F. Flynn and L. E. Glendenin, Phys. Rev. 116, 744 (1959).
} 

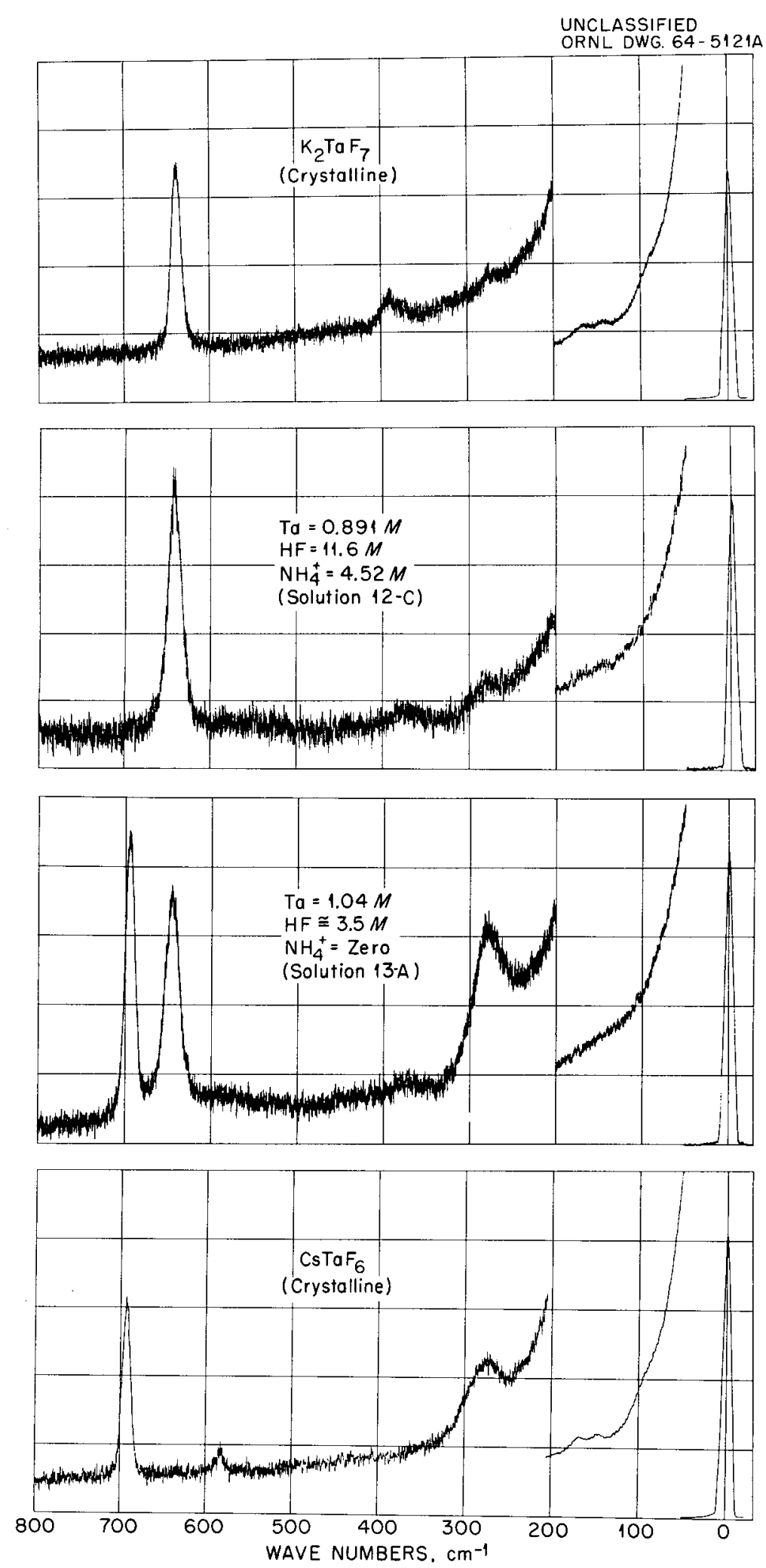

Fig. 2.1. Comparison of the Raman Spectra of $\mathrm{CsTaF}_{6}$ and $\mathrm{K}_{2} \mathrm{TaF}_{7}$ with $\mathrm{T}$ wo Solutions of Ta. 
of other pure beta emitters which had been standardized by $4 \pi$ beta counting methods, it could be shown that the extrapolated count rate was indeed identical with the absolute disintegration rate (Fig. 2.5) if the maximum beta energy is greater than $200 \mathrm{kev}$.

The results, shown in Table 2.1 , are based on six replicate chemical analyses and five replicate liquid scintillation counting samples. Overall relative standard deviation is estimated to be at about $2 \%$.

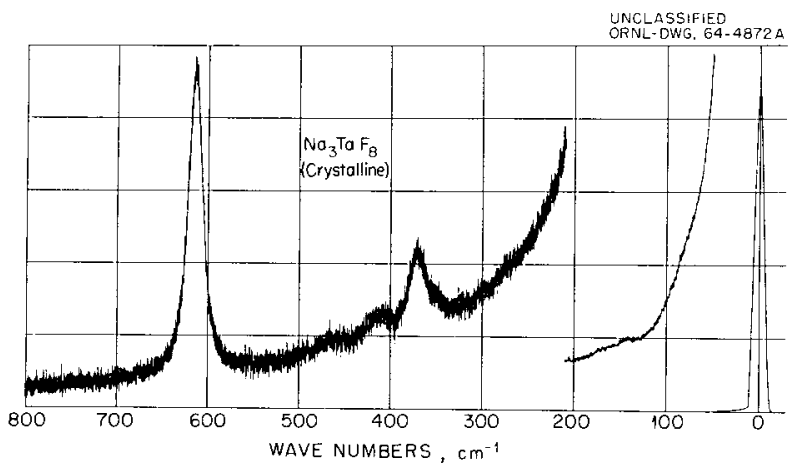

Fig. 2.2. Raman Spectrum of $\mathrm{Na}_{3} \mathrm{TaF}_{8}$.

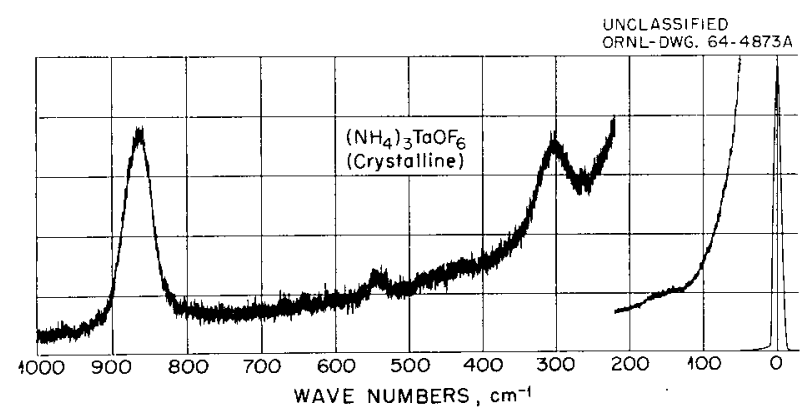

Fig. 2.3. Raman Spectrum of $\left(\mathrm{NH}_{4}\right)_{3} \mathrm{TaOF}_{6}$.

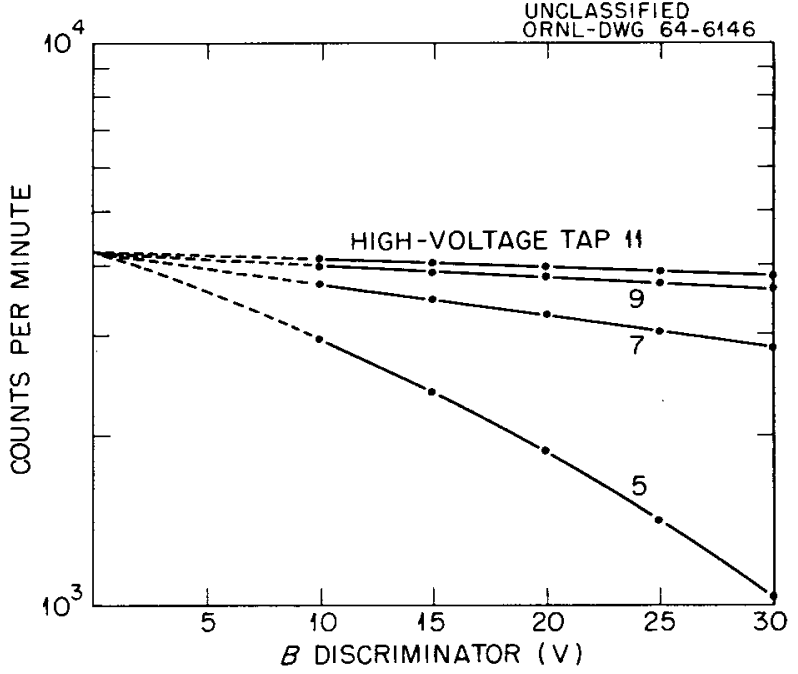

Fig. 2.4. Effect of High Voltage on Integral Counting Curve. ${ }^{99} \mathrm{Tc}, 1.17 \mu \mathrm{g}$; attenuator setting, 4 .

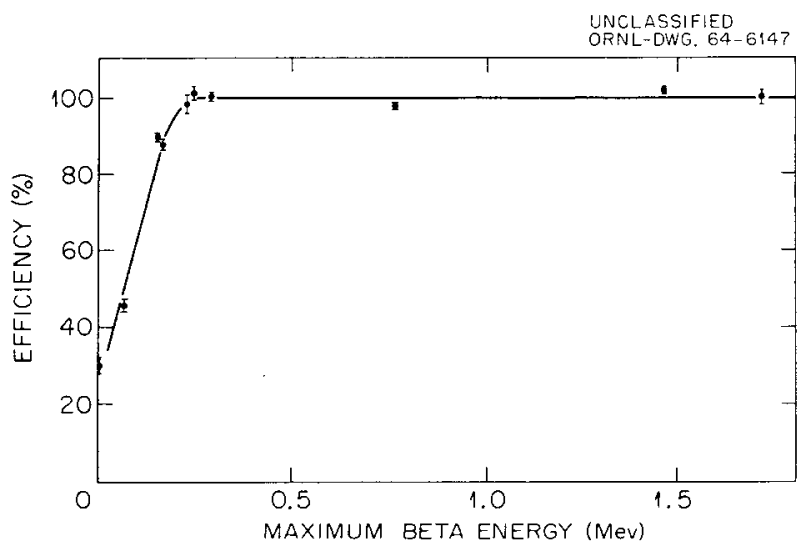

Fig. 2.5. Efficiency of Extrapolation Method as a Function of Beta Energy.

Table 2.1. Specific Activity of ${ }^{99} \mathrm{Tc}$

\begin{tabular}{|c|c|c|c|c|}
\hline \multirow{2}{*}{$\begin{array}{l}\text { Nominal Concentration } \\
\qquad(\mathrm{mg} / \mathrm{ml})\end{array}$} & \multicolumn{2}{|c|}{ Coulometry } & \multicolumn{2}{|c|}{ Liquid Scintillation } \\
\hline & $\mathrm{mg} / \mathrm{m} 1$ & Standard Deviation & $\mathrm{dis} / \mathrm{min}$ & Standard Deviation \\
\hline 1 & 0.944 & 0.014 & $0.355 \times 10^{8}$ & 0.002 \\
\hline 5 & 4.73 & 0.07 & $1.77 \times 10^{8}$ & 0.015 \\
\hline \multicolumn{5}{|c|}{ Specific activity: $(3.75 \pm 0.07) \times 10^{4}$ dis $\min ^{-1} \mu \mathrm{g}^{-1}$} \\
\hline Half-life: & \multicolumn{4}{|c|}{$(2.14 \pm 0.05) \times 10^{5}$ years } \\
\hline
\end{tabular}




\section{Crystal-Field Analysis of the Visible Spectrum of Rhenium Trichloride in Hydrochloric Acid}

\section{R. H. Busey}

A recent study ${ }^{6}$ of the crystal structure of $\mathrm{ReCl}_{3}$ shows that the coordination around the $\mathrm{Re}^{3+}$ ion is tetrahedral to a good approximation. Further evidence of the tetrahedral coordination is furnished by the isolation of such salts as $\mathrm{CsReCl}_{4}$, whose crystal structure has also been determined. ${ }^{7}$ It was considered to be of interest to examine by crystal-field theory the visible spectrum of $\mathrm{ReCl}_{3}$ in hydrochloric acid to see if the spectrum is consistent with the $\mathrm{Re}^{3+}$ ion being in tetrahedral coordination.

The visible spectrum of $\mathrm{ReCl}_{3}$ in $12 \mathrm{M} \mathrm{HCl}$ consists of two strong absorption bands at 19,200 and $13,000 \mathrm{~cm}^{-1}$, a weak band at $10,300 \mathrm{~cm}^{-1}$, and a band (or bands) with a maximum below 8500 $\mathrm{cm}^{-1}$. Absorption by the solvent precludes observations below $8500 \mathrm{~cm}^{-1} .8$ Third transition series elements invariably form complexes exhibiting strong crystalline fields; that is, they are spin-paired complexes. Referring to a TanabeSugano diagram $^{9}$ for the electronic configuration $d y^{4}$ (tetrahedral), which tetrahedral $\operatorname{Re}^{3+}$ would have, shows the ground state to be ${ }^{1} A_{1}$ (ref. 10). Two relatively strong spin-allowed bands, ${ }^{1} T_{1}$ and ${ }^{1} T_{2}$, and two relatively weak spin-forbidden bands, ${ }^{3} T_{1}$ and ${ }^{3} T_{2}$, should be observed.

${ }^{6} \mathrm{~F}$. A. Cotton and J. T. Mague, Inorganic Chemistry (in press).

${ }^{7}$ J. A. Bertrand, F. A. Cotton, and W. A. Dollase, Inorg. Chem. 2, 1166 (1963).

${ }^{8}$ Further confirmation of the analysis given here could be obtained by observing the spectrum of $\mathrm{ReCl}$ in 1 to $2 M \mathrm{HCl}$. This solvent would permit observations to $\sim 7500 \mathrm{~cm}^{-1}$.

${ }^{9}$ Y. Tanabe and S. Sugano, J. Phys, Soc. Japan 9, 753,766 (1954).

${ }^{10}$ For the significance of ${ }^{1} A$, etc., see, for example, L. E. Orgel, An Introduction to Transition-Metal Chemistry, Methuen, London, 1960.
If the two observed strong bands at 13,000 and $19,000 \mathrm{~cm}^{-1}$ are assigned to ${ }^{1} T_{1}$ and ${ }^{1} T_{2}$, respectively, the two triplet bands ${ }^{3} T_{1}$ and ${ }^{3} T_{2}$ should appear at approximately $8160 \mathrm{~cm}^{-1}$ and 11,000 $\mathrm{cm}^{-1}$ respectively. The observed weak band at $10,300 \mathrm{~cm}^{-1}$ is thus assignable to ${ }^{3} T_{2}$, and the band with a maximum $<8500 \mathrm{~cm}^{-1}$ indicated by the spectrum would be the ${ }^{3} T_{1}$ band. The observed spectrum is thus consistent with the tetrahedral assignment, and further, no fit of the spectrum could be obtained by assuming an octahedral ion with a $d \epsilon^{4}$ ground-state configuration.

The above assignment leads to a crystal-field splitting of $D q=816 \mathrm{~cm}^{-1}$ and a Racah parameter of $B=270 \mathrm{~cm}^{-1}$. Comparison of the crystal-field splittings and Racah parameters between the complex halide ions $\operatorname{ReX}_{6}{ }^{2-}$ and $\mathrm{TcX}_{6}{ }^{2-}$ (ref. 11) shows that the Racah parameters are approximately the same and that the crystal-field splittings in the technetium complexes are $80 \%$ of those in the rhenium complexes. If a similar correlation is assumed to exist between the rhenium and technetium trivalent chloride complexes, it becomes possible to estimate the visible spectrum of trivalent technetium chloride complex in hydrochloric acid, since the complex is most probably tetrahedral. The calculation gives ${ }^{1} T_{1}=12,200 \mathrm{~cm}^{-1}$ and ${ }^{1} T_{2}=18,900 \mathrm{~cm}^{-1}$ for the location of the two strong spin-allowed transitions, or absorption bands at approximately 8200 and $5300 \mathrm{~A}$ respectively. Trivalent technetium chloride complex has at present only been prepared in low concentration $\left(10^{-4} M\right)$, and only its ultraviolet spectrum has been observed. $^{12}$ Preparation of more concentrated solutions and determination of the visible spectrum of the technetium complex should be of considerable interest.

\footnotetext{
${ }^{11}$ R. H. Busey, Chem. Div. Ann. Progr. Rept. June 20, 1961, ORNL-3176, p. 12 .

${ }^{12}$ R. H. Busey, Chem. Div. Ann. Progr. Rept. June 20, 1960, ORNL-2983, p. 10.
} 


\section{Isotope Chemistry}

\section{Ion Exchange Studies in Ethylenediamine}

\section{A. Lee}

The rate of exchange and the selectivity coefficients of Dowex 50 resins for alkali metal ions were studied in ethylenediamine solutions. The systems were completely anhydrous. Various alkali metal ion combinations using ${ }^{134} \mathrm{Cs}$ as a tracer have been reported. ${ }^{1}$ To supplement these data experiments were performed using an ${ }^{22} \mathrm{Na}$ tracer. In these experiments, $\mathrm{Li}^{+}$and $\mathrm{Na}^{+}$, which are solvated by ethylenediamine, were studied in Dowex 50-X1, X8, and X16 resins. The diffusion and selectivity coefficients in the systems listed are tabulated in Table 3.1.

The relatively slow diffusion found for $\mathrm{Li}^{+}$and $\mathrm{Na}^{+}$suggests that diffusion occurs with both ions solvated; when either of these ions is paired with $\mathrm{Cs}^{+}$, the observed diffusion rate is greater because $\mathrm{Cs}^{+}$is not solvated by ethylenediamine. The relatively small selectivity coefficients are reasonable in view of the small difference in the radii of $\mathrm{Na}^{+}$and $\mathrm{Li}^{+}$. Separations of $\mathrm{Na}^{+}$and $\mathrm{Li}^{+}$ in ethylenediamine do not appear practical in highly crosslinked resins because of the extraordinarily long equilibrium time involved.

${ }^{1}$ D. A. Lee, Chem. Div. Ann. Progr. Rept. June 20, 1963, ORNL-3488, p. 21.

\section{The Effect of Eluant Concentration on the Separation Factor for Lithium Isotopes by Ion Exchange Chromatography}

D. A. Lee

The effect of eluant concentration on the separation factor, $a$, for lithium isotopes was determined for three ion exchange systems. In these systems the band elution of natural mixtures of lithium isotopes in ion exchange columns was performed. The systems studied were $\mathrm{HCl}$ elution from a sulfonated coal exchanger, Zeo-Karb, $\mathrm{HCl}$ elution from Dowex 50-X12, and ammonium acetate elution from Dowex 50-X12.

The experimental procedure was the same as that described previously. ${ }^{2-4}$ The results are shown in Table 3.2. In each case the separation decreases with an increase in the eluant concentration. This is consistent with the hydration model we have assumed for these separations; the magnitude of $\alpha$ is dependent upon the difference in the degree of hydration of the lithium species in the two phases. These results are also consistent with the results found for the selectivity

${ }^{2}$ D. A. Lee and G. M. Begun, J. Am. Chem. Soc. 81, 2332 (1959).

${ }^{3}$ D. A. Lee, J. Phys. Chem. 64, 187 (1960).

${ }^{4}$ D. A. Lee, J. Am. Chem. Soc. 83, 1801 (1961).

Table 3.1. Ion Exchange Diffusion and Selectivity Coefficients in Ethylenediamine

\begin{tabular}{|c|c|c|}
\hline System & $\begin{array}{c}D^{i} \\
\left(\mathrm{~cm}^{2} / \mathrm{sec}\right)\end{array}$ & $K_{\mathrm{Li}_{\mathrm{i}}}^{\mathrm{Na}}$ \\
\hline Dowex $50-\mathrm{X} 1-\mathrm{Li}^{+}-{ }^{22} \mathrm{Na}^{+}$vs $0.1 \mathrm{~N}$ LiSCN-EDA & $3.4 \times 10^{-8}$ & 1.1 \\
\hline Dowex $50-\mathrm{X} 8-\mathrm{Li}^{+}-2{ }^{2} \mathrm{Na}^{+}$vs $0.1 \mathrm{NLiSCN}-\mathrm{EDA}$ & $5.8 \times 10^{-9}$ & 1.6 \\
\hline Dowex $50-\mathrm{X} 16-\mathrm{Li}^{+}-{ }^{22} \mathrm{Na}^{+}$vs $0.1 N$ LisCN-EDA & $5.2 \times 10^{-10}$ & 9.7 \\
\hline
\end{tabular}


Table 3.2. Isotopic Fractionation of Lithium Isotopes in Ion Exchange Systems as a Function of Eluant Concentration

\begin{tabular}{|c|c|c|c|}
\hline \multicolumn{2}{|c|}{ System } & \multirow{2}{*}{$\begin{array}{c}\text { Eluant } \\
\text { Concentration } \\
(M)\end{array}$} & \multirow{2}{*}{$\alpha$} \\
\hline Resin & Eluant & & \\
\hline \multirow[t]{3}{*}{ Dowex $50-X_{12}$} & $\mathrm{NH}_{4} \mathrm{Ac}$ & 0.2 & 1.00186 \\
\hline & & 1.0 & 1.00134 \\
\hline & & 5.0 & 1.00075 \\
\hline \multirow[t]{5}{*}{ Dowex $50-\mathrm{X}_{12}$} & $\mathrm{HCl}$ & 0.1 & 1.0030 \\
\hline & & 0.3 & 1.0027 \\
\hline & & 0.5 & 1.0023 \\
\hline & & 1.0 & 1.0020 \\
\hline & & 5.0 & 1.0010 \\
\hline \multirow[t]{4}{*}{ Zeo-Karb } & $\mathrm{HCl}$ & 0.1 & 1.0022 \\
\hline & & 0.5 & 1.0017 \\
\hline & & 1.0 & 1.0013 \\
\hline & & 5.0 & 1.00078 \\
\hline
\end{tabular}

coefficients for alkali metal ions in various solutions over a wide concentration range. 5,6

This work is complete and has been submitted for publication.

\section{Boron Isotope Exchange Studies}

\section{A. A. Palko}

Measurements were made of the isotopic equilibrium constants for the exchange reaction

$$
\begin{aligned}
{ }^{10} \mathrm{BF}_{3} \text { (gas) }+{ }^{11} \mathrm{BF}_{3} \cdot \text { Donor } \\
\left.={ }^{11} \mathrm{BF}_{3} \text { (gas }\right)+{ }^{10} \mathrm{BF}_{3} \cdot \text { Donor, }
\end{aligned}
$$

where the donor was ethyl sulfide, ethyl ether, triethylamine, or tetrahydrofuran. ${ }^{7}$ A summary of the isotopic equilibrium constants and derived thermodynamic data are given in Table 3.3, along with the calculated least-squares constants for the equation $\log \alpha=b / T-a$.

${ }^{5}$ W. A. Platek and J. A. Marinsky, J. Phys. Chem. $65,2113(1961)$.

${ }^{6}$ D. C. Whitney and R. M. Diamond, Inorg. Chem. 2, 1284 (1963).

${ }^{7}$ A. A. Palko and J. S. Drury, J. Chem. Phys. 40, 278-81 (1964).

\section{Coordination Compounds of Boron Halides}

$$
\text { A. A. Palko }
$$

During screening of compounds suitable for boron isotope separation, it was of interest to study the addition of $\mathrm{BF}_{3}$ and $\mathrm{BCl}_{3}$ to thiophenol, diphenyl sulfide, $N$-methyldiphenylamine, $N N$ dimethylaniline, and methyl isocyanide. A paper describing these compounds is being prepared for publication.

Although phenol ${ }^{8}$ forms two addition compounds with $\mathrm{BF}_{3}$, thiophenol does not add $\mathrm{BF}_{3}$ in any amount between -40 and $+40^{\circ} \mathrm{C}$. However, $\mathrm{BCl}_{3}$ forms a very weak compound with thiophenol which is completely dissociated at room temperature.

As with diphenyl ether, ${ }^{9} \mathrm{BF}_{3}$ does not react with diphenyl sulfide at any temperature from -60 to $+60^{\circ} \mathrm{C}$, but $\mathrm{BCl}_{3}$ forms a definite $1: 1$ compound with diphenyl sulfide. The melting point of the latter adduct is $\sim 50^{\circ} \mathrm{C}$. At $62^{\circ} \mathrm{C}$ the complex is completely dissociated into $\mathrm{BCl}_{3}$ and diphenyl sulfide. Boron trichloride can be removed quantitatively from both thiophenol and diphenyl sulfide

\footnotetext{
${ }^{8}$ A. A. Palko, J. S. Drury, and W. E. Bull, J. Chem. Phys. 35, 103 (1961).

${ }^{9}$ R. M. Healy and A. A. Palko, J. Chem. Phys. 28, 211-13 (1958).
} 
Table 3.3. $\log a=b / T-a ; \Delta H, \Delta F, \Delta S$ for the Reaction

$$
{ }^{10} \mathrm{BF}_{3} \text { (gas) }+{ }^{11} \mathrm{BF}_{3} \cdot \text { Org Donor (Liq) } \rightleftharpoons{ }^{1} \mathrm{BF}_{3}+{ }^{10} \mathrm{BF}_{3} \cdot \text { Org Donor (Liq) }
$$

\begin{tabular}{ccccccc}
\hline $\begin{array}{c}\text { Donor } \\
\text { Molecule }\end{array}$ & $a$ & $b$ & $\begin{array}{c}\alpha \\
\left(20^{\circ}\right)\end{array}$ & $\begin{array}{c}\Delta H \\
(\mathrm{cal} / \mathrm{mole})\end{array}$ & $\begin{array}{c}\Delta F(\mathrm{cal} / \mathrm{deg}) \\
\left(20^{\circ}\right)\end{array}$ & $\begin{array}{c}\Delta S \\
\left(\mathrm{cal}^{\mathrm{deg}} \mathrm{mole}^{-1}\right)\end{array}$ \\
\hline $\mathrm{Et}_{2} \mathrm{~S}$ & 0.02498 & 12.1440 & 1.0386 & -55.6 & -22.1 & 0.114 \\
$\mathrm{Et}{ }_{2} \mathrm{O}$ & 0.01749 & 9.1640 & 1.0323 & -41.9 & -18.5 & 0.080 \\
$\mathrm{Et}{ }_{3} \mathrm{~N}$ & 0.01159 & 6.4320 & 1.0241 & -29.4 & -13.9 & 0.053 \\
$\mathrm{THF}$ & 0.00634 & 5.2751 & 1.0272 & -24.1 & -15.6 & 0.029 \\
\hline
\end{tabular}

by gentle heating. An estimate of the heat of dissociation for $\mathrm{Ph}_{2} \mathrm{~S} \cdot \mathrm{BCl}_{3}$ compound was made from vapor pressure measurements. The observed value of $-8.7 \mathrm{kcal} / \mathrm{mole}$ may be compared with the value of $-5.3 \mathrm{kcal} / \mathrm{mole}$ found for the $\mathrm{Ph}_{2} \mathrm{O} \cdot \mathrm{BCl}_{3} \mathrm{com}-$ pound. ${ }^{9}$

Boron trifluoride destructively attacks methyl isocyanide at room temperature, immediately forming a black, tarry substance.

$N N$-Dimethylaniline and $\mathrm{BF}_{3}$ form a white crystalline 1:1 addition compound which melts at $92^{\circ} \mathrm{C}$.

$\mathrm{N}$-Methyldiphenylamine adds 0.58 mole of $\mathrm{BF}_{3}$ to form a brilliant emerald green compound which melts at $87^{\circ} \mathrm{C}$. A second diphenylamine adduct has the typical $1: 1$ amine/ $\mathrm{BF}_{3}$ composition. This molecular addition compound is white, and melts at $\sim 100^{\circ} \mathrm{C}$ with decomposition of the amine.

\section{The Fractionation of Carbon and Oxygen Isotopes in the $\mathrm{CO}_{2}$-Carbamate System}

\section{Lawrence Landau}

Previous investigations ${ }^{10}$ of the amine $+\mathrm{CO}_{2}$ systems to determine the isotopic separation factor between the oxygen of the gaseous $\mathrm{CO}_{2}$ and the oxygen of the amine carbamate have given results which have not always been reproducible. The mass spectra of those $\mathrm{CO}_{2}$ samples frequently showed peaks at $\mathrm{m} / \mathrm{e} 39,41,42$, and 43 , which made the ratio measurements of $46 / 44$ and $45 / 44$ open to suspicion.

In these studies extreme precautions were taken to eliminate contamination. Triple-distilled $\mathrm{CO}_{2}$ and $\mathrm{CaH}_{2}$-dried amine were measured into a grease-

\footnotetext{
${ }^{10}$ L. B. Yeatts, Chem. Div. Ann. Progr. Rept. June 20, 1960, ORNL-2983, p. 20.
}

free reaction vessel in which the carbamate was prepared and the final equilibration was performed. Samples of $\mathrm{CO}_{2}$ were withdrawn from the gas phase by means of a Teflon stopcock and a U-tube of sand which was precooled to $-78^{\circ} \mathrm{C}$. The mass spectra of the samples were then compared with the reference samples of $\mathrm{CO}_{2}$, which were identical to the $\mathrm{CO}_{2}$ from which the carbamate was made. These samples had mass spectra showing only very small impurity peaks along with the $\mathrm{CO}_{2}$ spectrum.

Diethylamine carbamate was studied at $62^{\circ} \mathrm{C}$ using amine: $\mathrm{CO}$ ratios of $1.4: 1,1.5: 1,1.6: 1$, $1.7: 1,1.8: 1$, and ${ }^{2} 1.9: 1$. The data for these runs are shown in Table 3.4 .

The carbon data give a separation factor of 1.002 with no trend with changing composition. The oxygen data show a pronounced rise with increased amine: $\mathrm{CO}_{2}$ ratio. The separation factor at $1.9: 1$ is $1.013_{0}$ and extrapolates to a $2: 1$ value of $1.013_{8}$.

In the same manner as the diethylamine carbamate, n-propylamine carbamate having a 1.9 to 1 mole ratio of amine to $\mathrm{CO}_{2}$ was equilibrated with $\mathrm{CO}_{2}$ at $82^{\circ} \mathrm{C}$. The data for the carbon and the oxygen isotope effects are shown in Table 3.5.

The carbon data, when combined with the results of Brown ${ }^{11}$ and Holmberg, ${ }^{12}$ seem to indicate that the important differences in the separation factors are due to different equilibration temperatures, with the nature of the amine contributing very little, as indicated in Fig. 3.1.

Experiments on sec-butylamine carbamate are now in progress.

\footnotetext{
${ }^{11}$ L. L. Brown, Chem. Div. Ann. Progr. Rept. June 20, 1960, ORNL-2983, p. 19

${ }^{12} \mathrm{~K}$. E. Holmberg, Acta Chem. Scand. 16, 2117-22 (1962).
} 
Table 3.4. Single-Stage Isotopic Fractionation Factors for the Diethylamine Carbamate-CO $\mathrm{Cystem}_{2}$ at $62^{\circ} \mathrm{C}$

\begin{tabular}{|c|c|c|c|}
\hline \multirow{2}{*}{ Amine: $\mathrm{CO}_{2}$} & \multirow{2}{*}{$\begin{array}{c}\text { Equilibration } \\
\text { Time } \\
(\mathrm{hr})\end{array}$} & $46 / 44$ (gas) & \multirow{2}{*}{$\frac{45 / 44(\text { reference })}{45 / 44 \text { (gas) }}$} \\
\hline & & $46 / 44$ (reference) & \\
\hline \multirow[t]{2}{*}{$1.4: 1$} & 20 & 1.0094 & 1.0023 \\
\hline & 26 & 1.0095 & 1.0010 \\
\hline \multirow[t]{2}{*}{$1.5: 1$} & 24 & 1.0092 & 1.0021 \\
\hline & 42 & 1.0100 & 1.0016 \\
\hline \multirow[t]{2}{*}{$1.6: 1$} & 24 & 1.0108 & 1.0028 \\
\hline & 26 & 1.0085 & 1.0025 \\
\hline \multirow[t]{2}{*}{$1.7: 1$} & 24 & 1.0097 & 1.0013 \\
\hline & 27 & 1.0139 & 1.0015 \\
\hline \multirow[t]{2}{*}{$1.8: 1$} & 23 & 1.0117 & 1.0027 \\
\hline & 28 & 1.0144 & 1.0015 \\
\hline \multirow[t]{2}{*}{$1.9: 1$} & 21 & 1.0135 & 1.0018 \\
\hline & 26 & 1.0117 & 1.0027 \\
\hline
\end{tabular}

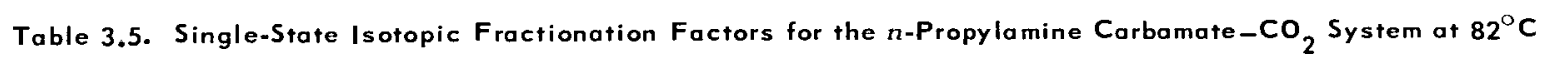

\begin{tabular}{cccc}
\hline Run No. & $\begin{array}{c}\text { Equilibration } \\
\text { Time } \\
(\mathrm{hr})\end{array}$ & $\frac{46 / 44 \text { (gas) }}{46 / 44 \text { (reference) }}$ & $\frac{45 / 44 \text { (gas) }}{45 / 44 \text { (reference) }}$ \\
\hline 3 & 22 & 1.0164 & 1.0018 \\
3 & 26 & 1.0163 & 1.0031 \\
4 & 25 & 1.0174 & 0.9997 \\
4 & 44 & 1.0166 & 1.0030 \\
5 & 20 & 1.0133 & 0.9987 \\
5 & 27 & 1.0134 & 1.0000 \\
\hline
\end{tabular}

Fig. 3.1. Variation of the Carbon Isotopic Fractiona. tion Factor with Temperature.

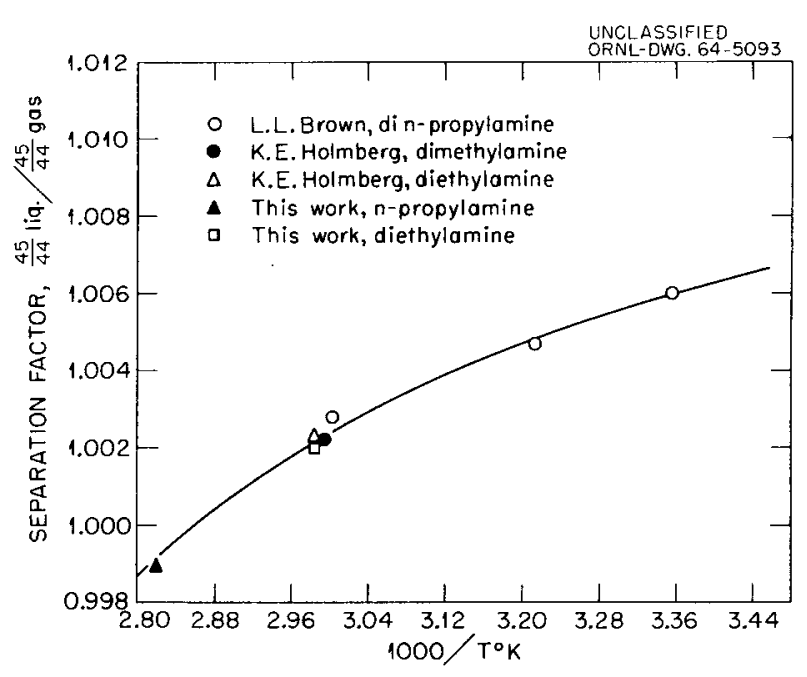




\section{Oxygen Isotope Enrichment}

\section{A. H. Narten}

Operation of the Oxygen-17 Facility continued without major interruptions during this report period. Two minor disturbances to the Water Distillation Cascade were experienced during this time. On June 10,1964, process water was lost from column 4 as a result of a leak at a soldered joint in a feed line. On June 22, 1964, a partial flooding of column 6 occurred when the column jacket water cooled following an electrical outage. It is estimated that these disturbances added about four weeks to the time required to achieve steady-state performance in the Water Distillation Cascade. At the present time, the peak ${ }^{17} \mathrm{O}$ and ${ }^{18} \mathrm{O}$ concentrations in this cascade are 1.3 and $82 \%$ respectively. Estimates based upon the current performance of the Water Distillation Cascade indicate that the maximum ${ }^{17} \mathrm{O}$ and ${ }^{18} \mathrm{O}$ concentrations which may be expected when isotopic equilibrium is achieved are 2.4 and $98 \%$ respectively.

The Thermal Diffusion Cascade began upgrading the intermediate product from the Water Distillation Cascade during January 1964. Despite the disturbing influence of several electrical outages, the current peak concentrations of ${ }^{17} \mathrm{O}$ and ${ }^{18} \mathrm{O}$ are 4.3 and $99.6 \%$ respectively. Based upon present performance, it appears the peak ${ }^{17} \mathrm{O}$ concentration should reach $40 \%$ by early fall, 1964 .

During this report period some $400 \mathrm{~g}$ of water, valued at more than $\$ 70,000$ and containing up to $1 \%$ ${ }^{17} \mathrm{O}$ and $80 \%{ }^{18} \mathrm{O}$, were withdrawn from the Oxygen17 Facility. This material was made available to interested scientists through the ORNL Isotopes Division inventory.

\section{The Nitrogen Isotope Effect in the Decomposition of Diazo Salts}

\section{L. Brown}

Previous studies of nitrogen isotope effects ${ }^{13}$ in the decomposition of diazonium compounds were extended to several additional salts and temperatures.

\footnotetext{
${ }^{13}$ L. L. Brown, Chem. Div. Ann. Progr. Rept. June 20, 1963, ORNL-3488, p. 26.
}

The isotope effect was determined by fractionally decomposing a portion of diazo salt (by dissolving it in $0.1 \mathrm{~N} \mathrm{HCl}$ ) and comparing the isotope ratio of the product $\mathrm{N}_{2}$ with $\mathrm{N}_{2}$ from a $100 \%$ decomposed sample.

The kinetics of $S_{N} 1$ reactions of aryl diazo salts are determined by the step

$$
\underset{\alpha \beta}{\operatorname{ArNN}^{+}} \rightarrow \mathrm{Ar}^{+}+\underset{\alpha \beta}{\mathrm{NN}} .
$$

In the rate-determining step, only the $\alpha$ nitrogen atom is isotopically fractionated; the $\beta$ nitrogen is unaffected. The kinetic effect equation has the form

$$
k^{14} / k^{15}=\log (1-f) / \log (1-r f),
$$

where

$$
f=\text { fraction decomposed, }
$$
$r=\left({ }^{15} \mathrm{~N} /{ }^{14} \mathrm{~N}\right)$ sample $/\left({ }^{15} \mathrm{~N} /{ }^{14} \mathrm{~N}\right)$ ref for the $\alpha \mathrm{N}$.

It was found that the isotope effect was independent of the kind of aryl substituent present in the molecule. An average value of $k^{14} / k^{15}$ was obtained at each temperature from the individual salt values, as shown in Table 3.6. The leastsquares line for $\log k^{14} / k^{15}$ vs $1 / T$ is:

$$
\log \left(k^{14} / k^{15}\right)=6.9487(1 / T)-0.002528
$$

Table 3.6. Nitrogen 1sotope Effects in the Decomposition of Diazonium Salts

\begin{tabular}{cccc}
\hline \multirow{2}{*}{ Salt } & \multicolumn{3}{c}{$k^{14} / k^{15}$} \\
\cline { 2 - 4 } & $6.9^{\circ} \mathrm{C}$ & $40.5^{\circ} \mathrm{C}$ & $68.5^{\circ} \mathrm{C}$ \\
\hline $\mathrm{C}_{6} \mathrm{H}_{5} \mathrm{NNCl}^{a}$ & & 1.0443 & \\
$\mathrm{C}_{6} \mathrm{H}_{5} \mathrm{NNBF}_{4}$ & 1.0431 & \\
${ }_{0}-\mathrm{CH}_{3} \mathrm{C}_{6} \mathrm{H}_{4} \mathrm{NNBF}_{4}$ & & 1.0454 & 1.0427 \\
$p-\mathrm{CH}_{3} \mathrm{C}_{6} \mathrm{H}_{4} \mathrm{NNBF}_{4}$ & & 1.0467 & 1.0426 \\
$\mathrm{~m}_{-} \mathrm{CH}_{3} \mathrm{C}_{6} \mathrm{H}_{4} \mathrm{NNBF}_{4}$ & 1.0528 & 1.0471 & \\
$m-\mathrm{ClC}_{6} \mathrm{H}_{4} \mathrm{NNBF}_{4}$ & 1.0534 & 1.0439 & \\
Average & 1.0531 & 1.0451 & 1.0426 \\
\hline
\end{tabular}

${ }^{a}$ Previous work. 


\section{Infrared Spectra and Predicted Is otope Effect for Diazonium Salts}

\section{L. Brown}

The infrared spectra of $\mathrm{C}_{6} \mathrm{H}_{5}{ }^{14} \mathrm{~N}^{14} \mathrm{NBF}$ and $\mathrm{C}_{6} \mathrm{H}_{5}{ }^{15} \mathrm{~N}^{14} \mathrm{NBF}_{4}$ were run to determine the fundamental frequencies of the $\mathrm{C}-\mathrm{N}$ bond. The nitrogen isotope effect observed in the decomposition of diazo salts occurs in the breaking of the C-N bond to release $\mathrm{N}_{2}$. The stretching frequency and its shift on isotopic substitution of ${ }^{15} \mathrm{~N}$ for ${ }^{14} \mathrm{~N}$ are needed to predict the isotope effect.

The results of the spectral work are presented in Table 3.7. A heavy absorption band obscured the region from 1200 to $1000 \mathrm{~cm}^{-1}$. Since this was the expected location of the $\mathrm{C}-\mathrm{N}$ stretching frequency, the latter could not be directly observed; instead, this frequency was computed from combination bands.

Assuming a diatomic model, $\mathrm{C}-\mathrm{N}$, with only the stretching frequency remaining uncanceled in the transition state, the predicted isotope effect is the product of two terms $\left(\nu_{14}^{*} / \nu_{15}^{*}\right)$, the temperatureindependent factor (TIF), and $[1-G(u) \Delta u]$, the temperature-dependent factor (TDF). The TIF term is obtained from the masses of the model

$$
\left(\nu_{14}^{*} / \nu_{15}^{*}\right)=\left[\left(1_{12}+1 / 14\right) /\left({ }_{12}^{1}+1 / 15\right)\right]^{1 / 2}=1.0157 .
$$

The TDF term is obtained from tabulated values of $G(u)$ (ref. 14), where

$$
u_{i}=(h c / k T) \nu_{i}
$$

Table 3.7. Infrared Spectra of $\mathrm{C}_{6} \mathrm{H}_{5} \mathrm{NNBF}_{4}$ Showing Isotope Shifts

\begin{tabular}{lrrl}
\hline Band & $\begin{array}{c}{ }^{14} \mathrm{~N} \\
\left(\mathrm{~cm}^{-1}\right)\end{array}$ & $\begin{array}{c}15 \mathrm{~N} \\
\left(\mathrm{~cm}^{-1}\right)\end{array}$ & \multicolumn{1}{c}{ Source } \\
\hline I & 455 & 451 & C-N bend \\
II & 533 & 526 & C-N bend \\
III & 620 & 618 & $(\mathrm{~V}-\mathrm{II})$ \\
IV & 910 & 902 & $2(\mathrm{I})$ \\
V & 1152 & 1139 & C-N stretch \\
VI & 2296 & 2251 & $\mathrm{~N}=\mathrm{N}$ stretch \\
VII & 3370 & 3330 & $2(\mathrm{~V}+\mathrm{II})$ \\
\hline
\end{tabular}

and

$$
\Delta u=(h c / k T) \Lambda_{\nu} .
$$

With $\nu_{14}=1152$ and $\Delta \nu=13 \mathrm{~cm}^{-1}$, the isotope effects shown in Table 3.8 were calculated.

Table 3.8. Isotope Effect in Decomposition of Diazonium Salts

\begin{tabular}{rcccc}
\hline $\begin{array}{r}\text { Temp } \\
\left({ }^{\circ} \mathrm{C}\right)\end{array}$ & TIF & TDF & Predicted & Observed \\
\hline 6.8 & 1.0157 & 1.0228 & 1.0389 & 1.0531 \\
40.5 & 1.0157 & 1.0192 & 1.0352 & 1.0451 \\
68.5 & 1.0157 & 1.0168 & 1.0327 & 1.0427 \\
\hline
\end{tabular}

\section{Potassium Isotope Separation}

\section{Donald Zucker}

Because of a discrepancy between two previously published results ${ }^{15,16}$ for the single-stage separation factor, $\alpha$, for potassium isotopes in the system: aqueous potassium hydroxide-potassium amalgam, this value was redetermined.

Multistage separation was achieved by a series of single-stage batch equilibrations. A batch of $\mathrm{KOH}$ containing radioactive ${ }^{42} \mathrm{~K}$ was electrolyzed with a mercury cathode until half the potassium was in the form of amalgam. It was equilibrated using a small holding current to prevent amalgam decomposition; then the phases were separated. The aqueous phase was filtered, and half of its potassium was electrolyzed into fresh mercury and equilibrated with the potassium remaining in the aqueous phase. This process was repeated several times. A similar process was used with the amalgam from the first equilibration, amalgams in each step being $50 \%$ decomposed by a reversed electrolys is with deionized water.

${ }^{14} \mathrm{~J}$. Bigeleisen and M. Goeppert-Mayer, J. Chem. Phys. 15, 261 (1947).

15 H. H. Garretson and J. S. Drury, J. Chem. Phys. 34, 1957-58 (1961).

${ }^{16} \mathrm{G}$. Ya. Ryskin and V. S. Rylov, Russ. J. Phys. Chem. 36, 1003-06 (1962). 
Two determinations of $\alpha$ were made. In the first case, with $7 \frac{1}{2}$ stages of separation, potassium samples were precipitated with dipicrylamine, converted to phosphate, and assayed by mass spectrometer. This gave $1.0008 \pm 0.0004$ as the value of $\alpha$ for ${ }^{39} \mathrm{~K}$ vs ${ }^{41} \mathrm{~K}$, the isotopes assayed. In the second case, with seven stages of separation, potassium samples from all stages were precipitated with sodium tetraphenylboron and weighed. Then the radiation from ${ }^{42} \mathrm{~K}$ was counted, and counts per gram were calculated. Separation factors for ${ }^{39} \mathrm{~K}$ vs ${ }^{42} \mathrm{~K}$ were determined by a leastsquares method for eight series of counts, with a correction for the ${ }^{41} \mathrm{~K}$ present. From the average of these, $\alpha$ for ${ }^{39} \mathrm{~K}$ vs ${ }^{41} \mathrm{~K}$ was calculated to be $1.0004 \pm 0.0003$. The two results were combined to give $1.0006 \pm 0.0004$.

Two samples from the experiment reported earlier from this laboratory ${ }^{15}$ were reassayed, yielding an $\alpha$ for ${ }^{39} \mathrm{~K}$ vs ${ }^{41} \mathrm{~K}$ of $1.0010 \pm 0.0005$. Considering the small separation, these results are in satisfactory agreement.

In all cases, the heavy isotope concentrated in the aqueous phase.

\section{Infrared Transmission of CsF}

Laurence Landau

An experiment was performed to determine whether a fluoride salt could be pressed into a pellet for infrared spectral studies within the pressure limitations of the commercial presses and dies usually available, and also to determine the spectral region of transmission. Cesium fluoride was chosen as the softest of the alkali fluorides and also the most likely to transmit to low frequencies. The $\mathrm{CsF}$ was found to be extremely deliquescent, but when care was taken to keep everything dry an acceptable pellet could be pressed at about 55 tons/in. ${ }^{2}$. The pellets showed strong absorptions mostly attributable to $\mathrm{CsOH}$ and water. However, the pellet did not show a cutoff and was still transmitting out to $250 \mathrm{~cm}^{-1}$.

It thus appears that, in selected instances, the preparation of samples as $\mathrm{CsF}$ pellets may be a useful alternative to the conventional but sometimes troublesome practice of preparing samples in the form of mulls.

\section{Is ot opic Mass Spectra}

Laurence Landau

Carbon dioxide equilibrated with water from the ${ }^{17} \mathrm{O}$ Water Distillation Cascade has been assayed regularly to determine the operating characteristics of the cascade and the rate of approach to equilibrium.

Oxygen taken from various positions along the ${ }^{17} \mathrm{O}$ Thermal Diffusion Cascade has also been assayed regularly.

Peak height measurements at $\mathrm{m} / \mathrm{e} 10$ and 11 were made to determine the ${ }^{10} \mathrm{~B} /{ }^{1} \mathrm{~B}^{1}$ ratios in $\mathrm{BF}_{3}$ samples taken from $\mathrm{BF}_{3} \cdot \mathrm{Et}_{2} \mathrm{~S}$ and $\mathrm{BF}_{3} \cdot \mathrm{THF}$ systems and compared with tank $\mathrm{BF}_{3}$ samples.

Precision dual-collector ratio measurements were made on many samples of nitrogen for the comparison of $\mathrm{m} / \mathrm{e} 29 / 28$ of the samples with the $m / e 29 / 28$ ratio of a reference sample. Similar measurements were made on $\mathrm{CO}_{2}$ samples both for the $46 / 44$ ratios and the $45 / 44^{2}$ ratios. One of these measurements was a continuing check of the mass spectrometer against a series of standards made up in 1958. This assay found the $45 / 44$ ratio of sample 1 to be 1.03024 times the ratio in sample 2. This is in satisfactory agreement with the average of previous determinations, ${ }^{17} 1.03032 \pm$ 0.00009 ( $95 \%$ C.L.).

\section{Nuclear Magnetic Resonance Studies of $\mathrm{BF}_{3}$ Addition Compounds}

A. C. Rutenberg

The following work is a continuation of the study of the exchange of $\mathrm{BF}_{3}$ between pairs of ether. $\mathrm{BF}_{3}$ molecular addition compounds. The system $\left(\mathrm{CH}_{3}\right)_{2} \mathrm{O}-\left(\mathrm{C}_{2} \mathrm{H}_{5}\right)_{2} \mathrm{O}-\mathrm{BF}_{3}$ has been previously described ${ }^{18,19}$ in detail. Experimentally,

\footnotetext{
${ }^{17}$ Chem. Div. Ann. Progr. Rept. June 20,1963, ORNL3488 , p. 33.

${ }^{18}$ A. C. Rutenberg and A. A. Palko, Chem. Div. Ann. Progr. Rept. June 20, 1963, ORNL-3488, p. 29.

${ }^{19}$ A. C. Rutenberg, A. A. Palko, and J. S. Drury, $J$. Am. Chem. Soc. 85, 2702 (1963).
} 
Table 3.9. Characteristics of Eigh $\mathrm{C}_{6} \mathrm{H}_{5} \mathrm{OCH}_{3}-\left(\mathrm{C}_{2} \mathrm{H}_{5}\right)_{2} \mathrm{O}-\mathrm{B} \mathrm{F}_{3}$ Mixtures

Concentrations, $\tau$ 's, and $R^{\prime}$ 's at $25^{\circ} \mathrm{C}$

\begin{tabular}{|c|c|c|c|c|c|c|c|}
\hline Mixture & $\begin{array}{c}\mathrm{C}_{6} \mathrm{H}_{5} \mathrm{OCH}_{3} \cdot \mathrm{BF}_{3} \\
\text { (moles } / \text { liter) }\end{array}$ & $\begin{array}{l}\left(\mathrm{C}_{2} \mathrm{H}_{5}\right)_{2} \mathrm{O} \cdot \mathrm{BF} \\
\text { (moles } / \text { liter })\end{array}$ & $\begin{array}{c}\mathrm{C}_{6} \mathrm{H}_{5} \mathrm{OCH}_{3} \\
\text { (moles/1iter) }\end{array}$ & $\begin{array}{c}\tau \times 10^{5} \\
(\mathrm{sec})\end{array}$ & $\begin{array}{c}R \times 10^{-3} \\
\left(\text { moles } 1 \text { iter }^{-1} \mathrm{sec}^{-1}\right)\end{array}$ & $\begin{array}{c}\Delta E^{\prime} \\
(\mathrm{kca} 1 / \mathrm{mole})\end{array}$ & $\begin{array}{l}95 \% \text { C.L. } \\
\text { on } \Delta E^{\prime}\end{array}$ \\
\hline A & 0.58 & 0.60 & 7.88 & 7.63 & 3.85 & 10.6 & 0.5 \\
\hline B & 1.30 & 1.31 & 6.08 & 8.61 & 7.56 & 12.5 & 0.5 \\
\hline $\mathrm{C}$ & 1.07 & 3.20 & 4.26 & 6.44 & 12.4 & 10.2 & 0.5 \\
\hline D & 2.08 & 2.08 & 4.14 & 14.4 & 7.22 & 12.0 & 0.6 \\
\hline$E$ & 3.06 & 1.05 & 4.09 & 16.3 & 4.80 & 13.2 & 0.8 \\
\hline F & 3.01 & 2.77 & 2.14 & 20.6 & 7.02 & 13.1 & 0.4 \\
\hline G & 3.02 & 3.86 & 0.90 & 30.2 & 5.60 & 14.4 & 0.5 \\
\hline $\mathrm{H}$ & 3.72 & 3.82 & 0.09 & 35.6 & 5.28 & 15.7 & 1.4 \\
\hline
\end{tabular}

the problem involves measuring ${ }^{19} \mathrm{~F}$ nuclear magnetic resonance (NMR) line widths and chemical shifts, which are related to the mean lifetimes of the $\mathrm{BF}_{3}$-containing species, as a function of temperature and mixture composition. The mixtures used in these studies were prepared by A. A. Palko.

Anisole- $\left(\mathrm{C}_{2} \mathrm{H}_{5}\right)_{2} \mathrm{O}-\mathrm{BF}_{3}$ System. - Some preliminary data on the exchange of $\mathrm{BF}_{3}$ between the anisole $\cdot \mathrm{BF}_{3}$ addition compound $\left(\mathrm{C}_{6} \mathrm{H}_{5} \mathrm{OCH}_{3} \cdot \mathrm{BF}_{3}\right)$ and $\left(\mathrm{C}_{2} \mathrm{H}_{5}\right)_{2}{ }_{2} \mathrm{O} \cdot \mathrm{BF}$ were presented in the previous report. ${ }^{18}$ Table 3.9 gives the compositions and some rate data for the eight mixtures studied. The experimental data were interpreted in terms of the two reactions given below:

$$
\begin{gathered}
\left(\mathrm{C}_{2} \mathrm{H}_{5}\right)_{2} \mathrm{O} \cdot \mathrm{BF}_{3}+\mathrm{C}_{6} \mathrm{H}_{5} \mathrm{OCH}_{3} \cdot \mathrm{BF}_{3} \stackrel{k}{\longrightarrow} \\
\left(\mathrm{C}_{2} \mathrm{H}_{5}\right)_{2} \mathrm{O} \cdot \mathrm{BF}_{3}+\mathrm{C}_{6} \mathrm{H}_{5} \mathrm{OCH}_{3} \cdot \mathrm{BF}_{3} \\
\left(\mathrm{C}_{2} \mathrm{H}_{5}\right)_{2} \mathrm{O} \cdot \mathrm{BF}_{3}+\mathrm{C}_{6} \mathrm{H}_{5} \mathrm{OCH}_{3} \stackrel{k_{2}}{\longrightarrow} \\
\left(\mathrm{C}_{2} \mathrm{H}_{5}\right)_{2} \mathrm{O}+\mathrm{C}_{6} \mathrm{H}_{5} \mathrm{OCH}_{3} \cdot \mathrm{BF}_{3} .
\end{gathered}
$$

Table 3.10 gives the calculated values of $k_{1}$ and $k_{2}$ based on the NMR measurements. The reader is referred to the published paper ${ }^{20}$ for details of the calculation.

Tetrahydrofuran- $\left(\mathrm{C}_{2} \mathrm{H}_{5}\right)_{2} \mathbf{O} \cdot \mathrm{BF}_{3}$. - Tetrahydrofuran $\left(\mathrm{C}_{4} \mathrm{H}_{8} \mathrm{O}\right)$ forms a stronger $\mathrm{BF}_{3}$ addition compound than the ethers involved in our previous

${ }^{20}$ A. C. Rutenberg, A. A. Palko, and J. S. Drury, $J$. Phys. Chem. 68, 976 (1964).
Table 3.10. Rate Constants and Activation Energies for Reactions of $\left(\mathrm{C}_{2} \mathrm{H}_{5}\right)_{2} \mathrm{O} \cdot \mathrm{BF}_{3}$ with $\mathrm{C}_{6} \mathrm{H}_{5} \mathrm{OCH}_{3} \cdot \stackrel{\mathrm{B}}{\mathrm{B}} \mathrm{F}_{3}$ and $\mathrm{C}_{6} \mathrm{H}_{5} \mathrm{OCH}_{3}$

All confidence limits at $95 \%$ level

Reaction (1) Reaction (2)

$\begin{array}{ccc}\begin{array}{c}\text { Rate constant, } \\ k \text { (liters mole }\end{array} & & \\ 25^{\circ} \mathrm{C} & 353 \pm 11 & 798 \pm 42 \\ 0^{\circ} \mathrm{C} & 28.5 \pm 2.2 & 155 \pm 13 \\ & 16.3 \pm 0.5 & 10.6 \pm 0.6 \\ \text { Activation energy, } & & \\ \Delta E \text { (kcal/mole) } & \end{array}$

NMR studies. It was of interest to determine the effect of this stronger complex on the rates and mechanisms of $\mathrm{BF}_{3}$ exchange.

In a mixture of $\mathrm{C}_{4} \mathrm{H}_{8} \mathrm{O},\left(\mathrm{C}_{2} \mathrm{H}_{5}\right)_{2} \mathrm{O}$, and $\mathrm{BF}$, there is a strong preference of the $\mathrm{BF}_{3}$ for the $\mathrm{C}_{4} \mathrm{H}_{8} \mathrm{O}$. The equilibrium constant

$$
K_{\text {eq }}=\frac{\left[\mathrm{C}_{4} \mathrm{H}_{8} \mathrm{O} \cdot \mathrm{BF}_{3}\right]\left[\left(\mathrm{C}_{2} \mathrm{H}_{5}\right)_{2} \mathrm{O}\right]}{\left[\left(\mathrm{C}_{2} \mathrm{H}_{5}\right)_{2} \mathrm{O} \cdot \mathrm{BF}_{3}\right]\left[\mathrm{C}_{4} \mathrm{H}_{8} \mathrm{O}\right]}>400
$$

was estimated from NMR observations at $-50^{\circ} \mathrm{C}$. The chemical shift between the two addition compounds varies with temperature and to a somewhat lesser degree with mixture composition. The $\mathrm{C}_{4} \mathrm{H}_{8} \mathrm{O} \cdot \mathrm{BF}{ }_{3}$ resonance occurred at a field strength 2.6 to $3.0 \mathrm{ppm}$ greater than the $\left(\mathrm{C}_{2} \mathrm{H}_{5}\right)_{2} \mathrm{O} \cdot \mathrm{BF}{ }_{3}$ peak in the same mixture. 
Table 3.11 gives the compositions and some rate data for the ten mixtures studied. The mean lifetimes $(\tau)$ were calculated ${ }^{21}$ from the experimental NMR measurements. The rates of exchange $(R)$ are related to $\tau$ by the equation

$$
R=\frac{\left[\left(\mathrm{C}_{2} \mathrm{H}_{5}\right)_{2} \mathrm{O} \cdot \mathrm{BF}{ }_{3}\right] p_{1}}{\tau}=\frac{\left[\mathrm{C}_{4} \mathrm{H}_{8} \mathrm{O} \cdot \mathrm{BF}_{3}\right] p_{2}}{\tau},
$$

in which $p_{1}$ and $p_{2}$ are the mole fractions of $\mathrm{C}_{4} \mathrm{H}_{8} \mathrm{O} \cdot \mathrm{BF}_{3}$ and $\left(\mathrm{C}_{2} \mathrm{H}_{5}\right)_{2} \mathrm{O} \cdot \mathrm{BF} \mathrm{F}_{3}$ respectively.

The rates of exchange decrease as a larger portion of the ethers is complexed. When no free ether remains, further addition of $\mathrm{BF}_{3}$ produces an increase in rate accompanied by a decrease in activation energy. The exchange between $\mathrm{BF}_{3}$ and $\mathrm{C}_{4} \mathrm{H}_{8} \mathrm{O} \cdot \mathrm{BF}$ in toluene solution has been studied by Brownstein et al., ${ }^{2}$ who measured an activation energy of $4.6 \mathrm{kcal} / \mathrm{mole}$ for that process. No detailed study of free $\mathrm{BF}_{3}$ dependence was

${ }^{21}$ J. A. Pople, W. G. Schneider, and H. J. Bernstein, High-Resolution Nuclear Magnetic Resonance, chap. 10, Mc Graw-Hill, New York, 1959.

${ }^{22}$ S. Brownstein, A. M. Eastham, and G. A. Latremouille, J. Phys. Chem. 67, 1028 (1963). attempted in our work since the free $\mathrm{BF}_{3}$ concentration was not known accurately and could only be varied over a small range. The remainder of the discussion will be limited to mixtures 1-8 (Table 3.11) which contained no free $\mathrm{BF}_{3}$.

A number of differences are apparent in comparing the tetrahydrofuran system (Table 3.11) with the anisole system (Table 3.9). In the $\mathrm{C}_{6} \mathrm{H}_{5} \mathrm{OCH}_{3}$ system the rate of exchange varied by about a factor of 3 over the entire concentration range and passed through a maximum. In the $\mathrm{C}_{4} \mathrm{H}_{8} \mathrm{O}$ system the exchange rate varied by a factor of 80 and was still increasing in the mixture having the lowest $\mathrm{BF}_{3}$ content. A pair of reactions analogous to those given for the anisole system would not account for the data.

The analysis of the $\mathrm{C}_{4} \mathrm{H}_{8} \mathrm{O}$ system rate data is still in progress and the following interpretations are of a preliminary nature. The $\mathrm{BF}_{3}$ exchange in the absence of free ether displays a higher activation energy and slower rate of exchange in the system containing $\mathrm{C}_{4} \mathrm{H}_{8} \mathrm{O} \cdot \mathrm{BF}_{3}$ than with the weaker $\mathrm{C}_{6} \mathrm{H}_{5} \mathrm{OCH}_{3}$ complex [compare mixtures 8 (Table 3.11) and $\mathrm{H}$.(Table 3.9)]. The concentration dependence of the reaction $\left(\mathrm{C}_{2} \mathrm{H}_{5}\right)_{2} \mathrm{O} \cdot \mathrm{BF}_{3}+$ $\mathrm{C}_{4} \mathrm{H}_{8} \mathrm{O} \cdot \mathrm{BF}_{3}$ cannot be readily determined because

Table 3.11. Characteristics of Ten $\mathrm{C}_{4} \mathrm{H}_{8} \mathrm{O}-\left(\mathrm{C}_{2} \mathrm{H}_{5}\right)_{2} \mathrm{O}-\mathrm{BF} \mathrm{F}_{3}$ Mixtures

Concentrations, $\tau$ 's, and $R^{\prime}$ 's at $25^{\circ} \mathrm{C}$

\begin{tabular}{|c|c|c|c|c|c|c|c|}
\hline Mixture & $\begin{array}{l}\mathrm{C}_{4} \mathrm{H}_{8} \mathrm{O} \cdot \mathrm{BF}_{3} \\
\text { (moles / liter) }\end{array}$ & $\begin{array}{l}\left(\mathrm{C}_{2} \mathrm{H}_{5}\right)_{2} \mathrm{O} \cdot \mathrm{BF}_{3} \\
\text { (moles/liter) }\end{array}$ & $\begin{array}{l}\left(\mathrm{C}_{2} \mathrm{H}_{5}\right)_{2} \mathrm{O} \\
\text { (moles } / 1 \text { iter) }\end{array}$ & $\begin{array}{r}\tau \times 10^{5} \\
(\mathrm{sec})\end{array}$ & $\begin{array}{c}R \times 10^{-3} \\
\left(\text { moles } l i t e r^{-1} \mathrm{sec}^{-1}\right)\end{array}$ & $\begin{array}{c}\Delta E^{\prime} \\
(\text { kcal } / \text { mole })\end{array}$ & $\begin{array}{l}95 \% \text { C.L. } \\
\text { on } \Delta E^{\prime}\end{array}$ \\
\hline 1 & 0.75 & 0.75 & 8.15 & 3.48 & 10.7 & 12.8 & 0.8 \\
\hline 2 & 1.91 & 1.01 & 6.71 & 7.88 & 8.36 & 12.0 & 1.2 \\
\hline 3 & 1.39 & 1.78 & 6.25 & 13.8 & 5.62 & 11.8 & 0.9 \\
\hline 4 & 1.51 & 3.06 & 4.50 & 30.7 & 3.30 & 12.1 & 0.8 \\
\hline 5 & 2.32 & 2.42 & 4.51 & 31.8 & 3.72 & 12.3 & 0.5 \\
\hline 6 & 3.28 & 3.27 & 2.43 & 72.1 & 2.27 & 12.9 & 0.5 \\
\hline 7 & 3.95 & 3.95 & 0.81 & 246 & 0.802 & 14.0 & 0.9 \\
\hline 8 & 4.32 & 4.13 & 0,19 & 1590 & 0.133 & 19.2 & 1.1 \\
\hline 9 & 4.26 & 4.26 & $0.00^{B}$ & 157 & 1.36 & 11.5 & 1.0 \\
\hline 10 & 4.22 & 4.21 & $0.00^{b}$ & 34.1 & 6.18 & 8.6 & 0.7 \\
\hline
\end{tabular}

${ }^{a}$ Sample contains trace of uncomplexed $\mathrm{BF}_{3}$.

${ }^{b}$ Sample contains $\sim 0.2$ mole $/$ liter uncomplexed $\mathrm{BF}_{3}$. 
Table 3.12. Rate Constants for $\mathrm{C}_{4} \mathrm{H}_{8} \mathrm{O}-\left(\mathrm{C}_{2} \mathrm{H}_{5}\right)_{2} \mathrm{O}-\mathrm{BF}{ }_{3}$ System

\begin{tabular}{|c|c|c|c|}
\hline & Term 1 & Term 2 & Term 3 \\
\hline \multicolumn{4}{|l|}{ Rate constant, $k$} \\
\hline $25^{\circ} \mathrm{C}$ & $<7$ liters mole sec $^{-1}$ & 236 liters mole ${ }^{-1} \mathrm{sec}^{-1}$ & 882 moles liter ${ }^{-1} \mathrm{sec}^{-1}$ \\
\hline $0^{\circ} \mathrm{C}$ & $<0.4$ liter $\mathrm{mole}^{-1} \mathrm{sec}^{-1}$ & 41 liters mole ${ }^{-1} \mathrm{sec}^{-1}$ & 117 moles liter ${ }^{-1} \mathrm{sec}^{-1}$ \\
\hline $\begin{array}{l}\text { Activation energy, } \\
\Delta E\end{array}$ & $19.2 \mathrm{kcal} / \mathrm{mole}$ & $11.4 \mathrm{kcal} / \mathrm{mole}$ & $13.0 \mathrm{kcal} / \mathrm{mole}$ \\
\hline
\end{tabular}

of the competing, rapid reaction with free ethyl ether. We have at present no suitable explanation for the continued increase in rate associated with the reduction in $\mathrm{BF}$ content in the mixtures which already have a high free-ether concentration.

The best mathematical fit of the data for the simple relationships thus far considered is

$$
\begin{aligned}
& R=k_{1}\left[\left(\mathrm{C}_{2} \mathrm{H}_{5}\right)_{2} \mathrm{O} \cdot \mathrm{BF}_{3}\right]\left[\mathrm{C}_{4} \mathrm{H}_{8} \mathrm{O} \cdot \mathrm{BF}_{3}\right] \\
& +k_{2}\left[\left(\mathrm{C}_{2} \mathrm{H}_{5}\right)_{2} \mathrm{O}\right]\left[\mathrm{C}_{4} \mathrm{H}_{8} \mathrm{O} \cdot \mathrm{BF}_{3}\right] \\
& +k_{3} \frac{\left[\left(\mathrm{C}_{2} \mathrm{H}_{5}\right)_{2} \mathrm{O}\right]}{\left[\left(\mathrm{C}_{2} \mathrm{H}_{5}\right)_{2} \mathrm{O} \cdot \mathrm{BF}_{3}\right]}
\end{aligned}
$$

which is the rate law for the anisole system plus the additional $k_{3}$ term. Table 3.12 gives estimates of the three rate constants using this expression. The upper limits for $k$, were based on mixture 8 (Table 3.11) only. The $k_{2}$ and $k_{3}$ values were calculated using rate and concentration data for mixtures 1-6 (Table 3.11).

Ethyl Sulfide- $\left(\mathrm{C}_{2} \mathrm{H}_{5}\right)_{2} \mathrm{O}-\mathrm{BF}_{3}$. - Experimental work has begun on a system containing $\left(\mathrm{C}_{2} \mathrm{H}_{5}\right)_{2} \mathrm{~S}$. $\mathrm{BF}_{3}$, which is an even weaker addition compound than $\mathrm{C}_{6} \mathrm{H}_{5} \mathrm{OCH}_{3} \cdot \mathrm{BF}_{3}$. An attempt to measure the relative stability of these two addition compounds failed since a mixture of $\mathrm{C}_{6} \mathrm{H}_{5} \mathrm{OCH}_{3},\left(\mathrm{C}_{2} \mathrm{H}_{5}\right)_{2} \mathrm{~S}$, and $\mathrm{BF}$ reacts, presumably ethylating the benzene ring. A preliminary value of $k_{1}$ has been obtained for the reaction $\left(\mathrm{C}_{2} \mathrm{H}_{5}\right)_{2} \mathrm{O} \cdot \mathrm{BF}_{3}^{1}+\left(\mathrm{C}_{2} \mathrm{H}_{5}\right)_{2} \mathrm{~S} \cdot{ }_{\mathrm{BF}}$. Table 3.13 gives the value of $k_{1}$ for the four systems studied to date, assuming all four reactions are first order with respect to both addition com-

\begin{tabular}{|c|c|}
\hline$L$ & $\left(\right.$ liters $\left.\mathrm{mole}^{-1} \sec ^{-1}\right)$ \\
\hline$\left(\mathrm{C}_{2} \mathrm{H}_{5}\right)_{2} \mathrm{~S}$ & 942 \\
\hline $\mathrm{C}_{6} \mathrm{H}_{5} \mathrm{OCH}_{3}$ & 352 \\
\hline$\left(\mathrm{CH}_{3}\right)_{2} \mathrm{O}$ & 194 \\
\hline $\mathrm{C}_{4} \mathrm{H}_{8} \mathrm{O}$ & $<7$ \\
\hline
\end{tabular}
pounds. The weaker complex yields a larger rate constant.

\section{Nuclear Magnetic Resonance Observations on $\mathrm{CIF}_{5}$ and $\mathrm{FClO}_{2}$}

A. C. Rutenberg

Samples of liquid $\mathrm{ClF}_{5}$ and $\mathrm{FClO}_{2}$ in 6-mm-OD quartz Raman tubes were observed at room temperature. The peaks were located relative to aqueous $\mathrm{KF}$ as an external standard. The $\mathrm{ClF}_{5}$ spectrum consisted of a fairly sharp doublet (four F's) and a broad quintuplet far downfield (one F). The data were consistent with the tetragonal pyramid structure obtained by Begun and Smith ${ }^{23}$ from infrared and Raman spectra. Table 3.14 gives the measured nuclear magnetic resonance (NMR) shifts and coupling constant for $\mathrm{ClF}_{5}$, along with data on analogous compounds by Muetterties and Phillips. ${ }^{24,25}$

${ }^{23}$ G. M. Begun, this report.

${ }^{24}$ E. L. Muetterties and W. D. Phillips, J. Am. Chem. Soc. 81, 1084 (1959).

${ }^{25}$ E. L. Muetterties and W. D. Phillips, J. Am. Chem. Soc. 79, 322 (1957). 
Table 3.14. Nuclear Magnetic Resonance Data on Halogen Pentafluorides

\begin{tabular}{lccc} 
& \multicolumn{2}{c}{$\begin{array}{c}\text { Chemical Shift } \\
\text { Compound }\end{array}$} & \multicolumn{2}{c}{$(\mathrm{ppm})$} & $J^{b}$ \\
\cline { 2 - 3 } & $\mathrm{F}$ & $\mathrm{F}_{4}$ & \\
\hline $\mathrm{C} 1 F_{5}$ & 2 & 171 & 133 \\
$\mathrm{BrF}_{5}$ & $158^{\mathrm{c}}$ & $288^{\mathrm{c}}$ & $76^{d}$ \\
$\mathrm{IF}_{5}$ & $369^{\mathrm{c}}$ & $411^{\mathrm{c}}$ & $81^{d}$ \\
\hline
\end{tabular}

${ }^{a}$ From $F_{2} \equiv 0$.

${ }^{b}$ Spin-spin coupling constants for ${ }^{19} \mathrm{~F}$.

${ }^{c}$ Data from ref. 24 .

${ }^{d}$ Data from ref. 25 .

The $\mathrm{FClO}_{2}$ peak appeared $97.4 \mathrm{ppm}$ above $F_{2} \equiv 0$. This may be compared to the values of 143.7 and 204.6 obtained by Agahigian et al. ${ }^{26}$ for $\mathrm{FClO}_{3}$ and $\mathrm{FClO}_{4}$.

\section{Raman Spectral Studies 27}

\section{G. M. Begun}

Observation and interpretation of the infrared and Raman spectra of various molecules and ions have continued. The study of xenon fluorides synthesized by D. F. Smith ${ }^{28}$ has been extended.

${ }^{26}$ H. Agahigian, A. P. Gray, and G. D. Vickers, Can. J. Chem. 40, 157 (1962).

${ }^{27} \mathrm{~W}$. H. Fletcher of the University of Tennessee Chemistry Department consulted on much of this work.

${ }^{2}$ Technical Division, Oak Ridge Gaseous Diffusion Plant, Oak Ridge, Tenn.
The Raman spectra of $\mathrm{XeF}_{2}, \mathrm{XeF}_{4}$, and $\mathrm{XeOF}_{4}$ reported previously ${ }^{29}$ have been confirmed. Attempts to observe the Raman spectrum of gaseous $\mathrm{XeF}_{6}$ in a specially constructed heated fluorothene Raman cell were unsuccessful. A rapid photodecomposition of $\mathrm{XeF}_{6}$ to yield $\mathrm{XeF}_{4}$ and $\mathrm{F}_{2}$ was noted in the blue radiation of the Raman spectrometer.

The Raman spectrum of liquid chloryl fluoride $\left(\mathrm{ClO}{ }_{2} \mathrm{~F}\right)$ was recorded and these observations combined with the infrared data of D. F. Smith. ${ }^{2} 8$ All the fundamental frequencies of the molecule have been observed in both the infrared and the Raman spectra. Figure 3.2 reproduces the Raman spectrum of liquid $\mathrm{ClO}_{2} \mathrm{~F}$. Raman frequencies are recorded in Table 3.15 and the infrared data are listed in Table 3.16. The sharpness of the infrared bands made it possible to resolve a large number of isotopic lines due to ${ }^{35} \mathrm{ClO}_{2} \mathrm{~F}$ and ${ }^{37} \mathrm{ClO}, \mathrm{F}$. Use of highly enriched ${ }^{18} \mathrm{O}$ made observations of some of the ${ }^{18} \mathrm{O}$ species lines possible.

Valence force constants were calculated for the $\mathrm{ClO}_{2} \mathrm{~F}$ molecule using the Wilson $F$ and $G$ matrix method of calculation. A machine iterative process similar to that developed by Overend and Scherer ${ }^{30}$ was used to converge on the best set of force constants. Table 3.17 lists the force constants for this model where $r$ is the Cl-O distance, $R$ the $\mathrm{Cl}-\mathrm{F}$ distance, $\alpha$ the $\mathrm{F}-\mathrm{Cl}-\mathrm{O}$ angle, and $\beta$ the $\mathrm{O}-\mathrm{Cl}-$ $O$ angle. This set of force constants is not unique

\footnotetext{
${ }^{29}$ Chem. Div. Ann. Progr. Rept. June 20, 1963, ORNL3488, pp. $34-41$.

$30 \mathrm{~J}$. Overend and J. R. Scherer, J. Chem. Phys. 32, 1289 (1960).
}

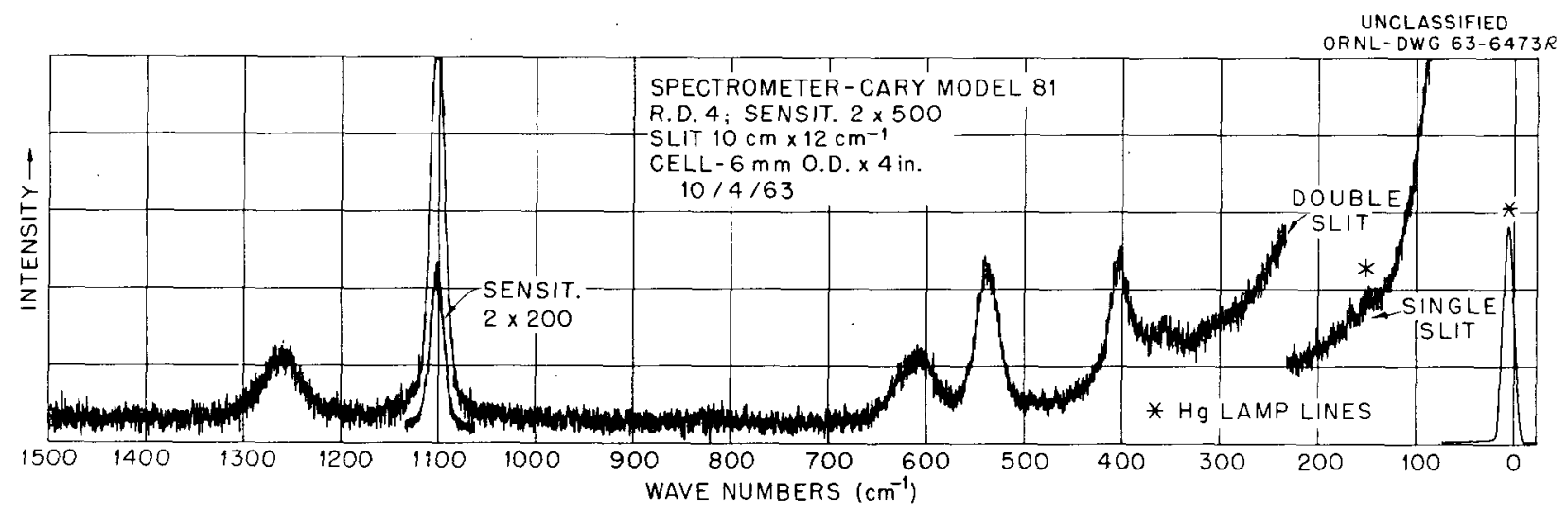

Fig. 3.2. Raman Spectrum of Liquid $\mathrm{ClO}_{2} \mathrm{~F}$. 
Table 3.15. Raman Bands of Liquid $\mathrm{ClO}_{2} \mathrm{~F}$

\begin{tabular}{cccl}
\hline $\begin{array}{c}\text { Frequency } \\
\left(\mathrm{cm}^{-1}\right)\end{array}$ & Polarization $^{a}$ & $\begin{array}{c}\text { Relative } \\
\text { Intensity }\end{array}$ & \multicolumn{1}{c}{ Assignment } \\
\hline 351 & & $0+$ & $\nu_{6}(\mathrm{O}-\mathrm{C} 1-\mathrm{F}$ bend, asym $)$ \\
398 & $\mathrm{P}(?)$ & 3 & $\nu_{4}(\mathrm{O}-\mathrm{C} 1-\mathrm{F}$ bend $)$ \\
533 & $\mathrm{P}$ & 5 & $\nu_{3}(\mathrm{O}-\mathrm{C} 1-\mathrm{O}$ bend $)$ \\
602 & $\mathrm{P}$ & 2 & $\nu_{2}(\mathrm{C} 1-\mathrm{F}$ stretch) \\
1097 & $\mathrm{P}$ & 10 & $\nu_{1}^{\prime}(\mathrm{C} 1-\mathrm{O}$ stretch) \\
1253 & $\mathrm{D}$ & 4 & $\nu_{5}(\mathrm{Cl}-\mathrm{O}$ stretch, asym) \\
\hline
\end{tabular}

${ }^{\mathbf{e}} \mathrm{P}=$ polarized; $\mathrm{D}=$ highly depolarized.

Table 3.16. Infrared Bands of Gaseous $\mathrm{Cl}^{16} \mathrm{O}_{2} \mathrm{~F}^{a}$

\begin{tabular}{|c|c|c|c|c|c|c|}
\hline \multicolumn{3}{|c|}{ Observed Frequencies $\left(\mathrm{cm}^{-1}\right)$} & \multirow{2}{*}{ Assignment } & \multicolumn{3}{|c|}{$\begin{array}{l}\text { Calculated from Fundamental } \\
\text { Frequencies }\left(\mathrm{cm}^{-1}\right)\end{array}$} \\
\hline${ }^{35} \mathrm{ClO}_{2} \mathrm{~F}$ & ${ }^{37} \mathrm{ClO}_{2} \mathrm{~F}$ & $\begin{array}{l}\text { Is otope } \\
\text { Shift }\end{array}$ & & ${ }^{35} \mathrm{ClO}_{2} \mathrm{~F}$ & ${ }^{37} \mathrm{ClO}_{2} \mathrm{~F}$ & $\begin{array}{c}\text { Is otope } \\
\text { Shift }\end{array}$ \\
\hline 367.0 & & & $\nu_{6}$ & & & \\
\hline 401.6 & & & $\nu_{4}$ & & & \\
\hline 546.5 & 543.0 & 3.0 & $\nu_{3}$ & & & \\
\hline 630.2 & 621.6 & 8.6 & $\nu_{2}$ & & & \\
\hline 700 & 693 & 7 & $\nu_{1}^{2}-\nu_{4}$ & 704.2 & 698.2 & 6.0 \\
\hline 771.5 & & & $\nu_{4}+\nu_{6}$ & 768.6 & 766.0 & 2.6 \\
\hline 809.8 & 806.9 & 2.9 & $2 \nu_{4}$ & 803.2 & 800.4 & 2.8 \\
\hline 907.1 & 895.6 & 11.5 & $\nu_{5}-\nu_{6}$ & 904.4 & 892.8 & 11.6 \\
\hline 949.3 & 945.4 & 3.9 & $\nu_{3}+\nu_{4}$ & 948.1 & 943.0 & 5.1 \\
\hline 1030.9 & 1021.1 & 9.8 & $\nu_{2}+\nu_{4}$ & 1031.8 & 1021.6 & 10.2 \\
\hline 1105.8 & 1098.4 & 7.4 & $\nu_{1}$ & & & \\
\hline 1174.2 & 1161.7 & 12.5 & $\nu_{2}+\nu_{3}$ & 1176.7 & 1164.6 & 12.1 \\
\hline 1271.4 & 1258.6 & 12.8 & $\nu_{5}$ & & & \\
\hline 1508 & & & $\nu_{1}+\nu_{4}$ & 1507.4 & 1498.6 & 8.8 \\
\hline 1627 & 1612 & 15 & $\nu_{5}+\nu_{6}$ & 1638.4 & 1624.4 & 14.0 \\
\hline 1675.0 & 1660 & 15 & $\nu_{5}+\nu_{4}$ & 1673.0 & 1658.8 & 14.2 \\
\hline 1735.2 & 1718.7 & 16.5 & $\nu_{1}+\nu_{2}$ & 1736.0 & 1720.0 & 16.0 \\
\hline 1808 & & & $\nu_{3}+\nu_{5}$ & 1817.9 & 1801.6 & 16.3 \\
\hline 1894 & 1872 & 22 & $\nu_{2}+\nu_{5}$ & 1901.6 & 1880.2 & 21.4 \\
\hline 2134 & $2119(?)$ & $15(?)$ & $\nu_{1}^{2}+\nu_{2}+\nu_{4}$ & 2137.6 & 2120.2 & 17.4 \\
\hline 2204 & 2189 & 15 & $2 \nu_{1}$ & 2211.6 & 2196.8 & 1.4 .8 \\
\hline 2362.5 & 2341 & 21.5 & $\nu_{1}+\nu_{5}$ & 2377.2 & 2357.0 & 20.2 \\
\hline 2526.3 & 2499.3 & 27.0 & $2 \nu_{5}$ & 2542.8 & 2517.2 & 25.6 \\
\hline 2742 & & & $2 \nu_{1}+\nu_{3}$ & 2758.1 & 2739.8 & 18.3 \\
\hline 2903 & 2878 (?) & $25(?)$ & $2 \nu_{5}+\nu_{6}$ & 2909.8 & 2883.0 & 26.8 \\
\hline 3292.9 & 3271.0 & 21.9 & $3 \nu_{1}$ & 3317.4 & 3295.2 & 22.2 \\
\hline 3443.6 & 3414.5 & 29.1 & $2 \nu_{1}+\nu_{5}$ & 3483.0 & 3455.4 & 27.6 \\
\hline
\end{tabular}

${ }^{a}$ Data taken by D. F. Smith, Oak Ridge Gaseous Diffusion Plant. 
but calculations using them reproduce the isotopic frequencies quite closely. Table 3.18 gives the observed and calculated fundamental vibrational frequencies of the various isotopic species of chloryl fluoride.

The observation of the infrared and Raman spectra of $\mathrm{XeOF}_{4}$ reported last year ${ }^{29}$ led to an investigation of the spectra of the series of molecules $\mathrm{XeOF}_{4}, \mathrm{IF}_{5}, \mathrm{BrF}_{5}$, and $\mathrm{ClF}_{5}$. This series of molecules has square pyramidal structures and the ir spectra are remarkably similar. Our data for $\mathrm{BrF}_{5}$ agree well with previously published data. For IF some discrepancies were found with the data of ${ }^{5}$ Lord and co-workers, ${ }^{3}{ }^{1}$ and reassignments of some of the frequencies were made. The preparation of $\mathrm{ClF}_{5}$ and some preliminary infrared data have been described previously by Smith. ${ }^{32}$

Table 3.19 gives the observed infrared and Raman frequencies that we have assigned as fundamental frequencies. Figure 3.3 shows the Raman spectra of all four molecules. Consideration of the spectral data establishes that the symmetry of the molecules is $C_{4 v^{\circ}}$. Thus the model of the structure of $\mathrm{XAF}_{4}$ consists of a tetragonal pyramid with the $\mathrm{X}$ atom ( $\mathrm{Xe}, \mathrm{I}, \mathrm{Br}$, or $\mathrm{Cl}$ ) situated either above, below, or in the plane of the four equidistant $F$ atoms. The $A$ atom ( $O$ or $F$ ) would be located at the apex of the pyramid. Burbank and Bensey ${ }^{3}$ report $x$-ray data on $\mathrm{BrF}_{5}$ which

\footnotetext{
${ }^{31}$ R. C. Lord et al., J. Am. Chem. Soc. 72, 522 (1950).

${ }^{32}$ D. F. Smith, Science 141, 1039 (1963).

${ }^{33}$ R. D. Burbank and F. N. Bensey, J. Chem. Phys. 27, 982 (1957).
}

indicate the A-X-F angle is slightly less (80.5$86.5^{\circ}$ ) than $90^{\circ}$. No data are available for the other molecules, although the close resemblance of the spectra of $\mathrm{XeOF}_{4}$ to that of $\mathrm{XeF}_{4}$ seems to indicate that the $\mathrm{XeF}_{4}^{4}$ (which is square planar) is altered very little to form $\mathrm{XeOF}_{4}$. Observations of the $\mathrm{F}-\mathrm{Cl}-\mathrm{F}$ angle in $\mathrm{ClF}_{3}{ }^{34}$ show this angle to be less than $90^{\circ}\left(87^{\circ} 29^{\prime}\right)$ and $\mathrm{ClF}_{5}$ might be expected to be similar. Nuclear magnetic resonance studies of $\mathrm{ClF}_{5}$ by $\mathrm{A}$. C. Rutenberg of ORNL, given elsewhere in this report, established the 1-4 pattern of $\mathrm{Cl}-\mathrm{F}$ bonds in $\mathrm{ClF}_{5}$.

${ }^{34}$ D. F. Smith, J. Chem. Phys. 21, 609 (1953).

Table 3.17. Valence Force Constants for $\mathrm{ClO}_{2} \mathrm{~F}$

\begin{tabular}{ccl}
\hline Constant & Millidynes $/ A$ & Description \\
\hline$f_{r}$ & 9.07 & C1-O stretch \\
$f_{R}$ & 2.53 & C1-F stretch \\
$f_{\alpha} / R r$ & 0.59 & F-Cl-O bend \\
$f_{\beta} / r r$ & 1.06 & O-Cl-O bend \\
$f_{r t}$ & -0.12 & Interaction \\
$f_{r \beta} / r$ & 0.38 & Interaction \\
$f_{r a} / \sqrt{R r}$ & -0.10 & Interaction \\
$f_{r a} / \sqrt{R r}$ & 0.10 & Interaction \\
$f_{\alpha \alpha^{\prime}} / R r$ & 0.13 & Interaction \\
$f_{\alpha \beta} / r \sqrt{R r}$ & 0.14 & Interaction \\
\hline
\end{tabular}

Table 3.18. Observed and Calculated Fundomental Vibrational Frequencies for $\mathrm{ClO}_{2} \mathrm{~F}$

Values in parentheses calculated by the product rule

\begin{tabular}{|c|c|c|c|c|c|c|c|c|c|c|c|c|}
\hline & \multicolumn{2}{|c|}{${ }^{35} \mathrm{ClO}_{2} \mathrm{~F}$} & \multicolumn{2}{|c|}{${ }^{37} \mathrm{ClO}_{2} \mathrm{~F}$} & \multicolumn{2}{|c|}{${ }^{35} \mathrm{Cl}^{18} \mathrm{O}_{2} \mathrm{~F}$} & \multicolumn{2}{|c|}{${ }^{37} \mathrm{Cl}^{18} \mathrm{O}_{2} \mathrm{~F}$} & \multicolumn{2}{|c|}{${ }^{35} \mathrm{Cl}^{16} \mathrm{O}^{18} \mathrm{OF}$} & \multicolumn{2}{|c|}{${ }^{37} \mathrm{Cl}^{16} \mathrm{O}^{18} \mathrm{OF}$} \\
\hline & Obs & Calc & Obs & Calc & Obs & Calc & Obs & Calc & Obs & Calc & Obs & Calc \\
\hline$\nu_{1}$ & 1105.8 & 1106.3 & 1098.4 & 1098.8 & 1060.4 & 1059.5 & 1052.6 & 1051.5 & 1080.7 & 1080.0 & 1072.4 & 1072.1 \\
\hline$\nu_{2}$ & 630.2 & 629.7 & 621.6 & 622.5 & 624.7 & 624.3 & 616.0 & 617.0 & 628.6 & 626.8 & 618.6 & 619.6 \\
\hline$\nu_{3}$ & 546.5 & 547.7 & 543.0 & 542.8 & 529.0 & 528.1 & & 523.4 & 537.8 & 538.2 & 534.0 & 533.4 \\
\hline$\nu_{4}$ & 401.6 & 401.6 & $(400.2)$ & 400.2 & $(391.7)$ & 391.7 & & 390.2 & & 397.3 & & 395.9 \\
\hline$\nu_{5}$ & 1271.4 & 1271.8 & 1258.6 & 1257.8 & 1229.6 & 1229.1 & 1215.0 & 1214.6 & 1253.6 & 1253.4 & & 1239.3 \\
\hline$\nu_{6}$ & 367.0 & 367.0 & $(365.8)$ & 365,8 & $(356.3)$ & 356.3 & & 355.2 & & 361.0 & & 360.0 \\
\hline
\end{tabular}




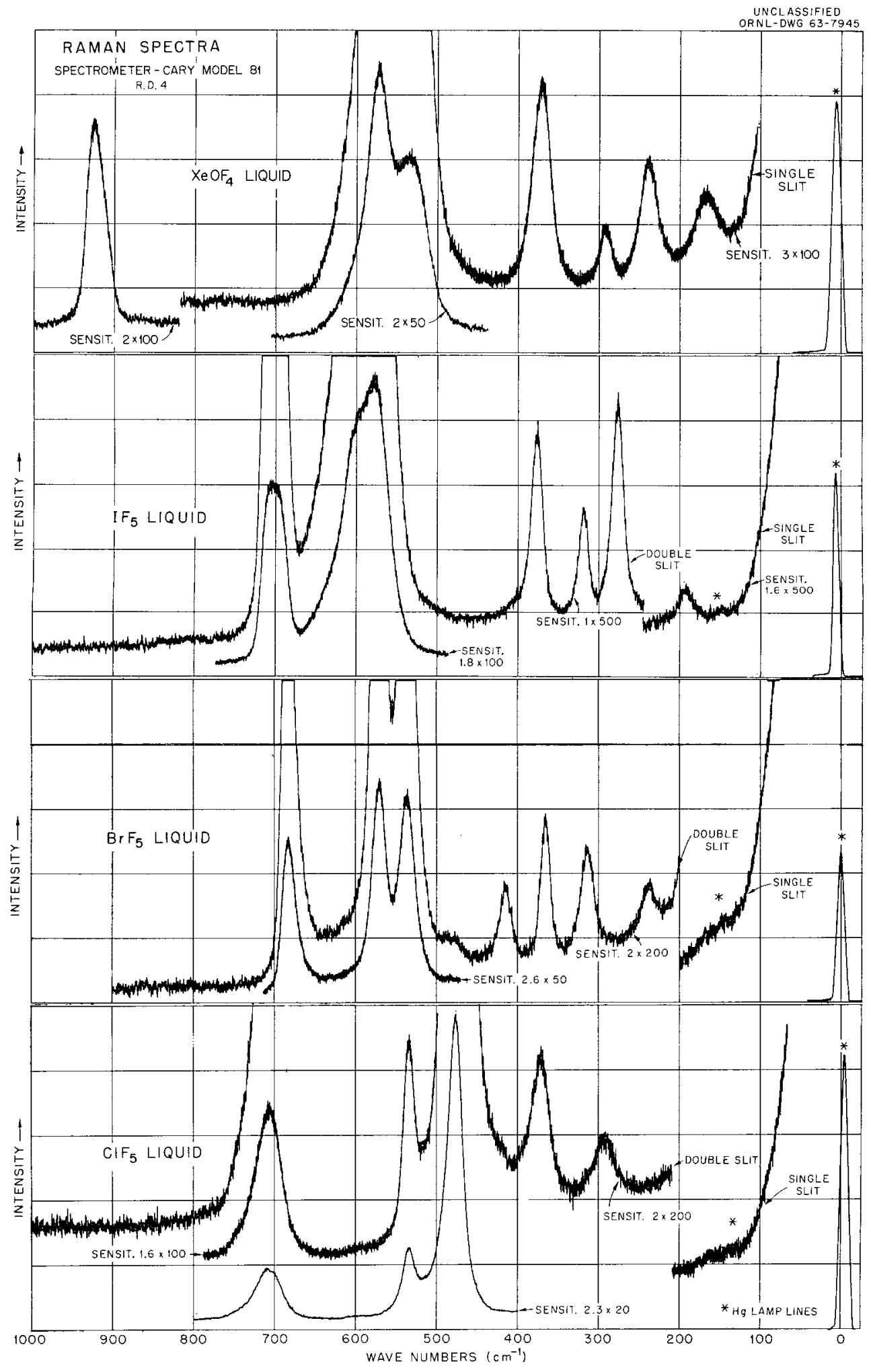

Fig. 3.3. Raman Spectra of Liquid $\mathrm{XeOF}_{4}, \mathrm{IF}_{5}, \mathrm{BrF}_{5}$, and $\mathrm{ClF}_{5}$. 
Table 3.19. Fundamental Vibrational Frequencies of $X X F_{4}$ Molecules $\left(\mathrm{cm}^{-1}\right)$

$\mathrm{P}=$ polarized; $\mathrm{s}=$ strong; $\mathrm{m}=$ medium; $\mathrm{v}=$ very

$\mathrm{Numbers}$ in parentheses refer to relative intens ities

Frequencies in brackets are estimated

\begin{tabular}{|c|c|c|c|c|c|c|c|c|}
\hline \multirow[b]{2}{*}{ Assignment } & \multicolumn{2}{|c|}{$\mathrm{XeOF}_{4}$} & \multicolumn{2}{|c|}{$\mathrm{IF}_{5}$} & \multicolumn{2}{|c|}{$\mathrm{BrF}_{5}$} & \multicolumn{2}{|c|}{$\mathrm{ClF}_{5}$} \\
\hline & $\begin{array}{l}\text { Raman } \\
\text { (liquid) }\end{array}$ & $\begin{array}{c}\text { Infrared } \\
\text { (gas) }\end{array}$ & $\begin{array}{l}\text { Raman } \\
\text { (liquid) }\end{array}$ & $\begin{array}{c}\text { Infrared } \\
\text { (gas) }\end{array}$ & $\begin{array}{l}\text { Raman } \\
\text { (liquid) }\end{array}$ & $\begin{array}{c}\text { Infrared } \\
\text { (gas) }\end{array}$ & $\begin{array}{l}\text { Raman } \\
\text { (liquid) }\end{array}$ & $\begin{array}{c}\text { Infrared } \\
\text { (gas) }\end{array}$ \\
\hline$A_{1} \nu_{1}$ & $920(2) \mathrm{P}$ & $926 \mathrm{~s}$ & $698(6) \mathrm{P}$ & $710 \mathrm{~s}$ & $682(7) \mathrm{P}$ & $683 \mathrm{~s}$ & 709 (3) $\mathrm{P}$ & {$[712]$} \\
\hline$\nu_{2}$ & $567(10) \mathrm{P}$ & $576 \mathrm{~m}$ & $593(10) \mathrm{P}$ & [595] & $570(10) \mathrm{P}$ & $587 \mathrm{~m}$ & 538 (1) $\mathrm{P}$ & $542 \mathrm{~m}$ \\
\hline$\nu_{3}^{2}$ & $285(0+) P$ & $294 \mathrm{~s}$ & 315 (1) $\mathrm{P}$ & $318 \mathrm{~m}$ & 365 (2) $\mathrm{P}$ & $369 \mathrm{~s}$ & $480(10) \mathrm{P}$ & $488 \mathrm{~s}$ \\
\hline$B_{1} \nu_{4}^{\nu_{4}}$ & $\begin{array}{l}527(4) \\
232^{a}\end{array}$ & & $\begin{array}{l}575(8) \\
257^{a}\end{array}$ & & $\begin{array}{l}535(10) \\
281^{a}\end{array}$ & & $\begin{array}{c}{[480]} \\
346^{a}\end{array}$ & \\
\hline$B_{2} \nu_{6}$ & $233(1)$ & & $273(2)$ & & $312(1)$ & & $375(1)$ & \\
\hline$E \quad \nu_{7}$ & & $608 \mathrm{vs}$ & & $640 \mathrm{vs}$ & & 644 vs & {$[\mathrm{r}, 0]$} & 732 vs \\
\hline$\nu_{8}$ & $\begin{array}{l}365(2) \\
161(0+)\end{array}$ & $361 \mathrm{~s}$ & $\begin{array}{l}374(2) \\
189(0+)\end{array}$ & $372 \mathrm{~m}$ & $\begin{array}{l}414(1) \\
237(0+)\end{array}$ & $415 \mathrm{~m}$ & $\begin{array}{l}{[440]} \\
296(0+)\end{array}$ & $288 \mathrm{~s}$ \\
\hline
\end{tabular}

${ }^{a}$ These frequencies were not observed but were calculated from our $F$ matrix.

In order to calculate force constants for these molecules, a molecular model shown in Fig. 3.4 was assumed and the bond distances of the various molecules estimated. The angles $\alpha$ and $\beta$ were taken as $90^{\circ}$. Symmetry coordinates were constructed and the Wilson $F$ and $G$ matrix method used to calculate valence force constants. A machine iterative process, as mentioned above, was used to converge in the best set of $F$ matrix elements. Real solutions could be found and the frequencies fit satisfactorily for $\mathrm{XeOF}_{4}, \mathrm{IF}_{5}$, and $\mathrm{BrF}_{5}$ with a diagonal $F$ matrix. For $\mathrm{ClF}_{5}$, no real solution could be found in this manner and it was necessary to use a value selected by trial and error for the off-diagonal element $F_{12}$. Table 3.20 lists the valence force constants calculated from the data. If it is assumed that $\nu_{5}$ is the missing frequency, it can also be calculated from the value of $F_{33}$ (see Table 3.19).

Tabulation of the calculated and observed frequencies showed all frequencies agreeing within $\pm 0.1 \mathrm{~cm}^{-1}$. Examination of the valence force constants in Table 3.20 shows a remarkable consistency throughout the series with the properties of xenon oxytetrafluoride agreeing well with those of $\mathrm{IF}_{5}$, with the exception, of course, of the Xe-O bond which has a considerably higher force constant than the unique $\mathrm{X}-\mathrm{F}$ bond in the other three compounds. As we proceed from the heavier to the lighter members of the series, we find the X-A and $\mathrm{X}-\mathrm{F}$ stretching force constants decreasing as does the stability of the compounds. In contrast,

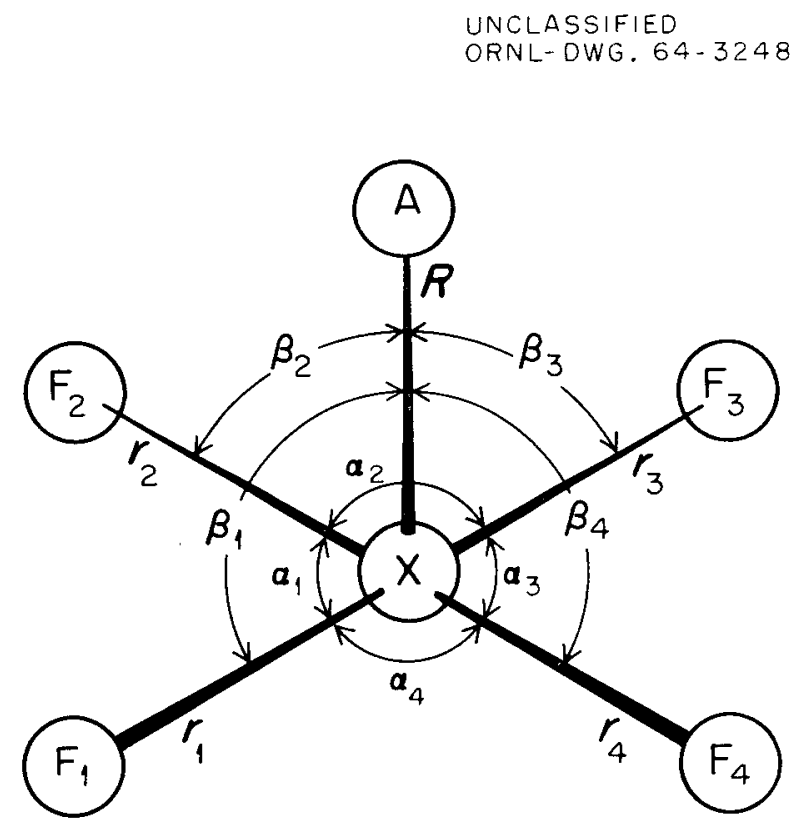

Fig. 3.4. Model of $\mathrm{XAF}_{4}$ Molecule. 
Table 3.20. Valence Force Constants for $X_{4}$ Molecules (millidynes/A)

\begin{tabular}{|c|c|c|c|c|c|}
\hline Constant & $\mathrm{XeOF}_{4}$ & $\mathrm{IF}_{5}$ & $\mathrm{BrF}_{5}$ & $\mathrm{ClF}_{5}$ & Description \\
\hline$f_{R}$ & 7.08 & 4.68 & 4.02 & 3.01 & $\mathrm{X}-\mathrm{A}$ stretch \\
\hline$f_{r}$ & 3.26 & 3.64 & 3.19 & 2.57 & $X-F$ stretch \\
\hline$f_{r r}{ }^{\prime}$ & 0.10 & 0.18 & 0.23 & 0.33 & Interaction \\
\hline$f_{\mathrm{rr}}$ & 0.12 & 0.06 & 0.11 & 0.17 & Interaction \\
\hline${ }_{R r}$ & & & & 0.25 & Interaction \\
\hline$f_{a / r^{2}}$ & 0.12 & 0.17 & 0.25 & 0.38 & $F-X-F$ bend \\
\hline$f_{\beta / r R}$ & 0.53 & 0.63 & 0.70 & 1.18 & $\mathrm{~F}-\mathrm{X}-\mathrm{A}$ bend \\
\hline$f_{\beta \beta^{\prime} / r R}$ & 0.14 & 0.16 & 0.18 & 0.49 & Interaction \\
\hline$f_{a a / r^{2}}$ & -0.02 & -0.02 & -0.01 & -0.01 & Interaction \\
\hline
\end{tabular}

the molecules become "stiffer" and the bending constants increase. The interaction constants representing distortions of the simple motions also increase as the molecules decrease in size and the atoms approach each other more closely.

This series of molecules forms a consistent and almost unique set. The square pyramidal structure with angles close to $90^{\circ}$ is in itself very unusual for six-atom molecules. That the normal vibrational frequencies can be so closely reproduced by a simple valence force field with small and consistent interaction terms is quite remarkable. Except in the case of $\mathrm{ClF}_{5}$, there seems to be very little mixing or interaction of vibrations. The fact that $\mathrm{XeOF}$ falls so naturally into place in the series leads one to believe that analogies exist not only in the geometry of the xenon fluorides and the interhalogen compounds, but also in the nature of the bonds formed in these compounds.

\section{Thermodynamic Effects of Mixing Light and Heavy Water}

\section{A. H. Narten}

The thermodynamic functions for the isotopic exchange reaction

$$
\mathrm{H}_{2} \mathrm{O}+\mathrm{D}_{2} \mathrm{O}=2 \mathrm{HDO}
$$

in the gas and liquid state were computed from recent experimental data. They differed from previously published values. Excess functions for liquid mixtures of the water isotopes were also derived. For ideal solutions of the water isotopes, these functions can be evaluated numerically. The calculated excess enthalpy of mixing is in agreement with the experimental heat of mixing. A detailed account of this study was prepared for publication. 


\section{Radiation Chemistry}

\section{Energy Transfer from Carbon Dioxide in the Radiation-Induced Synthesis of Water}
P. S. Rudolph
S. C. Lind

The kinetics of the radiation-induced synthesis of water in the presence of $\mathrm{CO}_{2}$ were discussed in the previous annual report. ${ }^{1}$ The scheme there proposed was somewhat modified, and it and the experimental data have been published. ${ }^{2}$ The abstract of the published article follows:

Previous attempts to explain the sensitizing effect of $\mathrm{CO}_{2}$, on the basis of charge transfer, in the radiation-induced synthesis of water from its elements were not in agreement with the experimental data. Hence, this reaction was reinvestigated and compared to the nonsensitized synthesis of water. A series of reactions to explain the role of $\mathrm{CO}_{2}$ as a sensitizing agent is postulated herewith. The same scheme (omitting the reactions involving $\mathrm{CO}_{2}$ ) is applicable to the nonsensitized reaction. Rate equations are derived from these mechanisms. The rate constant for the sensitized reaction in a sphere of $2.43 \mathrm{~cm}$ diameter $\left(K_{2.43}\right)$ is $7.3 \pm 0.2$ /curie. The constant for the unsensitized reaction is $K_{2.43}=7.3 \pm 0.3$ /curie. Carbon dioxide appears to enter into the mechanism even though no $\mathrm{CO}_{2}$ is consumed in the overall reaction. Evidence is also presented that there is no net reaction of $\mathrm{CO}_{2}$ with water vapor under alphaparticle irradiation.

\section{Radiolys is of Gaseous Methane}
J. F. Riley
T. C. Hung ${ }^{3}$

Gaseous methane was irradiated as part of a study of phase and temperature effects on hydrocarbon radiolysis. The need for analysis at very low conversions (small doses) and the important effects of even trace quantities of unsaturated hydrocarbons are now well recognized. ${ }^{4,5}$ There have been many studies of methane radiolysis, but generally either they were for large doses (high conversions) or specific precautions against trace impurities were not taken.

The final products of methane radiolysis are $\mathrm{H}_{2}$, $\mathrm{C}_{2} \mathrm{H}_{6},\left(\mathrm{CH}_{2}\right)_{x}$ polymer, $\mathrm{C}_{3} \mathrm{H}_{8}, \mathrm{C}_{4} \mathrm{H}_{10}$, and traces of saturated hydrocarbons. Ethylene and acetylene, however, are also radiolysis products ${ }^{5}$ and act as radical scavengers. Because the steady-state concentrations of $\mathrm{C}_{2} \mathrm{H}_{4}$ and $\mathrm{C}_{2} \mathrm{H}_{2}$ are rather low, it has been difficult to assess their roles or determine the initial yields. One approach has been to add an excess of these or other unsaturated hydrocarbons to either protect the initial yields or determine their fate.

Recent developments in chromatographic techniques of purification and analysis have been used in the present work to obtain results for incremental doses of less than $10^{19} \mathrm{ev} / \mathrm{g}$. Irradiations were with ${ }^{60} \mathrm{Co}$ gamma rays.

Induction Period in Methane Radiolysis. - An interesting induction period was observed in methane radiolysis, during which the ethane yield was only 0.2 molecule $/ 100$ ev (compared to the normal yield of 2.4) and the propane yield was approximately zero. The induction effect, also noted by Ausloos, ${ }^{6}$ is due to the presence of oxygen in the starting methane. With initial oxygen

\footnotetext{
${ }^{1}$ P. S. Rudolph and S. C. Lind, Chem. Div. Ann. Progr. Rept. June 20, 1963, ORNL-3488, p. 49.

${ }^{2}$ P. S. Rudolph and S. C. Lind, J. Chem. Phys. 40, 2601 (1964).

${ }^{3}$ Institute of Chemistry, Academia Sinica, Taipei, Taiwan, China, IAEA Fellow at ORNL.

${ }^{4}$ R. A. Back, J. Phys. Chem. 64, 124 (1960).

${ }^{5}$. W. Hummel, Discussions Faraday Soc. 36, 75 (1963).

${ }^{6}$ P. J. Ausloos, S. G. Lias, and R. R. Gorden, Jr., J. Chem. Phys. 39, 3341 (1963).
} 
contents of 40,75 , and $160 \mathrm{ppm}$, the induction doses were $1.8,2.5$, and $3.2 \times 10^{19}$ ev per gram of $\mathrm{CH}_{4}$.

After the induction dose, the ethane and propane yields were constant with dose; $G\left(\mathrm{C}_{2} \mathrm{H}_{6}\right)=2.36 \pm$ 0.12 and $\mathrm{G}\left(\mathrm{C}_{3} \mathrm{H}_{8}\right)=0.54 \pm 0.03$, based on five series of determinations and using nitrous oxide dosimetry $^{7}$ with $G\left(N_{2}\right)=11.0 \pm 0.3$.

During the induction period, oxygen is consumed almost linearly with dose. For oxygen initially present at 90-120 ppm, $G\left(-\mathrm{O}_{2}\right)=8.7 \pm 0.4$, based on four measurements. At higher oxygen contents, $\mathrm{G}\left(-\mathrm{O}_{2}\right)$ was larger; for example, at $370 \mathrm{ppm} \mathrm{O}_{2}, \mathrm{G}\left(-\mathrm{O}_{2}\right)$ was initially 13.3 and decreased gradually to 8.1 when the $\mathrm{O}_{2}$ concentration had dropped to $100 \mathrm{ppm}$.

An experimental procedure was devised for irradiation, removal of a portion of the sample for analysis, and further irradiation of the balance of the sample. This sequential method allowed the induction period to be followed in detail with each sample. Failure of others to recognize the induction behavior may explain the apparent dependence of $\mathrm{G}\left(\mathrm{C}_{2} \mathrm{H}_{6}\right)$ on irradiation dose at low conversions. ${ }^{8}$

Ethylene production, linear with dose, has been observed during induction periods. As the induction period ends, the ethylene concentration peaks and then falls (at first linearly); with additional irradiation, it tapers off to a low steadystate value.

The induction period may be reduced or avoided by removal of oxygen from the methane. Preirradition of methane to consume the oxygen, followed by low-temperature chromatographic treatment to remove radiolysis products, was employed to prepare methane of the highest purity.

Role of Ethylene in Methane Rodiolysis. - Irradiation of methane containing initial ethylene concentrations reveals something of the role of ethylene in the radiolysis. In other studies ${ }^{8}$ much higher ethylene concentrations were used and significant increases in $\mathrm{G}\left(\mathrm{C}_{2} \mathrm{H}_{6}\right)$ were found, as well as large yields of $\mathrm{C}_{3} \mathrm{H}_{8}$ and $\mathrm{C}_{4} \mathrm{H}_{10}$.

With initial ethylene concentrations of 90 and $220 \mathrm{ppm}, \mathrm{G}\left(-\mathrm{C}_{2} \mathrm{H}_{4}\right)$ was 6.5 and 8.1 molecules $/ 100$ ev. Of this ethylene disappearance, only 0.5 to

${ }^{7}$ J. A. Hearne and R. W. Humme1, Radiation Res. 15, 254 (1961).

${ }^{8}$ L. W. Sieck and R. H. Johnsen, J. Phys. Chem. 67, 2281 (1963).
$5 \%$ appeared in increased $\mathrm{C}_{2} \mathrm{H}_{6}$ formation. Butane formation accounted for about $45 \%$, and increased propane formation for about $25 \%$ of the consumed ethylene. The balance is assumed to lead to increased polymer formation.

Ethylene Yield in Methane Radiolysis. - Irradiation of methane with added oxygen (50-100 ppm) allows evaluation of the ethylene yield. As described above, ethylene production is linear with dose - oxygen protects it from radical attack. The ethylene yield was $0.83 \pm 0.01$ molecule $/ 100 \mathrm{ev}$. This result is higher than Hummel's value, ${ }^{5}$ $\mathrm{G}\left(\mathrm{C}_{2} \mathrm{H}_{4}\right)=0.65$, observed with 1 to $2 \%$ added oxygen.

Added acetylene also protects ethylene production against radical attack. The ethylene concentration rises, passes through a broad maximum, and falls off with increased dose. The initial ethylene yield depends on the amount of added acetylene. With $60 \mathrm{ppm} \mathrm{C}_{2} \mathrm{H}_{2}, \mathrm{G}\left(-\mathrm{C}_{2} \mathrm{H}_{2}\right)=$ 4.1 and $\mathrm{G}_{i}\left(\mathrm{C}_{2} \mathrm{H}_{4}\right)$ was 2.5 molecules $/ 100 \mathrm{ev}$; with $107 \mathrm{ppm} \mathrm{C}_{2} \mathrm{H}_{2}, \mathrm{G}\left(-\mathrm{C}_{2} \mathrm{H}_{2}\right)=5.0$ and $\mathrm{G}_{i}\left(\mathrm{C}_{2} \mathrm{H}_{4}\right)$ was 3.0 molecules $/ 100 \mathrm{ev}$. These results show that added acetylene should not be used to evaluate the ethylene yield in methane radiolysis because acetylene consumption also produces ethylene. If one accepts $\mathrm{G}\left(\mathrm{C}_{2} \mathrm{H}_{4}\right)=0.8$ from methane itself, then about $40 \%$ of the acetylene consumption leads to ethylene.

\section{Radiolysis of Condensed Methane}

$$
\text { J.F. Riley T. C. Hung }{ }^{9}
$$

Both phase and temperature effects are to be expected in the low-temperature radiolysis of methane. The condensed phase will manifest a "cage" effect which will increase the recombination of some fragments and alter both the extent and paths of decomposition. Low temperatures $\left(77\right.$ to $90^{\circ} \mathrm{K}$ ) will reduce or prevent reactions of high activation energies.

This study has been undertaken to learn the extent of these effects. Results will both complement and lay the foundation for extension of an existing interest in energy transfer problems. ${ }^{10}$

\footnotetext{
${ }^{9}$ Institute of Chemistry, Academia Sinica, Taipei, Taiwan, China, IAEA Fellow at ORNL.

${ }^{10}$ Chem. Div. Ann. Progr. Rept. June 20, 1963, ORNL-3488, pp. 42-43.
} 
Specially purified methane has been condensed and irradiated at 77 and $90^{\circ} \mathrm{K}$ with ${ }^{60} \mathrm{Co}$ gamma rays. Yields ( $G$ values) for ethane, hydrogen, propane, and butane were much less than in gas phase radiolysis. Ethane and hydrogen yields were reduced by a factor of 1.2 to 2 . Propane and butane yields were reduced by a factor of 2 to 5 .

At $77^{\circ} \mathrm{K}$, production of hydrogen, ethane, and butane was linear with dose to $1.3 \times 10^{20} \mathrm{ev}$ per gram of $\mathrm{CH}_{4} ; G\left(\mathrm{H}_{2}\right)=3.44 \pm 0.09, G\left(\mathrm{C}_{2} \mathrm{H}_{6}\right)=$ $1.90 \pm 0.01$, and $\mathrm{G}\left(\mathrm{C}_{4} \mathrm{H}_{10}\right)=0.051 \pm 0.005$ molecule $/ 100 \mathrm{ev}$. The propane yield was initially $G\left(\mathrm{C}_{3} \mathrm{H}_{8}\right)=0.11$ but decreased to 0.06 molecule $/ 100$ ev with dose. At $90^{\circ} \mathrm{K}$, results were not as reproducible as at $77^{\circ} \mathrm{K}$ and varied with the dose increment and the "warming history" of a sample. The ethane yield was initially 1.5 to 1.9 molecules $/ 100$ ev and decreased with dose. The propane yield showed even more scatter and ranged from zero to 0.08 molecule $/ 100 \mathrm{ev}$.

Methane containing $60 \mathrm{ppm}$ of acetylene was irradiated at $90^{\circ} \mathrm{K}$. The ethane yield was 1.3 molecules $/ 100$ ev while acetylene was present. The value of $\mathrm{G}\left(-\mathrm{C}_{2} \mathrm{H}_{2}\right)$ was initially 3.5 and $\mathrm{G}\left(\mathrm{C}_{3} \mathrm{H}_{8}\right)$ was 0.05 molecule $/ 100 \mathrm{ev}$ but decreased as the acetylene disappeared.

Methane containing $94 \mathrm{ppm}$ of ethylene was irradiated at $90^{\circ} \mathrm{K}$. The ethane yield was 1.0 molecule $/ 100$ ev while ethylene was present. The value of $\mathrm{G}\left(-\mathrm{C}_{2} \mathrm{H}_{4}\right)$ was initially 6.5 but decreased as the ethylene disappeared. Propane, butane, and acetylene were found as products; propane and butane concentrations leveled off as $\mathrm{C}_{2} \mathrm{H}_{4}$ disappeared; the acetylene concentration reached a maximum and then disappeared after the $\mathrm{C}_{2} \mathrm{H}_{4}$ was used up.

The $G$ value for polymer formation in methane at $77^{\circ} \mathrm{K}$ was recently reported by Davis and Libby ${ }^{11}$ to be $\sim 1$ molecule $/ 100 \mathrm{ev}$, in terms of methane consumption. For comparison, Sieck and Johnsen ${ }^{12}$ report $G$ (polymer) $=2.1$ for gaseous methane.

The $G$ value for methane disappearance may be estimated by adding the polymer yields and hydrocarbon product yields expressed in methane equivalents. Combining Davis and Libby's polymer yield with the $G$ values at $90^{\circ} \mathrm{K}$ for hydrocarbons through butane, $\mathrm{G}\left(-\mathrm{CH}_{4}\right)$ is estimated to be only

\footnotetext{
${ }^{11}$ D. W. Davis and W. F. Libby, Science 144, 991 (1964).

${ }^{12}$ L. W. Sieck and R. H. Johnsen, J. Phys. Chem. 67, 2281 (1963).
}

5.4 molecules $/ 100$ ev. Comparison with the estimates $^{12-14}$ for radiolysis of gaseous methane, $\mathrm{G}\left(-\mathrm{CH}_{4}\right)$ of 8 to 9 , shows the significant extent of low-temperature stabilization.

\section{A New Postulate in the Diffusion Model for the Radiolysis of Water}

T. J. Sworski

A quantitative inconsistency exists ${ }^{15}$ between the observed dependence of the yields of molecular products on solute concentration for cobalt gamma radiation and the theoretical dependence obtained from diffusion kinetics with the Samuel-Magee mode1. ${ }^{16}$ I suggest, as an explanation, that solute reacts in the spur with an intermediate denoted as $I$ which seems to disappear in a first-order process, the effect being markedly manifested for solute concentrations greater than $0.01 \mathrm{M}$.

Evidence to support this suggestion was obtained from a more detailed investigation of the previously reported ${ }^{17}$ enhancement of $G\left(\mathrm{Ce}^{3+}\right)$ by nitrate ion in the reduction of ceric ion in $0.8 N$ sulfuric acid. The observed enhancement, $\Delta G\left(\mathrm{Ce}^{3+}\right)$, for both $0.8 N$ and $0.084 N$ sulfuric acid solutions is given by the following equation:

$$
1 / \Delta G\left(\mathrm{Ce}^{3+}\right)=0.24+0.055 /\left[\mathrm{NO}_{3}{ }^{-}\right] \text {. }
$$

A reaction mechanism in which competition is assumed between first-order disappearance of $I$, $k_{1}[I]$, and reaction of $I$ with $\mathrm{NO}_{3}-, k_{2}[I]\left[\mathrm{NO}_{3}-\right]$, yields $k_{1}=0.2 k_{2}$. Similar data of Mahlman and Schweitzer ${ }^{18}$ for gamma radiation and Anta and $\operatorname{Costa}^{19}$ for alpha radiation can be interpreted to yield values for $k_{1}$ of $0.4 k_{2}$ and $0.2 k_{2}$ respectively. These are pseudounimolecular decay constants

\footnotetext{
${ }^{13}$ F. W. Lampe, J. Am. Chem. Soc. 79, 1055 (1957).

${ }^{14}$ J. Maurin, J. Chim. Phys. 59, 15 (1962).

${ }^{15}$ A. Kupperman, chap. III in vol. 5 of The Chemical and Biological Action of Radiations, ed. by M. Haissinsky, Academic, New York, 1961.

${ }^{16}$ A. H. Samue 1 and J. L. Magee, J. Chem. Phys. 21, 1080 (1953).

${ }^{17}$ T. J. Sworski, J.Am. Chem. Soc. 77, 4689 (1955).

${ }^{18}$ H. A. Mahlman and G. K. Schweitzer, J. Inorg. Nucl. Chem. 5, 213 (1958).

${ }^{19}$ M. C. Anta and A. M. Costa, J. Chim. Phys. 57, 1130 (1960).
} 
since $k_{2} / k_{1}$ is essentially independent of temperature and not proportional to $T / \eta$ as required by Smoluchowski's theory. ${ }^{20}$

The concentration of $I$ in space and time coordinates is given by the solution of the following diffusion equation:

$$
\partial[I] / \partial t=D \nabla^{2}[I]-k_{1}[I] .
$$

The application of this postulate requires identification of $I$ and specification of the reactions of $I$ both with intermediates in the spur and with solute. I suggest that $I$ is electronically excited water, $\mathrm{H}_{2} \mathrm{O}$, although an alternative mechanism in which $I$ is $\mathrm{H}_{3} \mathrm{O}$ can be invoked.

\section{Photochemical and Radiation Chemical Reduction of Ceric lon in Aqueous Sulfuric Acid Solutions. Effect of Formic Acid}

\section{T. J. Sworski}

The following is an abstract of a published paper. ${ }^{21}$

The $\mathrm{OH}$ radical was postulated ${ }^{22}$ as an intermediate in the photochemical reduction of ceric ion in sulfuric acid solutions. A comparative study of the radiolysis and photolysis of ceric ion-cerous ion-thallous ion mixtures yielded kinetic evidence in support of this postulate.

Although both thallous ion and formic acid enhance the radiolytic reduction of ceric ion in $0.4 \mathrm{M}$ sulfuric acid solutions, there is one striking difference. While enhancement by thallous ion is essentially dependent only on $\left[\mathrm{Tl}^{+}\right] /\left[\mathrm{Ce}^{3+}\right]$, the enhancement by formic acid is dependent not only on $[\mathrm{HCOOH}] /\left[\mathrm{Ce}^{3+}\right]$ but also markedly on the total concentration of cerous ion and formic acid at any particular $[\mathrm{HCOOH}] /\left[\mathrm{Ce}^{3+}\right]$. This difference was attributed to reaction of $\mathrm{OH}$ radical with sulfuric acid. The effect of formic acid on the photochemical reduction of ceric ion yielded further evidence for the $\mathrm{OH}$ radical as an intermediate and for reaction of $\mathrm{OH}$ radical with sulfuric acid.

\footnotetext{
${ }^{20}$ M. V. Smoluchowski, Z. Physik. Chem. 92, 129 (1918).

21 T. J. Sworski, J. Phys. Chem. 67, 2858 (1963).

${ }^{22}$ T. J. Sworski, J. Am. Chem. Soc. 77, 1074 (1955).
}

\section{Radiolysis of Sulfuric Acid Solutions}

$$
\text { J. W. Boyle }
$$

1. The effect of acid concentration on the radiolytic ceric ion reduction yield in air-saturated solutions has been reported for ${ }^{60} \mathrm{Co}$ gamma rays. ${ }^{23}$ The effect of dissolved gases, air, hydrogen, and helium on the cerous ion yield was also studied at various acidities between 0.04 and $4.0 \mathrm{M}$ sulfuric acid, but some of the results were not understood. Oxygen-purged, air-saturated, and helium-saturated solutions gave identical cerous ion yields at each acid concentration studied. Purging with helium during irradiation, however, appeared to lower the cerous ion yield slightly at low acidity (4 to $8 \%$ ) but reduced the yield approximately $50 \%$ in $4.0 \mathrm{M}$ acid. A similar lowering was noted between hydrogen-saturated and hydrogen-purged solutions. These lowerings are now known to be due to two effects. The small effect, noticed at low acidity, was due to an artifact. Although the purging gas was humidified by bubbling through a room-temperature solution identical to the sample being irradiated, the purging gas still caused loss of water from the sample because the sample was slightly warmer than the incoming gas. This loss of water caused an apparent lowering of the cerous ion yield and was found to be a function of the temperature difference between the sample and room temperature, purge rate, and length of purging. The lowering would also be expected to be a function of the sulfuric acid concentration and decrease with increasing acid concentration because the vapor pressure of water is lower over concentrated acid than dilute acid.

The larger effect was found to be associated with the buildup and reaction of peroxymonosulfuric acid (Caro's acid). The concentration of this acid builds up linearly with dose in solutions containing oxygen. ${ }^{23}$ In helium-purged and hydrogenpurged solutions, it reaches a steady-state value after approximately $25 \%$ of the ceric ions have been reduced, and remains essentially constant until the rest of the ceric ions are reduced. The cerous ion yield, after Caro's acid has attained this steady-state value, is equal to the cerous ion yield in air-saturated solution minus twice the Caro's acid yield in air-saturated solution. When

\footnotetext{
${ }^{23}$ J. W. Boyle, Radiation Res. 17, 427 (1962).
} 
oxygen is present in micromolar concentrations or greater, reaction of hydrogen atoms with oxygen predominates and Caro's acid builds up linearly with dose,

$$
\begin{gathered}
\mathrm{H}+\mathrm{O}_{2} \stackrel{k_{1}}{\longrightarrow} \mathrm{HO}_{2}, \\
\mathrm{H}+\mathrm{Ce}(\mathrm{IV}) \stackrel{k_{2}}{\longrightarrow} \mathrm{Ce}(\mathrm{III})+\mathrm{H}^{+}, \\
\mathrm{H}+\mathrm{H}_{2} \mathrm{SO}_{5} \stackrel{k_{3}}{\longrightarrow} \mathrm{H}_{2} \mathrm{O}+\mathrm{HSO}_{4} .
\end{gathered}
$$

The hydroperoxy radical reduces ceric ion but not Caro's acid. If oxygen is absent or at very low concentrations, the hydrogen atoms react with Caro's acid (if present) and ceric ions. Bisulfate radicals oxidize cerous ions so that when $\mathrm{H}$ atoms react with Caro's acid the net effect is a lowering of the cerous yield. With a few more experiments, it should be possible to determine the ratio of rate constants $k_{1} / k_{2} / k_{3}$. The results so far indicate $k_{1}>k_{3}>k_{2}$.

2. The effect of dissolved hydrogen on the cerous ion yield as a function of acidity was studied in order to determine the ratio of reaction rate constants for the competitions involving the $\mathrm{OH}$ radical,

$$
\begin{gathered}
\mathrm{OH}+\mathrm{Ce}(\mathrm{III}) \stackrel{k_{4}}{\longrightarrow} \mathrm{Ce}(\mathrm{IV})+\mathrm{OH}^{-}, \\
\mathrm{OH}+\mathrm{HSO}_{4}-\stackrel{k_{5}}{\longrightarrow} \mathrm{HSO}_{4}+\mathrm{OH}^{-}, \\
\mathrm{OH}+\mathrm{H}_{2} \stackrel{k_{6}}{\longrightarrow} \mathrm{H}+\mathrm{H}_{2} \mathrm{O} .
\end{gathered}
$$

The bisulfate and hydroxyl radicals oxidize cerous ions whereas hydrogen atoms reduce ceric ions. Reaction of $\mathrm{OH}$ with $\mathrm{H}_{2}$ causes an increase in the ceric ion reduction yield. The concentrations of acid, cerous ion, and dissolved hydrogen must be known in order to calculate the rate constants. Prior to the development of the analytical method reported below, the cerous ion concentration was not known precisely, as it was assumed to be zero in freshly prepared ceric ion solution. This assumption would lead to some error if cerous ions were initially present. The actual amount of cerous ion can now be determined to $\pm 0.2-0.5 \mathrm{micromole}$ per liter.

The method is an adaptation of Metzger's method first presented in 1909 in which $\mathrm{NaBiO}_{3}$ is used as an oxidizing agent. In the modified method, after the cerous ions have been oxidized, the ceric ion concentration is read directly on a spectrophotometer in the usual manner. The solid matter present from the oxidation step is first removed by centrifuging and ceric ion is measured in the supernatant. There is no optical interference from dissolved bismuth salts if the acidity is maintained at about half-molar sulfuric acid.

3. In order to learn something about the radiation chemistry of thallium ions, a number of ex- periments have been carried out in $2.5 \mathrm{M}$ sulfuric acid. A comparison of the reduction yields in airsaturated ceric and thallic solutions shows that similar results are obtained, which can be expressed as follows:

$$
\begin{aligned}
G \mathrm{Ce}(\mathrm{III})=2 \mathrm{G} \mathrm{TI}(\mathrm{I}) & =\mathrm{GH} \\
& +2 \mathrm{GH}_{2} \mathrm{O}_{2}-\mathrm{GOH}-\mathrm{GHSO}_{4} .
\end{aligned}
$$

Although the overall stoichiometry is similar, the mechanisms are different. This study has shown that although thallic ion and hydrogen peroxide do not react thermally, a chain reaction can be initiated between them in three ways - by gamma rays, ultraviolet light, or the addition of ceric ions. Although the mode of initiating the chain is different in each case, the chain-carrying steps are the same,

$$
\begin{aligned}
& \mathrm{HO}_{2}+\mathrm{Tl}(\mathrm{III}) \longrightarrow \mathrm{Tl}(\mathrm{II})+\mathrm{H}^{+}+\mathrm{O}_{2}, \\
& \mathrm{Tl}(\mathrm{II})+\mathrm{H}_{2} \mathrm{O}_{2} \longrightarrow \mathrm{Tl}(\mathrm{I})+\mathrm{H}^{+}+\mathrm{HO}_{2} .
\end{aligned}
$$

A chain length of $>5000$ has been measured in one radiation experiment. The chain-carrying intermediates $\mathrm{Tl}(\mathrm{II})$ and $\mathrm{HO}_{2}$ also react with $\mathrm{Ce}(\mathrm{IV})$. Preliminary results indicate that the reaction rate constants for reaction of $\mathrm{Tl}$ (II) with $\mathrm{Ce}(\mathrm{IV})$ and $\mathrm{Tl}(\mathrm{II})$ with $\mathrm{H}_{2} \mathrm{O}_{2}$ are about equal. The rate constant for the reaction of $\mathrm{HO}_{2}$ with $\mathrm{Tl}(\mathrm{III})$ is greater than the rate constant for the reaction of $\mathrm{HO}_{2}$ with $\mathrm{Ce}(\mathrm{IV})$ by a factor of about 1.6. 


\section{Track Effects in the Radiolys is of Solids}

\section{J. Hochanadel}

Production of Color in Polystyrene and in Polymethylmethacrylate. - The study of LET (linear energy transfer) effects, or track effects, is a valuable aid in determining mechanisms in the radiolysis of liquids and solids. Although extensive studies of LET effects have been made for aqueous systems, relatively little has been done with other materials. A few studies have shown that the aliphatic and aromatic hydrocarbons behave differently in this respect; for example, there is little effect of LET on $G\left(\mathrm{H}_{2}\right)$ for the aliphatic hydrocarbons, whereas $\mathrm{G}\left(\mathrm{H}_{2}\right)$ increases markedly with increase in LET for the aromatic hydrocarbons. ${ }^{24}$

A very simple technique which can give useful information on the radiolysis of materials of this type is the growth and decay of color in the aliphatic and aromatic plastics. Color production and annealing were studied in two plastics, polymethylmethacrylate and polystyrene. They were irradiated in the absence of oxygen with gamma rays and with alpha particles. It was found that the initial yield of color in polymethylmethacrylate is about three times as large for gamma rays as for alpha particles, whereas for polystyrene the yield is about the same for the two types of radiation. Both plastics assume an amber color on irradiation, with the absorption increasing continuously into the ultraviolet. The absorption in polymethylmethacrylate was measured at $2900 \mathrm{~A}$, and in polystyrene at $3500 \mathrm{~A}$. The measured initial yields expressed as $10^{-19}$ optical density unit $\times \mathrm{cm}^{2}$ per $100 \mathrm{ev}$ were: for polymethylmethacrylate, 3.7 for gamma rays and 1.2 for alpha particles; for polystyrene, 7.4 for gamma rays and 6.5 for alpha particles. It is known that some of the reactive intermediates such as free radicals, electrons, and positive holes can be stably trapped in plastics for long periods, and these may account for at least part of the color. It is also known that the resistivity is lowered by radiation and that it gradually recovers after irradiation. Part of the color also anneals out slowly on standing. The

\footnotetext{
${ }^{24}$ For a general discussion and a list of other references, see A. Chapiro, Radiation Chemistry of Polymeric Systems, Interscience, New York, 1962; A. Charlesby, Atomic Radiation and Polymers, Pergamon, New York, 1960.
}

annealing behavior of polystyrene is especially interesting. The absorbance increases with dose at a gradually diminishing rate until a saturation value is reached. If a dose somewhat less than that required for saturation is given and the sample is then allowed to stand out of radiation (in the absence of oxygen and light), part of the color anneals out. On reirradiation the color developes at a faster rate than it did initially, and on continued irradiation the points follow the original absorbance v's dose curve. The process can be repeated until saturation is reached, after which no annealing takes place. This behavior suggests a dynamic equilibrium during irradiation, probably involving trapped electrons. The fact that part of the color does not anneal out suggests another source of color - possibly associated with the formation of conjugated double bonds. The relevance of these measurements to the mechanism of radiation-induced chemical changes is not yet clear. It is interesting to note that for polystyrene, for which there is very little effect of LET in the production of color, there is also little effect of LET on the production of unpaired electrons (esr measurements). ${ }^{25}$ The yield of unpaired electrons is about the same for fast neutrons and gamma rays, whereas the yields of hydrogen, methane, benzene, and cross-links are several times larger for fast neutrons than for gamma rays.

Sodium Chlorate. - Chloride is a major product in the radiolysis of chlorates. For sodium chlorate irradiated with gamma rays at $25^{\circ} \mathrm{C}$, the yield of chloride is greatly enhanced by postirradiation annealing at $185^{\circ} \mathrm{C} .{ }^{26}$ For alphaparticle radiolysis, the chloride yield is considerably higher than for gamma rays, and there is little or no effect of post-irradiation annealing. ${ }^{27}$ This is in line with the idea that thermal effects in alpha-particle tracks are important. Other products of the decomposition are chlorite, hypochlorite, and chlorine dioxide. The hypochlorite, chlorine dioxide, and part of the chlorite are known to decompose on annealing to give additional chloride. The yield for the sum of these three

\footnotetext{
${ }^{25}$ W. W. Parkinson et al., Reactor Chem. Div. Ann. Progr. Rept. Jan. 31, 1964, ORNL-3591, pp. 224-26.

${ }^{26}$ P. F. Patrick and K. J. McCa1lum, Nature 194, 766 (1962).

${ }^{27}$ C. J. Hochanadel, J. Phys. Chem. 67, 2229 (1963).
} 
products was compared in the decomposition of sodium chlorate by gamma rays and by alpha particles at $25^{\circ} \mathrm{C}$. The initial yield for alpha particles was only half as large as for gamma rays, again in line with a thermal spike effect. The yields decrease with increased dose indicating that these products undergo further radiation decomposition.

Ammonium Nitrate. ${ }^{28}$ - As a preliminary to a proposed study of the hot-atom chemistry of ammonium nitrate via the $n\left({ }^{14} \mathrm{~N}, p\right){ }^{14} \mathrm{C}$ reaction, the radiation chemistry of this salt was studied. It has been reported ${ }^{29}$ that the principal decomposition products are $\mathrm{N}_{2} \mathrm{O}, \mathrm{N}_{2}$, and $\mathrm{H}_{2} \mathrm{O}$, whereas for the metal nitrates the products are nitrite and oxygen. ${ }^{30}$ This difference is not surprising since, for ammonium nitrate, both the anion and cation are susceptible to decomposition. We found, however, that in the decomposition of ammonium nitrate both by gamma rays and by alpha particles, nitrite is produced with a large yield, and that it disappears both by radiation-induced reaction and by post-irradiation reaction. Furthermore, the initial yield, $\mathrm{G}\left(\mathrm{NO}_{2}{ }^{-}\right)$, is about the same for decomposition by gamma rays and by alpha particles, the values being $2.4 \pm 0.1$ and $2.1 \pm 0.1$ molecules $/ 100$ ev respectively. Both the rate and extent of annealing increased with temperature in the range from 0 to $100^{\circ} \mathrm{C}$. It might have been expected that the yields for the two types of radiation would differ because of track effects resulting from a higher concentration of intermediates and higher temperature in the alpha-particle tracks. The several factors that determine the yield may exert opposing influences in this particular case.

\section{Radiolysis of Alkaline.Earth Bromates by ${ }^{60} \mathrm{Co}$ Gamma Rays}

J. W. Chase

Investigation of the ${ }^{60} \mathrm{Co}$ gamma radiolysis of the anhydrous alkaline-earth bromates was continued. ${ }^{31}$ The anhydrous salts were prepared by heating in a vacuum oven, ascertained anhydrous by thermogravimetric analysis, and irradiated at a fixed geometry in the ORNL Radiation Chemistry Group's 2900-curie ${ }^{60}$ Co source. ${ }^{32,33}$
Measurements were made of the decomposition of the $\mathrm{BrO}_{3}^{-}$ion, the production of oxidizing fragments, and the production of $\mathrm{Br}^{-}$ion in the calcium salt. The decomposition of the $\mathrm{BrO}_{3}^{-}$ ion was found to increase nonlinearly with the radiation dose. The rate of production of bromide ion showed an initial, gradual increase with dose (induction period) followed by an approximately constant rate. The yield of bromine oxidation states intermediate between bromate and bromide (oxidizing fragments) was found to increase nonlinearly with the radiation dose and appeared to approach saturation or "steady-state" values. Initial $100-\mathrm{ev}$ radiolytic yields were estimated to be: $G_{0}\left(-\mathrm{BrO}_{3}^{-}\right)=2.24, G_{0}\left(\mathrm{Br}^{-}\right)=0.44$, and $G_{0}(" O x ")=1.80$. The average oxidation number for the oxidizing fragments decreased smoothly from an initial value of approximately 3.5 to a constant value of 2.05 after about 0.5 mole \% decomposition.

The high initial average oxidation number indicates the presence of bromine species in rather high oxidation states, possibly bromite and positively charged bromine-containing ions. The trend of this number toward constancy with increasing decomposition suggests that perhaps several partially reduced bromine species were present and they, in turn, were radiolyzed or thermally decomposed so that ultimately a steadystate concentration of each was established. The observation of an induction period in the production of $\mathrm{Br}^{-}$ion followed by an approximately constant rate of formation possibly suggests that as radiolysis continued, increasing amounts of bromide ion were formed via intermediates in addition to direct formation from $\mathrm{BrO}_{3}-$.

The extent of the radiolys is of $\mathrm{Ba}\left(\mathrm{BrO}_{3}\right)_{2}$ was observed to increase with the temperature at

\footnotetext{
${ }^{28}$ In collaboration with Zenaida Bugay, University of Hawaii, visiting member of the Chemistry Division, summer 1963.

${ }^{29}$ T. Shirai et al., Sci. Papers Inst. Phys. Chem. Res. (Tokyo) 54, 219 (1960).

${ }^{30}$ A. O. Allen and J. A. Ghormley, J. Chem. Phys. 15, 208 (1947).

31 J. W. Chase and G. E. Boyd, Chem. Div. Ann. Progr. Rept. June 20, 1963, ORNL-3488, p. 48.

32 J. A. Ghormley and C. J. Hochanadel, Rev. Sci. Instr. 22, 473 (1951).

${ }^{33}$ J. F. Riley and C. J. Hochanade1, Chem. Div. Ann. Progr. Rept. June 20, 1962 , ORNL-3320, p. 44.
} 
Table 4.1. Dependence of Radiolysis of Anhydrous $\left.\mathrm{Ba}_{(\mathrm{BrO}}\right)_{2}$ upon Drying Temperature (Dose for all measurements $4.90 \times 10^{23} \mathrm{ev} / \mathrm{mole}$ )

\begin{tabular}{ccc}
\hline $\begin{array}{c}\text { Drying Temperature } \\
\left({ }^{\circ} \mathrm{C}\right)\end{array}$ & $\begin{array}{c}\text { Millimoles of } \mathrm{Br}^{-} \\
\text {per Mole of } \mathrm{BrO}_{3}{ }^{-}\end{array}$ & $\begin{array}{c}\text { Decomposition } \\
\text { per Mole of } \mathrm{BrO}_{3}{ }^{-}\end{array}$ \\
\hline 86 & $8.03^{a}$ & $14.65^{a}$ \\
105 & $8.35^{a}$ & $17.26^{a}$ \\
120 & $11.92^{a}$ & $28.96^{a}$ \\
& $11.75^{b}$ & $28.49^{b}$ \\
170 & $14.28^{b}$ & $37.40^{b}$ \\
\hline 200 & $(15.2)$ & \\
\hline
\end{tabular}

${ }^{a}$ Preparation No. 1.

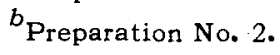

which the salt was dried in vacuum prior to irradiation. Table 4.1 shows the dependence of radiolysis upon drying temperature for two separate preparations of the barium salt.

This effect is tentatively attributed to a gradual phase change in the barium salt peaking at $\sim 180^{\circ} \mathrm{C}$ as shown by differential thermal analysis. Preliminary x-ray powder patterns appear to indicate a mixture of different composition to be present at each of the drying temperatures. The calcium and strontium salts did not show this behavior.

The magnesium salt turned out to be too unstable thermally to obtain a suitable sample for irradiation. A study of the strontium salt will be completed; preliminary work indicates behavior similar to that of the calcium salt but with a greater extent of radiolysis.

\section{The Rodiolysis of Crystalline $\mathrm{LiBrO}_{3}$ by ${ }^{6} \mathrm{Li}$ Fission Recoil Particles}
G. E. Boyd
T. G. Ward, Jr.

Measurements were made of the decomposition of $\mathrm{BrO}_{3}-$ ion and the production of oxidizing fragments in crystalline $\mathrm{LiBrO}_{3}$ by energetic tritons and alpha particles released following neutron capture in ${ }^{6} \mathrm{Li}$. The radiation doses deposited by the recoil particles were estimated from the percent ${ }^{6} \mathrm{Li}$ in the crystal, the thermalneutron flux, the effective cross section for the reaction ${ }^{6} \mathrm{Li}(n, \alpha){ }^{3} \mathrm{H}$, the energy release per fission, and the irradiation time, assuming that the recoils were stopped entirely within the solid. The maximum dose was $4 \times 10^{23} \mathrm{ev} / \mathrm{mole}$ which corresponded to a $6-\mathrm{hr}$ irradiation in the active lattice of the ORNL Graphite Reactor at a thermal-neutron flux of $6.7 \times 10^{11}$ neutrons $\mathrm{cm}^{-2} \mathrm{sec}^{-1}$.

A strong dependence of the radiolysis on the linear energy transfer (LET) was indicated by the initial $100 \mathrm{ev}$ yield for bromate decomposition, $G_{0}\left(-\mathrm{BrO}_{3}^{-}\right)=1.48$, which was five times larger than with ${ }^{60} \mathrm{Co}$ gamma rays. A correspondingly large yield, $G_{0}$ ("Ox") $=1.1$, of oxidizing fragments was also observed; this yield and the ease with which these fragments could be removed from the crystals by mild thermal annealing was interpreted as being inconsistent with a "thermal spike" radiolysis mechanism. A yield, $G_{0}\left(\mathrm{Br}^{-}\right)=0.38$, for bromide ion was estimated. A tenfold increase in the dose rate caused no change in the yields either for bromate decomposition or oxidizing fragment production. The observation that all the yields were approximately five times those observed with gamma rays also suggested that the mechanism for the radiolysis did not change with increasing LET. 


\section{Radiolysis of Molten $\mathrm{LiNO}_{3}$ by ${ }^{6} \mathrm{Li}$ Fission Product Recoils}

T. G. Ward, Jr.

This study was initiated to investigate the effect of a solid-liquid phase change on the radiolysis of lithium nitrate induced by ${ }^{6} \mathrm{Li}$ fission particles. It was also planned to look for differences in the retention of the expected gaseous decomposition products between the two phases, and to investigate the possibility of an LET effect by comparing the results with those for ${ }^{60} \mathrm{Co}$ gamma-ray radiolysis.

The irradiations were performed in the Bulk Shielding Reactor (BSR), a heterogeneous, enriched uranium, swimming pool type of reactor capable of operating at powers up to $1 \mathrm{Mw}$. The sample assembly consisted of a 5-g amount of $\mathrm{LiNO}_{3}$ sealed in a $100-\mathrm{cm}^{3}$ quartz-Pyrex capsule under a $50-\mathrm{mm}$ helium atmosphere and contained in a protective aluminum can. The can was inserted in a lightweight furnace, and after heating to melt the salt the whole apparatus was lowered into the reactor neutron flux in a 4-in.-OD aluminum tube extending from the pool surface to the core. It was necessary to circulate nitrogen gas around the capsule during a bombardment to overcome the heating caused by the high gamma-ray flux resulting from neutron capture in the water. The sample temperature was maintained between 5 and $15^{\circ}$ above the melting point of $254^{\circ} \mathrm{C}$.

After "cooling" a week, the samples were analyzed for nitrite ion and all gaseous decomposition products. To obtain satisfactory nitrite analyses using the colorimetric method of llosvay, ${ }^{34}$ it was necessary to prepare fresh $\alpha$ naphthylamine reagent for each analysis and to wait $2 \mathrm{hr}$ for maximum color development. Furthermore, the absorbance-concentration curve did not follow Beer's law; so it became necessary to calibrate the spectrophotometer repeatedly with freshly prepared standard nitrite solutions.

Four irradiations of molten $\mathrm{LiNO}_{3}$ samples containing 1.0 at. $\%{ }^{6} \mathrm{Li}$ were conducted, but the results of the last bombardment are not yet available. The three analyzed samples received fission doses of approximately $1.8,3.6$, and $7.0 \times$ $10^{17} \mathrm{Mev} / \mathrm{mole}$ resulting from $1 / 2^{-}, 1-$, and $2-\mathrm{hr}$

\footnotetext{
${ }^{34}$ N. L. Allport, Colorimetric Analysis, p. 152, Chapman \& Hall, London, 1945.
}

exposures in a thermal-neutron flux of $3.4 \times 10^{12}$ neutrons $\mathrm{cm}^{-2} \mathrm{sec}^{-1}$. The flux during each irradiation was measured with two dilute $(0.15 \%$ Co) cobalt-aluminum alloy monitors. The primary decomposition products were nitrite and oxygen in an approximate stoichiometric ratio of 2 to 1 . The yields of these products, shown in Fig. 4.1, can be represented by the following equations:

$$
\begin{aligned}
\mathrm{NO}_{2}{ }^{-}\left(\text {moles } / \text { mole LiNO }_{3}\right) & =3.18 \times 10^{-2}[1 \\
- & e^{\left.-2.82 \times 10^{-22} D\right]}, \\
\mathrm{O}_{2}\left(\text { moles } / \text { mole } \mathrm{LiNO}_{3}\right) & =1.19 \times 10^{-2}[1 \\
- & \mathrm{e}^{\left.-3.16 \times 10^{-22} D\right]},
\end{aligned}
$$

where $D$ is the dose in units of $100 \mathrm{ev} / \mathrm{mole}$. Nitrous oxide, nitric oxide, and nitrogen made up about $1.5 \%$ of the decomposition products, being present in amounts of about $10^{-4}$ mole per mole of $\mathrm{LiNO}_{3}$. The presence of $\mathrm{Li}_{2} \mathrm{O}$ in comparable amounts was inferred from the alkalinity of an aqueous solution of the irradiated salt.

Approximate initial $G_{0}$ values were calculated from the slopes of the yield curves at zero dose. Values of $G_{0}\left(\mathrm{NO}_{2}{ }^{-}\right)=5.4$ and $G_{0}\left(\mathrm{O}_{2}\right)=2.3$ were obtained which are about 25 times greater than values of 0.22 and 0.11 obtained from irradiations of the crystalline salt at $45^{\circ} \mathrm{C}$ in the Graphite Reactor. It was also observed that $99.9 \%$ of the gaseous decomposition products were released from the molten salt during its irradiation, whereas less than $0.1 \%$ was released from the solid.

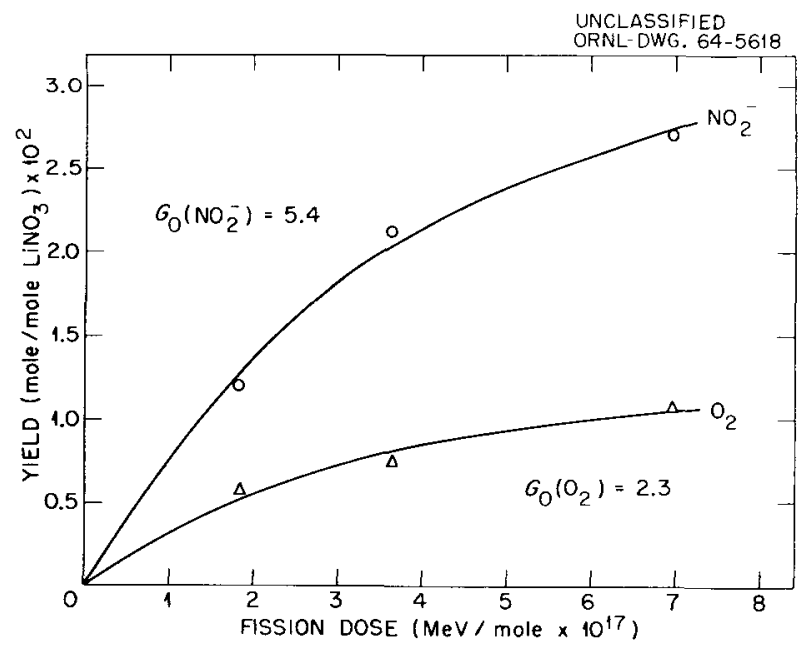

Fig. 4.1. Nitrite and Oxygen Produced in Molten Lithium Nitrate by ${ }^{6}$ Li Fission Particles. 
Furthermore, it was apparent that an LET effect existed in this particular radiolysis system since the $\mathrm{G}_{0}\left(\mathrm{NO}_{2}{ }^{-}\right)$values reported in the literature ${ }^{35-37}$ for both solid and molten $\mathrm{LiNO}_{3}$ for ${ }^{60} \mathrm{Co}$ gamma rays were all less than 0.2 . This was not unexpected since a similar effect was observed in comparing our results on the radiolysis of crystalline lithium bromate by ${ }^{6} \mathrm{Li}$ fission particles ${ }^{38}$ with ${ }^{60}$ Co gamma-ray data.

Two irradiations of 1- and 2-hr duration were made on molten ${ }^{7} \mathrm{LiNO}_{3}$ to assess the decomposition resulting from fast neutrons, capture gamma rays, and reactor gamma rays, but only the results of the 1-hr run are available at present. They indicate that less than $3 \%$ of the gross decomposition results from these latter radiations even though the ratio of the fast-neutron flux to the thermal-neutron flux is greater than 0.06 . This $3 \%$ correction will be applied to the data when the results of the second ${ }^{7} \mathrm{LiNO}_{3}$ irradiation become available.

The flux monitors placed on opposite sides of

\footnotetext{
${ }^{35} \mathrm{~J}$. Cunningham and H. G. Heal, Trans. Faraday Soc. 54,1355 (1958).

${ }^{36} \mathrm{~J}$. Cunningham, J. Phys. Chem. 65, 631 (1961).

${ }^{37}$ C. J. Hochanade1, Radiation Res. 16, 294 (1962).

${ }^{38}$ G. E. Boyd and T. G. Ward, J. Phys. Chem. (in press).
}

the 34-mm-diam irradiation capsule often gave fluxes differing by as much as $10 \%$, but their average was almost always between 3.4 and $3.5 \times$ $10^{12}$ neutrons $\mathrm{cm}^{-2} \mathrm{sec}^{-1}$. These differences probably arose from the flux gradient of $0.12 \times$ $10^{12}$ neutrons $\mathrm{cm}^{-2} \mathrm{sec}^{-1} \mathrm{~cm}^{-1}$ calculated from the BSR thermal-flux profile in the water $5 \mathrm{~cm}$ from the reactor face. ${ }^{39}$ Neutron self-shielding may also be responsible for errors up to $5 \%$ in the dose. It is planned to determine the extent of this effect by irradiating a sample containing trace amounts of cobalt distributed homogeneously throughout and comparing the specific activity of its solution with the conventional external dosimeter.

Another source of error which has not yet been completely investigated is the variation in the effective cross sections of ${ }^{59} \mathrm{Co}$ and ${ }^{6} \mathrm{Li}$ with the neutron spectrum corresponding to a particular irradiation facility. The values used in the calculations above correspond to the spectrum in the Graphite Reactor and cannot be expected to be completely valid for irradiations in the BSR. This situation will be corrected by a determination of the cadmium ratio of cobalt for the latter facility.

\footnotetext{
${ }^{39}$ F. C. Maienschein et al., Attenuation by Water of Radiations from a Swimming Pool Type Reactor, ORNL1891 (Sept. 7, 1955).
} 


\section{Organic Chemistry}

\section{Primary and Secondary Carbon-14 and Deuterium Isotope Effects}

$$
\text { C. J. Collins V. F. Raaen }
$$

The differential method was used to extend the study of small isotope effects in the reaction of aldehydes and ketones with 2,4-dinitrophenylhydrazine. ${ }^{1}$ No isotope effect was observed in the reaction with o-tolualdehyde that had been labeled in the methyl group with ${ }^{14} \mathrm{C}$. The results and conclusions of this investigation have been reported; ${ }^{2}$ no further work is contemplated.

\section{Determination of the Stereochemistry of 1,2-Glycols by Nuclear Magnetic Resonance Spectroscopy}
B. M. Benjamin
C. J. Collins

In the proton magnetic resonance spectra of alcohols it has been shown that the signals due to the hydroxylic protons are shifted to lower field by the formation of hydrogen bonds. ${ }^{3}$ The magnitude of the proton-signal shift is a function of the strength of the hydrogen bonds. Since the distance between hydroxyl groups is one of the

\footnotetext{
${ }^{1}$ Chem. Div. Ann. Progt. Repts. (a) June 20, 1960, ORNL-2983, p. 36; (b) June 20, 1961, ORNL-3176, p. 41; (c) June 20, 1962, ORNL-3320, p. 47; (d) June 20, 1963, ORNL-3488, p. 55; V. F. Raaen, A. K. Tsiomis, and C. J. Collins, J. Am. Chem. Soc. 82, 5502 (1960).

${ }^{2}$ V. F. Raaen et al., J. Am. Chem. Soc. 85, 3497 (1963); V. F. Raaen and C. J. Collins, Pure Appl. Chem. (in press).

${ }^{3}$ J. A. Pople, W. G. Schneider, and H. J. Bernstein, High Resolution Nuclear Magnetic Resonance, chap. 15, McGraw-Hill, New York, 1959.
}

factors which influences hydrogen bond strength, it follows that the geometry of molecules containing two hydroxyl groups will be responsible for the presence or absence of strong intramolecular hydrogen bonds. It appears possible to take advantage of the above facts to study the stereochemistry of diastereoisomeric pairs of 1,2glycols using nuclear magnetic resonance techniques.

Each stereoisomer of substituted ethylene glycols can exist in three conformations which are represented by the example in Fig. 5.1.

In the conformations $I a$ and $I b$ of the meso (R and $R_{1}$ are alike) or erythro ( $R$ and $R_{1}$ are different) series the two hydroxyl groups are gauche and an intramolecularhydrogen bond will be formed. In the remaining conformation Ic the trans relationship of the hydroxyl groups will prevent internal

$$
\begin{aligned}
& \text { UNCLASSIFIED } \\
& \text { ORNL-DWG. } 64-5406
\end{aligned}
$$

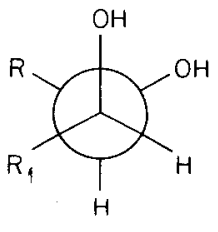

Ia

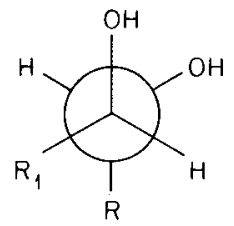

Ila<smiles>[R]C1C2CC3(O)C([R])C([R])C(C2O)C1C3O</smiles>

I b

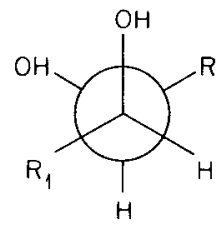

I I b<smiles>[R]C1C2CC3([R])CC1C(O)C(C2[R])C3O</smiles>

I C
Fig. 5.1. Configurations of erythro-(1) and threo-(11) Glycols. 
hydrogen bonding. There are likewise two conformations II $a$ and II $b$ which are hydrogen bonded and one IIc which is not in the racemic or threo series. Because of repulsive forces between the large groups $R$ and $R_{1}$, they will tend to be farthest apart in the most stable conformations. Therefore Ic and II $b$ would be expected to predominate in rotational equilibria, and since II $b$ can form a hydrogen bond and Ic cannot, the $\mathrm{OH}$ proton resonance signal of the racemic or threo isomer would be expected to appear at lower field than that for the meso or erythro form. ${ }^{4}$

In order to test the above ideas and to examine the generality of the method, nuclear magnetic resonance spectra were obtained for several pairs of diastereoisomers, including different types of compounds. In most cases the spectra were taken at several concentrations in deuteriochloroform solutions with tetramethylsilane as internal standard. The change in chemical shift of the hydroxylic protons, measured in cycles per second as a function of concentration, is shown in Fig. 5.2 for the erythro and threo forms of 1-phenyl-2p-tolylethylene glycol. Throughout the range of

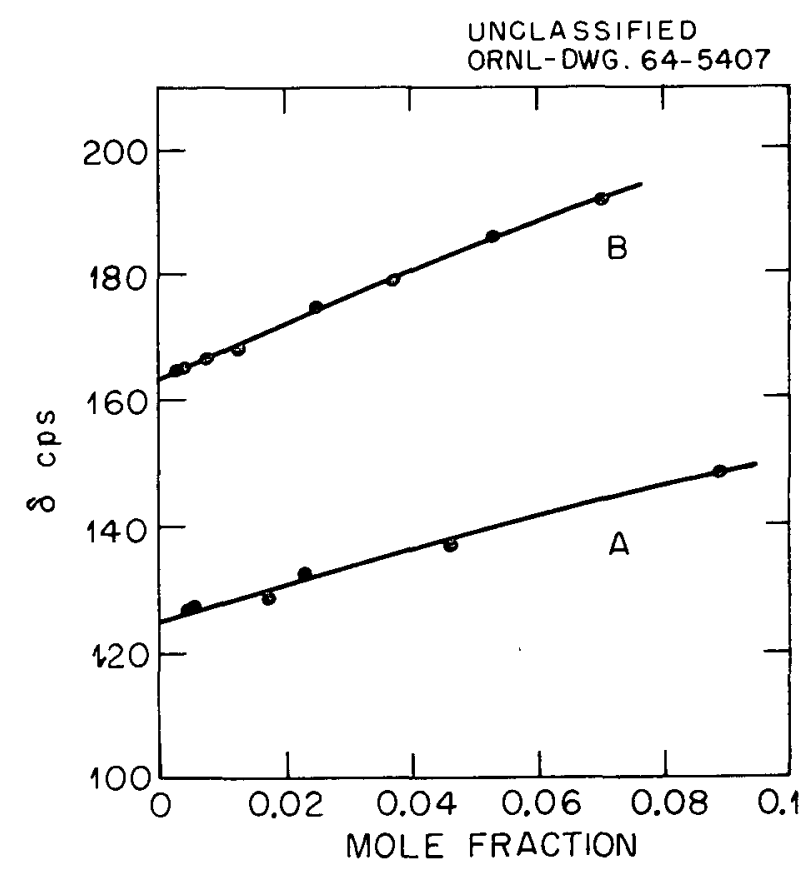

Fig. 5.2. Chemical Shifts of the Hydroxyl Protons of I-Phenyl-2-p-tolylethylene Glycol. A, erythro; B, threo. Chemical shifts are measured downfield from tetra. methylsilane standard at 0 , solvent deuteriochloroform, probe temperature $37^{\circ} \mathrm{C}$. concentrations studied the $\mathrm{OH}$ signal for the threo compound is distinctly downfield from that of the erythro compound.

As shown in Table 5.1, the expected results were obtained for the isomeric pairs of compounds III, IV, and V. The very small shift recorded for erythro- and threo-VI probably results from the different concentrations at which the spectra were recorded. It is known ${ }^{5}$ that the phenyl and $p$-tolyl groups exhibit approximately the same steric requirements and therefore the populations of rotational conformations should not differ significantly for the diastereoisomers of VI. This is confirmed by the experimental results.

It is not clear whether the data recorded for meso- and $d$-dimethyl tartrate (VII) are meaningful. The limited solubility in chloroform of the meso ester prevented the recording of accurate chemical shifts. However, the highly polar nature of the two terminal carbomethoxyl groups may stabilize certain conformations which could reverse the sign of the chemical shift change. The data suggest that compounds of this type should be studied further.

The OH signal for trans-1,2-cyclohexanediol is at lower field strength than that for the cis isomer. From molecular models it can be seen that the dihedral angle between the two hydroxyl groups is about $60^{\circ}$ for both isomers, and hydrogen bonding should be about the same. The difference in chemical shift is understandable because the trans isomer is stablized in the chair conformation with the two hydroxyl groups equatorial; whereas one hydroxyl group of the cis isomer is axial and the latter molecule undergoes conformational reorientation. This probably decreases the hydrogen bond energy. The known ${ }^{6}$ increased shielding of axial. groups relative to equatorial groups of cyclohexane compounds further accounts for the observed higher field chemical shift of the cis isomer.

More work is planned on the project as suitable compounds become available.

\footnotetext{
${ }^{4}$ This statement is valid for solutions of pairs of isomers in equal concentration. The chemical shift of hydroxylic protons changes with concentration (see ref. 3).

5 J. H. Stocker et al., J. Am. Chem. Soc. 82, 3913 (1960).

${ }^{6}$ J. A. Pople, W. G. Schneider, and H. J. Bernstein, High Resolution Nuclear Magnetic Resonance, chap. 14. McGraw-Hill, New York, 1959.
} 
Table 5.1. Chemical Shift Differences Between the Hydroxylic Protons of Diastereoisomeric Glycols

\begin{tabular}{|c|c|c|c|c|}
\hline Compound & Is omer & $\begin{array}{l}\text { Concentration } \\
\text { (mole fraction) }\end{array}$ & $\begin{array}{c}\text { Chemical } \\
\text { Shift } \\
\text { (cps) }\end{array}$ & $\Delta$ \\
\hline \multirow[t]{2}{*}{ III 1-phenyl-2-p-tolylethylene glycol } & erythro & 0.06 & 141.6 & \multirow{2}{*}{46.8} \\
\hline & threo & 0.06 & 188.4 & \\
\hline \multirow[t]{2}{*}{ IV 2,3-dipheny1-2,3-butanediol } & meso & 0.1 & 140.1 & \multirow[b]{2}{*}{20.5} \\
\hline & racemate & 0.1 & 160.6 & \\
\hline \multirow{6}{*}{ V 1,2-dipheny 1-1,2-propylene glycol } & erythro & 0.06 & & \multirow{6}{*}{$\begin{array}{r}10.1 \\
9.8\end{array}$} \\
\hline & secondary $\mathrm{OH}$ & & 151.1 & \\
\hline & tertiary $\mathrm{OH}$ & & 153.9 & \\
\hline & threo & & & \\
\hline & secondary $\mathrm{OH}$ & 0.06 & 161.2 & \\
\hline & tertiary $\mathrm{OH}$ & & 163.7 & \\
\hline \multirow{6}{*}{$\begin{array}{l}\text { VI 1-pheny1-1,2-di-p-tolylethylene } \\
\text { glycol }\end{array}$} & erythro & & & \\
\hline & secondary $\mathrm{OH}$ & 0.033 & 147.5 & \\
\hline & tertiary & & 183.0 & \\
\hline & threo & & & \\
\hline & secondary $\mathrm{OH}$ & 0.046 & 149.0 & 1.5 \\
\hline & tertiary $\mathrm{OH}$ & & 185.6 & 2.0 \\
\hline \multirow[t]{2}{*}{ VII dimethyl tartrate } & meso & 0.010 & 195.2 & \multirow[t]{2}{*}{-5.4} \\
\hline & $d$ & 0.010 & 189.8 & \\
\hline \multirow{2}{*}{ VIII 1,2-cyclohexanediol } & trans & 0.1 & 255 & \multirow{2}{*}{-61} \\
\hline & cis & 0.1 & 194 & \\
\hline
\end{tabular}

\section{Mechanism of Pyrolysis of Iron Salts of Carboxylic Acids}

Robert Beach V.F. Raaen

The thermal decarboxylation of iron salts of aliphatic carboxylic acids produces symmetrical dialkyl ketones in good yield. Similarly, heating a mixture of the iron salts of an aliphatic acid and of benzoic acid affords good yields of alkyl phenyl ketones. If the benzoic acid is labeled with ${ }^{14} \mathrm{C}$ in the carboxyl group, the resulting ketone has the same activity (except for a small isotope effect) as the benzoic acid. A convenient route is thereby provided for the synthesis of ${ }^{14} \mathrm{C}$-labeled alkyl phenyl ketones and for the degradation of labeled aliphatic acids.

Studies were made in which iron laurate was heated with the iron salt of another aliphatic acid (carboxyl-labeled); the acids used were acetic, propionic, butyric, isobutyric, valeric, and pivalic. In this series the fraction of ${ }^{14} \mathrm{C}$ contributed to the unsymmetrical ketone product varied from about $29 \%$ for methyl undecyl ketone to $100 \%$ for tert-butyl undecyl ketone. The data support the idea that a cyclic intermediate is formed:

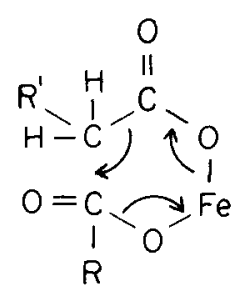

Such an intermediate was once proposed $^{7}$ for ketonic decarboxylations catalyzed by thoria aerogel.

\footnotetext{
${ }^{7}$ A. L. Miller, N. C. Cook, and F. C. Whitmore, J. Am. Chem. Soc. 72, 2732 (1950).
} 
The results of these experiments with the mixed salts of aliphatic acids can be explained in terms of the steric requirements of the molecules in the cvclic intermediate. Substitution of bulky groups on or near the carbon alpha to the carboxyl group makes that carbon less available for carbon-carbon bond formation. The ketonization reaction catalyzed by thoria aerogel can proceed through the intervention of hydrogen that is beta as well as alpha to the carboxyl group. If the ketonization reaction of iron salts is to occur, at least one of the participating carboxylic acids must have a hydrogen alpha to the carboxyl group. Tritium labeling was used to show that hydrogen alpha to the carboxyl group is labile under the conditions of iron salt formation. The investigation is not complete.

\section{Coupling of Aroyl Cyanides in Photochemical Reactions}

\author{
V. F. Raaen
}

The photochemical reactions of aroy 1 cyanides $^{8}$ were investigated further. Aroyl cyanides (in ether solution) were irradiated by means of a 400-w, immersion-type Hanovia lamp. Benzophenone was used as an energy-transfer agent. When subjected to these conditions benzoyl cyanide, $m$ - and $p$-toluyl cyanides, anisoyl cyanide, and p-chlorobenzoyl cyanide all give the corresponding benzils in yields that vary from 25 to $70 \%$. Naphthoyl cyanide and the sterically hindered o-toluyl cyanide are not affected by ultraviolet radiation. The one aliphatic compound (lauroyl cyanide) irradiated did not yield a diketone. Other aroyl cyanides, such as p-nitrobenzoyl cyanide and phthaloyl cyanide, could not be adequately purified for use in the irradiation study. The presence of unreacted aroyl halide in the irradiated cyanide inhibits benzil formation; as much as 10 mole \% prevents benzil formation altogether. Irradiation of an ether solution of benzoyl cyanide, benzoyl chloride, and benzophenone results in the formation of an unidentified white solid whose molecular

\footnotetext{
${ }^{8}$ Chem. Div. Ann. Progr. Rept. June 20, 1963, ORNL3488 , p. 56.
}

weight and elemental analysis are satisfied by the empirical formula $\mathrm{C}_{16} \mathrm{H}_{12} \mathrm{O}_{2} \mathrm{~N}_{2}$. The solid is converted to benzil by heating or by irradiation with ultraviolet light. All the aroyl cyanides that yield the corresponding benzil in the absence of the acid chloride will, in its presence, be converted to the white addition product. All the addition products are converted to the expected benzil on heating. The source of hydrogen in excess of that furnished by the aroyl cyanide is thought to be the ether solvent. Benzoyl cyanide in dry carbon tetrachloride is unaffected by ultraviolet radiation. The compound $\mathrm{C}_{16} \mathrm{H}_{12} \mathrm{O}_{2} \mathrm{~N}_{2}$ is, therefore, a possible intermediate in the conversion of benzoyl cyanide to benzil.

\section{The Pinacol Rearrangement of 2-Phenylnorbornane-2,3-cis-exo-diol \\ C. J. Collins \\ R. G. Werth ${ }^{10}$ \\ Z. K. Cheema ${ }^{9}$ \\ B. M. Benjamin}

In connection with their work on the performate oxidation of 2-phenylnorbornene (IV), Kleinfelter and Schleyer ${ }^{11}$ noted that one of the compounds available through their route - namely, 2-phenylnorbornane-2,3-cis-exo-diol (VI) - upon being heated with a dilute aqueous-dioxane-sulfuric acid mixture, yielded 3-endo-pheny1-2-norbornanone (VII). The stereochemical relationship of reactant (VI) and product (VII) was not specified.

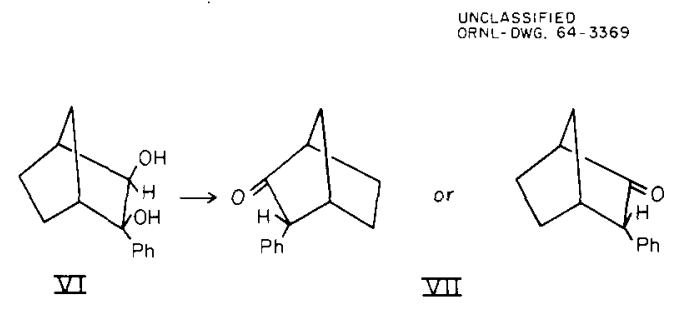

\footnotetext{
${ }^{9}$ Research participant of the Oak Ridge Institute of Nuclear Studies, June-September 1962.

${ }^{10}$ Research participant of the Oak Ridge Institute of Nuclear Studies, September 1962-May 1963.

${ }^{11}$ D. C. Kleinfelter and P. von R. Schleyer, J. Am. Chem. Soc. 83, 2329 (1961).
} 
The fact that phenyl is endo in both VI and VII precludes a simple loss of tertiary hydroxyl followed by a 1,2-shift of hydrogen during the rearrangement. Three conceivable, but unattractive, mechanisms remain as possibilities of which Kleinfelter and Schleyer ${ }^{11}$ seem to prefer "vinyl dehydration," 12 a theory which has been effectively negated, whenever tested, by the demonstration that deuterium undergoes intramolecular 1,2shift during pinacol rearrangement. ${ }^{13,14}$ The prejudice of one of us ${ }^{15}$ against "vinyl dehydration" caused us to reinvestigate the pinacol rearrangement of VI. Our approach to the problem was to study the consequences of tritium and ${ }^{14} \mathrm{C}$ labeling during the transformation VI $\rightarrow$ VII with an examination of its stereochemistry. We used concentrated sulfuric acid at $0^{\circ} \mathrm{C}$ to bring about the rearrangements, rather than the conditions employed by Kleinfelter and Schleyer, because of the known ${ }^{13}$ tendency of warm, dilute acids to favor exchange of hydrogen alpha to carbonyl groups.

The first series of experiments was concerned with the synthesis and rearrangement of 2-phenylnorbornane-2,3-cis-exo-diol-3- ${ }^{3} \mathrm{H}_{1}$ (VIa). The reaction sequence is shown in Chart 5.1 and was carried out twice. In the first experiments the molar radioactivities, in millicuries, for selected compounds in the series were: IIIa, 1.177; IVa, 0.6192; Va, 0.6266; VIa, 0.6263; and VIIa, 0.3058. Thus approximately half of the tritium was retained during the rearrangement of VIa $\rightarrow \mathrm{VII}$, and subsequent work-up, signifying that at least half of the reaction proceeded with intramolecular migration of tritium. In order to determine whether the partial loss of radioactivity was a consequence of duality of mechanism or of exchange of hydrogen for the tritium in VIla during work-up, we repeated the experiment, but isolated the product quickly and, in addition, kept wash solutions as nearly neutral as possible. Tritium determinations, in millicuries per mole, for key compounds in the second experiments were: $\mathrm{Va}, 0.4901$; VIa, 0.4869 ; and VIla, 0.4148 , corresponding to $15 \%$ loss of the

${ }^{12}$ M. Tiffeneau, Bull. Soc. Chim. 33, 759 (1923).

${ }^{13}$ C. J. Collins et al., J. Am. Chem. Soc. 81, 460 (1959).

${ }^{14}$ W. B. Smith et al., J. Am. Chem. Soc. 81, 997 (1959).

${ }^{15}$ C. J. Collins, Quart. Rev. 14, 363-67 (1960). tritium during rearrangement of VIa. Finally, a crude kinetic experiment was performed which indicated that in very weakly basic solution, exchange of tritium for the hydrogen of VII is complete within a few hours. It has been established, therefore, that the hydrogen at position 3 of the glycol VI migrates intramolecularly to the extent of more than $85 \%$, and it is possible that the intramolecularity is complete. From these results we can see that "vinyl dehydration" is not an important mechanism in the rearrangement of VI. Since the two remaining mechanisms require inversion of configuration during rearrangement, VIa is drawn to show that the inversion has taken place.

Our next series of experiments was constructed to differentiate rearrangement of the norbornyl carbon skeleton from secondary hydroxyl removal followed by a C-2 $\rightarrow \mathrm{C}-3$ migration of the endo phenyl. The sequence is shown in Chart 5.2, in which the asterisk now refers to the ${ }^{14} \mathrm{C}$ label.

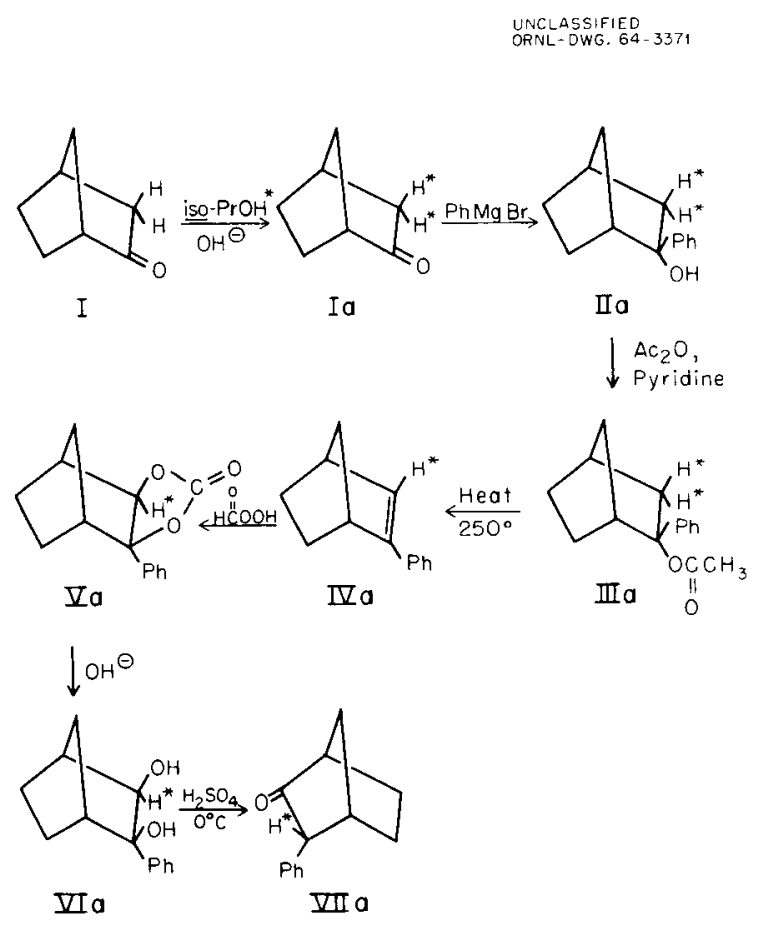

Chart 5.1 
UNCLASSIFIED

ORNL-DWG. $64-3372$

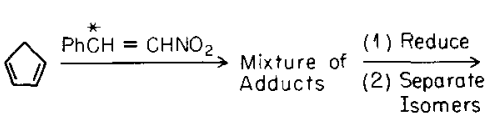

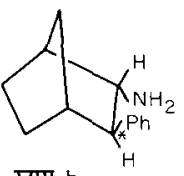

VIII b

(1) Dimethylate

(2) Oxidize

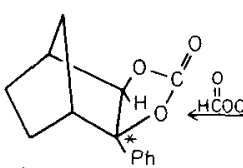

$1.00 \mathrm{mc} / \mathrm{mole}$

I b

$\downarrow$

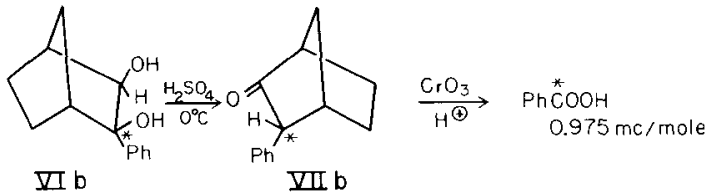

$\downarrow \mathrm{H}^{\mathrm{CrO}_{3}}$

$\mathrm{Ph} \stackrel{*}{\mathrm{COOH}}$

$1.00 \mathrm{mc} /$ mole
The results are unequivocal, demonstrate that the labeled carbon remains attached to phenyl during rearrangement, and show conclusively that secondary hydroxyl removal followed by a Nametkin-type phenyl migration to the secondary (C-3) position cannot have occurred to any significant extent.

It remained only to establish the stereochemistry of the transformation VI $\rightarrow$ VII. The stereochemical study is outlined in Chart 5.3. Optically pure ketone (+)-VII was formed upon rearrangement of the optically pure glycol (-)-VI. Since the enantiomers (t)-IV and (-)-IV in the sequence shown in Chart 5.3 both yield the same (+)-ketone (VII), it is clear that (-) VI afforded ( + )-VII whose configuration had been inverted during the rearrangement.

Thus pinacol rearrangement of 2-phenylnorbornane-2,3-cis-exo-diol (VI) proceeds with intramolecular migration of hydrogen from $\mathrm{C}-3$ to $\mathrm{C}-2$, the configuration of the ketone (VII) produced is inverted with respect to the configuration of VI, and the phenyl remains attached to the same carbon atom throughout the rearrangement. One mechanism

Chart 5.2

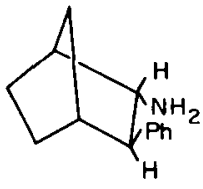

$(+)-\mathrm{VIII}^{a}$

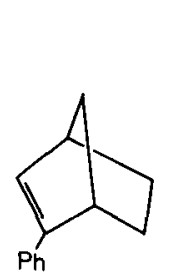

$(+)-\mathrm{IV}^{\mathrm{a}}$
(1) Dimethylate

(2) $\mathrm{H}_{2} \mathrm{O}_{2}$

(3) Pyrolyze

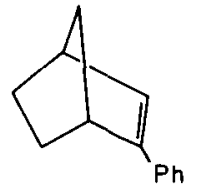

$(-)-$ IZ

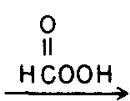

$\stackrel{\mathrm{HCOOH}}{\longrightarrow}$

UNCLASSIFIED

ORNL-DWG. 64-3374

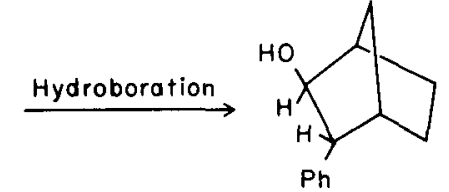

$(+)-X$

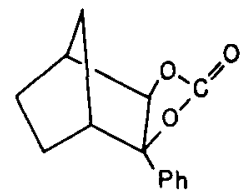

$(+)-Z$

$\downarrow_{\text {LiAlH }}$<smiles>OCC1C2CCC(C2)C1O</smiles>

$(-)-\bar{Z}$

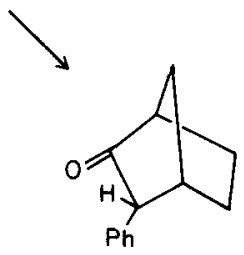<smiles>[14CH3]</smiles>

$(+)-\nabla I I$

(a) Absolute configurations not intended.

Chor 5.3 
which can be written for these results includes the formation of the classical carbonium ion $A$,

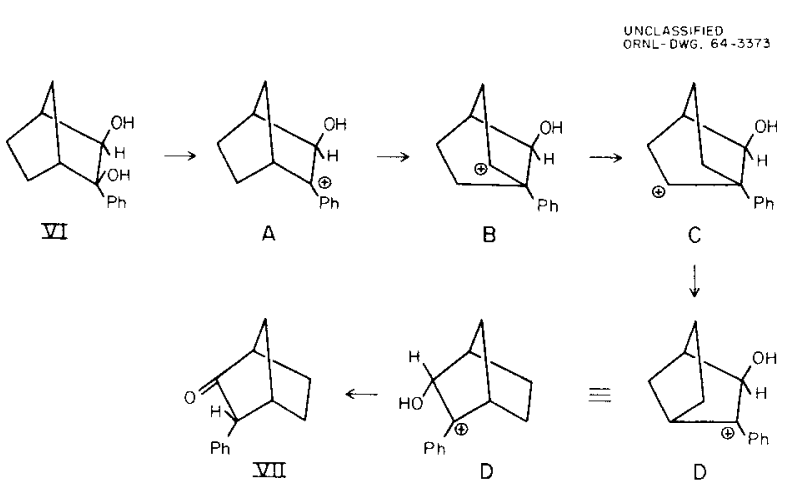

followed by rearrangement through ions $B$ and $C$ (with accompanying 6-1 shift of hydrogen) ${ }^{16}$ to the classical ion $D$, which then yields the ketone VII. This mechanism, however, does not tell us why the exo-hydrogen of ion $D$ undergoes such easy migration to the 2-position, whereas the endohydrogen in ion $A$ does not. Further, rearrangement of the stable tertiary benzyl-type ion $A$ to the secondary ion $B$ seems unlikely. A much more satisfactory interpretation employs the nonclassical, bridged intermediates $E$ and $F$, in which $E$ rearranges to $F$ accompanied by a hydride shift. ${ }^{16}$ Migration of the 3-endo-hydrogen in $E$ is not possible because of bridging from the 6-position to the same side of $\mathrm{C}-2$ to which the hydrogen, if it migrated, would shift. In ion $F$, however, bridging is on the opposite side from the exo-hydrogen at $\mathrm{C}-3$, which can now migrate without difficulty.

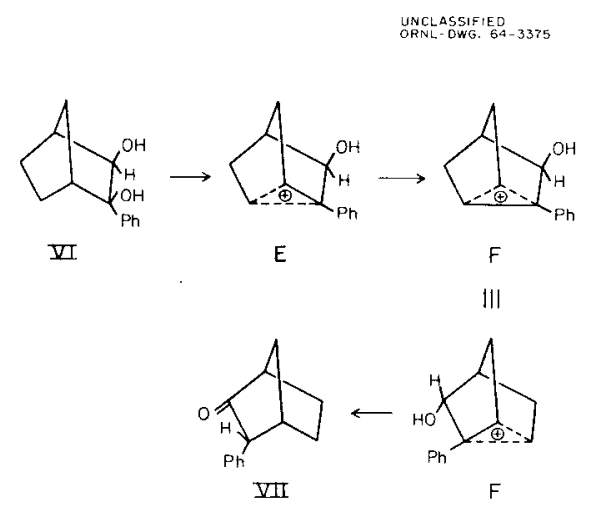

${ }^{16}$ J. D. Roberts, C. C. Lee, and W. H. Saunders, Jr., J. Am. Chem. Soc. 76, 4501 (1954).

\section{The Deamination of 3eendoo Amino-2-endo- phenylnorborneol ( 1 ) and of 3 endoo Amino-20exoophenylnorborneol (VI)}
I. T. Glover ${ }^{17}$
C. J. Collins

We prepared the title compounds (I and VI) in order to compare the results of their deaminations with the pinacol rearrangement of 2-phenylnorbornane-2,3-cis-exo-diol, reported earlier in this section.

After several unsuccessful attempts to prepare I by other methods, it was finally obtained in low yield (4.1\% based on II) by rearrangement of 2,3cis-exo-dihydroxy-2-phenylnorbornane, II, in a sulfuric acid-dioxane mixture at $0^{\circ}$ to 3 endophenyl-2-norbornanone, III, followed by alpha hydroxylation of III with concentrated nitric acid in glacial acetic acid to give 3-exo-hydroxy-3phenyl-2-norbornanone, IV. Treatment of IV with hydroxylamine hydrochloride in pyridine afforded the corresponding oxime, $\mathrm{V}$, which was reduced with lithium aluminum hydride to $\mathrm{I}$.

Treatment of I with nitrous acid gave a mixture of hydroxy, ketonic, and olefinic products. Chromatography of this mixture gave an unsaturated ketone (3-cyclohexenyl phenyl ketone) and hydroxy and ketonic fractions which could not be definitely characterized. The absence of III from this mixture indicated that no endo-phenyl -migration had occurred, but the complexity of the mixture suggested that extensive rearrangement of the norbornane skeleton had taken place and presented an interesting problem in identification and synthesis of the products.

Since we needed larger quantities of starting material (I) if we were ever to identify all of the deamination products, and because we were unable to increase the very poor yield of I obtained by our method of synthesis, we temporarily abandoned work on compound $I$ in favor of the other title compound (VI), which, fortunately, was prepared in fair yields as follows: 3-Oximino-2norbornanone, VII, was obtained by the reaction of norbornanone, VIII, with $t$-amyl nitrite and potassium $t$-butoxide in petroleum ether. Addition of one mole of phenyllithium to VII gave 2-oximino3-exo-phenyl 3-hydroxynorbornane, IX, which, on reduction with lithium aluminum hydride, afforded

\footnotetext{
${ }^{17}$ AEC Postdoctoral Fellow from the University of Virginia.
} 
VI. Deamination of VI according to the procedure used with I, followed by chromatography on a column of alumina, gave a mixture of 3-cyclohexenyl phenyl ketone, $\mathrm{X}$, three compounds thought to be diols, and a hydroxyl ketone. Nuclear magnetic resonance and infrared spectrographs of the compounds isolated from the deamination products gave several clues as to their identity, and we are presently synthesizing some of these suspected products by independent means, for the purpose of direct comparisons of the known and unknown compounds.

\section{The Chlorinolysis of Sulfenate Esters}

$$
\text { E. N. Givens }{ }^{18} \quad \text { C. J. Collins }
$$

The enantiomeric and racemic erythro- and threo-3-phenyl-2-butyl-1- ${ }^{14} \mathrm{C}$ 2,4-dinitrobenzenesulfenates have been chlorinated in both acetic acid and chloroform; the products were examined. The cleavage of the carbon-oxygen bond results in two fragments. The 2,4-dinitroben zenesulfenyl group was shown to form the sulfinyl chloride by the isolation of its pyridine derivative, 2,4-dinitrobenzenesulfinylpyridinium chloride. The 3phenyl-2-butyl moiety was found as the chloride, acetate, and alcohol products of phenyl, methyl, and hydrogen migration. We interpreted the effect of lithium perchlorate on product distribution to indicate the existence of ion pairs. The yields, optical properties, and ${ }^{14} \mathrm{C}$ scrambling lead to a mechanistic interpretation of the reaction. An open methyl-1-phenylethylcarbonium ion, which can be attacked from either side by the anion, is probably the first intermediate formed. We believe the bridged phenonium ion is formed itreversibly from the open methyl-1-phenylethylcarbonium ion and then collapses with the appropriate anion to yield a 3-phenyl-2-buty1 product. We can explain phenyl migration to the extent of almost $50 \%$, as well as steric control of product configuration by assuming bridged ion intermediates. Ground state conformational control of product distribution is important but to a lesser extent than in the deamination reaction.

\footnotetext{
${ }^{18}$ Predoctoral Fellow of the Oak Ridge Institute of Nuclear Studies from the University of Delaware. Project jointly directed by Profess or $H$. Kwart.
}

\section{Amides of Carboxylic Acids as Solvents for the Extraction of Electrolytes}

\author{
W. H. Baldwin C. E. Higgins
} J. M. Schmitt ${ }^{19}$

The electron-donating properties of neutral organic molecules that have been successfully employed for the extraction of electrolytes are found in the amides of carboxylic acids ( $\mathrm{RCONR}_{2}^{\circ}$ ). For example, Bull, Madan, and Willis ${ }^{20}$ have prepared solid addition compounds from dimethyl acetamide and a number of salts, while Siddall ${ }^{21}$ has measured the distribution of electrolytes between aqueous nitrate systems and amides of high molecular weight.

We have decided to study the relationships that exist between the structure of amides and the distribution of electrolytes between these amides and aqueous nitric acid solutions. The amides of carboxylic acids are particularly suited for the study of the effects of varying the structure of the molecule because synthetic methods and starting compounds are available for the preparation of a great variety of different structures. It is to be expected that the differences in structure may result in different electronic densities around the carbonyl oxygen and in different steric effects.

Acids were converted to the corresponding acyl chlorides by reaction with an excess of thionyl chloride by mixing at room temperature and completing the reaction by refluxing for $1 \mathrm{hr}$. The acyl chlorides were distilled through a 10-in. Vigreux column. The reaction of the acyl chloride with the amine will be illustrated by the following general procedure. To a stirred solution of 1 mole triethyl amine and 1 mole of primary or secondary amine in 1 liter of ether (cooled to $0^{\circ} \mathrm{C}$ ) there was added, dropwise, 1 mole of acyl chloride dissolved in $200 \mathrm{ml}$ dry ether during 1 to $2 \mathrm{hr}$. Stirring was continued for $1 \mathrm{hr}$ after the addition and the solution was then allowed to warm to room temperature. The reaction mixture was extracted twice with 1 liter of water each time, with 1-liter portions of $5 \%$ hydrochloric acid until the washings were acid, with 1-liter portions of $5 \%$ sodium hydroxide until the washings were alkaline, and

\footnotetext{
${ }^{19}$ Chemical Technology Division.

${ }^{20}$ W. E. Bul1, S. K. Madan, and J. E. Willis, J. Inorg. Chem. 2, 303 (1963).

${ }^{21}$ T. H. Siddall III, J. Phys. Chem. 64, 1863 (1960).
} 
Table 5.2. Amides Prepared from the Reaction of Acyl Chloride and Amines RCONR'

\begin{tabular}{|c|c|c|c|c|c|}
\hline \multirow{2}{*}{$R$} & \multirow{2}{*}{$R^{\prime}$} & \multicolumn{2}{|c|}{ Boiling Temperature } & \multicolumn{2}{|c|}{ Neutral Equivalent ${ }^{a}$} \\
\hline & & $\left({ }^{\circ} \mathrm{C}\right)$ & $(\mathrm{mm} \mathrm{Hg})$ & Found & Calculated \\
\hline \multirow{8}{*}{$\mathrm{C}_{4} \mathrm{H}_{9} \mathrm{CH}\left(\mathrm{C}_{2} \mathrm{H}_{5}\right)$} & $\mathbf{H}$ & M. $103-4^{b}$ & & & \\
\hline & $\mathrm{H}, \mathrm{CH}_{3}$ & M. $\quad 68-69^{c}$ & & 158 & 157 \\
\hline & $\mathrm{CH}_{3}$ & $99-100$ & 8 & 175 & 171 \\
\hline & $\mathrm{C}_{2} \mathrm{H}_{5}$ & $120-22$ & 12 & 202 & 199 \\
\hline & $n-\mathrm{C}_{3} \mathrm{H}_{7}$ & $140-41$ & 13 & 230 & 227 \\
\hline & $i \oplus \mathrm{C}_{3} \mathrm{H}_{7}$ & $77-79$ & 2 & 230 & 227 \\
\hline & $n-\mathrm{C}_{4} \mathrm{H}_{9}$ & $111-12$ & $\sim 1$ & 255 & 255 \\
\hline & Morpholino & 100 & $\sim 1$ & 215 & 213 \\
\hline \multirow[t]{2}{*}{$n-C_{7} H_{15}$} & $\mathrm{n}-\mathrm{C}_{3} \mathrm{H}_{7}$ & $108-9$ & $\sim 1$ & 228 & 227 \\
\hline & $i=\mathrm{C}_{3} \mathrm{H}_{7}$ & $117-19$ & $\sim 1$ & 230 & 227 \\
\hline $\mathrm{C}_{9} \mathrm{H}_{19} \mathrm{C}\left(\mathrm{CH}_{3}\right)_{2}^{d}$ & $\mathrm{CH}_{3}$ & 103 & $\sim 1$ & 243 & 241 \\
\hline
\end{tabular}

finally with water until neutral. The ether layer was then tested for the presence of salt and acid by withdrawing a 5-m1 aliquot, diluting with $20 \mathrm{ml}$ of $50 \%$ aqueous ethanol, and passing it through a column of cation exchange resin in the hydrogen form and washing the column with $50 \%$ aqueous ethanol. The eluate from the column was titrated to a phenolphthalein end point with $0.1 \mathrm{~N}$ sodium hydroxide. Whenever more than two drops of sodium hydroxide were required the ether solution was again washed with $5 \%$ sodium hydroxide and with water. The ether layer was dried by gravity flow through a column of Drierite, the ether removed at atmospheric pressure, and the residue distilled through a 10-in. Vigreux column under reduced pressure. Yields generally exceeded $90 \%$.

The equivalent weight of the amides was determined by potentiometric titration with perchloric acid in acetic anhydride solutions as described by Wimer. ${ }^{2}$
Data for the amides that have been prepared are summarized in Table 5.2.

The testing of the amides in solvent extraction studies has been reported by the Chemical Technology Division. ${ }^{23}$ The most significant finding is the dramatic difference between the distribution coefficients of uranium and thorium using $N, N$ dimethy1 neo-tridecanamide, $\mathrm{C}_{9} \mathrm{H}_{19} \mathrm{C}\left(\mathrm{CH}_{3}\right)_{2} \mathrm{CON}$ $\left(\mathrm{CH}_{3}\right)_{2}$. Less dramatic differences were obtained with $\stackrel{2}{N}, N$-dimethyl 2-ethylhexanamide, $\mathrm{C}_{4} \mathrm{H}_{9} \mathrm{CH}$ $\left(\mathrm{C}_{2} \mathrm{H}_{5}\right) \mathrm{CON}\left(\mathrm{CH}_{3}\right)_{2}$. In general, the distribution coefficients for either uranium or thorium decreased as the sizes of the substituents on nitrogen were increased from methyl up through $n$-butyl.

\footnotetext{
${ }^{22}$ D. C. Wimer, Anal. Chem. 30, 77 (1958).

${ }^{23}$ K. B. Brown, C. A. Blake, and J. M. Schmitt, (a) Chem. Technol. Div. Ann. Progr. Rept. May 31, 1963, ORNL-3452, p. 178, (b) Chem. Technol. Div. Chem. Develop. Sect. C, Progr. Rept. Separations Chem. and Separations Process Res. Jan.-June 1963, ORNL3496; (c) Chem. Technol. Div. Ann. Progr. Rept. May 31,1964 (to be issued).
} 


\section{Acid-Catalyzed Hydrolysis of Dibutyl Dimethylphosphoramidate}
C. E. Higgins
W. H. Baldwin

In an extension of our study of the distribution of electrolytes between water and amides of carboxylic acids, the dimethyl amide of dibutyl phosphoric acid was prepared by the method of Atherton, Openshaw, and Todd. ${ }^{24}$ The product, obtained in $87 \%$ yield, boiled at 85 to $86^{\circ} \mathrm{C}$ at $<1 \mathrm{~mm}$ pressure. Nitrogen found, $5.8 \%$; calculated for $\mathrm{C}_{10} \mathrm{H}_{24} \mathrm{NO}_{3} \mathrm{P}, 5.9 \%$.

Additional tests to establish the purity of this preparation included the estimation of free acid after passage through a cation exchange resin in the hydrogen form. A sample, $25 \mathrm{ml}$ of $0.05 \mathrm{M}$ solution in $50 \%$ ethanol, was allowed to flow through $23 \mathrm{cc}$ of Amberlite $200 \mathrm{H}^{+}$resin in a $20-\mathrm{mm}-\mathrm{ID}$ column at $25^{\circ} \mathrm{C}$, whereby $22 \%$ of the original material appeared in the eluate as free acid. Another $25-\mathrm{ml}$ aliquot of $0.05 \mathrm{M}$ solution was recycled nine times through the column, and $80 \%$ of the starting material was recovered as free acid.

The free acid was separated and shown to be dibutyl hydrogen phosphate by its neutral equivalent (found, 212; calculated, 210) and by the melting point of the dibenzylammonium salt alone and when mixed with an authentic specimen (107 to $108^{\circ} \mathrm{C}$ ). The identification of the acid as dibuty 1 hydrogen phosphate indicates the scission of the $\mathrm{P}-\mathrm{N}$ bond.

Further evidence for acid-catalyzed hydrolysis was obtained by equilibrating equal volumes of $0.2 M$ dibutyl dimethylphosphoramidate in hexane and $0.1 M$ aqueous hydrochloric acid for $3 \mathrm{hr}$ at room temperature. An aliquot of the aqueous phase contained over $30 \%$ of the amide as dibutyl phosphoric acid after passage through the resin column.

Control tests were made in which equal volumes of distilled water and $0.2 \mathrm{M}$ dibutyl dimethylphosphoramidate in hexane were equilibrated for times varying from $5 \mathrm{~min}$ to $22 \mathrm{hr}$. The results were the same for each time; $3 \%$ of the amide appeared as acid after passage of the aqueous phase through the resin column. These results obtained with water reflect the distribution of the amidate into water and the fact that little hydroly. sis occurs with distilled water.

Dimethyl ammonium dibutylphosphate was synthesized as a model compound to be expected from the hydrolysis of the amidate. This dimethyl ammonium salt when equilibrated with equal volumes of hexane and water was found to be almost quantitatively in the aqueous phase.

\section{Triallyl Phosphate as the Stationary Liquid Phase in the Gas Chromatographic Separation of Light Hydrocarbons}
C. E. Higgins
W. H. Baldwin

Our previous work on the gas chromatographic separation of butene isomers and 1,3-butadiene ${ }^{25}$ showed that the use of triethyl phosphate as the stationary liquid phase produced better resolution of butene-1, cis- and trans-butene-2, and 1,3butadiene than did tributyl phosphate. We have now tested triallyl phosphate as the stationary liquid phase for these separations. Triallyl phosphate, $\left(\mathrm{CH}_{2}=\mathrm{CHCH}_{2} \mathrm{O}\right)_{3} \mathrm{PO}$, has a molecular weight between those of triethyl and tributyl phosphate and possesses three double bonds in the molecule.

Retention values for several alkanes and alkenes are listed in Table 5.3. The use of triallyl phosphate as the stationary liquid phase gave complete resolution for butene-1, cis- and trans-butene-2, and 1,3-butadiene, being more nearly like triethyl phosphate than tributyl phosphate.

\footnotetext{
${ }^{24}$ F. R. Atherton, H. T. Openshaw, and A. R. Todd, J. Chem. Soc. 660 (1945).

${ }^{25}$ C. E. Higgins and W. H. Baldwin, Anal. Chem. 36. 473 (1964)
} 
Table 5.3. Relative Retention Ratios Using Triallyl Phosphate ${ }^{a}$

\begin{tabular}{|c|c|c|}
\hline Constituent & $\begin{array}{c}25^{\circ} \mathrm{C} \\
\text { (butene- } 1=1.00=4.99 \mathrm{~min} \text { from air) }\end{array}$ & $\begin{array}{c}0^{\circ} \mathrm{C} \\
\text { (butene-1 }=1.00=9.57 \mathrm{~min} \text { from air) }\end{array}$ \\
\hline $\mathrm{CO}_{2}$ & 0.15 & 0.13 \\
\hline Is obutane & 0.45 & 0.40 \\
\hline n-Butane & 0.70 & 0.66 \\
\hline Neopentane & 0.71 & 0.67 \\
\hline Butene-1 & 1.00 & 1.00 \\
\hline Isobutylene & 1.04 & 1.04 \\
\hline $\operatorname{trans-Butene-2}$ & 1.27 & 1.31 \\
\hline Is opentane & 1.47 & 1.53 \\
\hline cis-Butene-2 & 1.52 & 1.63 \\
\hline 1,3-Butadiene & 1.83 & 2.00 \\
\hline$n$-Pentane & 1.94 & 2.11 \\
\hline Pentene-1 & 2.65 & 3.07 \\
\hline trans-Pentene-2 & 3.29 & 3.96 \\
\hline cis-Pentene-2 & 3.61 & 4.39 \\
\hline$n$-Hexane & 5.17 & 6.59 \\
\hline
\end{tabular}

${ }^{a}$ Column $-10 \mathrm{ft} \times 1 / 4$ in. copper tubing packed with trially1 phosphate on Celite (ratio $=4$ to 10 ), 50-70 mesh; carrier gas - helium; flow rate $=50 \mathrm{ml} / \mathrm{min}$; pressure, inlet $=13.7$ psi at $25^{\circ} \mathrm{C}, 12.5 \mathrm{psi}$ at $0^{\circ} \mathrm{C}$; outlet $=$ atmospheric; sample size $=0.1 \mathrm{ml}$ of gas; time from sample injection to air peak $=1.31 \mathrm{~min}$ at $25^{\circ} \mathrm{C}, 1.39 \mathrm{~min}$ at $0^{\circ} \mathrm{C}$. 


\section{Chemistry of Aqueous Systems}

\section{The Thermodynamic Properties of Deuterium Chloride Solutions}
M. H. Lietzke
R. W. Stoughton

Introduction. - Measurements of the emf of the cell

$$
\mathrm{Pt}_{2} \mathrm{D}_{2}(p)|\mathrm{DCl}(m)| \mathrm{AgCl}, \mathrm{Ag}
$$

have been used to determine the thermodynamic properties of $\mathrm{DCl}$ solutions in $\mathrm{D}_{2} \mathrm{O}$ as well as the standard potential of the cell to $225^{\circ} \mathrm{C}$. In addition, the original emf data obtained in $\mathrm{HCl}$ solutions have been used to recalculate the properties of these solutions in a manner consistent with that used in the present calculations of the properties of DCl solutions. Thus a direct comparison can be made of the thermodynamic properties of $\mathrm{HCl}$ and $\mathrm{DCl}$ solutions over a wide range of concentration and temperature.

Experimental. - The experimental apparatus and the preparation of electrodes were the same as described previously. ${ }^{1-3}$

The emf measurements were made on $\mathrm{DCl}$ solutions (in $\mathrm{D}_{2} \mathrm{O}$ ) of $0.0102,0.0196,0.0502,0.0735$, $0.1004,0.1983,0.495$, and $1.127 \mathrm{~m}$ concentration at temperatures of about $25,60,90,125,150,175$, 200 , and $225^{\circ} \mathrm{C}$. The $\mathrm{DCl}$ was purchased from Merck, Sharp and Dohme of Canada, Ltd., in $50-\mathrm{g}$ ampuls containing $38 \%$ by weight $\mathrm{DCl}$ solution in $\mathrm{D}_{2} \mathrm{O}$. The mass spectrographic assay of the $\mathrm{DCl}$ indicated $97.3 \% \mathrm{DCl}$ by weight; because of the rapid exchange of $\mathrm{H}^{+}$with the $\mathrm{D}_{2} \mathrm{O}$ in the final solution the isotopic composition of the $\mathrm{DCl}$ under the experimental conditions is determined by that of the $\mathrm{D}_{2} \mathrm{O}$. The $\mathrm{D}_{2} \mathrm{O}$ was prepared by

\footnotetext{
${ }^{1}$ R. S. Greeley et al., J. Phys. Chem. 64, 652 (1960).

${ }^{2}$ R. S. Greeley et al., J. Phys. Chem. 64, 1445 (1960).

${ }^{3}$ M. B. Towns, R. S. Greeley, and M. H. Lietzke, $J$. Phys. Chem. 64, 1861 (1960).
}

twice distilling nominally $99.7 \% \quad \mathrm{D}_{2} \mathrm{O}$ under an atmosphere of nitrogen that had been dried over $\mathrm{Mg}\left(\mathrm{ClO}_{4}\right)_{2}$ : the first distillation was made from a $1 \mathrm{~m} \mathrm{D}_{2} \mathrm{SO}_{4}$ and $0.5 \mathrm{~m} \mathrm{~K}_{2} \mathrm{Cr}_{2} \mathrm{O}_{7}$ solution and the second from $2 \% \mathrm{KMnO}_{4}$ and $0.04 \mathrm{~m} \mathrm{NaOD}$. Extreme precautions were taken at all times to exclude any contamination by $\mathrm{H}_{2} \mathrm{O}$. Final mass spectrographic assay of the $\mathrm{D}_{2} \mathrm{O}^{2}$ indicated $99.4 \%$ $\mathrm{D}_{2} \mathrm{O}$ by weight. The $\mathrm{D}_{2}$ gas was obtained in a cylinder from the Y-12 Plant of the Nuclear Division of Union Carbide Corporation. Mass spectrographic analysis indicated an assay of $99.84 \%$ $\mathrm{D}_{2}$ by weight.

Results and Discussion. - In treating the results, the deuterium pressure was calculated by subtracting the vapor pressure of the solution from the observed total pressure, while the vapor pressure of the solution was obtained by taking the vapor pressure of pure $\mathrm{D}_{2} \mathrm{O}$ (ref. 4) at the temperature of measurement and correcting for the presence of $\mathrm{DCl}$ in solution by Raoult's law. Each emf value was corrected to $1.00 \mathrm{~atm}$ of deuterium pressure by subtracting $(R T / 2 F) \ln f_{\mathrm{D}_{2}}$, where the deuterium fugacity $t_{\mathrm{D}_{2}}$ was taken equal to the deuterium pressure in atmospheres. The solubility of $\mathrm{AgCl}$ was neglected and the ionic strength was taken to be equal to the DCl molality. The corrected emf values $E$ at each ionic strength were plotted as a function of temperature and the values corrected to the round values of the temperature $25,60,90,125,150,175,200$, and $225^{\circ} \mathrm{C}$. The temperature of measurement was usually no more than $1^{\circ}$ from the corresponding round temperature. These corrected values are given in Table 6.1. At the higher temperatures, the emf values were considered unreliable at the lowest acidities because of hydrolysis of the $\mathrm{AgCl}$ and at the highest

\footnotetext{
${ }^{4}$ E. H. Riesenfeld and T. L. Chang, Z. Physik. Chem. (Leipzig) B 33, 120 (1936).
} 
Table 6.1. Values of the EMF in Volts for the Cell Pt-D $(p)|\mathrm{DCl}(m)| \mathbf{A g C l}, \mathbf{A g}$ and Deviations ${ }^{a}$ of the EMF Values Calculated from Smoothed Activity Coefficients

\begin{tabular}{|c|c|c|c|c|c|c|c|c|}
\hline \multirow{2}{*}{$m$} & \multicolumn{8}{|c|}{ Temperature $\left({ }^{\circ} \mathrm{C}\right)$} \\
\hline & 25 & 60 & 90 & 125 & 150 & 175 & 200 & 225 \\
\hline \multirow[t]{2}{*}{0.0102} & 0.4505 & 0.4529 & 0.4481 & 0.4359 & 0.4215 & & & \\
\hline & -3 & 0 & 0 & 5 & -6 & & & \\
\hline \multirow[t]{2}{*}{0.0196} & 0.4195 & 0.4175 & 0.4092 & 0.3922 & & & & \\
\hline & 7 & 2 & -3 & -13 & & & & \\
\hline \multirow[t]{2}{*}{0.0502} & 0.3760 & 0.3685 & 0.3552 & 0.3350 & 0.3161 & 0.2954 & 0.2718 & 0.2435 \\
\hline & 22 & 13 & -1 & 2 & -2 & 6 & 11 & -8 \\
\hline \multirow[t]{2}{*}{0.0735} & 0.3576 & 0.3478 & 0.3345 & 0.3119 & 0.2923 & 0.2706 & 0.2464 & 0.2164 \\
\hline & 18 & 7 & 10 & 5 & 5 & 11 & 18 & -12 \\
\hline \multirow[t]{2}{*}{0.1004} & 0.3417 & 0.3315 & 0.3148 & 0.2913 & 0.2719 & 0.2499 & 0.2248 & 0.1940 \\
\hline & 6 & 8 & -11 & -12 & -2 & 8 & 11 & -23 \\
\hline \multirow[t]{2}{*}{0.1983} & 0.3100 & 0.2974 & 0.2742 & 0.2538 & 0.2328 & & & \\
\hline & 10 & 26 & -30 & 26 & 34 & & & \\
\hline \multirow[t]{2}{*}{0.495} & 0.2621 & 0.2451 & 0.2229 & 0.1915 & 0.1677 & & & \\
\hline & -22 & 1 & -6 & -19 & -12 & & & \\
\hline \multirow[t]{2}{*}{1.127} & 0.2174 & 0.1933 & 0.1680 & & & & & \\
\hline & 7 & -13 & 15 & & & & & \\
\hline
\end{tabular}

${ }^{a}$ The deviations are given below each emf as observed emf values less the value calculated from smoothed activity coefficients. Thus a positive deviation indicates that the emf reported here is algebraically larger. These deviations have been computed on an equal-moles-of-solvent basis (with HCl).

acidities because of corrosion of the bomb. Hence these values are not given in the table.

The emf values for the cell

$$
\mathrm{Pt}-\mathrm{H}_{2}(p)|\mathrm{HCl}(m)| \mathrm{AgCl}, \mathrm{Ag},
$$

which had been previously reported, 1 had been smoothed with respect to temperature variation by the method of least squares. For the purposes of the present study the original data on $\mathrm{HCl}$ were replotted, and the values of the emf at round temperatures were read from the curves. These values, which differ slightly from those smoothed by least squares, are presented in Table 6.2.

For the purpose of determining the $E^{0}$ of the cell, values of $E^{0}$, , defined by Eq. (1), were calculated for each data point. In this equation

$$
E^{0 \prime}=E+\frac{2 R T}{F} \ln m-\frac{2 R T}{F} \& \frac{\rho^{1 / 2} \sqrt{m}}{1+A \sqrt{m}}
$$

$E$ is the emf at 1 atm $\mathrm{D}_{2}$ at temperature $T, m$ is the molality of the DCl solution (which equals the ionic strength), $F$ is the Faraday constant, is the Debye-Hückel limiting slope (at temperature $T$ ), and $A$ was assigned a constant value of 1.5 in all the present calculations. Multiplication by the square root of the density $\rho$ of the solvent approximately corrects the molality term to one in volume concentration as required by the DebyeHückel equation.

In computing the values of $\rho^{1 / 2}$ at temperature $T$, it is necessary to know the density and dielectric constant of $\mathrm{D}_{2} \mathrm{O}$ as a function of temperature. Values of the density of $\mathrm{D}_{2} \mathrm{O}$ from 30 to $250^{\circ} \mathrm{C}$ are given by Heiks et al., ${ }^{2}$ while the dielectric constant from 4 to $100^{\circ} \mathrm{C}$ has been measured by Malmberg. ${ }^{6}$ Above $100^{\circ} \mathrm{C}$ the dielectric constant of $\mathrm{H}_{2} \mathrm{O}$ was used in preference to extrapolating the $\mathrm{D}_{2} \mathrm{O}$ values, since the experimental values for the two solvents tended to merge at $100^{\circ} \mathrm{C}$, and since different expressions for $\mathrm{D}_{2} \mathrm{O}$

\footnotetext{
5. R. Heiks et al., J. Phys. Chem. 58, 488 (1954).

${ }^{6}$ C. G. Malmberg, J. Res. Nat1. Bur. Std. 60, 609 (1958).
} 
Table 6.2. Values of the EMF in Volts for the Cell $\mathrm{Pt}_{-} \mathrm{H}_{2}(p)|\mathrm{HCl}(\mathrm{m})| \mathrm{AgCl}, \mathrm{Ag}$ and Deviations ${ }^{a}$ of the EMF Values Calculated from Smoothed Activity Coefficients

\begin{tabular}{|c|c|c|c|c|c|c|c|c|}
\hline \multirow{2}{*}{$m$} & \multicolumn{8}{|c|}{ Temperature $\left({ }^{\circ} \mathrm{C}\right)$} \\
\hline & 25 & 60 & 90 & 125 & 150 & 175 & 200 & 225 \\
\hline \multirow[t]{2}{*}{0.005} & 0.4983 & 0.5057 & 0.5065 & & & & & \\
\hline & 3 & -4 & -4 & & & & & \\
\hline \multirow[t]{2}{*}{0.0075} & 0.4778 & 0.4826 & 0.4814 & 0.4759 & & & & \\
\hline & -1 & -11 & -11 & 11 & & & & \\
\hline \multirow[t]{2}{*}{0.01} & 0.4640 & 0.4675 & 0.4654 & 0.4578 & 0.4477 & 0.4350 & 0.4171 & 0.3982 \\
\hline & 3 & -4 & 0 & 17 & 20 & 29 & 11 & -41 \\
\hline \multirow[t]{2}{*}{0.025} & 0.4198 & 0.4181 & 0.4108 & 0.3983 & 0.3855 & 0.3691 & 0.3493 & 0.3252 \\
\hline & 10 & 0 & -6 & 10 & 20 & 25 & 0 & -3 \\
\hline \multirow[t]{2}{*}{0.05} & 0.3861 & 0.3798 & 0.3706 & 0.3545 & 0.3396 & 0.3212 & 0.2984 & 0.2716 \\
\hline & 9 & -12 & -7 & 8 & 22 & 31 & 19 & -9 \\
\hline \multirow[t]{2}{*}{0.075} & 0.3662 & 0.3584 & 0.3473 & 0.3288 & 0.3131 & 0.2934 & 0.2708 & 0.2452 \\
\hline & 7 & -10 & -7 & 4 & 23 & 32 & 36 & 32 \\
\hline \multirow[t]{2}{*}{0.1} & 0.3519 & 0.3436 & 0.3312 & 0.3112 & 0.2945 & 0.2730 & 0.2460 & 0.2224 \\
\hline & 3 & -5 & -4 & 5 & 25 & 25 & -5 & 20 \\
\hline \multirow[t]{2}{*}{0.2} & 0.3187 & 0.3062 & 0.2905 & 0.2685 & 0.2497 & 0.2267 & 0.2021 & 0.1747 \\
\hline & 11 & -10 & -16 & 6 & 26 & 35 & 50 & 58 \\
\hline \multirow[t]{2}{*}{0.5} & 0.2721 & 0.2546 & 0.2357 & 0.2085 & 0.1870 & 0.1631 & 0.1305 & 0.0928 \\
\hline & 13 & -19 & -24 & -17 & 3 & 27 & -14 & -44 \\
\hline \multirow[t]{2}{*}{1.0} & 0.2335 & 0.2125 & 0.1908 & 0.1620 & 0.1385 & 0.1129 & 0.0852 & \\
\hline & 4 & -6 & -5 & 6 & 9 & 11 & 4 & \\
\hline
\end{tabular}

${ }^{a}$ See footnote $a$ of Table 6.1.

gave widely different values on extrapolating to higher temperatures (some higher and some lower than the $\mathrm{H}_{2} \mathrm{O}$ values). The $\mathrm{H}_{2} \mathrm{O}$ values used were computed at each temperature using the equation given by Akerlof and Oshry. ${ }^{7}$

By the use of the Nernst equation and the assumption that the logarithm of the activity, coefficient of $\mathrm{DCl}$ can be expressed at each temperature as the sum of a Debye-Hückel term and a linear term in ionic strength $B m$ (at least to $0.1 \mathrm{~m}$ ), one obtains the relation $E^{0}=E^{0}-(2 R T / F) B m$. With the further assumption that $\Delta C_{p}$ for the cell reaction is independent of temperature, the temperature-dependent equation for $E^{0}$ becomes

${ }^{7}$ G. C. A ${ }^{\circ}$ erlof and H. J. Oshry, J. Am. Chem. Soc. 72,2844 (1950).

$$
\begin{aligned}
E^{0 "}=a_{0}+a_{1} T & +a_{2} T \ln T \\
& -\frac{2 R T}{F}\left(a_{3} / T+a_{4}+a_{5} \ln T\right) m .(2)
\end{aligned}
$$

The values of $E^{0}$ " in the range 0.0102 to $0.1004 \mathrm{~m}$ were fitted by the method of least squares using Eq. (2) to determine the six coefficients $a_{0}$, $a_{1}, \ldots, a_{5}$. The three terms involving $a_{0}, a_{1}$, and $a_{2}$ give the value of $E^{0}$ for the cell at any temperature $T$, while the terms involving $a_{3}, a_{4}$, and $a_{5}$ give the linear term $B$ in the expression for the logarithm of the activity coefficient of $\mathrm{DCl}$. In carrying out the least-squares determination each data point was assigned a weight equal to the reciprocal of the product of the absolute 
temperature and the molality (the two independent variables) associated with the point. This scheme of weighting effectively equalized the contribution of each data point to the overall fit. The values of $E^{0}$ were calculated both on a molal basis and on an equal-moles-of-solvent basis (i.e., moles of solute per 55.51 moles of solvent rather than $1000 \mathrm{~g}$ of solvent) and are presented in Table 6.3, while the coefficients for Eq. (2) are given in Table 6.4 .
The values of $E^{0 "}$ for $\mathrm{DCl}$ were also fitted to an equation in which $T^{2}$ was used instead of $T \ln$ $T$. In this case the standard error of fit was slightly larger than when the $T \ln T$ term was used $\left(2.6 \times 10^{-8}\right.$ vs $\left.1.4 \times 10^{-8}\right)$. Since Eq. (2) is based on the thermodynamic assumption that $\Delta C_{p}$ is constant while the equation involving $T^{2}$ is purely empirical, and since the standard error of fit is smaller when the $T \ln T$ term is used, only the coefficients and $E^{0}$ values obtained in

Table 6.3. Values of the Standard Potentials $E^{0}$ in Volts of the Cells: $\mathrm{Ag}, \mathrm{AgCl}$ vs Hydrogen and vs Deuterium Electrodes

\begin{tabular}{|c|c|c|c|c|c|c|c|c|}
\hline \multirow{4}{*}{$\begin{array}{l}\text { Temp } \\
\left({ }^{\circ} \mathrm{C}\right)\end{array}$} & \multicolumn{5}{|c|}{$E^{0}(v)$} & \multicolumn{3}{|c|}{$\Delta E^{0}(\mathrm{HCl}-\mathrm{DCl})(\mathrm{mv})$} \\
\hline & \multicolumn{3}{|c|}{$\mathrm{D}_{2}-\mathrm{DCl}$} & \multicolumn{2}{|c|}{$\mathrm{H}_{2}-\mathrm{HC} 1$} & \multicolumn{2}{|c|}{ Molal Basis } & \multirow{3}{*}{$\begin{array}{l}\text { Equal-Moles-of- } \\
\text { Solvent Basis }\end{array}$} \\
\hline & \multicolumn{2}{|c|}{ Molal Basis } & \multirow{2}{*}{$\begin{array}{l}\text { Equal-Moles-of- } \\
\text { Solvent Basis }\end{array}$} & \multirow{2}{*}{ This Work } & \multirow{2}{*}{ Ref. 8} & \multirow{2}{*}{ This Work } & \multirow{2}{*}{ Ref. 8} & \\
\hline & This Work & Ref. 8 & & & & & & \\
\hline 25 & 0.2094 & 0.2127 & 0.2146 & 0.2220 & 0.2224 & 12.6 & 9.7 & 7.4 \\
\hline 50 & $(0.1913)$ & 0.1931 & & $(0.2052)$ & 0.2046 & (13.9) & 11.5 & \\
\hline 60 & 0.1828 & & 0.1886 & 0.1973 & & 14.5 & & 8.7 \\
\hline 90 & 0.1531 & & 0.1594 & 0.1699 & & 16.8 & & 10.5 \\
\hline 125 & 0.1111 & & 0.1180 & 0.1313 & & 20.2 & & 13.3 \\
\hline 150 & 0.0766 & & 0.0838 & 0.0998 & & 23.2 & & 16.0 \\
\hline 175 & 0.0386 & & 0.0462 & 0.0650 & & 26.4 & & 18.8 \\
\hline 200 & -0.0027 & & 0.0053 & 0.0274 & & 30.1 & & 22.1 \\
\hline 225 & -0.0471 & & -0.0388 & -0.0131 & & 34.0 & & 25.7 \\
\hline
\end{tabular}

Table 6.4. Parameters of Eq. (2)

\begin{tabular}{cccc}
\hline Parameter & DCl (molal basis) & $\begin{array}{c}\text { DC1 } \\
\text { (equal-moles-of-solvent bas is) }\end{array}$ & -0.235985 \\
$a_{0}$ & -0.308117 & -0.310350 & 0.0136202 \\
$a_{1}$ & 0.0151850 & 0.0152514 & -0.00212092 \\
$a_{2}$ & -0.00236052 & -0.00236780 & -4.17975 \\
$a_{3}$ & -16.4883 & -14.7245 & 27.9216 \\
$a_{4}$ & 113.631 & 101.579 & -1161.13 \\
$a_{5}$ & -5979.35 & -5355.82 & $1.6 \times 10^{-8}$ \\
$\sigma_{f}{ }^{a}$ & $1.3 \times 10^{-8}$ & $1.3 \times 10^{-8}$ & \\
\hline
\end{tabular}

${ }^{a}$ Standard error of fit. 
the former case are tabulated. Attempts were also made to fit an equation like (2) in which quadratic terms in $T$ were added to the expressions for $E^{0}$ and $B$; such expressions would be consistent with a linear dependence of $\Delta C$ on $T$. However, the least-squares procedure (on a computing machine) would not converge, presumably because the data are not sufficiently precise to evaluate the coefficients of both $T \ln T$ and $T^{2}$ terms.

For comparison purposes values of $E^{0}$ " were also computed for $\mathrm{HCl}$ and fitted using Eq. (2). The values of $E^{0}$ so obtained, as well as the coefficients of Eq. (2) for $\mathrm{HCl}$, are also given in Tables 6.3 and 6.4. It is interesting to note that the value of $E^{0}$ for the cell involving $\mathrm{DCl}$ and $\mathrm{D}_{2} \mathrm{O}$ is lower than that of the corresponding protonated system and that this difference becomes larger the higher the temperature.

The standard emf of the cell

$$
\mathrm{Pt}^{-\mathrm{D}_{2}}(\mathrm{p})|\mathrm{DCl}(\mathrm{m})| \mathrm{AgCl}, \mathrm{Ag}
$$

has recently been determined from 5 to $50^{\circ} \mathrm{C}$ by Gary, Bates, and Robinson. ${ }^{8}$ In Table 6.3 their $E^{0}$ and $\Delta E^{0}\left(E_{\mathrm{HCl}}^{0}-E_{\mathrm{DCl}}^{0}\right)$ values at 25 and $50^{\circ} \mathrm{C}$ are compared with ours (our calculated values at $50^{\circ} \mathrm{C}$ being enclosed in parentheses). The difference between the two values of $E^{0}$ for the deuterated system at each temperature appears to be larger than expected. The difference may in part result from the methods of smoothing as to temperature and concentration.

\footnotetext{
${ }^{8}$ Robert Gary, R. G. Bates, and R. A. Robinson, $J$. Phys. Chem. (in press).
}

After the $E^{0}$ values for the cells had been determined, Eq. (3) was used to calculate an activity coefficient value $y$ for each experimental concentration at each round temperature to $225^{\circ} \mathrm{C}$ over

$$
E=E^{0}-\frac{2 R T}{F} \ln m-\frac{2 R T}{F} \ln \gamma
$$

the entire concentration range 0.0102 to $1.127 \mathrm{~m}$ for $\mathrm{DCl}$ and 0.005 to $1.0 \mathrm{~m}$ for $\mathrm{HCl}$. These activity coefficients were then fitted by the method of least squares using Eq. (4),

$$
\log y=\frac{-£ \rho^{1 / 2} \sqrt{m}}{1+1.5 \sqrt{m}}+B m+C m^{2}
$$

where $B$ and $C$ were taken as

$$
B=b_{0} / T+b_{1}+b_{2} \log T
$$

and

$$
\mathrm{C}=\mathrm{c}_{0} / T+\mathrm{c}_{1}+\mathrm{c}_{2} \log T,
$$

consistent with $\Delta C_{p}$ equal to a constant.

The values of the parameters $b_{0}, b_{1}, b_{2}, c_{0}$, $c_{1}$, and $c_{2}$ which were obtained in the fits to Eq. (4) are given in Table 6.5. For concentrations below $0.1 \mathrm{~m}$ the parameters in Table 6.4 should give more nearly correct values for the activity coefficients.

Values of the emf $E$ were calculated from the $E^{0}$ values and the smoothed values of the activity coefficients for the experimental conditions in

Table 6.5. Parameters of Eq. (4) Which May Be Used to Calculate the Activity Coefficients of $\mathrm{DCl}$ and $\mathrm{HCl}$

\begin{tabular}{cccc}
\hline Parameter & DCl (molal basis) & $\begin{array}{c}\text { DC1 } \\
\text { (equal-moles-of-solvent basis) }\end{array}$ & HC1 \\
\hline$b_{0}$ & -1935.96 & -1637.96 & -20.7158 \\
$b_{1}$ & 39.9021 & 33.7150 & 6.85004 \\
$b_{2}$ & -13.4953 & -11.3949 & -1381.23 \\
$c_{0}$ & 2505.34 & 1834.31 & 25.9846 \\
$c_{1}$ & -51.6705 & -37.7763 & -8.64215 \\
$c_{2}$ & 7.60646 & 12.8003 & $8.5 \times 10^{-6}$ \\
$\sigma_{f}$ & $2.3 \times 10^{-6}$ & $2.1 \times 10^{-6}$ & \\
\hline
\end{tabular}


both $\mathrm{DCl}$ and $\mathrm{HCl}$ solutions by the use of Eqs. (3) and (4). The algebraic differences between the observed $E$ values and those calculated with the smoothed coefficients are given below the observed $E$ values in Tables 6.1 and 6.2.

By the use of the parameters in Table 6.5 values of $\log y$ for both $\mathrm{HCl}$ and $\mathrm{DCl}$ (on an equal-molesof-solvent basis) vs $\sqrt{m}$ at 25,90 , and $200^{\circ} \mathrm{C}$ were calculated; these are shown in Fig. 6.1.

As seen in Fig. 6.1, (1) the activity coefficient of $\mathrm{DCl}$ (in $\mathrm{D}_{2} \mathrm{O}$ ) is lower than that of $\mathrm{HCl}$ in $\mathrm{H}_{2} \mathrm{O}$ at all temperatures and concentrations; (2) the difference between the two activity coefficients is greater at 25 and $200^{\circ} \mathrm{C}$ than at $90^{\circ} \mathrm{C}$; and (3) for any curve the lower the minimum value of the activity coefficient (vs $\sqrt{m}$ ) the higher the value of $m$ at the minimum. The fact that the $\mathrm{DCl}$ curves at 25 and $90^{\circ} \mathrm{C}$ lie below the $\mathrm{HCl}$ curves is consistent with a lower dielectric constant for

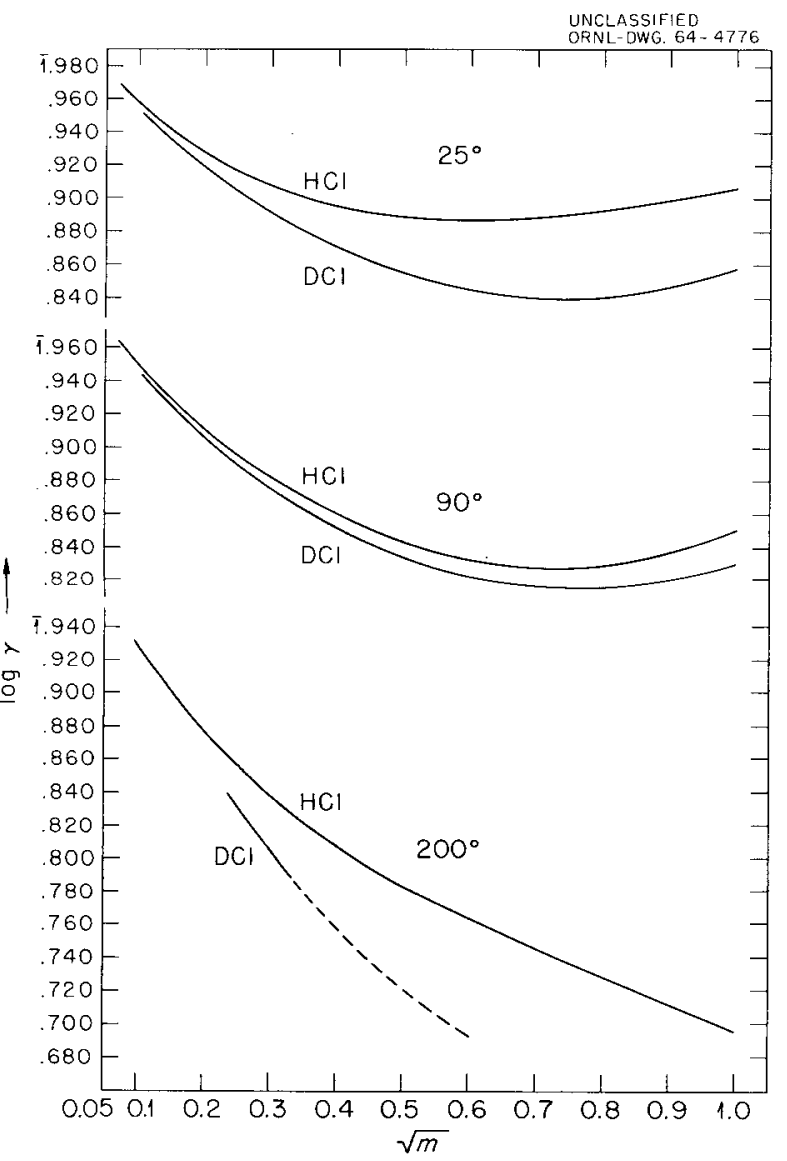

Fig. 6.1. Plots of $\log \gamma$ vs $\sqrt{m}$ for $\mathrm{HCl}$ and $\mathrm{DCl}$ Solutions at 25,90 , and $200^{\circ} \mathrm{C}$.
$\mathrm{D}_{2} \mathrm{O}$ at each temperature. The fact that the two curves are closer together at 90 than at $25^{\circ} \mathrm{C}$ is consistent with a smaller difference in dielectric constant at the higher temperature. Interestingly enough, the difference at $200^{\circ} \mathrm{C}$ is consistent with a greater difference in dielectric constant at that temperature than at $90^{\circ} \mathrm{C}$. This would imply that values of the two dielectric constants become closer together at about $100^{\circ} \mathrm{C}$ and then diverge again at the higher temperature with that of $\mathrm{D}_{2} \mathrm{O}$ always remaining lower than that of $\mathrm{H}_{2} \mathrm{O}$. It is hoped that accurate measurements be made of the dielectric constant of $\mathrm{D}_{2} \mathrm{O}$ above $100^{\circ} \mathrm{C}$ in order to check this suggestion.

The partial molal free energy $\vec{G}$, entropy $\bar{S}$, and enthalpy $\vec{H}$ for either $\mathrm{DCl}$ or $\mathrm{HCl}$ may be expressed in terms of the standard values and the parameters in Table 6.5 by the following equations:

$$
\begin{aligned}
\bar{G}-\bar{G}^{0}=4.606 R T & {\left[\log m-\frac{\rho^{1 / 2} \sqrt{m}}{1+1.5 \sqrt{m}}\right.} \\
+ & \left(\frac{b_{0}}{T}+b_{1}+b_{2} \log T\right) m \\
& \left.+\left(\frac{c_{0}}{T}+c_{1}+c_{2} \log T\right) m^{2}\right] \\
\bar{S}-\bar{S}^{0}=4.606 R & {[-\log m} \\
+ & \frac{\sqrt{m}}{1+}+1.5 \sqrt{m} \frac{\partial}{\partial T}\left(T \rho^{1 / 2}\right) \\
- & \left(b_{1}+b_{2} \log T+\frac{b_{2}}{2.303}\right) m \\
& \left.-\left(c_{1}+c_{2} \log T+\frac{c_{2}}{2.303}\right) m^{2}\right]
\end{aligned}
$$

and

$$
\begin{gathered}
\bar{H}-\bar{H}^{0}=4.606 R T\left\{-\frac{\sqrt{m}}{1+1.5 \sqrt{m}}\right. \\
\quad \times\left[\& \rho^{1 / 2}-\frac{\partial}{\partial T}\left(T \& \rho^{1 / 2}\right)\right] \\
\left.+\left(\frac{b_{0}}{T}-\frac{b_{2}}{2.303}\right) m+\left(\frac{c_{0}}{T}-\frac{c_{2}}{2.303}\right) m^{2}\right\},
\end{gathered}
$$

where \& has the value consistent with Eq. (4), that is, on a common-logarithm basis. 


\section{A Comporis on of Several Methods for Inverting Large Symmetric Positive Definite Matrices}

\section{H. Lietzke R. W. Stoughton}

Introduction. - In any least-squares fit involving the determination of a large number of parameters the accumulation of round-off error during the course of the computation, resulting in a loss of significance, is one of the most serious restrictions. Since the evaluation of a large number of parameters and their variances by a least-squares procedure on a high-speed computer involves the inversion of a symmetric, positive-definite matrix, it becomes important to choose an inversion scheme in which the effects of the accumulation of round-off error are minimized. This is especially true if limited memory space for storage precludes the use of double-precision arithmetic. In this report a comparison of several direct methods for inverting such matrices is given. An attempt has been made to consider the effects of both condition and order of the matrix to be inverted on the closeness of the computed inverse to the exact inverse.

The matrix inversion methods compared are the Gauss-Jordan, ${ }^{9}$ Choleski, ${ }^{10}$ congruent transformation, ${ }^{11}$ and rank annihilation ${ }^{12}$ schemes. To give a fair comparison of the methods, each was programmed in IBM 7090 FORTRAN II (version 2) using only single-precision arithmetic (good to about eight decimal digits). The error indicators were then computed using double-precision arithmetic (good to about 16 decimal digits) so that the latter calculation was not a limiting factor. In the following discussion the symbols for matrices will be underlined while other symbols will not be.

The Test Matrices. - The first matrix chosen for testing the inversion routines was $\underline{A}^{*}$ where the elements $a_{i j}$ of $\underline{\mathrm{A}}$ are given by

$$
a_{i j}=\left\{\begin{aligned}
2 & (i=j) \\
-1 & (|i-j|=1) \\
0 & (|i-j|>1) .
\end{aligned}\right.
$$

\footnotetext{
${ }^{9}$ Anthony Ralston and H. S. Wilf, Mathematical Methods for Digital Computers, p. 39, Wiley, New York, 1960.

${ }^{10}$ Contribution to the Solution of Systems of Lineat Equations and the Determination of Eigenvalues, p. 31, U.S. Department of Commerce, National Bureau of Standards Applied Mathematics Series 39, 1954.
}

The inverse of $\underline{A}$ is given by $\underline{C} /(n+1)$ where the elements $c_{i j}$ of $\underline{\underline{C}}$ are given by

$$
c_{i j}= \begin{cases}i(n-i+1) & (i=j) \\ c_{i, j-1}-i & (j>i) \\ c_{j i}=c_{i j} & (j<i),\end{cases}
$$

and $n$ is the order of the matrix; $\underline{A}$ is a symmetric positive definite matrix; it has a $P$-condition number ${ }^{13}$ of approximately $4 n^{2} / \pi^{2}$. In respect to both form and condition the matrix $\underline{A}$ is analogous to a least-squares matrix derived from a welldesigned experiment. In addition to $\underline{A}$ the matrices $\underline{A}^{2}$ and $\underline{A}^{3}$ were also inverted. The inverse of $\underline{A}^{2}$ is given by $\underline{C}^{2} /(n+1)^{2}$, while the inverse of $\underline{A}^{3}$ is given by $\overline{\mathrm{C}}^{3} /(n+1)^{3}$. The latter two matrices have $P$-condition numbers of $16 n^{4} / \pi^{4}$ and $64 n^{6} / \pi^{6}$ respectively and are hence progressively more illconditioned. In this respect they correspond to least-squares matrices derived from increasingly more poorly designed experiments.

In addition to the three matrices just mentioned, two other test matrices were used. They are $B$, whose elements $b_{i j}$ are given by

$$
b_{i j}= \begin{cases}2 & (i=j) \\ 1 & (i \neq j)\end{cases}
$$

and $\underline{\mathrm{D}}$, whose elements $d_{i j}$ are given by

$$
d_{i j}=n-|i-j|
$$

The exact inverse of $\underline{B}$ is given by $\underline{B}$ INV whose elements $b i n v_{i j}$ are

$$
b i n v_{i j}=\left\{\begin{array}{lll}
n /(n+1) & \text { if } & i=j \\
-1 /(n+1) & \text { if } & i \neq j
\end{array}\right.
$$

while the exact inverse of $\underline{D}$ is given by DINV whose elements $d i n v_{i j}$ are

\footnotetext{
${ }^{11}$ W. R. Busing and H. A. Levy, Commun, Assoc. Computing Machinery 5, 445 (1962).

${ }^{12}$ Anthony Ralston and H. S. Wilf, op. cit., p. 73.

${ }^{13}$ Morris Newman and John Todd, J. Soc. Ind. Appl. Math, 6, 466 (1958).
} 


$$
\operatorname{dinv}_{i j}= \begin{cases}(n+2) /(2 n+2) & \text { if } i=j=1 \text { or } n \\ 1 & \text { if } i=j \neq 1 \text { or } n \\ -1 / 2 & \text { if }|i-j|=1 \text { and } n \neq 2 \\ -1 / 3 & \text { if }|i-j|=1 \text { and } n=2 \\ 1 /(2 n+2) & \text { if }|i-j|=n-1=1 \\ 0 & \text { if } 1<|i-j|<n-1 .\end{cases}
$$

The Error Indicators. - In carrying out the comparison of the various inversion methods the test matrix was generated and inverted by each method to give (M) $)^{-1}$ approx. Then the exact inverse was generated (using the above formulas and doubleprecision arithmetic) and as a measure of error the quantity $Q$ defined as

$$
Q=\left(1 / n^{2}\right) \sum_{i j}\left|(\underline{\mathrm{M}})_{\mathrm{exact}}^{-1}-(\underline{\mathrm{M}})_{\mathrm{approx}}^{-1}\right|_{i j}
$$

was computed for each method, where $\mathrm{M}$ represents the matrix inverted. The computations were performed with matrices of order $10,15,20,25$, and 30. In addition to $Q$ two other quantities, recommended as error measures by Newman and Todd, ${ }^{13}$

$$
a=\left(1 / n^{2}\right) \underset{i j}{\mathbf{\Sigma}}\left|\boldsymbol{r}_{i j}\right|
$$

and

$$
f=(1 / n)\left\{\sum_{i j} r_{i j}^{2}\right\}^{1 / 2},
$$

were calculated, where $\underline{\mathrm{R}}=\left(r_{i j}\right)$ is the error matrix taken as

$$
\underline{\mathrm{R}}=(\underline{\mathrm{M}})_{\mathrm{approx}}^{-1}(\underline{\mathrm{M}})-I,
$$

where $I$ is the identity matrix. The number $Q$ obviously reflects the per term average of the overall difference between the approximate inverse matrix and the exact inverse matrix.

Results of the Computations. - The $\underline{A}$ Matrix. All the methods tried gave an approximate inverse that was very close to the exact inverse of the $A$ matrix for all orders from 10 to 30 except the rank annihilation method, in which case the routine used failed to invert the $A$ matrix. The reason for this failure was evidently peculiar to the exact integers in the matrix and the particular computer procedure for the rank annihilation method; the procedure could undoubtedly be rewritten to obviate this particular failure although it was not considered warranted in the current comparative study. Hence, any one of the methods would be suitable for a well-conditioned least-squares matrix in this range. All elements of the inverse matrix produced by the congruent transformation method were good to one in the eighth significant figure even for order 30. The Gauss-Jordan method and the Choleski method were close behind in that order. Not only did the congruent transformation method produce an inverse closest to the exact inverse of the $A$ matrix but the values of $a$ and $f$ [as defined by Eqs. (2) and (3)] computed from the approximate inverse were lower than the corresponding values derived from the Gauss-Jordan and Chloeski inversion routines. All the methods produced inverse matrices, all elements of which were smaller in magnitude than the exact inverse for all orders from 10 to 30. (The reason for this is unknown.)

The $\underline{A}^{2}$ Matrix. - In the inversion of the $\underline{A}^{2}$ matrix the effect of the condition of the matrix starts to become apparent. This matrix is not as well conditioned as the A matrix; in fact, its condition number is the square of the condition number for the $\underline{A}$ matrix and hence is proportional to the fourth power of the order.

In the inversion of the $\underline{A}^{2}$ matrix for all orders from 10 to 30 the Gauss-Jordan method produced an inverse matrix closest to the exact inverse. The congruent transformation, the Choleski, and the rank annihilation methods gave very similar results and were somewhat inferior to the GaussJordan method. All elements of the inverse matrix produced by the latter method were good to one part in 600,000 for order 10 to one part in 20,000 for order 30 . The corresponding figures for the other methods were one part in about 150,000 for $n=10$ to one part in about 3000 for $n=30$.

The $A^{3}$ Matrix. - The values of $Q$ computed for the $\underline{A}^{3}$ matrix indicated that the Gauss-Jordan routine produced an inverse matrix closest to the exact inverse for all orders from 10 to 30 . A1l elements of the inverse matrix produced by this routine are good to one part in 80,000 for $n=10$, to one part in 1100 for $n=20$, and one part in 400 for $n=30$. Close behind the Gauss-Jordan routine for $n=10$ is the congruent transformation method; however, for $n=15$ to 30 the Choleski method produced a more nearly exact inverse. At 
$n=30$ the rank annihilation method appears slightly better than the congruent transformation method, producing an inverse each element of which is good to one part in 16 .

In addition to the above observations concerning the closeness of the approximate inverse of the $\mathrm{A}^{3}$ matrix to the exact inverse it should be noted that the Gauss-Jordan and congruent transformation routines produced inverse matrices whose elements were, in all cases, smaller in magnitude than those of the exact inverse, while the inverse matrices produced by the rank annihilation method were for all orders greater than the exact inverse. The Choleski routine produced an inverse matrix at orders 10 and 15 with elements smaller than those of the exact inverse, while at orders 20,25 , and 30 the inverse matrix elements were greater than those of the exact inverse. The low value of $Q$ at $n=15$ for the Choleski method reflects the fact that the elements of the approximate inverse are passing through a transition from all being too small to all being too large.

The $\underline{B}$ Matrix. - The $\underline{\mathrm{B}}$ matrix is apparently so well conditioned that all four methods produced inverse matrices very close to the true inverse. In fact the inverse matrix produced by the rank annihilation routine varied at most by one in the eighth significant figure from the exact inverse, and the values of $Q$ computed were in all cases 0.0 to eight decimal digits.

The $\underline{D}$ Matrix. - The $\underline{\mathrm{D}}$ matrix is also well conditioned and all the methods except the rank annihilation method produced inverse matrices close to the exact inverse. The rank annihilation routine failed to invert properly the $\underline{D}$ matrix, undoubtedly because of the peculiar form of this matrix and the peculiarities of the computer program as written.

A Comparison of the Indices of Error $a, f$, and Q. - The following observations may be made concerning the results of the computations:

1. The value of $a$ is, in all cases, lower than the value of $t$.

2. The values of $a$ and $f$ are not, by themselves, reliable estimates of the closeness of the computed inverse to the exact inverse. For example, if the $a$ and $f$ values alone were used to compare the approximate inverses of the $\mathrm{A}^{3}$ matrix produced by the various inversion methods, then the congruent transformation method would appear to be as good as the
Gauss-Jordan method. However, the GaussJordan routine produced an inverse for $n=30$ good to one part in 400 while the inverse produced by the congruent transformation method was good only to one part in 15 . Thus the $Q$ values (which follow this pattern) reflect the observed relation between the exact and approximate inverse matrices while the $a$ and $f$ values may not. A possible explanation in the latter case may be in the fact that the $\underline{A}^{3}$ matrix contains elements of alternating sign while all the elements of the inverse matrix are positive. Hence there may be some cancellation of errors in forming the $(\underline{M})_{\text {approx }}^{-1} \underline{M}$ product in Eq. (4), this effect becoming more pronounced as the matrix becomes more illconditioned. Also the $\mathrm{A}^{3}$ matrix contains many zeros (in fact a higher proportion the larger the order) and hence the errors in some of the inverse matrix elements do not show up in the $a$ and $f$ values.

As shown above, the value of $Q$, defined by Eq. (1), reflects the overall difference between the approximate inverse matrix and the exact inverse matrix. This quantity can be computed only if the exact inverse matrix is known, as it is in the case of the test matrices used in this report. In general, however, this will not be the case and yet it is desirable to have some method for estimating at least an upper bound of the difference which does not depend on knowing the exact inverse matrix. Such an upper bound is given by the following inequality: ${ }^{14}$

$$
\left\|\underline{A}^{-1}-\underline{C}\right\| \leqq\|\underline{C} \underline{H}\| /(1-\|\underline{H}\|) ，
$$

where $\underline{A}^{-1}$ is the exact inverse of the matrix $\underline{A}$, $\underline{C}$ is the computed inverse, and $\underline{H}$ is a matrix defined by

$$
\underline{H}=\underline{I}-\underline{A} \underline{C},
$$

where $\underline{I}$ is the identity matrix. (Enclosure within the double vertical lines indicates that the maximum row sum of magnitudes of the elements of the appropriate matrix is taken.)

For comparison purposes values of both the left and right side of the inequality [Eq. (5)] were computed for all the test matrices studied.

${ }^{14}$ A. S. Householder, The Theory of Matrices in Numerical Analysis, chap. 4, Ginn, Boston, 1964. 
It was found that the right side of the inequality [Eq. (5)] was indeed usually greater than the term on the left, which is the maximum row sum of the matrix formed by subtracting the computed inverse from the exact inverse. In the few cases where the inequality did not seem to hold, the apparent violation can probably be attributed to the particular method of rounding used in the arithmetic subroutines of the program and the consequent accumulation of round-off error. Hence it is possible to get an estimate at least of an upper bound of the term on the left of the inequality without knowing the exact inverse of a matrix.

Conclusions. - From the foregoing calculations it appears that any one of the matrix inversion methods tried will invert a well-conditioned leastsquares matrix of order 10 to 30 . When the matrix becomes ill-conditioned, then the Gauss-Jordan method appears to be clearly superior (at least for the matrices studied). However, if memory capacity must be considered and only a triangular array can be tolerated, then the Choleski and congruent transformation methods appear to offer an advantage for large $n$. Only in the case of the relatively poorly conditioned $\underline{A}^{3}$ matrix did the Choleski method appear to be the better of these two for evaluating the inverse matrix. From a study involving the inversion of several wellconditioned least-squares matrices of orders to $n=29$, all the methods tried gave $a$ and $f$ values about two to three orders of magnitude smaller than those obtained with the $\underline{A}^{3}$ matrix and consistent with those obtained with the $\underline{A}$ matrix.

\section{Technique for Spectrophotometry over Wide Ranges of Temperature and Pressure}

\section{W. C. Waggener A. J. Weinberger \\ R. W. Stoughton}

Our latest cell assembly ${ }^{15.16}$ for the standard Cary model 14 spectrophotometer provides routine spectrophotometry of fluid and frozen samples from -80 to $280^{\circ} \mathrm{C}$ and 0 to $2000 \mathrm{psia}$. It has operated flexibly and without trouble for more than 100

\footnotetext{
${ }^{15}$ W. C. Waggener, A. J. Weinberger, and R. W. Stoughton, Chem. Div. Ann. Progr. Rept. June 20, 1962, ORNL-3320, p. 73.

${ }^{16}$ W. C. Waggener, A. J. Weinberger, and R. W. Stoughton, Chem。Div. Ann. Progr。 Rept. June 20, 1963, ORNL-3488, p. 78.
}

runs in studies with a number of pure solvents during the last eight months.

Both the sample cell and the reference cell are designed to permit gas-liquid equilibration and have identical temperature and pressure capabilities. Other features include (1) interchangeability of cells, (2) heating and cooling rates up to $10-15^{\circ} \mathrm{C} / \mathrm{min}$, (3) temperature control to at least $\pm 0.1^{\circ} \mathrm{C}$, (4) borescopic viewing of cell windows and contents, and (5) arrangements which allow necessary operations to be performed without disconnecting piping, namely, (a) addition and withdrawal of samples, $(b)$ metered additions of gases to cells at operating temperature and pressure, (c) cell washing and back-washing, and (d) drying by alternate gas purge and evacuation.

The resolving power and reproducibility of the basic instrument have not been compromised in the adaptation. For example, the base-line absorbance of $\mathrm{D}_{2} \mathrm{O}$ vs $\mathrm{D}_{2} \mathrm{O}$ in $3.81-\mathrm{cm}$ sample and reference cells identically controlled from 5 to $250^{\circ} \mathrm{C}$ was less than \pm 0.01 over the spectral region from 0.4 to $1.8 \mu$.

The Absorption Spectrum of $\mathrm{CO}_{2}$ in the NearInfrared Region as a Function of Temperature from Below the Freezing Point to Above the Critical Point
W. C. Waggener
A. J. Weinberger

R. W. Stoughton

Introduction. - We have made an exploratory study of the effects of temperature upon the nearinfrared bands of liquid $\mathrm{NH}_{3}$, absolute $\mathrm{CH}_{3} \mathrm{CH}_{2} \mathrm{OH}$, $\mathrm{H}_{2} \mathrm{O}$, and $\mathrm{D}_{2} \mathrm{O}$ in the region of the third harmonic of the $\mathrm{NH}, \mathrm{OH}$, and $\mathrm{OD}$ stretching modes and found that these relatively broad, complex bands are orders of magnitude more sensitive to intermolecular forces than are the simpler, much-studied bands of the respective fundamental vibration frequencies. It should be helpful in the further elucidation of intermolecular forces to compare the near-infrared temperature sensitivities of the above liquids in which specific interactions such as $\mathrm{H}$ bonding are a factor with liquids in which general long-range or van der Waals forces alone appear to govern the bulk properties. Carbon dioxide belongs in the latter category. The fact that it is one of the most thoroughly studied molecules, is noncorrosive, and its liquid range 
lies within the capabilities of our spectrophotometric technique made it a logical choice for the present study.

Experimental. - The absorption data were taken with the equipment described in the foregoing section.

Spectral measurements were made with 3.81 $\mathrm{cm}$ titanium cells using $\mathrm{CCl}_{4}$ at $25^{\circ} \mathrm{C}$ in the reference cell. Liquid $\mathrm{CO}_{2}$ was introduced into the evacuated sample cell by direct connection to the stock cylinder ${ }^{17}$ after cooling several degrees below room temperature. Any slight contamination of noncondensable gases was removed by bleeding from the vapor phase until the cell pressure agreed with the vapor pressure of $\mathrm{CO}_{2}$.

The liquid level was adjusted above the optical path during filling, and the position of the meniscus was followed with the aid of the borescope during operation of the cell, particularly near the critical point.

Spectroscopic Measurements. - Our procedure for measuring the spectrum of a sample as a function of temperature and pressure involves adjusting the sample to heat or cool slowly enough so that the data taken are independent of the rate of temperature change. The chart drives for the spectrophotometer and temperature recorders are synchronized with the clock and the spectral range of interest is scanned repetitively. Wavelengths are recorded timewise with a fiducial mark at $100-\mathrm{A}$ or $1000-\mathrm{A}$ intervals. It is then a simple matter to correlate the spectral record with temperature and plot any parameters as a function of temperature.

The above method minimizes the time and effort required for data-taking while optimizing the precision of the measured or related parameters.

The data for $\mathrm{CO}_{2}$ were obtained in the fluid range $\left(-56.6\right.$ to $\left.+65^{\circ} \mathrm{C}\right)$ in separate experiments run at 0.3 and $0.1 \% \mathrm{~min}$. There was no discernible difference in the fits of the two sets of data. In these experiments the scanning speed was 5 $\mathrm{A} / \mathrm{sec}$ with a chart display of $150 \mathrm{~A} / \mathrm{in}$. The minimum resolution of our instrument was $\sim 3.5 \mathrm{~A}$ and the spectral measurements were insensitive to slit changes of $\pm 10 \%$.

An aspect of the versatility of our cell assembly lies in the ability to freeze a sample in situ and examine the corresponding spectrum of the solid.

\footnotetext{
17 Mathes on carbon dioxide, Coleman grade, minimum purity by volume, $99.99 \%$.
}

Samples of $\mathrm{CO}_{2}$ were carefully frozen over periods of 1 to $2 \mathrm{hr}$, the process being followed either visually with the borescope or spectrophotometrically using dispersed radiation $(0.589 \mu)$ through the sample.

The light loss due to scattering in a sample at the freezing point was large but uniform (90 to $95 \%)$ over the region of interest $(1.66$ to $1.25 \mu)$ and nearly constant with time. The established base line rose less than 0.001 of an absorbance unit per minute under stress of the heating effect of the undispersed radiation from the infrared source lamp.

At $-80^{\circ} \mathrm{C}$ the sample was less stable under stress of the infrared heating as indicated by a more rapid rise in the established base line, namely, 0.002 to 0.003 absorbance unit per minute. The increase in slit width necessary to compensate for the scattering in the solid decreased the minimum resolution to $6.1 \mathrm{~A}$.

Results and Discussion. - The spectrum of $\mathrm{CO}_{2}$ in the condensed state exhibits nine principal bands between 1.19 and $1.66 \mu$. Seven of these correspond to the harmonic and combination bands previously studied in gaseous $\mathrm{CO}_{2}$ (ref. 18). In the condensed state the contours of $P$ and $R$ rotation bands observed for the respective bands in the gas are collapsed to single sharp maxima located at the band center of the missing $Q$ branch. These absorption bands in liquid $\mathrm{CO}_{2}$ at its freezing point are quite sharp $\left(\Delta \nu_{1 / 2}=10^{2}\right.$ to $22 \mathrm{~cm}^{-1}$; cf. 200 for $\mathrm{NH}_{3}, \sim 1000$ for $\mathrm{H}_{2} \mathrm{O}$ ) but show considerable temperature broadening (75 to $300 \%$ increase at the critical point; cf. $24 \%$ for $\mathrm{NH}_{3}$ ) due to kinetic effects, characteristic of the relatively weak van der Waals forces. Freezing of the liquid abruptly increases the band heights and decreases the band widths by at least a factor of 2.

The effect of temperature upon the position of the $\mathrm{CO}_{2}$ band maxima above the freezing point is extremely small and linear to $0^{\circ} \mathrm{C}(d \nu / d t$ averaging $0.05 \mathrm{~cm}^{-1} /{ }^{\circ} \mathrm{C}$; cf. 0.27 for $\mathrm{NH}_{3}$ near its freezing point and $\mathrm{H}_{2} \mathrm{O}$ and $\mathrm{D}_{2} \mathrm{O}$ above $100^{\circ} \mathrm{C}$ ). Above $0^{\circ} \mathrm{C} \mathrm{d \nu /dt}$ increases rapidly, reaching 0.2 to 0.5 for the $\mathrm{CO}_{2}$ bands in the transcritical region, which is comparable to $\mathrm{NH}_{3}$ above its critical point. The effects of temperature and change of

\footnotetext{
${ }^{18} \mathrm{G}$. Herzberg, Infrared and Raman Spectra of Poly* atomic Molecules, p. 271, Van Nostrand, New York, 1945.
} 
phase upon these near-infrared bands are consistent with the presence of the weaker intermolecular forces in the case of $\mathrm{CO}_{2}$ compared with the hydrogen-containing molecules.

At this time we are continuing to analyze the data obtained. The $\left(3 \nu_{3}\right),\left(2 \nu_{1}+2 \nu_{2}+v_{3}\right)$, and the $\left(\nu_{1}+4 \nu_{2}+\nu_{3}\right)$ bands are sufficiently intense to allow a reasonably precise study of the effect of temperature upon band contour and other parameters. The third harmonic asymmetric stretch band exhibits a slight asymmetry due to the presence of at least one unresolved component centered on the low-frequency side of the band, and we have not yet attempted its analysis. However, we have found that the $\left(2 \nu_{1}+2 \nu_{2}+\nu_{3}\right)$ and the $\left(\nu_{1}+\right.$ $4 \nu_{2}+\nu_{3}$ ) bands can be fitted to a good approximation over the entire fluid range ( -56.6 to $+65^{\circ} \mathrm{C}$ ) by a Lorenz function which assumes a statistical distribution of perturbations of each molecule by its neighbors.

\section{Hydralysis of Metal Ions; Activity Coefficients in Three-Component Solutions}

\section{J. Aveston ${ }^{19}$ R. M. Rush J. S. Johnson}

During the past year our hydrolysis studies have been mostly of isopolyacids, or anionic hydrolytic polymers. In addition, we have completed evaluation of equilibrium ultracentrifugation as a technique for the study of activity coefficients in three-component aqueous solutions.

Hydrolysis. - Since work on Mo(VI) polyanions carried out since last year's annual report has not modified the conclusions given at that time, we shall deal here with species formed on acidification of tungstate solutions and with the species of $\mathrm{Ta}(\mathrm{V})$ in basic solution.

Tungsten(VI). ${ }^{20}$ - Polytungstates have received attention over the past few decades comparable to polymolybdates, and there are a comparable number of proposals concerning species formed. Many have, however, postulated aggregates consisting of six, or a multiple of six, tungstates, with seven or nine protons bound per six tungstates. (The average number of protons bound per tungstate, p, is given by the stoichiometry for solutions

\footnotetext{
${ }^{19}$ Visiting scientist from the National Chemical Laboratory, Teddington, England.

${ }^{20}$ Some of this work was carried out at the National Chemical Laboratory.
}

having seven or nine moles of $\mathrm{HClO}_{4}$ per six moles of $\mathrm{Na}_{2} \mathrm{WO}_{4}$, since the free acid is negligible.) There are also reports that equilibria in acidified tungstate solutions are reached only slowly at room temperature.

Our ultracentrifugation results confirm these observations and conclusions. With a solution of $\mathrm{p}=7 / 6$ prepared by addition of $\mathrm{HClO}_{4}$ to a solution of $\mathrm{Na}_{2} \mathrm{WO}_{4}$, and containing $1 \mathrm{M}^{4} \mathrm{NaClO}_{4}$ as supporting electrolyte, it was necessary to centrifuge at $50^{\circ} \mathrm{C}$ in order to reach chemical and centrifugation equilibrium in a reasonable time; precipitation eventually occurred from $0.05 M \mathrm{~W}(\mathrm{VI})$ at $25^{\circ} \mathrm{C}$. The values of average degree of polymerization, $N_{w}$, increased with W(VI) concentration, even when computed for zero charge (Fig. 6.2); there is obviously an equilibrium between species of different $N_{w^{*}}$. Since aggregation occurs on addition of acid, and solutions of lower W(VI) concentration are more acidic, it appears that the equilibrium is not very, if at all, dependent on acidity. An identical value of $N_{w}$ was obtained at equilibrium for a $0.05 M \mathrm{~W}(\mathrm{VI})$ solution prepared from sodium paratungstate, a solid having the same value of $\mathbf{p}$; however, centrifugation equilibrium was approached from the direction of higher $N_{w}$, rather than lower $N_{w}$ as in the case of solutions prepared by addition of acid to sodium tungstate.

Extrapolation to zero time of experiments carried out with the columns short in the radial direction

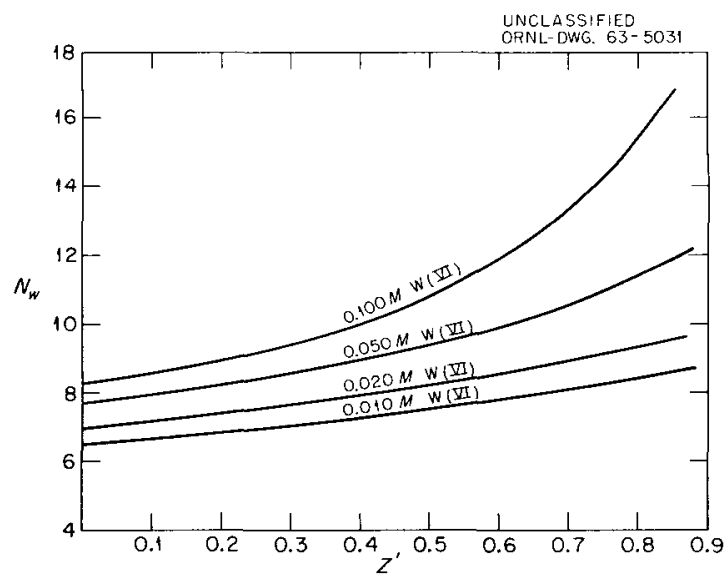

Fig. 6.2. Weight Average Degree of Polymerization of

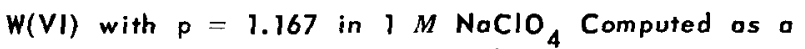
Function of Assumed Charge $z^{\prime}$ per Monomer Unit. Temperature $50^{\circ} \mathrm{C}$. 
(which reach centrifugation equilibrium quickly and thus reflect more accurately the progress of aggregation-deaggregation reactions) indicated that solutions prepared from paratungstate solid initially contained dodecameric tungstate species, which bound sodium ions to a considerable extent. These results are consistent with an $x$-ray study, ${ }^{21}$ on the basis of which dodecameric units in solid sodium paratungstate $\left(\mathrm{Na}_{10} \mathrm{~W}_{12} \mathrm{O}_{41} \cdot 28\right.$ $\mathrm{H}_{2} \mathrm{O}$ ) were proposed. An equilibrium between a hexameric and dodecameric species, both of $p=7 / 6$, was found to fit adequately the values of $N_{w}$ in Fig. 6.2, which were obtained with long columns.

Centrifugation of a solution of $p=1.5$ indicated a monodisperse distribution and a degree of polymerization of about 12 for $z^{\prime}=0.5$. In summary it appears that the principal species formed in solutions of 0.01 to $0.1 M \mathrm{~W}(\mathrm{VI}), \mathrm{p}=7 / 6$, are $\mathrm{HW}_{6} \mathrm{O}_{21}{ }^{5-}$ and $\mathrm{W}_{12} \mathrm{O}_{41}{ }^{10-}$; and at $\mathrm{p}=9 / 6$, $\mathrm{W}_{12} \mathrm{O}_{39}{ }^{6-}$. (Possible waters of hydration and bound sodiums are not indicated in these formulas.)

This scheme was confirmed by acidity measurements. In Fig. 6.3, experimental values of $p$ are compared with curves computed from the formation quotients, defined by

$$
k_{p, q}=\frac{\left[\mathrm{H}_{p}\left(\mathrm{WO}_{4}\right)_{q}{ }^{(2 q-p)-}\right]}{\left[\mathrm{H}^{+}\right]^{p}\left[\mathrm{WO}_{4}{ }^{2-}\right]^{q}} .
$$

The values of $k_{p, q}$ were obtained by a leastsquares fit to all data and are listed in the legend.

A further confirmation of the $(14,12)$ species was obtained by comparison of Raman spectra of a concentrated solution of $p=7 / 6$, in which most of the W(VI) should be in the dodecameric species, with the crystalline paratungstate. The correspondence of the two spectra (Fig. 6.4) indicates that the same species are present in solution and solid.

The scheme differs from those of Sasaki, ${ }^{22}$ based on extensive titrations at 25 and $80^{\circ} \mathrm{C}$; he postulated only a series of protonated hexamers. $\mathrm{His}$ measurements, however, were made shortly after the addition of acid and may refer to the

\footnotetext{
${ }^{21}$ I. Lindquist, Acta Cryst. 5, 667 (1952).

${ }^{22}$ Y. Sasaki, Acta Chem. Scand. 15, 175 (1961): Ab. stracts Proceedings 7th International Conference on Coordination Chemistry, Stockholm, 1962.
}

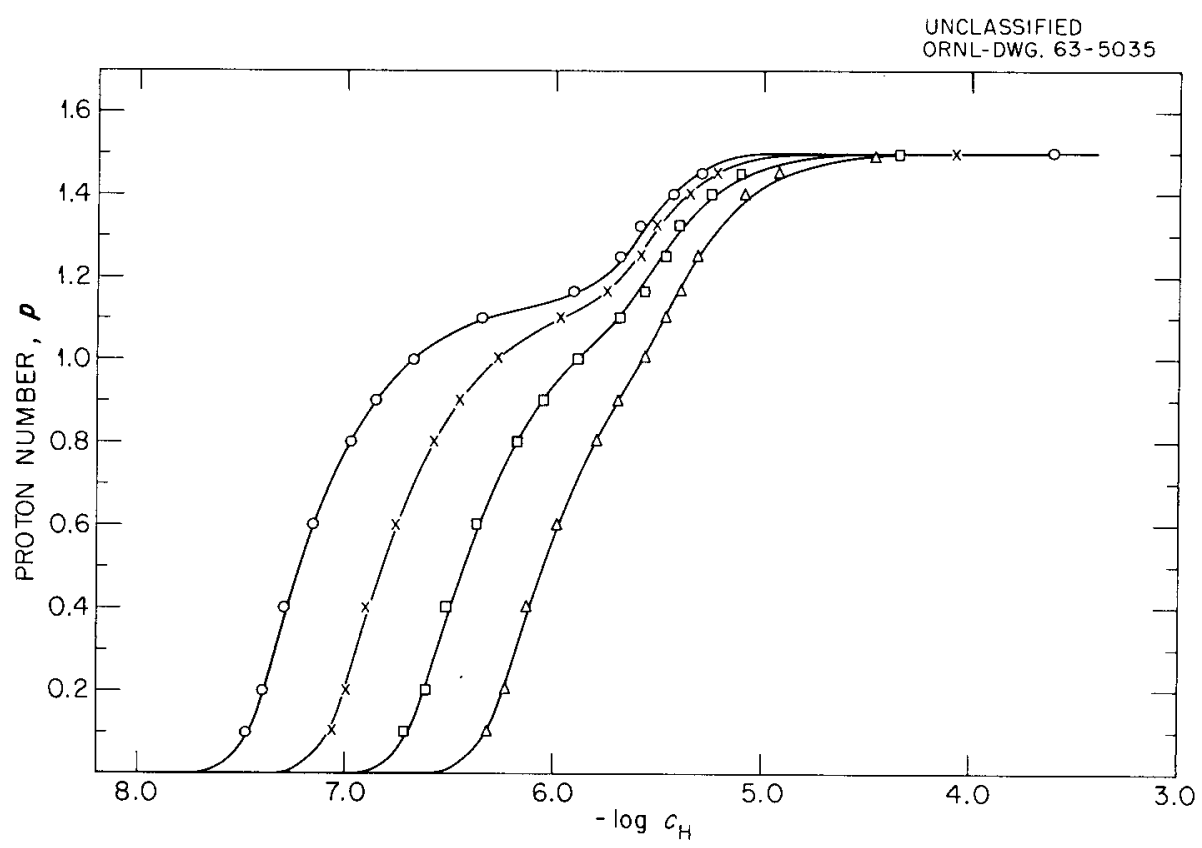

Fig. 6.3. Hydrolysis of $\mathrm{Li}_{2} \mathrm{WO}_{4}$ in $3 \mathrm{M} \mathrm{Li} \mathrm{Cl}, 50^{\circ} \mathrm{C}$. Curves computed with following formation constants: $\log k_{7,6}=53.98, \log k_{14,12}=110.03$, and $\log k_{18,12}=132.51$. Symbols represent total molarity of W(VI) as: $0=0.1986, x=0.0596, \square=0.0179, \Delta=0.00536$. 


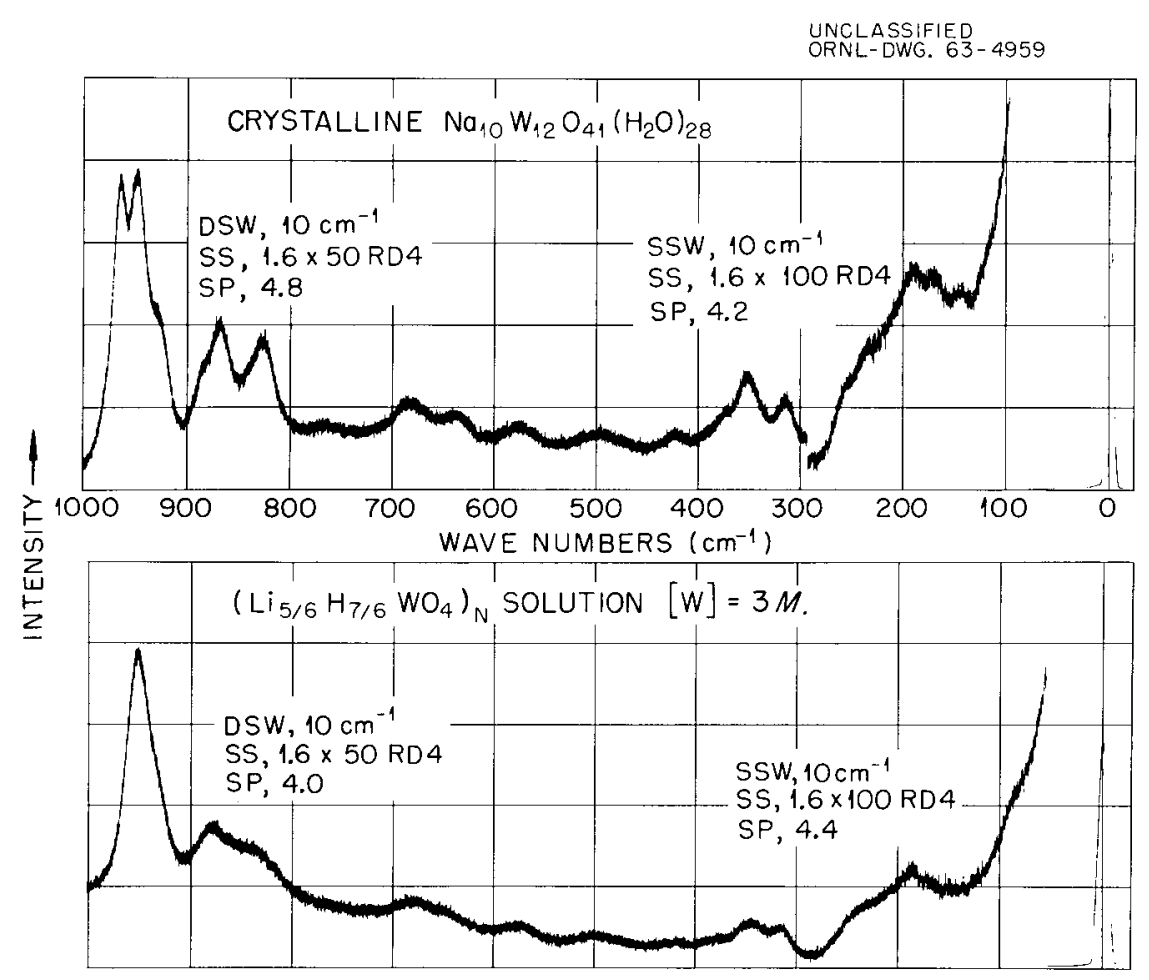

Fig. 6.4. Comparison of Raman Spectra of Crystalline Sodium Paratungstate with Lithium Tungstate Solution Acidified to $p=7 / 6$. Cary model 81; lamp current $13.5 \mathrm{amp}$; scan speed $0.25 \mathrm{~cm} / \mathrm{sec}$. Period control setting 0.5 ; abbreviations: $S S=$ Sensitivity Setting, $S P=$ Suppression Setting, $S S W=$ Single Slit Width, and DSW = Double Slit Width.

initial species formed, rather than the equilibrium species. Acidity measurements in any case are much less sensitive to the hexamer-dodecamer equilibrium than ultracentrifugation.

$T a(V)$. - There have been relatively few studies of the species formed by $\mathrm{Ta}(\mathrm{V})$ in basic solution. Diffusion measurements have been interpreted in terms of a pentamer, whereas Nelson and Tobias ${ }^{23}$ in recent light-scattering and ultracentrifugation measurements of $\mathrm{K}_{1.33} \mathrm{TaO}_{3.16}$ in $1 \mathrm{M} \mathrm{KCl}$ have concluded that hexamers were formed. We have concurrently carried out ultracentrifugation in $1 \mathrm{M}$ $\mathrm{KCl}$ and extended the $\mathrm{pH}$ range of measurements to $1 M \mathrm{KOH}$; our results confirm that hexamers of much less than the maximum possible charge are present (Fig. 6.5). Comparison of the Raman spectra of crystalline $\mathrm{K}_{8} \mathrm{Ta}_{6} \mathrm{O}_{19}$, in which $\mathrm{x}$-ray studies ${ }^{24}$ have indicated hexamers, with spectra

\footnotetext{
${ }^{23}$ W. H. Nels on and R. I. Tobias, Inorg. Chem. 2, 985 (1963).

${ }^{24}$ I. Lindquist and B. Arånss on, Arkiv Kemi 7, 49 (1955).
}

of concentrated tantalate solutions, gives further evidence for this species (Fig. 6.6).

Discussion. - The results for $\mathrm{W}(\mathrm{VI})$ and $\mathrm{Ta}(\mathrm{V})$, in conjunction with the study of $M o(V I)$, from which we concluded that heptameric and octameric polyanions predominate, indicate that metal ions are as individualistic in the formation of negatively charged hydrolytic species as they are with cationic species. The monomeric species found some years back in basic $\mathrm{Pb}$ (II) and $\mathrm{Sn}(\mathrm{IV})$ solutions are another example. There seems to be no definite pattern, even with elements whose chemistry might be expected to be similar, such as $\mathrm{Mo}(\mathrm{VI})$ and $\mathrm{W}(\mathrm{VI})$. The examples cited here confirm that some of the structures found in hydrolyzed solids are also found in solution, and it appears that the large number of basic and polyanionic salts may be paralleled by a similar complexity in aqueous media. It is still possible to hope, however, that all of the multitude of species found in solid phases may not occur, or at least not be very important, in solution. 
Fig. 6.5. Reciprocal of Degree of Polymerization, $N$, of $\mathrm{Ta}(\mathrm{V})$ Computed as a Function of Assumed Charge per Monomer Unit, $Z^{\prime}$. Solid lines refer to $1 M \mathrm{KCl}$ and broken lines to $1 M \mathrm{KOH}$ supporting electrolytes.

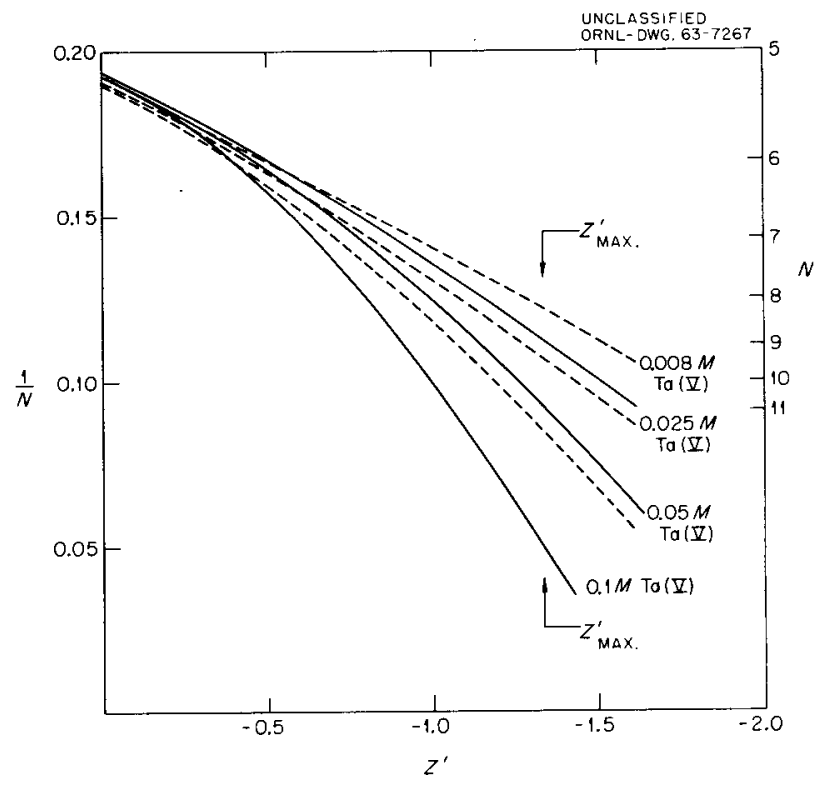

UNCLASSIFIED
ORNL-OWG. $63-7593$

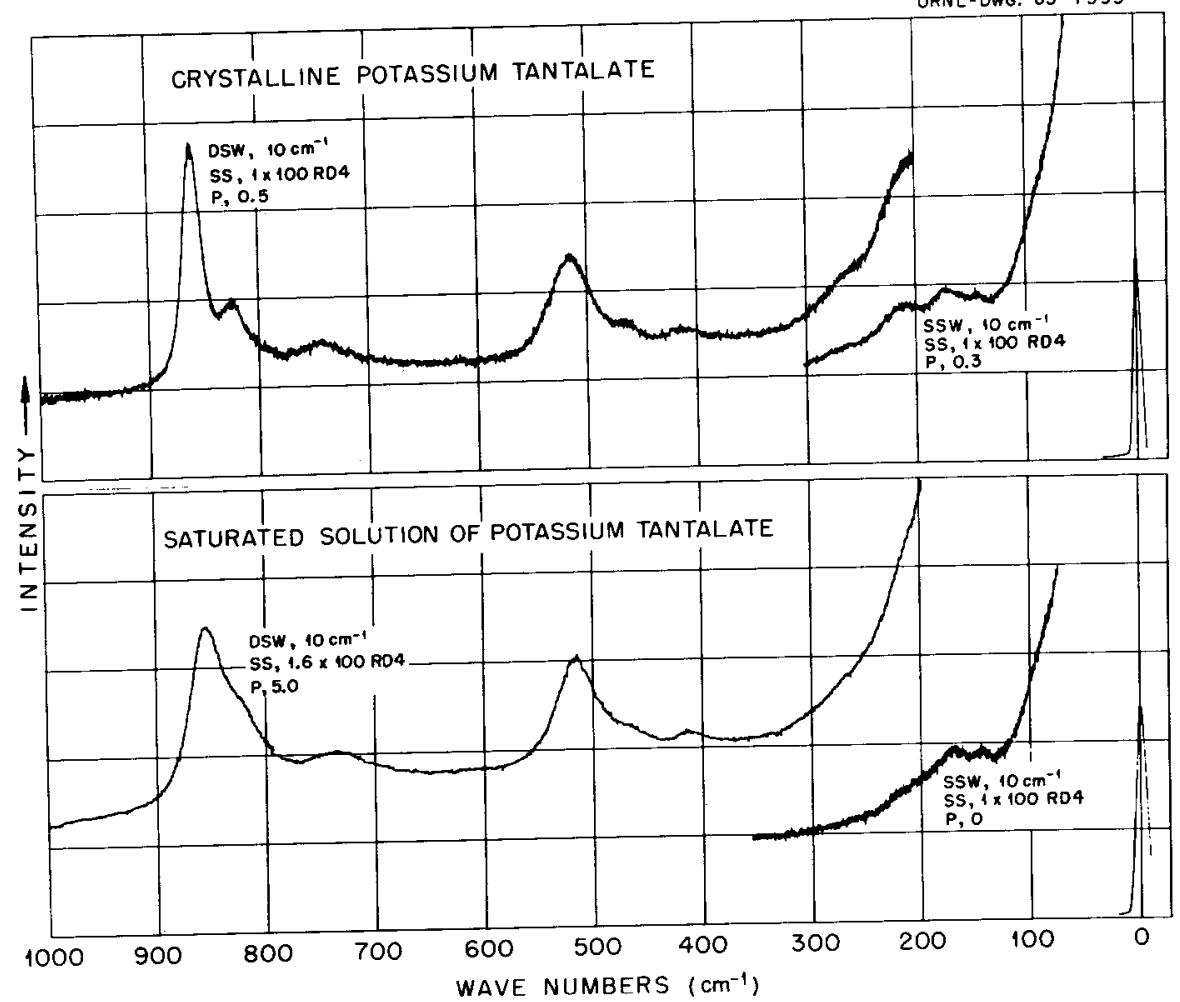

Fig. 6.6. Comparison of Raman Spectra of Potassium Tantalate in Solution with Crystalline $\mathrm{K}_{8} \mathrm{Ta}_{6} \mathrm{O}{ }_{19} \cdot 16 \mathrm{H}_{2} \mathrm{O}$ Abbreviations: $S S=$ Sensitivity Setting, SSW = Single Slit Width, DSW = Double Slit Width, and P = Period Control. 
Activity Coefficients of Three.Component Solutions by Equilibrium Ultracentrifugation. - Assumptions concerning ideality of three-component solutions are basic, among other things, to studies of complex formation, of ion exchange and solvent extraction, of biochemical processes, and to molecular weight determination by light scattering or ultracentrifugation. There are, however, very few data available concerning activity coefficients of three-component systems about which one can be fairly confident concerning the nature of the species present in solution; with such data, one would be in a better position to estimate validity of ideality assumptions in unknown cases.

We have tested equilibrium ultracentrifugation by a study of the $\mathrm{BaCl}_{2}-\mathrm{HCl}-\mathrm{H}_{2} \mathrm{O}$ system to see what contribution to filling this gap might be possible by the technique. Interpretation involved finding parameters in empirical equations for activity coefficients which gave agreement between experimental and computed equilibrium interference fringe patterns. These parameters must be consistent with the Bjerrum restriction

$$
\nu_{A}\left(\frac{\partial \log \gamma_{ \pm A}}{\partial m_{B}}\right)_{m_{A}}=\nu_{B}\left(\frac{\partial \log \gamma_{ \pm_{B}}}{\partial m_{A}}\right)_{m_{B}},
$$

$\nu_{i}$ being moles of ions per mole of solute $i ; \gamma_{ \pm}$ mean ionic activity coefficient; and $m$, molality. Here, and probably in most cases of interest, only the terms involving the concentration of both solutes need be determined, since activity coefficients for many two-component systems are available in the literature. In addition, for the case in question, since $\mathrm{HCl}$ obeys Harned's linear relationship,

$$
\log \gamma_{ \pm \mathrm{HC} 1}=\log \gamma_{ \pm \mathrm{HC} 1}^{0}-\alpha_{12} I_{\mathrm{BaCl}_{2}},
$$

very closely, the problem was to evaluate $\alpha_{12}$ and its variation with total ionic strength, $I .{ }^{12}$ The superscript ( 0$)$ indicates the activity coefficients of $\mathrm{HCl}$ in a two-component $\mathrm{HCl}$-water solution of the same ionic strength as the mixed solution in question.

Some other techniques were unconventional besides analysis by comparison of computed and experimental refractive index patterns. In the background compartment of the ultracentrifuge cell we placed a two-component solution of known activity coefficients, whose distribution could be computed,

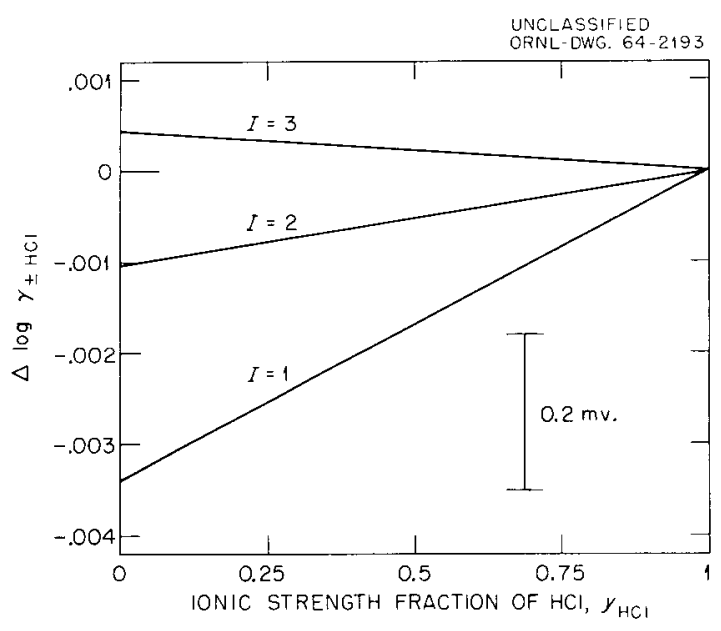

Fig. 6.7. Deviations of log $\gamma_{ \pm \mathrm{HCl}}$ from the Ultracentrifuge Results from Those Given by EMF.

at a concentration which made the effective light path approximately equal to that in the other compartment; in this way, good fringes were obtained in spite of the high concentrations involved. Corrections for the effect of pressure on refractive indices were made through the Tait-Gibson equations for compressibility, combined with the Gladstone-Dale or Lorenz-Lorentz equations for refractivity.

An indication of the capabilities of the technique in its present development is given in Fig. 6.7, a comparison of our ultracentrifugation results with emf data. ${ }^{25}$ The maximum deviation is equivalent to $0.4 \mathrm{mv}$. In those few cases for which good reversible electrodes are available, emf is clearly the method of choice for accuracy. With respect to the isopiestic method, ultracentrifugation compares more favorably, though still not on equal terms. It can, however, be used with volatile solutes, as the isopiestic technique cannot.

\section{The Hydration of Alkali lons}

\section{Fred Vaslow}

This report is, in large part, a summary of the work contained in J. Phys. Chem. 67, 2772 (1963). It has generally been considered that the hydration

${ }^{25}$ H. S. Harned and R. Gary, J. Am. Chem. Soc. 76, 5924 (1954). 
structures of the alkali ions in solution consist of symmetrical tetrahedra or octahedra of water molecules surrounding the ion, with the negative end of the water dipole pointing toward the center of the ion. The basis of this structure lies in the high interaction energy of the water dipole with the ion charge, which for small ions is large enough to disrupt any inherent water structure and limit the water molecule to a relatively fixed position with respect to the ion. The dipole moment, however, represents only the first term in the series expansion of the electric potential of a complex charge distribution and for water molecules it is highly probable that the quadrupole and higher terms are important at short distances. Since the spatial dependence of the higher terms is in general different from that of the dipole term, the orientation of the water molecule with respect to a small ion may be quite different from that calculated on the basis of the dipole alone.

Using the quadrupole moment of water derived by Buckingham ${ }^{26}$ in his calculation of hydration energies of the alkali halides, in the general equation of electrical potential, it was found to be energetically possible that two or more water molecules adjacent to the same ion could be oriented so as to form hydrogen bonds with each other. The ions could satisfy their hydration requirements without necessarily disrupting inherent hydrogen bond structures of liquid water.

Use of the concept allows a plausible explanation of several properties of the solutions of the small alkali ions such as the apparent molal volume, structure-making and breaking properties, and the activity coefficients of $\mathrm{Li}^{6}$ with $\mathrm{OH}^{-}$or $\mathrm{OC}_{2} \mathrm{H}_{5}$ - anions.

Experimental work presently being done is related to further properties of the model. If there are actually quasi-stable discrete structures in water with which the ion can associate and the number of ions associated with such structures is limited (either by the number of sites or by destruction of the structure), then on approaching this number of ions in solution, small but relatively abrupt changes should occur in structurally sensitive properties of the solution. Likely properties are the apparent molal volumes and relative viscosities of the salt solutions, and the changes

${ }^{26}$ A. D. Buckingham, Discussions Faraday Soc, 24, 151 (1957). would be of curvature with no discontinuities of any sort to be expected.

Careful examination of literature data has shown that there may be evidence of such changes. However, in no case is there either a sufficient number of experimental points or are the points of sufficient accuracy to make possible any statistical or mathematical test of the reality of such an effect.

In the experimental part of this work, measurements are being made of the density and later of the viscosity of salt solutions with sufficient precision and with a sufficient number of points that mathematical tests may be made of the reality of effects that could be due to solvent structure.

\section{Precise Density Measurements on Aqueous Solutions}

\section{Fred Vaslow}

The apparatus for the precise measurement of apparent molal volumes of electrolytes has been completed and also analytical techniques of the required accuracy have been developed.

The apparatus is very similar to that described by Redlich and Bigeleisen ${ }^{27}$ and consists simply of two 450-ml fused quartz bobs suspended from the pans of a semimicro balance, one bob in pure water and the second in the solution to be measured. The balance is read to $0.1 \mathrm{mg}$, which gives a calculated sensitivity of 2.2 parts in $10^{7}$ in the density. Tests have indicated a reproducibility and sensitivity close to this value.

Several small changes from the Redlich and Bigeleisen apparatus have been made and have improved the accuracy and speed of the measurements. The changes are in the use of quartz rather than Pyrex bobs minimizing possible uncertainties due to adsorption of salt or water on the bulb. A 0.002-in.-diam tungsten wire, rather than a $0.01-i n$. platinum wire, is used as the suspension, making uncertainties due to surface tension and wire displacement almost negligible and also making possible a much more rapid approach of the balance to its equilibrium position. Third, a motor-driven Teflon stirrer has been added, which makes rapid mixing of stock solution possible.

\footnotetext{
${ }^{27}$ O. Redlich and J. Bigeleisen, J. Am. Chem. Soc. 64, 758 (1942).
} 
The analytical techniques are those of differential titration of chloride with silver nitrate at low concentrations and direct weighing of the dried salt for higher concentrations. The necessary accuracy of $0.01 \%$ can be reached with either method.

Preliminary measurements on $\mathrm{NaCl}$ solutions have given excellent agreement with the previous work of Kruis. ${ }^{28}$ The apparent limiting molal volume of $\mathrm{NaCl}$ was found to be $16.60 \mathrm{ml}$, compared to Kruis' value of $16.60_{7}$, and the limiting slope 1.85 compared to the theoretical 1.86 . The validity of the linear relationship between $\sqrt{C}$ and the volume is confirmed in agreement with Kruis and in disagreement with the small deviations found by Wirth. ${ }^{29}$

${ }^{28}$ A. Kruis, Z. Physik. Chem. B 26, 81 (1934).

${ }^{29}$ H. E. Wirth, J. Am. Chem. Soc. 62, 1128 (1940).

\section{Physical Chemistry of Ion Exchangers: Isopiestic Vapor Pressure Measurements on Alkali-Metal Cation Salts of $p$-Ethylbenzene Sulfonic Acid}
A. Schwarz
Q. V. Larson
G. E. Boyd

The osmotic coefficients of the pure $\mathrm{Li}, \mathrm{Na}, \mathrm{K}$, and $C s$ salts of $p$-ethylbenzene sulfonic acid ( $p$-EBS) were measured as a function of concentration at $25^{\circ} \mathrm{C}$ by the isopiestic vapor pressure comparison method. The data are shown in Fig. 6.8 , together with osmotic coefficients reported by O. D. Bonner ${ }^{30}$ for the acid. p-Ethylbenzene sulfonic acid is the monomer unit of the Dowex 50 cation exchange resins and, as such, is expected to be a useful model compound.

${ }^{30}$ O. D. Bonner et a1., J. Am. Chem. Soc. 77, 242 (1955).

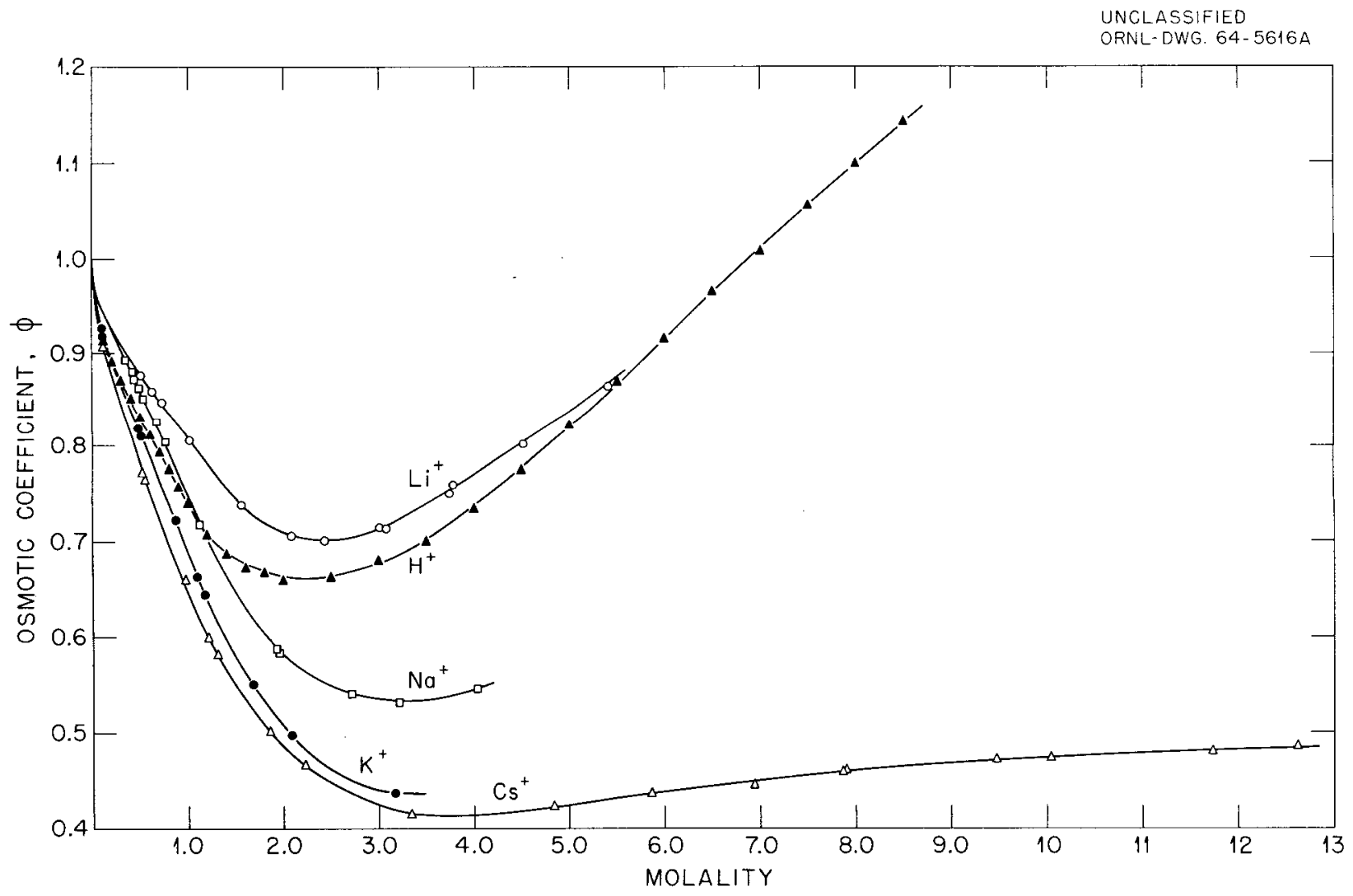

Fig. 6.8. Concentration Dependence of the Osmotic Coefficients for p-Ethylbenzene Sulfonic Acid and Its Alkali-Metal Salts at $25^{\circ} \mathrm{C}$. 
At any given concentration in the range studied, the osmotic coefficients of the alkali-metal salts of $p$-EBS follow the order $\mathrm{Li}>\mathrm{Na}>\mathrm{K}>\mathrm{Cs}$ which is the usual sequence for most alkali-metal salts. The ionic selectivities observed with polystyrene sulfonic acid cation exchangers (i.e., Dowex 50) also follow this trend (e.g., Cs is preferred over $\mathrm{Na}$, etc.).

Mean molal activity coefficients, $\gamma_{+}$, will be computed from the measured osmotic coefficients, $\phi$, with Eq. (1),

$-2.303 \log \gamma_{ \pm}=(1-\phi)+2 \int_{0}^{\sqrt{m}} \frac{(1-\phi)}{\sqrt{m}} d \sqrt{m}$

and then the free energy of dilution to infinite dilution will be obtained from the relation

$$
\Delta G_{D}=2 R T\left[\phi-\ln \left(m \gamma_{ \pm}\right)\right]
$$

Differences in the dilution free energies taken for initial concentrations corresponding to those in various cross-linked polystyrene sulfonates (i.e., Dowex 50) will be compared with standard free energies of cation exchange, $\Delta F^{\circ}$, for $\mathrm{Na}^{+}$ion with $\mathrm{H}^{+}, \mathrm{Li}^{+}, \mathrm{K}^{+}$, and $\mathrm{Cs}^{+}$to determine the extent of validity of the hypothesis that organic ion exchangers are analogous to concentrated aqueous electrolyte mixtures.

\section{Physical Chemistry of lon Exchangers: Heat and Entropy Changes in the $\mathrm{Li}^{+} / \mathrm{Cs}^{+}$Ion Exchange Reaction with a Weak-Acid Cation Exchanger}

\section{Siegfried Lindenbaum}

Selectivity coefficients and heats of exchange have been measured for the exchange of $\mathrm{Li}^{+}$and $\mathrm{Cs}^{+}$on a lightly cross-linked polymethylacrylic acid type cation exchanger (Amberlite IRC 50, 1\% cross-linked). Similar measurements have been reported previously ${ }^{31}$ for the exchange of alkalimetal cations on strong-acid cation exchangers (Dowex 50). On Dowex 50 the selectivity of the ions is in the order $\mathrm{Cs}>\mathrm{K}>\mathrm{Na}>\mathrm{Li}$. In all

\footnotetext{
${ }^{31}$ G. E. Boyd, Fred Vaslow, and Siegfried Lindenbaum, J. Phys. Chem. 68, 590 (1964).
}

cases the heat of exchange, $\Delta H^{\circ}$, for the exchange of the preferred ion was negative and the corresponding entropy, $\Delta S^{\circ}$, was small and also negative.

Since for the weak-acid exchanger the selectivity pattern is the opposite of that observed on the strong-acid exchanger, a study of the heat and entropy of ion exchange was of interest.

Free energy and heat measurements were performed in single experiments in a solution calorimeter. ${ }^{31}$ The wet swollen resin in the $\mathrm{Li}^{+}$or $\mathrm{Cs}^{+}$salt form was contained in the sample pipet. The calorimeter Dewar initially contained $500 \mathrm{ml}$ of a pure solution of $0.1 N \mathrm{CsOH}$ or $\mathrm{LiOH}$ or appropriate mixtures. Heats of exchange were measured as previously described. The resin was filtered from the solution; the resin was eluted with $\mathrm{HCl}$, and $\mathrm{Li}$ and $\mathrm{Cs}$ were determined ${ }^{32}$ on the equilibrium solution and resin eluate., From these data, partial molal heats of exchange, $\Delta \bar{H}$, and selectivity coefficients, $D$, could be calculated. These are shown in Figs. 6.9 and 6.10 as a function of $x_{L_{i}}$, the mole fraction of the resin in the lithium form. From the values of $D$ as a function of $\mathrm{x}_{\mathrm{Li}}, \Delta F^{\circ}$ could be obtained by integrating as follows:

$$
-\Delta F^{\circ}=2.303 R T \int_{0}^{1} \log D d x_{\mathrm{Li}}
$$

Values of $\Delta H^{\circ}$ were obtained from the heats of exchange by integrating

$$
\Delta H=\int_{0}^{1} \Delta \bar{H} d x_{\mathrm{Li}}
$$

and correcting for the difference in the relative apparent molal heat contents of the two $0.1 \mathrm{~N}$ aqueous solutions. ${ }^{3}$ The thermodynamic quantities thus calculated at $25^{\circ} \mathrm{C}$ are: $\Delta F^{\circ}=-107 \mathrm{cal}$, $\Delta H^{\circ}=+374 \mathrm{cal}$, and $\Delta S^{\circ}=+1.6$ eu for the uptake of the preferred ion $\left(\mathrm{Li}^{+}\right)$by the exchanger. The fact that the heat and entropy for the exchange are opposite in sign to the values obtained for the strong-acid exchangers suggests that a different type of interaction is responsible for the

\footnotetext{
${ }^{32}$ Thanks are due to T. C. Rains of the ORNL Analytical Chemistry Division for the flame photometric Cs and $L i$ analyses.

${ }^{33}$ F. D. Rossini et al., Natl. Bur. Stand. (U.S.), Circ. 500 (1952).
} 
ionic selectivity exhibited by the weak-acid exchange resin. Since dehydration of ions is accompanied by a positive entropy change, it is suggested that the exchange of ions on these weak-acid exchangers involves specific interaction of the ions and the exchange site which requires a partial dehydration of the exchanging cation. This is in contrast to the findings for strong-acid cation exchange, for which the thermodynamic data suggest a nonspecific ion association within the resin phase.

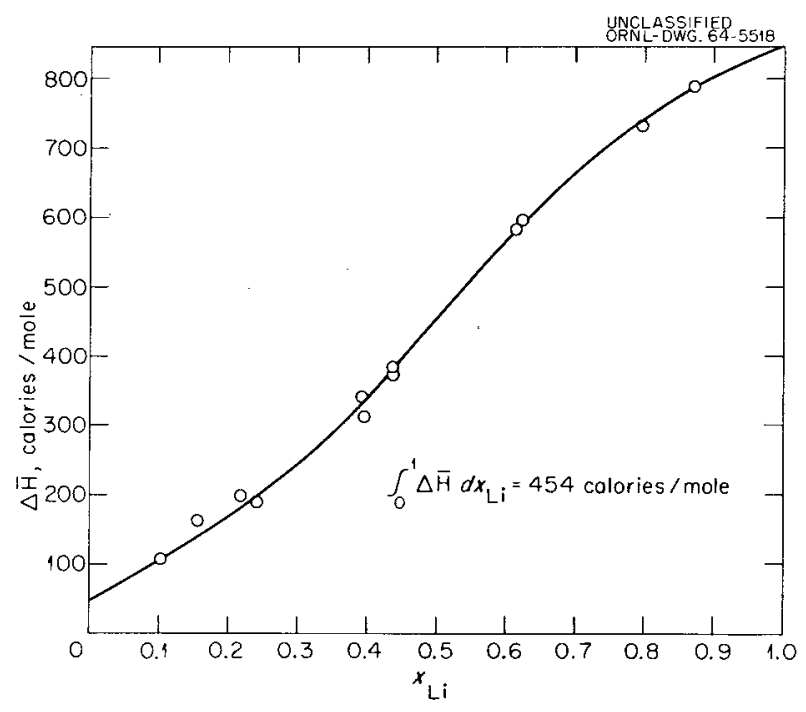

Fig. 6.9. Differential Heats of Exchange of Lithium with Cesium on Amberlite IRC 50 (1\% DVB).

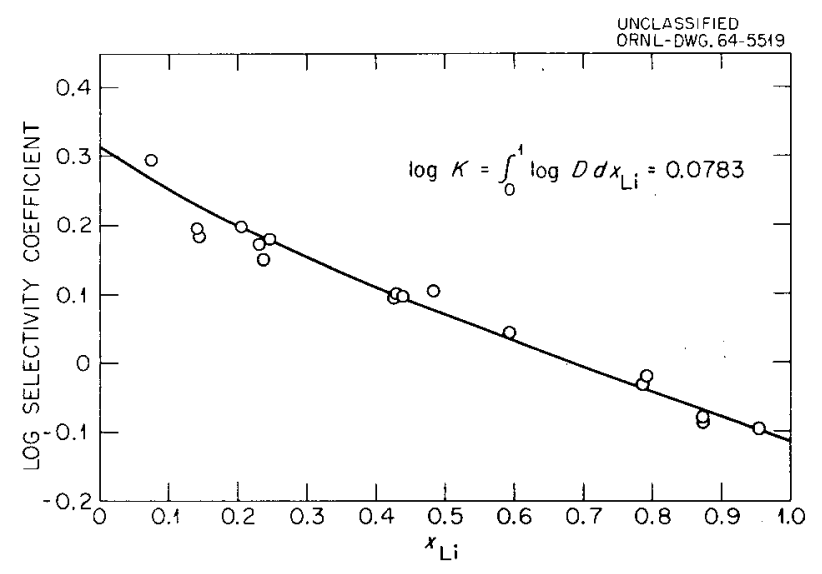

Fig. 6.10. Selectivity Coefficients for the LithiumCesium Exchange on Amberlite IRC 50 (1\% DVB).

\section{Physical Chemistry of Ion Exchangers: Identity of the Fe(III) Ion Taken Up from Concentrated Aqueous Halide Solutions by Strong-Acid Cation Exchangers ${ }^{34}$}
G. E. Boyd
Siegfried Lindenbaum

\section{Q. V. Larson}

Spectrophotometric examinations and chemical analyses were conducted on a cross-linked polystyrene sulfonate (Dowex $50 \quad 0.5 \%$ DVB) and on a liquid cation exchanger prepared by dissolving dinonyl naphthalene sulfonic acid in toluene in an attempt to find an explanation for the anomalous increase in absorption of $\mathrm{Fe}$ (III) from concentrated aqueous $\mathrm{HBr}$ and $\mathrm{LiBr}$ solutions by strong-acid cation exchangers. The characteristic ligand field bands of the tetrahedral anion, $\mathrm{FeBr}^{4-}$, were observed in both exchangers when they had been brought to equilibrium with solutions more concentrated than $5 \mathrm{M}$ in $\mathrm{Br}^{-}$ion. Measurements of the $\mathrm{Li}^{+}$(or $\mathrm{H}^{+}$) ion content of the liquid exchanger showed that the amount in excess of the exchange capacity was sufficient to give $\mathrm{LiFeBr}_{4}$ (or $\mathrm{HFeBr}_{4}$ ). It was concluded that the absorption of $\mathrm{Fe}$ (III) from concentrated $\mathrm{HBr}$ and $\mathrm{LiBr}$ involved the $\mathrm{FeBr}^{4}$ - complex ion, and that the ion pairs, $\mathrm{H}^{+} \mathrm{FeBr}{ }_{4}{ }^{-}$and $\mathrm{Li}^{+} \mathrm{FeBr}_{4}{ }^{-}$, were "salted" into the organic cation exchange phase. Thus, in special circumstances, ion exchangers may, essentially, extract salts by a solvent extraction mechanism involving ion association complexes.

\section{The Heats of Dilution of Polystyrene Sulfonic Acid and the Li, Na, K, and $C_{s}$ Salts}

\section{Fred Vaslow}

The heats of dilution and solution of polystyrene sulfonic acid and of the $\mathrm{Li}, \mathrm{Na}, \mathrm{K}$, and $\mathrm{Cs}$ salts have been calorimetrically measured from initial concentrations of 0.04 equivalent per kilogram of water to 12 equivalents $/ \mathrm{kg}$ and to a final concentration of about $1 \times 10^{-3}$ equivalent $/ \mathrm{kg}$. Since it is probable that there are large and unknown changes in the apparent molal heat contents of the polyelectrolytes below $10^{-3}$ equivalent $/ \mathrm{kg}$, it is not possible to relate the values obtained to

\footnotetext{
${ }^{34}$ Inorganic Chemistry (in press).
} 
Table 6.6. Comparison of Heat of Dilution Differences with Standard Heats of Exchange

\begin{tabular}{|c|c|c|c|c|c|}
\hline $\begin{array}{c}\text { Res in } \\
(\% \text { diviny lbenzene) }\end{array}$ & System & $\mathrm{Na}^{+} / \mathrm{H}^{+}$ & $\mathrm{Na}^{+} / \mathrm{Li}^{+}$ & $\mathrm{K}^{+} / \mathrm{Na}^{+}$ & $\mathrm{Cs}^{+} / \mathrm{Na}^{+}$ \\
\hline \multirow[t]{2}{*}{2} & $\Delta \phi \mathrm{dil}$ & -520 & -670 & -20 & -270 \\
\hline & $\Delta H^{\circ}$ exch & -460 & -650 & -290 & -560 \\
\hline \multirow[t]{2}{*}{4} & $\Delta \phi \mathrm{dil}$ & -980 & -980 & -120 & -290 \\
\hline & $\Delta H^{\circ}$ exch & -860 & -1080 & -410 & -620 \\
\hline \multirow[t]{2}{*}{8} & $\Delta \phi \mathrm{dil}$ & -1240 & -1130 & -320 & -390 \\
\hline & $\Delta H^{\circ}$ exch & -1180 & -1460 & -550 & -770 \\
\hline \multirow[t]{2}{*}{16} & $\Delta \phi \mathrm{di} 1$ & -1550 & -1410 & & -690 \\
\hline & $\Delta H^{\circ}$ exch & -1250 & -1700 & & -1190 \\
\hline
\end{tabular}

any simple well-defined standard state. Comparing the measured values of the polyelectrolytes with those of the monomers (p-ethylbenzene sulfonic acid salts) previously reported, ${ }^{35}$ it was found that above 3 to 4 equivalents $/ \mathrm{kg}$ the curves are essentially parallel, and except for the interchange of the $\mathrm{H}^{+}$and $\mathrm{Li}^{+}$curves, the curves are in the same order. At lower concentrations the monomer curves approach the Debye-Hückel limiting law, while the polymer curves all rise to a maximum at about 0.1 equivalent $/ \mathrm{kg}$. For concentrations where the mean nearest distance between all ions in solution is smaller than the interionic distance along the chain, the apparent heat contents of chain and monomer can be assumed the same, and a heat of separation of polymer into monomer (excluding bond energies) can then be estimated at lower concentrations. Below 3 equivalents $/ \mathrm{kg}$ these heats of separation gradually increase until, at about 0.04 equivalent $/ \mathrm{kg}$, they reach maxima of $1140,1170,710$, 520 , and $470 \mathrm{cal} /$ equivalent for the acid and its $\mathrm{Li}^{+}, \mathrm{Na}^{+}, \mathrm{K}^{+}$, and $\mathrm{Cs}^{+}$salts respectively. At present there appears to be no theoretical basis for understanding these results.

The differences in heats of dilution between the $\mathrm{Na}^{+}$polyelectrolyte and the $\mathrm{H}^{+}, \mathrm{Li}^{+}, \mathrm{K}^{+}$, and $\mathrm{Cs}^{+}$salts may again be compared ${ }^{35}$ with corresponding standard heats of exchange on Dowex 50 resins. These results are shown in Table 6.6 for the various resins and salts.

As previously noticed for other anion salts, the agreement appears to be relatively good for systems of strongly hydrated ions and poor for the weakly hydrated ions.
Heat effects on the addition of alkali salts to dilute solutions of the linear polyelectrolytes were small, endothermic, and nonspecific except where $\mathrm{Cs}^{+}$ions were involved. Heat was evolved on the addition of $\mathrm{CsCl}$ to the $\mathrm{Na}^{+}$polyelectrolyte with a slightly larger amount of heat than for the nonspecific reaction being absorbed in the converse process.

\section{ION EXCHANGE STUDIES}

\section{Ion Exchange in Concentrated $\mathrm{HCl}$ and $\mathrm{HClO}_{4}$ "Solutions}
F. Nelson
K. A. Kraus

The broad survey of the cation exchange behavior of the elements in $\mathrm{HCl}$ and $\mathrm{HClO}_{4}$ solutions, which was mentioned in the last Chemistry Division annual report, ${ }^{36}$ has been written up and published in the Journal of Chromatography. ${ }^{37}$ This paper gives details of our measurements of distribution coefficients of most elements in dilute and concentrated $\mathrm{HCl}$ and $\mathrm{HClO}_{4}$ solutions. The results are summarized in the form of two "periodic tables." A considerable number of illustrations of the application of these high-ionic-strength cation exchange techniques for separations is discussed.

\footnotetext{
${ }^{35}$ Chem. Div. Ann. Progr. Rept. June 20, 1962, ORNL3320 , p. 77 .

${ }^{36}$ F. Nelson, T. Murase, and K. A. Kraus, Chem. Div. Ann. Progr. Rept. June 20, 1963, ORNL-3488, p. 82.

${ }^{37}$ F. Nelson, T. Murase, and K. A. Kraus, J. Chromatog. 13, 503 (1964).
} 
Measurements were also reported on the variation of distribution coefficients of $\mathrm{Eu}(\mathrm{III})$ and Th(IV) with loading at high ionic strength; these were much more ideal than would have been expected for these media where electrolyte invasion of the resin occurs to a large extent.

The paper also contains a discussion of the thermodynamic aspects of ion exchange at high ionic strength; reasons for the unusually high selectivities which were observed could, however, not be given.

Most analyses for this work were carried out radiometrically. A somewhat unusual aspect of the study was that in its course it involved approximately 80 different tracers.

\section{Adsorption of the Elements from $\mathrm{HCl} \cdot \mathrm{HClO}_{4}$ Mixtures \\ F. Nelson K. A. Kraus}

In continuation of the evaluation of the usefulness of cation exchange at high ionic strength for separations, distribution coefficients have been measured in $9 \mathrm{M} \mathrm{HCl}-\mathrm{HClO}_{4}$ mixtures for all those elements which show moderate or strong adsorption in either concentrated $\mathrm{HCl}$ or $\mathrm{HClO}_{4}$. The results of the studies are summarized in Fig. 6.11 , a semilogarithmic plot of $D_{v}$ vs $F_{\mathrm{HC} 1}$ where $D_{v}$ is the volume distribution coefficient and $F_{\mathrm{HC} 1}$ the fraction of $\mathrm{HCl}$ in acid mixtures of constant $(9 M)$ acidity. The measurements were carried out at $25^{\circ} \mathrm{C}$ with a Dowex $50-\mathrm{X} 4$ resin. The results may be summarized as follows:

1. Adsorbability of a number of elements [e.g., $\mathrm{Cd}(\mathrm{II}), \mathrm{Bi}(\mathrm{III})$, and $\mathrm{U}(\mathrm{VI})]$ decreases very rapidly with increasing $F_{\mathrm{HC} 1}$ and becomes negligible at relatively low values of $F_{\mathrm{HCl}}$. The rapid decrease in adsorbability for these elements may be attributed to formation of nonadsorbable or weakly adsorbed chloride complexes.

2. Adsorbability of a number of elements [e.g., $\mathrm{Ca}$ (II) and rare earths(III)] decreases only gradually with increasing $F_{\mathrm{HCl}}$. These elements are presumably only weakly or negligibly complexed by chloride ions even at these

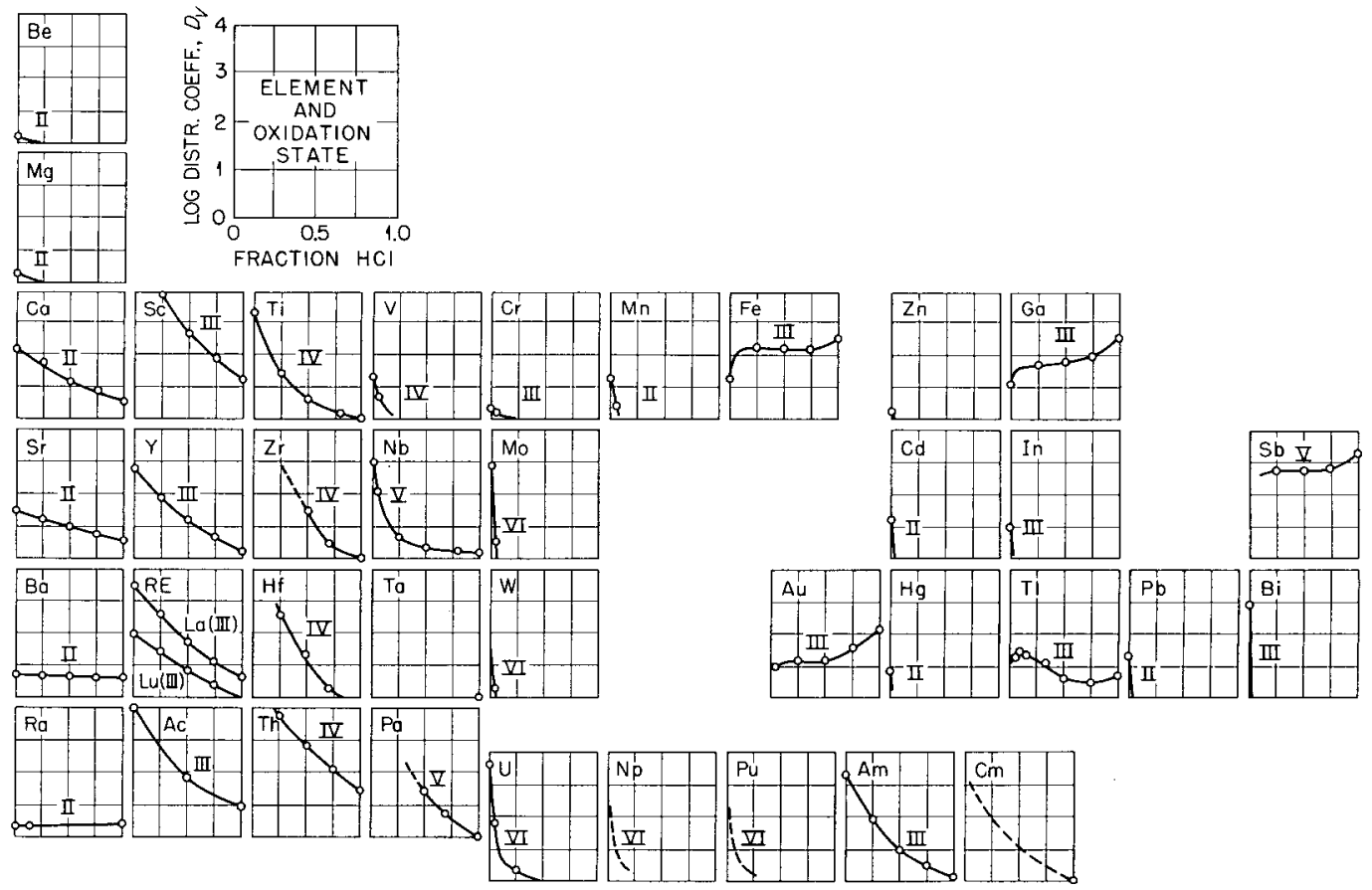

Fig. 6.11. Adsorption of Elements from $9 \mathrm{M} \mathrm{HClO}_{4}-\mathrm{HCl}$ Mixtures by a Cation Exchange Resin. 
high ionic strengths. The decrease in adsorbability of these elements with increasing $F_{\text {HCl }}$ presumably is caused principally by differences in the adsorbabilities of the uncomplexed species.

3. Adsorbability of a few elements [e.g., Fe(III), $\mathrm{Ga}(\mathrm{III}), \mathrm{Au}(\mathrm{III})$, and $\mathrm{Sb}(\mathrm{V})]$ shows little change with increasing $F_{\mathrm{HCl}}$ or even shows an increase with $F_{\mathrm{HCl}^{*}}$ These elements presumably are adsorbed as negatively charged complexes by the cation exchanger. ${ }^{38}$

4. The enormous variability of the adsorbabilities of many elements in $\mathrm{HCl}_{-} \mathrm{HClO}_{4}$ mixtures can form the basis of numerous high-ionic-strength ion exchange separations; through control of the chloride-perchlorate ratio at high acidity a much larger variety of separations can be achieved than with either $\mathrm{HClO}_{4}$ or $\mathrm{HCl}$.

\section{Activity Coefficients of $\mathrm{HCl}$ and $\mathrm{HClO}_{4}$ in a Cation Exchanger}

\section{F. Nelson}

Activity coefficient ratios $\Gamma=\gamma_{ \pm(r)} / \gamma_{ \pm}$of $\mathrm{HClO}_{4}$ and $\mathrm{HCl}$ were determined with a cation exchange resin (Dowex 50-X4) over a wide range of acid concentrations and for mixtures of these two acids. For the two-component systems, $\Gamma_{\mathrm{HC} 1}$ and $\Gamma_{\mathrm{HClO}_{4}}$ were found to be approximately unity in the region 1 to $16 M$. The activity coefficient ratios for mixtures of the acids were also not markedly different from unity although $\Gamma_{\mathrm{HC1}}$ in these mixtures was slightly lower than $\Gamma_{\mathrm{HClO}_{4}}$.

\section{Adsorption of In(III) by a Cation Exchanger from $\mathrm{HBr}$ Solutions}

\section{F. Nelson D. C. Michelson}

During the examination of the cation exchange behavior of In(III) in various mineral acids it was found that this element is strongly adsorbed from concentrated $\mathrm{HBr}$ solutions. This unusual behavior may be utilized for separations involving In(III).

\footnotetext{
${ }^{38} \mathrm{~K}$. A. Kraus, D. C. Michels on, and F. Nelson, $J$. Am. Chem. Soc. 81, 3204 (1959).
}

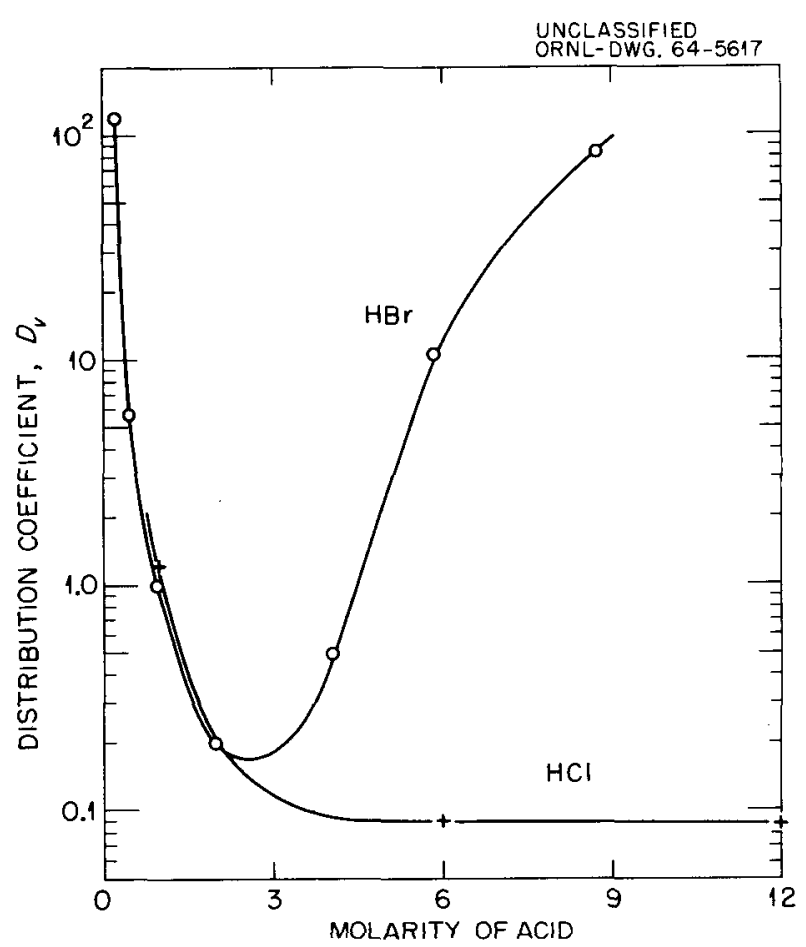

Fig. 6.12. Adsorption of $\ln$ (III) from $\mathrm{HCl}$ and $\mathrm{HBr}$ by a Cation Exchange Resin. (Dowex 50-X4, 25 C.)

The adsorption function of $\operatorname{In}(\mathrm{III})$ in $\mathrm{HBr}$ is shown in Fig. 6.12 together with earlier data for In(III) in $\mathrm{HCl}$. While for the latter, adsorption is significant only in very dilute solutions, adsorbability in $\mathrm{HBr}$ reaches a minimum near $3 M$ and then increases rapidly with $M \mathrm{HBr}$ to $D_{v}=$ ca. 100 in $9 \mathrm{MHBr}$. At this high ionic strength In(III) adsorbs presumably as $\mathrm{InBr}_{4}$ - in a manner analogous to the adsorption of the negatively charged chloride complexes $\mathrm{MCl}_{4}$ - of $\mathrm{Fe}$ (III), $\mathrm{Ga}$ (III), and $\mathrm{Au}(\mathrm{III}) .^{39}$ One is tempted to conclude that failure of In(III) to adsorb significantly from concentrated $\mathrm{HCl}$ solutions implies that $\mathrm{InCl}_{4}{ }^{-}$is not formed to an appreciable extent in concentrated $\mathrm{HCl}$ solutions; this would be in disagreement with conclusions of Dietz, Mendez, and Irvine 40 who postulated from solvent extraction data that $\mathrm{InCl}_{4}-$ predominates in these media.

\footnotetext{
${ }^{39}$ K. A. Kraus, D. C. Michelson, and F. Nelson, $J$. Am. Chem. Soc. 81, 3204 (1959).

${ }^{40}$ R. J. Dietz, Jr., J. Mendez, and J. W. Irvine, Jr., Radioisotopes Phys. Sci. Ind., Proc. Conf. Use, Copenhagen, 1960, vol. III, p. 415 (1962).
} 


\section{Development of on Ion Exchange Separations Scheme}
F. Nelson
D. C. Michelson
E. L. Lind $^{41}$
K. A. Kraus

Work has continued on the development of a general separations scheme based principally on ion exchange. Several special procedures for carrying out separations of limited numbers of elements have been published in the Journal of Chromatography or are in press. These include:

1. An anion exchange $\operatorname{method}^{42}$ for separating trace amounts of neptunium and niobium from macro amounts of zirconium. It makes use of the fact that $\mathrm{Zr}(\mathrm{IV})$ in $\mathrm{HCl}-\mathrm{HF}$ media at high $\mathrm{HCl}$ concentrations is essentially nonadsorbable under conditions where $\mathrm{Np}(\mathrm{VI})$ and $\mathrm{Nb}(\mathrm{V})$ are strongly adsorbed; these may then be sequentially eluted.

2. An anion exchange method ${ }^{43}$ for separating uranium, neptunium, and plutonium from each other and from many nonadsorbable elements. In this procedure uranium is adsorbed in the (VI) state while neptunium and plutonium are adsorbed presumably in the (IV) state. Plutonium is selectively reduced to $\mathrm{Pu}$ (III) and eluted under conditions where $\mathrm{Np}(\mathrm{IV})$ and U(VI) remain adsorbed; these are eluted in separate fractions with $\mathrm{HCl}-\mathrm{HF}$ mixtures.

3. A cation exchange procedure ${ }^{44}$ for recovering carrier-free $\mathrm{UX}_{1}\left({ }^{234} \mathrm{Th}\right)$ from uranyl nitrate solution. Two ion exchange columns are used, one for initial concentration and the other for final purification.

4. A cation exchange procedure ${ }^{45}$ for separating $\mathrm{Ba}(\mathrm{II})$ and $\mathrm{Ra}$ (II) (at low concentrations) from each other. The method makes use of the substantial differences in adsorbability of these elements in dilute ammonium ethylenediaminetetraacetate solutions. Selective elution of $\mathrm{Ba}$ and $\mathrm{Ra}$ is achieved through control of $\mathrm{pH}$.

5. A cation exchange procedure ${ }^{46}$ for isolating ${ }^{227} \mathrm{Ac}$ from milligram amounts of ${ }^{231} \mathrm{~Pa}$ and from ${ }^{227} \mathrm{Ac}$ daughters. The method makes use of the negligible adsorption of $\mathrm{Pa}$ from $\mathrm{HCl}-\mathrm{HF}$ media under conditions where $\mathrm{Ac}$ (III) is strongly adsorbed; in the final purification step, ${ }^{227} \mathrm{AC}$ is adsorbed from $8.5 \mathrm{M} \mathrm{HClO}_{4}-0.5 \mathrm{M} \mathrm{HCl}-$ $0.1 M \mathrm{HF}$ on a cation exchange column and then selectively eluted with $6 \mathrm{MHNO}_{3}$.

\section{Adsorption on Inorganic Materials}
F. Nelson
H. O. Phillips
K. A. Kraus

Studies of the adsorption and ion exchange behavior of a variety of inorganic materials have continued. This work was under dual sponsorship of the Office of Saline Water and the AEC, and details are described in the section of this report dealing with the Water Research Program.

\footnotetext{
${ }^{41}$ ORINS research participant, Central Washington State College.

${ }^{42} \mathrm{~J}$. H. Holloway and F. Nelson, J. Chromatog. 14, 255 (1964).

${ }^{43}$ F. Nelson, D. C. Michelson, and J. H. Holloway, J. Chromatog. 14, 258 (1964).

${ }^{44}$ T. Murase, E. L. Lind, and F. Nelson, $J$. Chromatog. (in press).

${ }^{45} \mathrm{~F}$. Nelson, $J$. Chromatog. (in press).

${ }^{46} \mathrm{~F}$. Nelson, J. Chromatog. (in press).
} 


\section{Electrochemical Kinetics. and Its Application to Corrosion}

Ion Exchange at the Surface of Passive Metals

\section{G. H. Cartledge}

Although the passive surface of a metal is usually treated as a relatively inactive oxide film, it was shown in a previous paper ${ }^{1}$ that the film on stainless steel interacts with aqueous ions by an ion exchange process, as well as, perhaps, by mere physical adsorption. Further studies are being made on the kinetics of the process as a possible means of gaining a better understanding of the chemical and electrical state of the passive interface. During the past year, the measurements have been extended to a range of temperatures, to a variety of exchanging anions, and to surfaces of pure iron and pure chromium plated over iron.

To interpret the data on the rate of exchange of ${ }^{51} \mathrm{Cr}(\mathrm{VI})$ with various anions, it is necessary to assume a complex process which involves two or sometimes three concurrent steps, depending on the circumstances. The exchange is fast initially and generally follows Eq. (1):

$$
\frac{d q}{d t}=S_{0}\left(\frac{w_{0}-q}{w_{0}}\right) \exp (-k q),
$$

in which $q$ is the amount of ${ }^{51} \mathrm{Cr}$ exchanged at time $t, S_{0}$ is the initial rate (usually taken at 1 min after the admission of exchanging electrolyte), $w_{0}$ is the total amount of ${ }^{51} \mathrm{Cr}$ exchanged at infinite time, and $k$ is a constant equal to $t / f R T$ of ref. 1.

This fast process is followed by one or, in certain cases, two first-order steps. By conducting some of the experiments in such a way

${ }^{1}$ G. H. Cartledge and D. H. Spahrbier, J. Electrochem. Soc. 110, 644 (1963). that the electrode potential of the specimen remained essentially constant, it was shown that the complexity of the process is not associated with the change in potential which occurred in the experiments previously described. Further experiments done with pure iron and chromium plated over iron showed the same complexity, so that the complexity observed on stainless steel is not due to reactions at chemically differing sites on that alloy.

In a series of experiments the stainless steel was passivated in ${ }^{51} \mathrm{Cr}_{2} \mathrm{O}_{7}{ }^{2-}$ at $\mathrm{pH} 2.35$ and extracted by a ${ }^{52} \mathrm{Cr}_{2} \mathrm{O}_{7}{ }^{2-}$ solution at the same $\mathrm{pH}$ value but at temperatures ranging from 24 to $77.5^{\circ} \mathrm{C}$. Two slow first-order processes followed the fast process, and the first-order rate constants gave apparent activation energies of 9.2 and $4.2 \mathrm{kcal} / \mathrm{mole}$ for the terminal and intermediate processes respectively.

In alkaline solutions ( $\mathrm{pH} 9.0$ to 9.2), extractions by phosphate, sulfate, chromate, and molybdate gave results so similar that it must be assumed that the exchange is effected by the hydroxide ion.

Experiments on the influence of the potential upon the rate constants are incomplete owing to technical difficulties, but provisional results indicate that the exchange rate increases as the potential is made less negative. If this behavior is confirmed, it will be significant for the theory of the passive interface.

\section{Adsorption Effects in Iron Dissolution Kinetics \\ E. J. Kelly}

The mechanism of iron dissolution in noninhibiting media, such as acidic sulfate solution, may be represented by Eqs. (1-3): 


$$
\begin{aligned}
& \mathrm{Fe}+\mathrm{H}_{2} \mathrm{O} \rightleftharpoons(\mathrm{FeOH})_{\mathrm{ads}}+\mathrm{H}^{+}+\mathrm{e}^{-} \\
&(\mathrm{FeOH})_{\mathrm{ads}} \longrightarrow(\mathrm{FeOH})^{+} \\
&+\mathrm{e}^{-} \text {(rate determining) } \\
&(\mathrm{FeOH})^{+}+\mathrm{H}^{+} \rightleftharpoons \mathrm{Fe}^{2+}+\mathrm{H}_{2} \mathrm{O}
\end{aligned}
$$

According to this reaction scheme, if the fraction of the surface occupied by the adsorbed reaction intermediate, $(\mathrm{FeOH})_{a d s}$, is small compared to unity, the steady-state anodic current density corresponding to the iron dissolution reaction, $i_{a, \infty}$, is given by Eq. (4):

$$
i_{a, \infty} / F=2 k_{2}\left(k_{1} / k_{-1} a_{\mathrm{H}}+\exp (3 F E / 2 R T),\right.
$$

where $E$ is the electrode potential, and the other symbols have their customary meanings. Equation (4) has been experimentally verified. ${ }^{2}$

In the preceding formulation of the reaction mechanism, the "bare metal" concept has been employed; that is, that fraction of the electrode surface not occupied by $(\mathrm{FeOH})_{\text {ads }}$ has been regarded as bare metal. A more realistic physical picture is obtained if reaction (1) is replaced by reactions $(5),(6)$, and $(7)$ :

$$
\begin{gathered}
\mathrm{Fe}+\mathrm{H}_{2} \mathrm{O} \rightleftharpoons \mathrm{Fe}\left(\mathrm{H}_{2} \mathrm{O}\right)_{\mathrm{ads}}, \\
\mathrm{Fe}\left(\mathrm{H}_{2} \mathrm{O}\right)_{\mathrm{ads}} \rightleftharpoons \mathrm{Fe}\left(\mathrm{OH}^{-}\right)_{\mathrm{ads}}+\mathrm{H}^{+}, \\
\mathrm{Fe}\left(\mathrm{OH}^{-}\right)_{\mathrm{ads}} \rightleftharpoons(\mathrm{FeOH})_{\mathrm{ads}}+\mathrm{e}^{-},
\end{gathered}
$$

which take formal account of the simultaneous coverage of the electrode surface by adsorbed water dipoles, hydroxyl ions, and the surface intermediate, $(\mathrm{FeOH})_{\text {ads. }}$. An analysis of this reaction scheme shows that the derivation of Eq. (4) is contingent on the fact that the total fraction of the electrode surface occupied by $\mathrm{Fe}\left(\mathrm{OH}^{-}\right)$ads and $(\mathrm{FeOH})_{\mathrm{ads}}$ is negligible compared to that occupied by adsorbed water molecules. ${ }^{3}$ Although, from a

\footnotetext{
${ }^{2}$ E. J. Kelly, Chem. Div. Ann. Progr. Rept. June 20, 1963, ORNL-3488, p. 93.

${ }^{3}$ E. J. Kelly, “The Active Iron Electrode. I. Iron Dissolution and Hydrogen Evolution Reactions in Acidic Sulfate Solutions," submitted to Joumal of the Electrochemical Society.
}

kinetic standpoint, the two formulations of the reaction mechanism for a noninhibited system are equivalent, Eqs. (2-3) and (5-7) provide a more meaningful mechanistic base for the interpretation of the changes produced in the kinetics and mechanistics of iron dissolution as a result of adsorption of an inhibitor.

In the presence of adsorbed benzoate ion, the current density corresponding to the iron dissolution reaction takes the form shown in Eq. (8), where $\theta_{T}$ represents the fraction of the electrode surface occupied by the organic inhibitor:

$$
\begin{aligned}
& i_{\mathrm{obs}}=k_{n}\left(1-\theta_{T}\right) \exp (3 F E / 2 R T) \\
&+k^{*} \theta_{T}\left(1-\theta_{T}\right) \exp (F E / R T) \\
&+k_{\mathrm{ecd}} \theta_{T} \exp (3 F E / 2 R T) .
\end{aligned}
$$

The first term on the right side of Eq. (8) corresponds to the normal anodic current density [cf. Eq. (4)] corrected for the coverage effect of the inhibitor on reaction (5). The second term arises from surface interactions of the adsorbed inhibitor with the adsorbates of Eqs. (5-7), and the third term represents a Faradaic desorption of the inhibitor. Although the contribution of the third term to the observed current is always negligible, the presence of this term accounts for the fact that as the electrode potential becomes increasingly positive, $\theta_{T}$ decreases and ultimately approaches zero. The current density is then given by just the first term of Eq. (8); it should therefore be equal to that observed in noninhibiting media. This conclusion was verified experimentally.

Other predictions of Eq. (8) were also tested. It was observed that for constant values of $\theta_{T}$ (fast polarization experiments) near unity, the anodic Tafel slope, $d E / d \log i_{\text {obs }}$, is equal to $R T / F$; that is, only the second term in Eq. (8) is significant when $\theta_{T} \approx 1$. Under these conditions, it follows from Eq. (8) that $\left(d i_{\text {obs }} / d t\right)_{E}$ is proportional to $-\left(d \theta_{T} / d t\right)_{E}$; that is, at constant potential a decrease in $\theta_{T}$ due to Faradaic desorption of the inhibitor is accompanied by an increase in the current density. This effect was observed, and, in addition, it was possible to account quantitatively for the variation of $i_{\text {obs }}$ with time. 


\section{Rotating-Disk Studies of the Dissolution of Zirconium in Aqueous Solutions of Hydrofluoric Acid}

\section{R. E. Meyer}

The anodic dissolution of zirconium may be represented by the following equation:

$$
\mathrm{Zr}+b \cdot \mathrm{HF} \rightarrow \mathrm{ZrF}_{b}{ }^{4-b}+b \cdot \mathrm{H}^{+}+4 e^{-},
$$

where $b$ is about 3 to 5 for the ratios of HF to zirconium encountered in this work. An investigation of this reaction has shown that its kinetics are complicated, in that the continuous formation and dissolution of a film, probably $\mathrm{ZrO}_{2}$, are involved. ${ }^{4}$ The dissolution reaction, which occurs at the interface between the film and the solution, is further complicated in that it is controlled by the rate of mass transfer of undissociated $\mathrm{HF}$ to the interface. ${ }^{4,5}$ The concentration of $\mathrm{HF}$ at the interface is therefore reduced considerably below its value in the bulk of the solution, and if normal methods of stirring are used, the concentration at the interface can be estimated only roughly. A rotating-disk electrode assembly was therefore used for the investigation; with this system, the concentration at the interface is uniform across the surface of the electrode, and it can be calculated with precision.

Levich ${ }^{6}$ has shown that if certain experimental conditions can be met, the mass transfer flux (moles $\mathrm{cm}^{-2} \mathrm{sec}^{-1}$ ) to the surface of a rotating disk is given by the relation

$$
f=A\left(C_{0}-C_{i}\right) \omega^{1 / 2},
$$

where $A=1.91 D^{2 / 3} \gamma^{-1 / 6}$. Here $C_{0}$ is the concentration of the migrating species in the bulk of the solution (moles $/ \mathrm{cm}^{3}$ ), $C_{i}$ is the concentration at the interface, $\omega$ is the rotational velocity (rpm), $D$ is the diffusion coefficient $\left(\mathrm{cm}^{2} / \mathrm{sec}\right)$, and $y$ is the kinematic viscosity $\left(\mathrm{cm}^{2} / \mathrm{sec}\right)$. The reaction rate at the surface might be represented by the equation

$$
r=\bar{k} C_{i}^{p}
$$

\footnotetext{
${ }^{4}$ R. E. Meyer, J. Electrochem. Soc. 111, 147 (1964).

${ }^{5}$ T. Smith and G. R. Hill, J. Electrochem. Soc. 105, 117 (1958).

${ }^{6}$ V. G. Levich, Physicochemical Hydrodynamics, Prentice-Ha11, Englewood Cliffs, N.J., 1962.
}

where $\bar{k}$ is an electrochemical specific rate constant, and $p$ is the order of the reaction. For steady-state conditions, $r=f$, and if $p=1$, these equations may be combined into the following form, where rate is expressed in terms of current $(i=$ $\left.n F_{r}\right)$ :

$$
\frac{1}{i}=\frac{1}{n F C_{0} \bar{k}}+\frac{1}{n F C_{0} A \omega^{1 / 2}} .
$$

The rate constant may be evaluated by extrapolating a plot of $1 / i$ vs $1 / \omega^{1 / 2}$ to infinite frequency. At infinite frequency, $1 / \omega^{1 / 2}$ is equal to zero, and the reciprocal current density, $1 / i$, is equal to $1 / n F C_{0} \vec{k}$. If the order is not equal to unity, more complicated equations result, and the evaluation of $p$ and $\bar{k}$ is considerably more difficult.

Dissolution experiments were performed in the systems $\mathrm{HF}-\mathrm{HNO}_{3}$ and $\mathrm{HF}-\mathrm{H}_{2} \mathrm{SO}_{4}$ by determining the current as a function of $\mathrm{rpm}$ at constant potential. In these experiments the concentration of HF was varied from $0.0011 N$ to $0.044 N$, the $\mathrm{HNO}_{3}$ concentration was usually $1.2 \mathrm{~N}$, and the $\mathrm{H}_{2} \mathrm{SO}_{4}$ concentration was usually $1.8 \mathrm{~N}$. The potential was maintained at values of -300 , $-400,-500$, and $-600 \mathrm{mv}$ vs the S.C.E. with a potentiostat. These potentials were sufficiently anodic to the open-circuit dissolution potential to ensure that there was no interference from the cathodic process.

The experiments in $\mathrm{HF}-\mathrm{HNO}_{3}$ showed that the reaction was essentially first order, for the plots of $1 / i$ vs $1 / \omega^{1 / 2}$ were linear. The currents at infinite frequency $\left(1 / \omega^{1 / 2}=0\right)$ varied from about $2 \times 10^{-1} \mathrm{amp} / \mathrm{cm}^{2}$ at $0.0426 \mathrm{~N} \mathrm{HF}$ to about $1.2 \times$ $10^{-3} \mathrm{amp} / \mathrm{cm}^{2}$ at $0.0011 \mathrm{~N} \mathrm{HF}$. A more exact numerical analysis of the data showed that the order was actually slightly greater than 1 and increased as the concentration of $\mathrm{HF}$ was reduced. The effect of changing the potential was to decrease the rates very slightly as the potential became more anodic.

The results obtained in $\mathrm{HF}-\mathrm{H}_{2} \mathrm{SO}_{4}$ were considerably different from those in $\mathrm{HF}^{4}-\mathrm{HNO}_{3}$. The currents, all other factors being equal, were lower in $\mathrm{H}_{2} \mathrm{SO}_{4}$, and the $1 / i$ vs $1 / \omega^{1 / 2}$ plots were not linear at higher rotational velocities. These results show that the sulfate ion has a marked influence on the surface reaction, and it appears that the sulfate ion is adsorbed on the surface of the electrode. The effect of changing the potential was similar to the effect observed in 
$\mathrm{HF}-\mathrm{HNO}_{3}$ solutions in that the rate decreased slightly as the potential became more anodic. However, this effect was somewhat larger in the $\mathrm{H}_{2} \mathrm{SO}_{4}$ solutions than in the $\mathrm{HNO}_{3}$ solutions.

The curvature in the $1 / i$ vs $1 / \omega^{1 / 2}$ plots for $\mathrm{H}_{2} \mathrm{SO}_{4}$ solutions is due to the fact that the surface reaction is not first order with respect to HF. Detailed analysis of the data showed that the order is actually about 1.8 , or roughly second order. Since the surface reaction is second order and since the mass transfer is first order, the rate of the surface reaction becomes relatively faster as the concentration of $\mathrm{HF}$ is increased. The dissolution reaction therefore becomes more and more under surface or kinetic control as the concentration of $\mathrm{HF}$ is reduced. At the lowest concentration used, $0.0011 N \mathrm{HF}$, the reaction is almost completely under kinetic control, while with $\mathrm{HF}-\mathrm{HNO}_{3}$ solutions, the reaction is still almost completely under mass transfer control at the same concentration of $\mathrm{HF}$. In fact, only a slight anodic pulse will cause the zirconium to passivate and form a thick film in solutions containing $\mathrm{H}_{2} \mathrm{SO}_{4}$ and small concentrations of $\mathrm{HF}$.
An expression for the current as a function of concentrations at the interface can be derived if it is assumed that both $\mathrm{HF}$ and the sulfate ion are adsorbed on the surface and compete for adsorption sites. Dissolution is assumed to occur only at sites where HF is adsorbed. The resulting expression has the form

$$
r=\frac{A(\mathrm{HF})^{2}}{B+C(\mathrm{HF})+D\left(\mathrm{SO}_{4}{ }^{2-}\right)+E(\mathrm{HF})\left(\mathrm{SO}_{4}{ }^{2-}\right)} .
$$

The constants $A$ to $E$ are related to the rate constants of the several individual reactions. Inspection of the equation shows that the reaction will be second order with respect to HF if the concentration of the sulfate ion is high enough. As the concentration of $\mathrm{SO}_{4}{ }^{2-}$ is reduced, the reaction will be either first or second order, depending on the relative importance of the first two terms of the denominator. In fact, the reaction order in $\mathrm{HNO}_{3}$ was slightly greater than unity and did increase as the concentration of $\mathrm{HF}$ was reduced. 


\section{Nonaqueous Systems at High Temperatures}

\section{MOLTEN-SALT_METAL SOLUTIONS}

\section{Electrical Conductivity and Cryoscopy in Solutions of Alkaline-Earth Metals in Their Molten Chlorides, Bromides, and lodides}
A. S. Dworkin
H. R. Bronstein

\section{A. Bredig}

The study of solutions of metals in their molten halides, especially of the alkaline-earth-metal solutions, was continued. Electrical conductivity was correlated with cryoscopic behavior in the endeavor to identify the solute species. Apparatus (all-molybdenum metal conductance cell) and procedures used have been described previously. ${ }^{1,2}$

Solutions of calcium metal in calcium chloride, bromide, or iodide, and, in preliminary measurements, of strontium metal in strontium chloride or bromide had been found ${ }^{2,3}$ to exhibit a behavior closely resembling that of sodium in its moltensalt solutions. In these solutions, the rate of increase in electrical conductivity decreases with increasing metal concentration. This corresponds to a decreasing solute conductivity and indicates the trapping of electrons in pairs to form diatomic molecule ions $\mathrm{Ca}_{2}{ }^{2+}$, that is, $(\mathrm{Ca}: \mathrm{Ca})^{2+}$ or, better, $\left(\mathrm{Ca}^{2+} \mathrm{e}_{2} \mathrm{Ca}^{2+}\right)$, similar in electronic structure to the well-known diatomic $\mathrm{Na}$ molecules. Figure 8.1, based on additional and improved measurements, shows that strontium solutions behave indeed quite similarly to the calcium solutions. At

${ }^{1}$ H. R. Bronstein, A. S. Dworkin, and M. A. Bredig, J. Phys. Chem. 66, 44 (1962).

${ }^{2}$ A. S. Dworkin, H. R. Bronstein, and M. A. Bredig, Discussions Faraday Soc. 32, 188 (1962).

${ }^{3}$ H. R. Bronstein, A. S. Dworkin, and M. A. Bredig, Chem. Div. Ann. Progr. Rept. June 20, 1962, ORNL3320 , p. 100 .

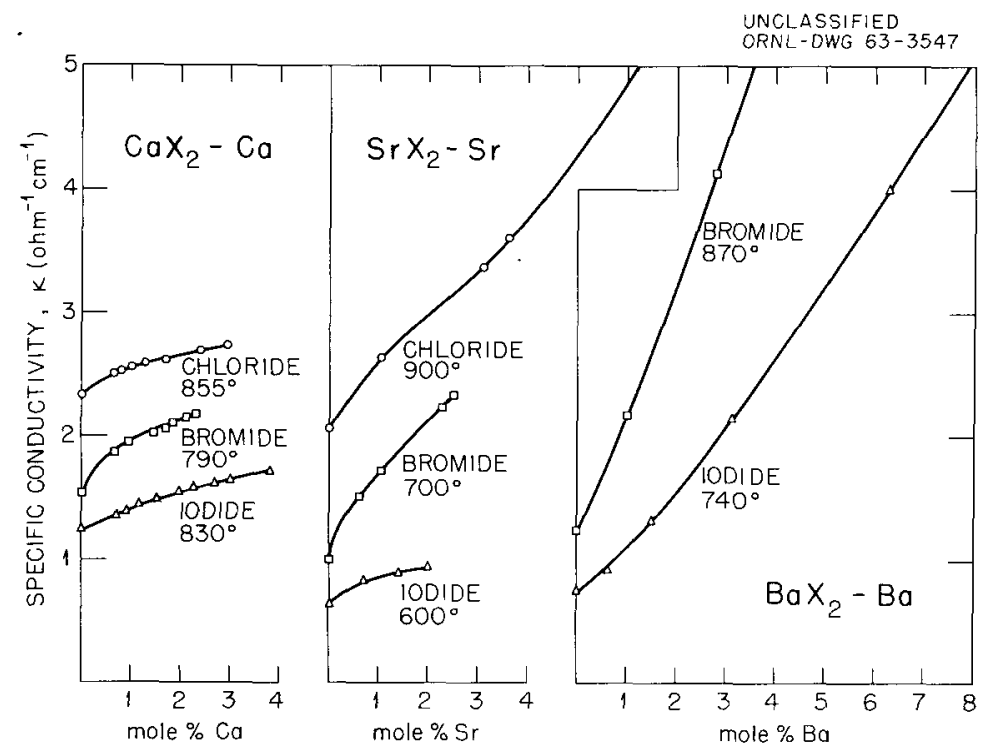

Fig. 8.1. Electrical Conductivity of Solutions of Alkaline-Earth Metals in Their Molten Halides. 
the higher temperatures, however, the conductivity curve of the chloride solutions exhibits a reversal to an increase in the rate of increase after an initial decrease in that rate. This is similar to the findings for the sodium-sodium bromide solutions. An explanation is that the somewhat higher metal solubility at the higher temperature of $900^{\circ} \mathrm{C}$ permits an increasing overlap of the electron orbitals of the molecule ions which leads gradually to metallic conduction.

Barium metal solutions in barium bromide or iodide melts (Fig. 8.1) showed the predicted ${ }^{2}$ increase in the rate of conductivity increase with metal concentration; this correlates well with the much higher solubility of the barium metal in its molten halides as compared with those of calcium and strontium. The metal concentrations that could be studied in the present apparatus were limited by their high conductivities $\left(35 \mathrm{ohms}^{-1}\right.$ $\mathrm{cm}^{-1}$ at 20 mole $\%$ metal). The chloride solutions could not be investigated in this apparatus because of the high temperatures required, causing excessive volatilization of the barium metal.

In line with the proposed explanation of the differences between the conductance behavior of the barium solutions and that of the calcium and strontium solutions, it would appear that the stability of the diatomic alkaline earth metal ions, $\mathrm{M}_{2}{ }^{2}+$, decreases with increasing size or atomic number similarly to that of the electronically analogous neutral diatomic molecules of the alkali metals.

The so-called "iodide effect," 4 observed in both alkali-metal and the calcium metal solutions, was again observed in the strontium and barium systems. This is the sharp drop of the equivalent conductance of the metal solute at infinite dilution, $\Lambda_{M}^{\infty}$, in going from the bromide to the iodide systems, after a sharp rise in going from the chloride to the bromide solutions (Table 8.1). This behavior had been tentatively connected in the alkali-metal systems with the divergent effects, upon the mobility of the electron, of the size and of the polarizability of the negative ion; namely, size inhibiting and polarizability promoting electron mobility.

In the alkaline-earth solutions, another effect is apparent from Table 8.1, namely, in the bromide

\footnotetext{
${ }^{4}$ A. S. Dworkin, H. R. Bronstein, and M. A. Bredig, Chem. Div. Ann. Progr. Rept. June 20, 1963, ORNL3488 , p. 96.
}

Table 8.1. Equivalent Conductance of Metal Solute at Infinite Dilution, $\Lambda_{M}^{\infty}$, in Alkaline-Earth-Metal-Halide $\left(M-M X_{2}\right)$ Melts

\begin{tabular}{cccc}
\hline $\mathrm{M}$ & $\begin{array}{c}\mathrm{X}=\mathrm{Cl} \\
\left(\mathrm{ohm}^{-1} \mathrm{~cm}^{2}\right)\end{array}$ & $\begin{array}{c}\mathrm{Br} \\
\left(\mathrm{ohm}^{-1} \mathrm{~cm}^{2}\right)\end{array}$ & $\begin{array}{c}\mathrm{I} \\
\left(\mathrm{ohm}^{-1} \mathrm{~cm}^{2}\right)\end{array}$ \\
\hline $\mathrm{Ca}$ & 890 & 4200 & 860 \\
$\mathrm{Sr}$ & 1600 & 5100 & 1570 \\
$\mathrm{Ba}$ & & 2830 & 1300 \\
\hline
\end{tabular}

and iodide systems, a drop of $\Lambda_{M}^{\infty}$ in going from the strontium to the barium solutions, after a rise in going from the calcium to the strontium systems. (For comparison of the chloride systems, the data for $\mathrm{BaCl}-\mathrm{Ba}$ are missing.) This particular influence of the cation has not as yet been observed in the alkali-metal-halide systems, though it may also exist there: $\Lambda_{\mathrm{N} \text { a }}^{\infty}$ and $\Lambda_{\mathrm{K}}^{\infty}$, somewhat similarly to $\Lambda_{\mathrm{S}_{\mathrm{r}}}^{\infty}$ and $\Lambda_{\mathrm{Ba}}^{\infty}$, were approximately in the ratio $2: 1$, but measurements which might prove $\Lambda_{L_{\mathrm{i}}}^{\infty}$ to be similar to $\Lambda_{\mathrm{C} \text { a }}^{\infty}$ and $\Lambda_{\mathrm{K}}^{\infty}$ have been impossible thus far because of the special experimental difficulties with lithium systems. The dependence of $\Lambda_{M}^{\infty}$ on the nature of $\mathrm{M}=\mathrm{Ca}, \mathrm{Sr}$, and $\mathrm{Ba}$ is not better understood at present than it was for the $\mathrm{Na}$ and $\mathrm{K}$ solutions.

It has previously been postulated ${ }^{5}$ that conductivity results obtained in systems $M-M_{z}$ for different $z$ (namely, $z=1,2$, or 3 for a given $X$, as in $\mathrm{K}-\mathrm{KCl}, \mathrm{Sr}-\mathrm{SrCl}_{2}$, and $\mathrm{La}-\mathrm{LaCl}_{3}$, or in $\mathrm{K}-\mathrm{KI}$ and La-LaI ${ }_{3}$ ) could be correlated (complications by diatomic species assumed to be absent) if the stoichiometry, or the value of $z$, was included as a parameter. This was taken to mean that rather than electron concentration alone, the product of electron and metal ion concentration was significant. In Figs. 8.2 and 8.3, this correlation is attempted again for the present data, namely, the systems $\mathrm{K}-\mathrm{KBr}, \mathrm{Ba}-\mathrm{BaBr}{ }_{2}$, and $\mathrm{La}-\mathrm{LaBr}{ }_{3}$, and $\mathrm{K}-\mathrm{KI}, \mathrm{Ba}-\mathrm{BaI}{ }_{2}$, and $\mathrm{La}-\mathrm{LaI}_{3}{ }_{3}$.

While in the bromide systems a good correlation is achieved for $\mathrm{Ba}-\mathrm{BaBr}{ }_{2}$ with $\mathrm{K}-\mathrm{KBr}$, the correlation of $\mathrm{La}-\mathrm{LaBr}_{3}$ is not very satisfactory (Fig. $8.2 b$ ) even though it represents a great improvement over Fig. 8.2a showing the lack of correlation with electron concentration, $N_{\mathrm{M}}$, alone. Figure $8.3 b$ shows very poor agreement in the curves

\footnotetext{
${ }^{5}$ M. A. Bredig, J. Chem. Phys. 37, 914 (1962).
} 


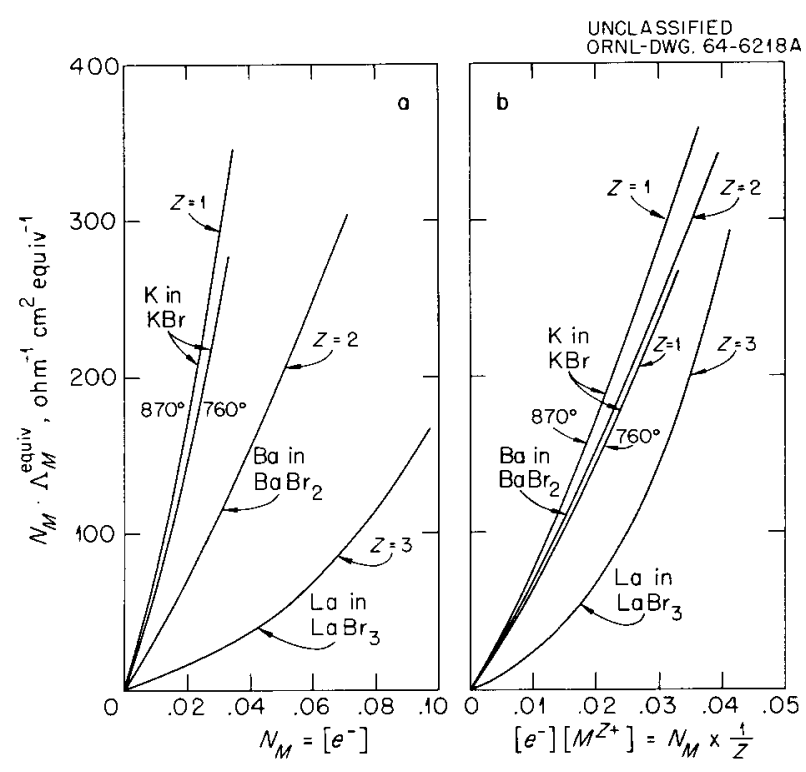

Fig. 8.2. Electronic Contribution, $N_{M} \cdot \Lambda_{M^{\prime}}$ to Equivalent Conductance of Metal-Bromide Melts (a) vs Metal Valence Electron Concentration, $N_{M} ;(b)$ vs Product, $N_{M} / z$, of Metal Valence Electron Concentration, $N_{M}$. and Metal lon Concentration, $1 / z$.
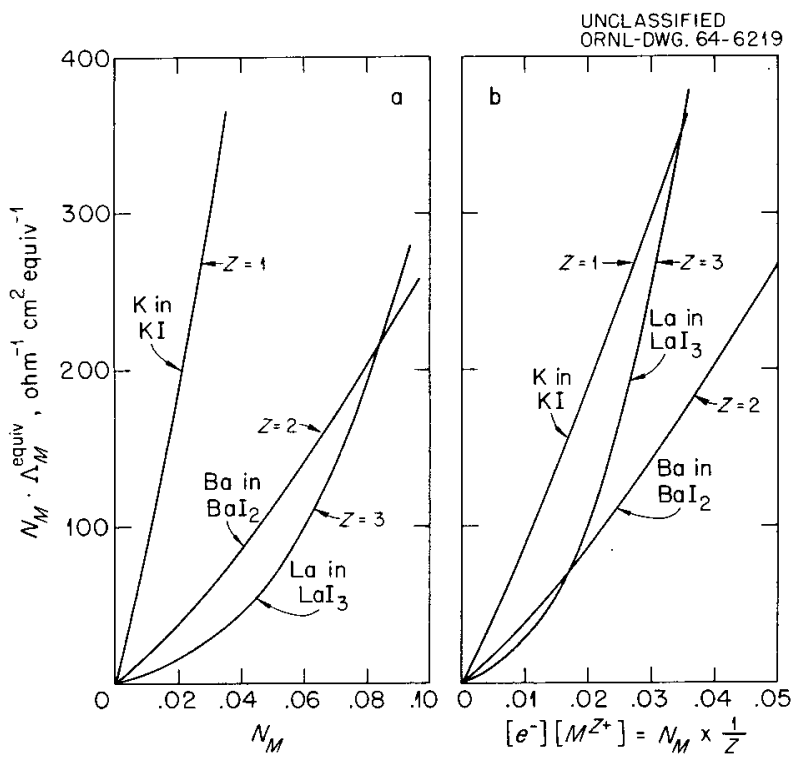

Fig. 8.3. Electronic Contribution, $N_{M} \cdot \Lambda_{M}$, to Equivalent Conductance of Metal-lodide Melts (a) vs Metal Valence Electron Concentration, $N_{M} ;(b)$ vs Product, $N_{M} / z$, of Metal Valence Electron Concentration, $N_{M}$ and Metal Ion Concentration, 1/z. for $\mathrm{Ba}-\mathrm{BaI}_{2}$ and $\mathrm{K}-\mathrm{KI}$, which raises serious doubts as to the value of the correlation. (There may be a connection with the "iodide effect," above, being much larger in the $\mathrm{Ba}$ than in the $\mathrm{K}$ systems.) One significant result, however, is the observation that the curvatures for the two alkali-metal and two alkaline-earth systems are all very small, while they are much larger for the two rare-earth systems. This striking difference may be deserving of further consideration, a connection with the almost certain absence of diatomic species in the rare-earth systems being thought to be possible.

Measurements of the lowering of the freezing point, $T_{m}$, of the salt to the freezing temperatures, $T$, of mixtures of the salt with increasing added small amounts of metal were less accurate than was hoped for, mainly because of strong supercooling. However, the number $n$ of particles produced at low concentrations by one atom of metal solute,

$$
n=\frac{T_{m}-T}{N_{\mathrm{M}}} \cdot \frac{\Delta H_{m}}{T_{m}^{2}}
$$

(which applies under the assumption that the metal is not soluble in the solid salt), was almost always considerably larger than unity $(\approx 1.5 \pm 0.2)$. The reactions

$$
\mathrm{M}+\mathrm{M}^{2+} \rightarrow \mathrm{M}_{2}^{2+}
$$

and

$$
\mathrm{M} \rightarrow \mathrm{M}^{2+}+2 \mathrm{e}
$$

correspond to $n=1$ and to $n=2$, respectively. There seems to be a decrease in $n$ towards unity with increasing metal concentration. An example is shown in Fig. 8.4. These observations, if not actually furnishing independent confirmation, are at least not in disagreement with the above interpretation of the curvature of the conductivity vs concentration curves, according to which reaction (2) leading to two mobile electrons per metal atom gradually changes with increasing metal concentration to reaction (1) providing electron traps. This is equivalent to an equilibrium $2 \mathrm{M}^{2+}+2 \mathrm{e} \rightleftharpoons$ $\mathrm{M}_{2}{ }^{2+}$ [as by deducting Eq. (2) from Eq. (1)].

The measured melting point depression in $\mathrm{SrCl}_{2}-$ Sr favors $n=1$ rather than $n=2$, even at lowest 


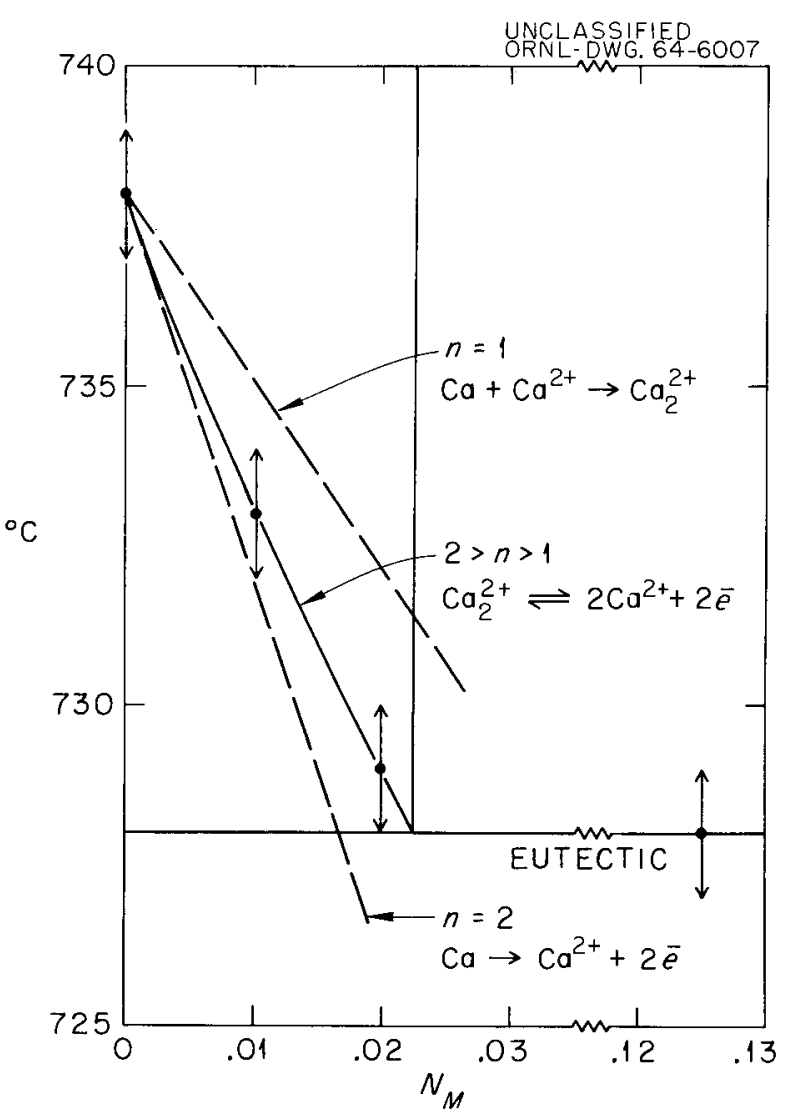

Fig. 8.4. Cryoscopy in Calcium Metal-Bromide System.

metal concentration. It seems certain that in this case the high solubility ${ }^{6}$ of the metal in the solid $\mathrm{SrCl}_{2}$ (see the section on $\mathrm{CaF}_{2}$-Ca solid solutions in this chapter; $\mathrm{SrCl}_{2}$ has the $\mathrm{CaF}_{2}$ type of structure) interferes with the simple interpretation of the melting point depression, but, at the same time, is indicative of $n>1$, or $\mathrm{Sr} \rightarrow \mathrm{Sr}^{2+}+2 e$, at least at low metal concentration.

The salt-rich eutectic and monotectic melt compositions in the systems $M X_{2}-M$ derived from the cryoscopic data are in good agreement with those obtained from the conductivity and solubility measurements at slightly higher temperatures. Agreement is also good with results on some of

${ }^{6}$ E. Mollwo, Nachr. Ges. Wiss. Göttingen, Math.Physik. K1., Fachgruppe II I, 79-89 (1934).

${ }^{7} \mathrm{~L}$. Staffanss on (with J. W. Tomlinson and F. D. Richardson), Ph.D. Thesis, London, 1960.

${ }^{8}$ J. A. Hinkebein, Ph.D. Thesis, Iowa State College, 1958.

${ }^{9}$ D. Peterson and J. A. Hinkebein, J. Phys. Chem. 63, 1360 (1959). these systems reported in the recent literature. ${ }^{7-9}$ There is large disagreement with older, ${ }^{10}$ as well as a few rather recent, ${ }^{11}$ reports. The experimental technique used in those studies, namely, the determination at room temperature of the presumed equilibrium solubilities after more or less rapid cooling from the test temperature, has been proved to be entirely unreliable. Proposals ${ }^{11}$ of curious complex cations such as $\mathrm{Ca}_{3}{ }^{2+}$ and $\mathrm{Sr}_{4}{ }^{2+}$ are totally at variance with our results.

\section{Miscibility of Barium Metal with Its Molten Halides}

\section{A. S. Dworkin H. R. Bronstein}

M. A. Bredig

In the alkali-metal-metal-halide systems, miscibility of the metal with the salt had been found to increase with the size of either the metal or the halide ion, that is, apparently with the decrease in cohesive, or interionic, forces. ${ }^{12}$ It was, therefore, of interest to determine whether this was indeed a general trend for metal-salt miscibility, by performing measurements on alkalineearth systems as the next step. A consolute temperature of $1010-1018^{\circ}$ in the $\mathrm{BaCl}_{2}-\mathrm{Ba}$ system as compared with $1320^{\circ}(\mathrm{F}), 1340^{\circ}(\mathrm{Cl}$ or $\mathrm{Br})$, and $1380^{\circ} \mathrm{C}$ (I) for the four calcium systems had already been observed and had given an indication that, in the alkaline-earth systems, the variation with the size of the halide ion was much smaller than with that of the metal ion, and possibly even reversed in trend.

The experimental results shown in Fig. 8.5 for three $\mathrm{BaX}_{2}-\mathrm{Ba}$ systems are mainly based on thermal analysis (cooling and heating curves) which was carried out with the samples contained in tantalum metal capsules in an apparatus described earlier.

Some difficulty was encountered with the purification of the barium metal. Vacuum distillation finally produced a reasonably satisfactory material though still containing $600 \mathrm{ppm}$ oxygen, $200 \mathrm{ppm}$

${ }^{10}$ D. D. Cubicciotti and C. D. Thurmond, J. Am. Chem. Soc. 71, 2149 (1949).

${ }^{11}$ H. H. Emons et al., Z. Anorg. Allgem. Chem. 323 , 114 (1963); Z. Chem. 2, 313, 377 (1962).

${ }^{12} \mathrm{~F}$ or a discussion of earlier data, as well as detailed literature references, cf. M. A. Bredig, "Mixtures of Metals with Molten Salts" in Molten Salt Chemistry, ed. by M. Blander, Interscience, New York, 1964; or ORNL-3391 (August 1963). 


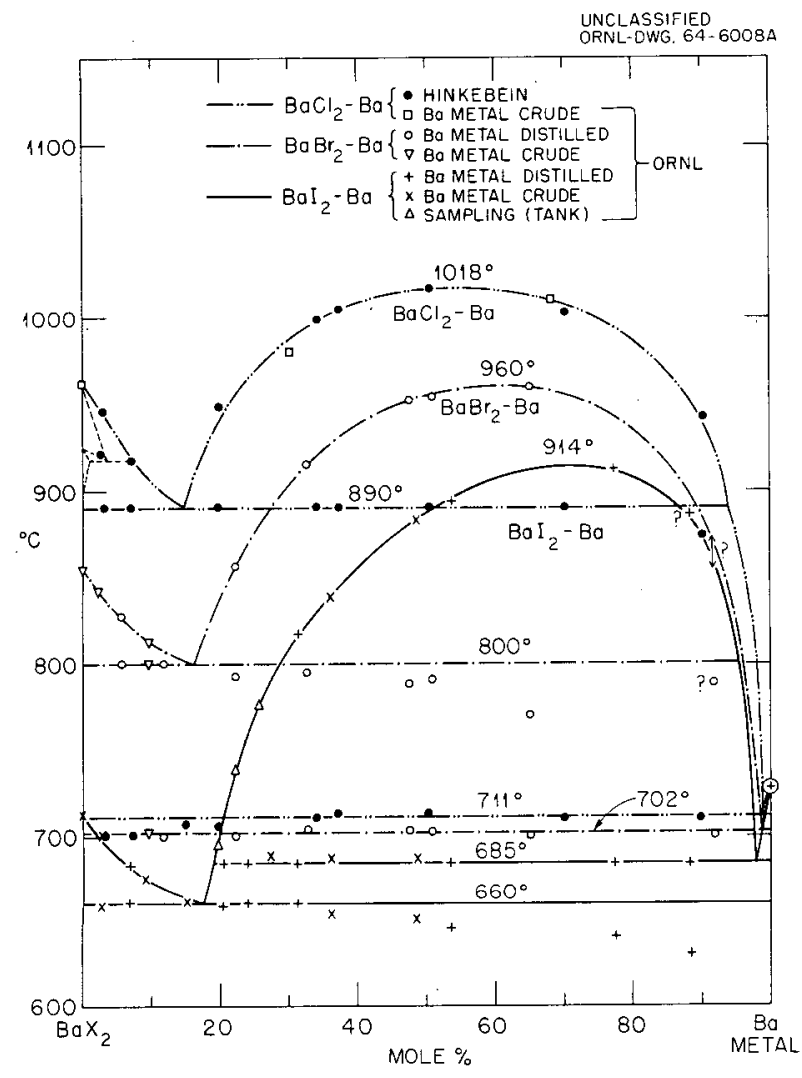

Fig. 8.5. Equilibrium Phase Diagrams of the $\mathrm{BaX}_{2}-$ Ba Systems $(X=C I, B r, I)$.

nitrogen, and $300 \mathrm{ppm}$ hydrogen and melting at $725 \pm 1^{\circ} \mathrm{C}$. This residual contamination amounting in the case of hydrogen to as much as 2 mole \% $\mathrm{BaH}_{2}$ is thought to be responsible both for the drop, with increasing metal content, of the observed monotectic temperature in the $\mathrm{BaBr}_{2}-\mathrm{Ba}$ system and of the eutectic temperature in the $\mathrm{BaI}_{2}-\mathrm{Ba}$ system, as well as for the very weak thermal effects still observed even after purification in the iodide experiments below the eutectic temperature of $660^{\circ}$ (Fig. 8.5). These, and some other thermal effects, greatly weakened or entirely eliminated by the purification of the metal, had been quite strong in the experiments with the undistilled metal and were accompanied by the appearance in the cooled samples of x-ray diffraction patterns entirely different from those of $\mathrm{BaX}_{2}$ or Ba metal. These $\mathrm{x}$-ray patterns must be ascribed to double salts of the general formulas $\mathrm{BaO} \cdot\left(\mathrm{BaX}_{2}\right)_{x}$ and $\mathrm{BaH}_{2} \cdot\left(\mathrm{BaX}_{2}\right)_{x}$, apparently not previously de- scribed in the literature, except for $\mathrm{BaH}_{2} \cdot \mathrm{BaCl}_{2}$ $(=\mathrm{BaClH})$. The influence of the impurities on the miscibility of metal and halide appeared to be surprisingly small.

Figure 8.5 shows that the critical solution temperature, $T_{c}$, drops from 1018 to 960 to $914^{\circ} \mathrm{C}$ for the chloride, bromide, and iodide systems, respectively. This means that with increasing size of the halide ion, or decreasing interionic forces in the salt, the miscibility of barium metal with its molten halides increases, similarly to that of the alkali metals with their halides, but oppositely to that of calcium metal with its salts as quoted above from the literature. It remains to be determined whether the data for the calcium systems are real or due to experimental uncertainties. If real, they might indicate a new trend within the alkaline-earth systems, namely, a change, with the nature of the metal, in the sign of the dependence of its miscibility on the nature of the halide ion. The strontium systems might, in further studies, turn out to be intermediate between the calcium and barium systems by exhibiting essentially no dependence of the miscibility on the size of the halide ion. An explanation for such possible complex behavior in the alkaline-earth systems is not apparent.

Significantly, the critical composition changes from 54 to 62 to 70 mole \% metal for the chloride, bromide, and iodide systems, respectively. This increase in the solubility of the metal in the molten salt may be attributed to the increase in the volume ratio of the two components, a reasonably well-understood relationship observed in other molten-salt-metal systems and in binary systems in general.

Finally, Fig. 8.5 shows clearly the kind of curvature of the liquidus curve for the crystallization of salt that is the result of increasing positive deviation from ideal solution behavior and is characteristic of systems with limited miscibility in the liquid state. In this, the batium-salt solutions resemble the potassium-salt solutions as they do in other respects, for example, electrical conductivity (cf. preceding section).

The so-called "iodide effect," that is, the failure of the miscibility to increase in going from the bromide to the iodide system as much as would be expected from the change in miscibility in going from the chloride to the bromide system, is observed but is not as strong as in the alkalimetal systems. 
Solid Solutions of Calcium in Calcium Fluoride
B. D. Lichter
M. A. Bredig

Phase equilibria and electrical conductance of of some metal-halide-metal systems indicate that in dilute solution the metal dissolves in its molten halide $\mathrm{MX}$ by being ionized according to $\mathrm{M}=$ $\mathrm{M}^{z+}+\mathrm{ze}^{-}$, but that at higher concentration, the electrons associate in pairs to form molecules or molecule ions such as $\mathrm{Na}$ or $\mathrm{Ca}_{2}{ }^{2+}$. The latter species was thought by Rogers, Tomlinson, and Richardson ${ }^{13}$ to exist even in dilute solutions of $\mathrm{Ca}$ in $\mathrm{CaF}_{2}$; but in order to support this hypothesis, a heat of fusion of $\mathrm{CaF}_{2}$ as high as $10 \mathrm{kcal} /$ mole, rather than $7.1 \mathrm{kcal} /$ mole measured calorimetrically, as well as insolubility of calcium in solid $\mathrm{CaF}_{\text {, }}$ had to be assumed. Since evidence for solid solution, yet of a rather unreasonably high degree, existed in the literature, determination of the true extent of such solid solution was made the objective of the work reported in the following excerpt of a paper which has been submitted for publication in the Journal of the Electrochemical Society:

"Solid $\mathrm{CaF}$ in equilibrium with calcium vapor and a saturated molten solution of $\mathrm{CaF}_{2}$ in calcium metal was found to contain slightly more than 2 mole percent of calcium metal in solid solution at the monotectic temperature of $1290^{\circ} \mathrm{C}$.

"The observed solubility of calcium in solid $\mathrm{CaF}_{2}$ is considered in an analysis of the meltingpoint depression of $\mathrm{CaF}_{2}$. Hypothetical liquidus curves corresponding to possible solution mechanisms for calcium in $\mathrm{CaF}_{2}$ are calculated on the basis of (1) the known heat of fusion of $\mathrm{CaF}_{2}$, (2) the tentative assumption that the solution mechanism is the same in very dilute solid and liquid solutions, and (3) the adoption of an estimated solidus curve (Fig. 8.6). Comparison with existing liquidus data suggests that the reaction

$$
\mathrm{Ca}+\mathrm{Ca}^{++}=\mathrm{Ca}_{2}{ }^{++}
$$

is limited to higher metal concentrations. This result is similar to the findings in the other three

${ }^{13}$ P. S. Rogers, J. W. Tomlinson, and F. D. Richardson, p. 909 in Physical Chemistry of Process Metallurgy, ed. by G. R. St. Pierre ("Metallurgical Society Conferences," vol, 8), Interscience, New York, 1961. calcium-calcium halide systems where, on the basis of electrical conductance measurements, the ionization

$$
\mathrm{Ca}=\mathrm{Ca}^{++}+2 e^{-}
$$

was assumed in dilute solutions."

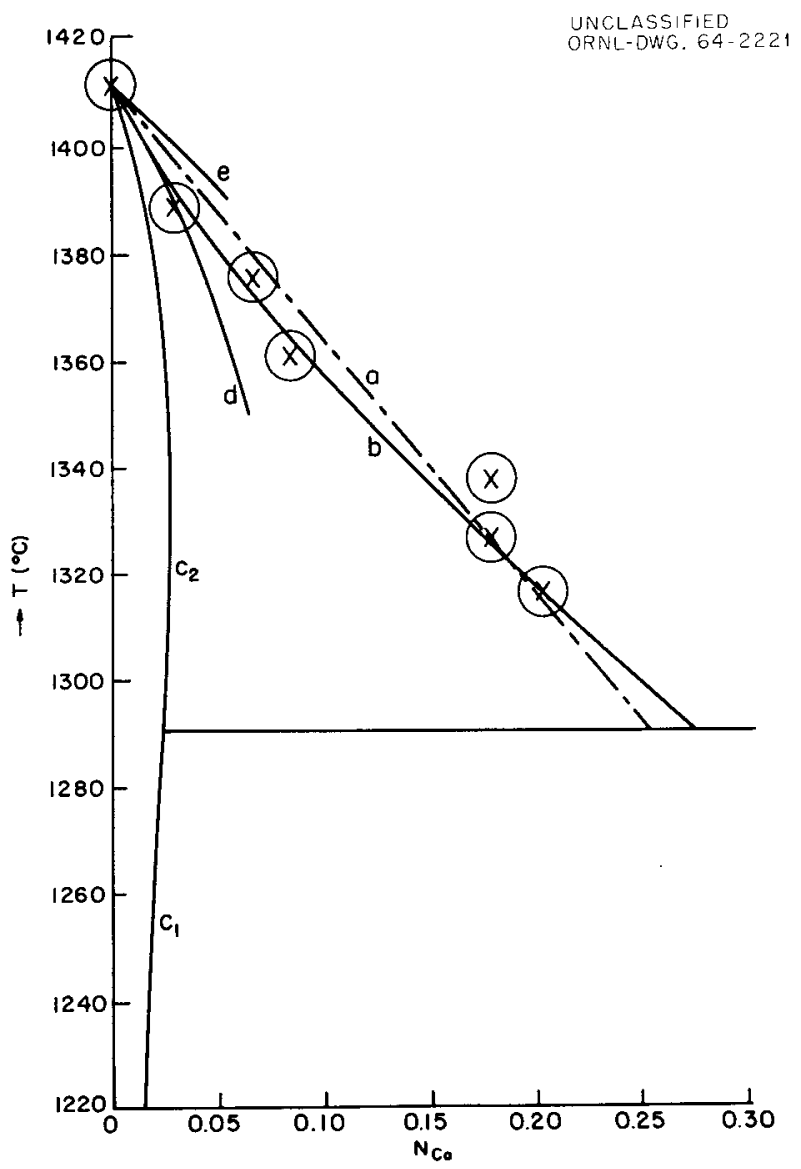

Fig. 8.6. Liquidus and Solidus Curves for System

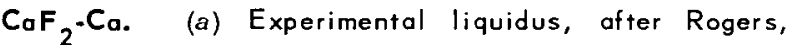
Tomlinson, and Richardson. (b) Experimental liquidus after Lichter and Bredig from data of Rogers, Tomlinson, and Richardson. $\left(c_{1}\right)$ Solidus, experimental. $\left(c_{2}\right)$ Solidus, estimated. (d) "Ideal" liquidus, $T=T_{m}$ $\left(2 R T_{m}^{2} / \Delta H_{m}\right)\left(N_{C_{a}}^{(l)}-N_{C_{a}}^{(s)}\right)$ for $\mathrm{Ca} \rightarrow \mathrm{Ca}^{2+}+2 e^{-} \cdot{ }^{m}(e)$ "Ideal" liquidus, $T=T_{m}-\left(R T_{m}^{2} / \Delta H_{m}\right)\left(N_{C_{a}}^{(1)}-N_{\mathrm{Ca}}^{(s)}\right)$ for $\mathrm{Ca}+\mathrm{Ca}^{2+} \rightarrow \mathrm{Ca}_{2}^{2+}$. Note identity of curves $b$ and $d$ for $N_{\mathrm{Ca}}^{(1)}<0.02$ and increasing positive deviation of $b$ from $d$ at higher metal concentrations. 


\section{Chemical Physics}

\section{MICROWAVE AND RADIO-FREQUENCY SPECTROSCOPY}

\section{Paramagnetic Resonance Study of Photolyzed Hydrogen Peroxide}

\section{R. W. Holmberg Ralph Livingston}

In the last annual report ${ }^{2}$ five paramagnetic resonance spectra that form in $100 \% \mathrm{H}_{2} \mathrm{O}_{2}$ single crystals upon photolysis with uv were described. These spectra were given numbers, and the status of measurements and analyses was given.

The spectrum formed in by far the highest yield (spectrum I) is observed upon photolysis at $64^{\circ} \mathrm{K}$. Measurements are made at this temperature since the spectrum disappears at high temperatures. Measurements at 24,000 Mc have been made with the applied magnetic field parallel to three different planes of the crystal, (110), (001), and $(100)$. The data are very complex; one significant finding thus far is that the species responsible for the spectrum is in a triplet state. The strength of the spin-spin interaction is of the order of $0.01 \mathrm{~cm}^{-1}$. This finding is quite significant because it shows that simple radicals such as $\mathrm{OH}$ or $\mathrm{HO}_{2}$ cannot be responsible for this prominent spectrum. It is quite possible, however, that pairs of these radicals are weakly coupled to give the observed triplet species.

As a further aid in unraveling these spectra, measurements have been made on single crystals of pure $\mathrm{D}_{2} \mathrm{O}_{2}$. The $\mathrm{D}_{2} \mathrm{O}_{2}$ was prepared by ex-

\footnotetext{
${ }^{1}$ R. W. Holmberg and Ralph Livingston, Chem. Div. Ann. Progr. Rept. June 20, 1963, ORNL-3488, p. 103.
}

change using $\mathrm{D}_{2} \mathrm{O}$ and $\mathrm{H}_{2} \mathrm{O}_{2}$. Approximately $70 \% \mathrm{H}_{2} \mathrm{O}_{2}$ was vacuum distilled to give a distillate of nearly pure water. The volume in the distillation flask was kept constant by addition of $\mathrm{D}_{2} \mathrm{O}$. The exchange was rapid, and the progress of the deuteration was followed by nuclear magnetic resonance. A final distillation was used to concentrate the $\mathrm{D}_{2} \mathrm{O}_{2}$.

The paramagnetic species corresponding to spectrum I has been observed, and measurements have recently been made for two planes. Results with $\mathrm{D}_{2} \mathrm{O}_{2}$ showed one important difference from those with $\mathrm{H}_{2} \mathrm{O}_{2}$. For $\mathrm{H}_{2} \mathrm{O}_{2}$, upon warming to $77^{\circ} \mathrm{K}$, a new, much weaker spectrum (spectrum II) ${ }^{1}$ appeared. In $\mathrm{D}_{2} \mathrm{O}_{2}$ spectrum $\mathrm{I}$ also vanishes at $77^{\circ} \mathrm{K}$, but a new spectrum of comparable strength grows in as the original one fades. This species is not the same as the one in $\mathrm{H}_{2} \mathrm{O}_{2}$. It has been measured for three planes and is clearly a triplet species. The spectra are sufficiently simple (very little hyperfine structure is resolved) that a complete analysis of the $g$ and $D$ tensors can probably be made.

A species with extreme anisotropy in $g$ value (spectrum IV) ${ }^{1}$ has been further investigated. This spectrum has $g$ values ranging from about 0.5 to 4. It is not seen in $\mathrm{H}_{2} \mathrm{O}_{2}$ upon photolysis at $64^{\circ} \mathrm{K}$, but grows in when the sample is warmed to $77^{\circ} \mathrm{K}$. The $g$ values have been found to be frequency-dependent, particularly at low $g$ values. An analysis of the spectrum that looks promising is that this species is also in a triplet state, but a very large spin-spin interaction splits one level away by several wave numbers. This leaves a pair of levels between which transitions are observed. Atomic oxygen trapped in the peroxide lattice may very well be the species responsible for this spectrum. 
Paramagnetic Resonance Study of Free Radicals Formed in Liquids During Ultraviolet Photolysis

\section{Ralph Livingston Henry Zeldes}

We have recently observed and identified at steady state rather simple, short-lived organic free radicals in liquids at room temperature during intense uv photolysis. The systems thus far studied are alcohols containing small amounts of hydrogen peroxide. These systems have previously been studied ${ }^{2}$ as frozen solids (glasses) where the radicals are stably trapped. The lines in solids are broad, and positive identification of the radicals cannot always be made. On the other hand, the spectra in liquids are exceedingly sharp; therefore, finer detail can be resolved, and the relative intensities of resolved hyperfine components give a much more reliable measure of whether or not protons are equivalent.

In a typical experiment a solution of $0.5 \%$ of $\mathrm{H}_{2} \mathrm{O}_{2}$ in isopropyl alcohol was prepared, the system was freed of oxygen by purging with helium, and the liquid was flowed through a quartz cell contained in the microwave cavity of the spectrometer. A typical flow rate was $10 \mathrm{ml} / \mathrm{min}$. The sample was irradiated in the cavity with light from a high-pressure mercury arc (type AH-6) and the spectrum was observed during irradiation. In a similar manner spectra have been observed with methanol, ethanol, and ethylene glycol. In each case the radical forms by loss of an a hydrogen from the alcohol. The $\mathrm{H}_{2} \mathrm{O}_{2}$ is photolyzed to give $\mathrm{OH}$ which in turn abstracts the hydrogen from the alcohol.

In methanol the $\mathrm{CH}_{2} \mathrm{OH}$ radical forms, and the spectrum consists of hyperfine components from all protons, one family of two equivalent protons with a much weaker coupling from the hydroxyl proton. In ethanol the radical is $\mathrm{CH}_{3} \mathrm{CHOH}$. In ethylene glycol the radical is $\mathrm{CHOHCH}_{2} \mathrm{OH}$ with all protons giving resolved splittings except for the hydroxyl proton remote from the position lacking hydrogen. In isopropyl alcohol the radical is $\mathrm{CH}_{3} \mathrm{COHCH}_{3}$. The six equivalent protons give a seven-line spectrum of relative intensities 1-6-15-20-15-6-1. The lines of unit intensity have been too weak to be observed. The other lines are in the correct intensity ratio. They are split by the weak interaction from the hydroxyl proton.

${ }^{2}$ J. F. Gibson et al., Trans. Faraday Soc. 53, 914 (1957).
In order to improve the intensity of the spectra our equipment has been refined. We have included provisions for cooling the liquids so the effects of lower temperatures can be studied. Also better provisions for making quantitative measurements have been included. These measurements are now being started.

\section{Paramagnetic Resonance Study of Irradiated Dimethylglyoxime}

Henry Zeldes Ralph Livingston

Experimental work on two paramagnetic species in gamma-irradiated single crystals of dimethylglyoxime is nearly finished. In the last annual report $^{3}$ parameters of the spin Hamiltonian for one of the species, a radical with an electron spin of $1 / 2$, were given. The spectrum had large hyperfine splittings from one of the nitrogen atoms in dimethylglyoxime. It was also reported that a species with an electron spin of 1 (triplet) was present. Measurements of this triplet state have now been completed for three crystal planes. This was done at room temperature rather than at a lower temperature even though the spectrum became very weak after a few days. The orientation of the crystal in the applied magnetic field could be ascertained more accurately in this way. The allowed transitions $\left(\Delta m_{s}=1\right)$ consisted of two widely spaced groups of five lines. The twofold splitting is due to an anisotropic electron spinspin coupling, and the fivefold splitting is due to magnetic hyperfine coupling of the unpaired electrons with two equivalent nitrogen nuclei. Measurements were also made of the forbidden $\left(\Delta m_{s}=2\right)$ transitions which occur at about one-half the field for the allowed transitions.

The triplet-state species has been identified as an interacting pair of the doublet-state radicals whose parameters were given in the last annual report. $^{3}$ The paramagnetic resonance measurements give only the anisotropic part of the electron spin-spin interaction; the amount of isotropic exchange interaction is unknown. It was reported $^{3}$ that this species is a ground-state triplet since it persisted without decay at $77^{\circ} \mathrm{K}$. It is now realized that this need not be the case.

\footnotetext{
${ }^{3}$ Henry Zeldes and Ralph Livingston, Chem. Div. Ann. Progr. Rept. June 20, 1963, ORNL-3488, p. 102.
} 
Table 9.1. Principal Values and Directions for $g$ and $A$ for the Triplet Species and for the Doublet Rodical

\begin{tabular}{|c|c|c|c|c|c|}
\hline \multirow{2}{*}{ Species } & \multirow{2}{*}{ Tens or } & \multirow{2}{*}{$\begin{array}{c}\text { Principal Value } \\
\text { (in gauss for } A / \beta \text { ) }\end{array}$} & \multicolumn{3}{|c|}{ Degrees to Crystal Axis } \\
\hline & & & $a$ & $b$ & c \\
\hline Triplet & $g$ & 2.0118 & 50.3 & 37.0 & 131.7 \\
\hline Doublet & & 2.0098 & 52.0 & 33.8 & 130.9 \\
\hline Triplet & & 2.0026 & 124.7 & 53.1 & 93.8 \\
\hline Doublet & & 2.0025 & 125.4 & 56.2 & 89.6 \\
\hline Triplet & & 2.0072 & 58.8 & 87.5 & 42.0 \\
\hline Doublet & & 2.0065 & 57.7 & 89.8 & 40.9 \\
\hline Triplet & $A / \beta$ & 85.3 & 51.3 & 116.6 & 97.2 \\
\hline Doublet & & 91.8 & 47.8 & 114.6 & 96.2 \\
\hline Triplet & & 46.3 & 118.8 & 153.1 & 44.3 \\
\hline Doublet & & 47.6 & 121.5 & 155.4 & 50.6 \\
\hline Triplet & & 50.6 & 127.9 & 93.8 & 133.4 \\
\hline Doublet & & 52.6 & 121.6 & 89.6 & 140.0 \\
\hline
\end{tabular}

The spin Hamiltonian appropriate for an interacting pair of identical radicals was solved by first-order perturbation theory. The parameters were evaluated with the help of a digital computer using programs which selected parameters by the criterion of a least-square fit of the data. Table 9.1 lists principal values and directions for the tensors $g$ and $A$. Parameters for the triplet species and the previously reported ${ }^{3}$ doublet species are given. The close agreement clearly indicates that the triplet species is a coupled pair of doubletstate radicals. This interpretation is further supported by the parameters for the tensor $D$ which appear in the triplet-state spin Hamiltonian to describe the anisotropic spin-spin interaction, $S \cdot D \cdot S$. The principal values and directions of $D / \beta$ (where $\beta$ is the Bohr magneton) are given in Table 9.2. The tensor is approximately axially symmetric, and the major principal value of 179.3 gauss makes an angle of $3.9^{\circ}$ to the crystal a axis. ${ }^{4}$ If the coupled pair of doublet radicals were separated by one unit cell distance along the crystal a axis, and if the unpaired electron in each radical were localized at a single point, the $D$ tensor would be axially symmetric about this axis with the value 163.8 gauss for this direction. This agreement is impressive, especially when considering the approximate nature of a pointelectron model and the strong dependence of the

${ }^{4}$ L. L. Merritt, Jr., and E. Lanterman, Acta Cryst. 5, 811 (1952).
Table 9.2. Principal Values and Directions for $D / \beta$

\begin{tabular}{crrr}
\hline \multirow{2}{*}{$\begin{array}{c}\text { Principa1 Value } \\
\text { (gauss) }\end{array}$} & \multicolumn{3}{c}{ Degrees to Crystal Axis } \\
\cline { 2 - 4 } & \multicolumn{1}{c}{$a^{\circ}$} & \multicolumn{1}{c}{$b$} & $c$ \\
\hline 179.3 & 3.9 & 79.5 & 86.6 \\
-86.8 & 93.9 & 101.5 & 22.5 \\
-92.5 & 89.7 & 164.3 & 67.8 \\
\hline
\end{tabular}

interaction on distance $\left(1 / r^{3}\right)$. The fit is even closer if the electron is distributed on nitrogen and oxygen as suggested by an analysis of the hyperfine tensor.

The doublet-state radical is believed to be formed by the removal of a hydrogen atom from one of the $\mathrm{N}-\mathrm{O}-\mathrm{H}$ groups of the parent molecule. The hydrogen atom frequently abstracts a similarly located hydrogen atom from one of the neighboring molecules to produce a relatively high yield of the triplet species.

\section{A Machine for Integrating Chart Recordings}

\section{Ralph Livingston}

Paramagnetic resonance spectra that are chartrecorded usually are obtained in the form of the derivative of absorption as a function of magnetic 
field strength. It is occasionally desirable to integrate these recordings so that the absorption itself may be directly examined, and sometimes a second integration is needed so that areas of absorption lines may be quantitatively compared. An electronic integrating device may be incorporated in the spectrometer so as to perform this operation at the time the initial spectrum is observed. Normally the derivative would be simultaneously recorded and preserved since this is a record that accentuates subtle features of the spectrum. This mode of operation usually requires the spectrum to be traced more than once since uncompensated base-line drift or failure to set the integrator at an exact "zero" on the base line will quickly accumulate enough signal to drive the integrated recording off scale.

The idea behind the present machine is to integrate existing derivative recordings. In operating the spectrometer all attention is focused on making good derivative recordings that are stored for record purposes. An integrated chart can then be prepared from any stored.record, and if need be this chart in turn can be run through the machine to give a second integral. The important finding, more important than details of construction of the machine, is that this mode of operation is convenient and offers several advantages, including surprisingly good accuracy.

The integrating machine is semiautomatic and is based on a Brown Electronik recorder. One recorder is used to trace the original chart. The paper transport mechanism is left intact; none of the original measuring circuitry is used. The original slide-wire drum of the recorder was replaced by a three-turn Helipot and cabled to a stylus (in place of the original pen) in such a way that when the Helipot is rotated (manually) the stylus moves. The chart is fed through the recorder, a typical rate being $90 \mathrm{in.} / \mathrm{hr}$, and the Helipot rotated so that the stylus traces the recording. A battery across the Helipot develops a voltage, and it is this signal that is electronically integrated with an operational amplifier and then recorded on a standard Brown recorder. With moderate care an accuracy of $2 \%$ is obtainable, and this can be reduced to about $1 \%$ with great care in manually tracing with the stylus. A certain amount of compensation for base-line drift can be made. If this drift is such that the base line is straight on the integrated chart then complete compensation can be achieved. The integrated record may be easily expanded or compressed by suitable selection of chart speeds and its height may also be scaled to any desired value.

\section{CALORIMETRY}

\section{Molar Enthalpies of Mixing in the Molten LiF-NaF System}
R. A. Gilbert
R. H. Busey

The measurements reported here are a continuation of a study of the enthalpies of mixing in molten alkali fluoride systems. The method, which utilizes a high-precision drop calorimeter, has been described previously. ${ }^{5}$ The enthalpy determinations were made at $1278^{\circ} \mathrm{K}$. The data are presented in Fig. 9.1 where the apparent molar

${ }^{5}$ R. A. Gilbert, J. Phys. Chem. 67, 1143 (1963).

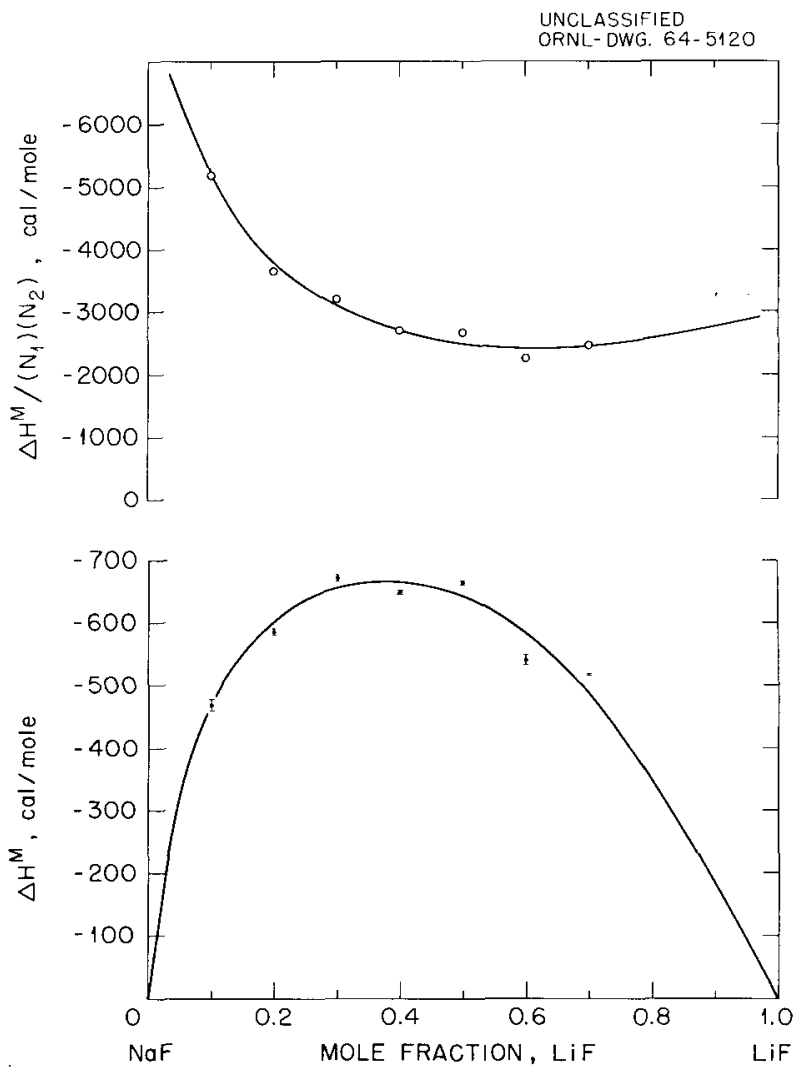

Fig. 9.1. Apparent Molar Enthalpies of Mixing $\left(\Delta H^{M}\right)$ in Mixtures of LiF-NaF at $1278^{\circ} \mathrm{K}$. 
heat of mixing, $\Delta H^{M}$, and the deviation function, $\Delta H^{M} / N_{1} N_{2}$, are plotted as a function of the mole fraction of $\mathrm{LiF}, N_{1}$.

A comparison of these data with those on the similar system LiF-KF (ref. 5) revealed that anomalous results were being obtained. This is evident in the very large asymmetry of $\Delta H^{M}$ vs $N_{1}$ which is clearly shown by the deviation plot. The method of measurement requires that the molten solution of the two salts at $1278^{\circ} \mathrm{K}$ give only the pure, crystalline salt phases when quenched in the ice calorimeter, with no solid solution or glass formation, and no change in crystal structure from that stable at $0^{\circ} \mathrm{C}$. This is a prerequisite of any enthalpy measurement employing a drop calorimeter. The data indicated that this prerequisite was not being met.

The samples were examined petrographically for evidence of glass formation with negative results. No evidence of slow heat evolution was observed which might result if a temporary, metastable glass was formed on quenching. Since both $\mathrm{LiF}(\mathrm{c})$ and $\mathrm{NaF}(\mathrm{c})$ show no change in crystal structure from room temperature to their melting points, the possibility of obtaining a different crystal structure was ruled out.

This left the possibility of solid solution formation, and indeed, since these measurements were completed, a determination of the crystalline solubility in the LiF-NaF system has been published. ${ }^{6}$ Short and Roy observed a solubility of 8 mole \% $\mathrm{LiF}$ in $\mathrm{NaF}$ and 1.5 mole $\% \mathrm{NaF}$ in $\mathrm{LiF}$ at $625^{\circ} \mathrm{C}$, a temperature just below the eutectic temperature. The observed apparent $\Delta H^{M}$ (Fig. 9.1) is consistent with this in that the values for high mole fraction of $\mathrm{NaF}$ deviate the most from the expected values, in which region the solubility of the $\mathrm{LiF}$ in the $\mathrm{NaF}$ would have the greatest effect.

In order to obtain true values of the heat of mixing, as distinct from the observed apparent heats of mixing, it is planned to observe by solution calorimetry the heat contents of the quenched samples relative to prepared pure mixtures. Although the rate of solution of $\mathrm{LiF}$ in water is

\footnotetext{
${ }^{6} \mathrm{~J}$. M. Short and Rustum Roy, J. Am. Ceram. Soc. 47. 149 (1964).
}

very slow, the rate in $2 \mathrm{~N} \mathrm{H}_{2} \mathrm{SO}_{4}$ is sufficiently rapid for heat of solution measurements as observed in a preliminary experiment.

\section{Thermodynamic Properties of Rhenium Trichloride}
R. B. Bevan, Jr.
R. H. Busey
R. A. Gilbert

Following the low-temperature heat capacity measurements on $\mathrm{ReCl}_{3}$ reported previously, ${ }^{7}$ the performance of the calorimeter was checked by measuring a Calorimetry Conference standard sample of benzoic acid. The check indicated the calorimeter was giving low results due to improper thermal anchoring of the heater leads, a situation inadvertently created in the course of rewiring the cryostat. The calorimeter was observed to give results agreeing to better than $0.1 \%$ on the standard sample after this defect was corrected.

The $\mathrm{ReCl}_{3}$ measurements were repeated, giving results differing only slightly from the previous data and confirming the unusual behavior in the temperature range 7 to $50^{\circ} \mathrm{K}$ observed previously. ${ }^{7}$ Table 9.3 lists the thermodynamic properties.

A recent measurement of the crystal structure of $\mathrm{ReCl}_{3}$ (ref. 8) shows that the $\mathrm{Re}^{3+}$ ion is essentially in tetrahedral coordination with a ground-state electronic configuration $d \gamma^{4}$; consequently, the crystalline $\mathrm{ReCl}_{3}$ should be diamagnetic except possibly for a small Van Vleck temperature-independent paramagnetism. The apparent excess heat capacity previously derived is therefore probably fortuitous. The behavior of the low-temperature heat capacity is most likely explicable in terms of the vibrational energy states $^{9}$ of the $\mathrm{Re}_{3} \mathrm{Cl}_{9}$ clusters present in the crystal. The low-temperature heat capacity of

\footnotetext{
${ }^{7}$ R. B. Bevan, Jr., R. A. Gilbert, and R. H. Busey, Chem. Div. Ann. Progr. Rept. June 20, 1963, ORNL. 3488 , p. 119 .

${ }^{8} \mathrm{~F}$. A. Cotton and J. T. Mague, Inorganic Chemistry (in press).

${ }^{9}$ Assuming a $D_{3 h}$ point symmetry for the $\operatorname{Re}_{3} \mathrm{Cl}_{9}$ clusters, a total of 20 vibrational energy states would be present. No vibrational spectrum is available at the present.
} 
crystalline benzene, which shows a similar but more pronounced effect than that exhibited by $\mathrm{ReCl}_{3}$, has been so explained. ${ }^{10}$

Table 9.3. Thermodynamic Properties of $\mathrm{ReCl}_{3}(c)$ (cal deg ${ }^{-1}$ mole $^{-1}$ )

\begin{tabular}{lcccc}
\hline$T\left({ }^{0} \mathrm{~K}\right)$ & $C_{p}^{0}$ & $S^{0}$ & $\left(H^{0}-H_{0}^{0}\right) / T$ & $-\left(F^{0}-H_{0}^{0}\right) / T$ \\
\hline 10 & 0.492 & 0.264 & 0.174 & 0.090 \\
15 & 1.039 & 0.565 & 0.369 & 0.196 \\
25 & 2.076 & 1.336 & 0.842 & 0.494 \\
50 & 5.510 & 3.760 & 2.267 & 1.493 \\
100 & 12.64 & 9.898 & 5.767 & 4.131 \\
150 & 17.13 & 15.948 & 8.870 & 7.078 \\
200 & 19.64 & 21.254 & 11.279 & 9.975 \\
250 & 21.12 & 25.807 & 13.110 & 12.697 \\
273.15 & 21.62 & 27.700 & 13.810 & 13.890 \\
298.15 & 22.08 & 29.614 & 14.549 & 15.065 \\
\hline
\end{tabular}

\section{NEUTRON AND X-RAY CRYSTALLOGRAPHY}

\section{Machine-Plotted Crystal Structure Diagram with Thermal-Motion Probability Ellipsoids}

\section{K. Johnson}

When three-dimensional intensity data are used in a crystal structure refinement it is common to correct for thermal motion by fitting anisotropic temperature factor coefficients to the major atoms of the crystallographic asymmetric unit. The high-precision intensity measurements currently possible and the widespread availability of computational facilities for refining the model to convergence suggest that many of the recent accurate structure analyses contain meaningful information about thermal motion and that these results warrant more thorough analysis. A major preliminary to any analysis is a visualization of

\footnotetext{
${ }^{10}$ R. C. Lord, J. E. Ahlberg, and D. H. Andrews, J. Chem. Phys. 5, 649 (1937).
}

the complete mathematical model which is described by the combined positional and thermal parameters. The present project was undertaken to facilitate this step.

The graphic representation for the thermal motion of each atom is an ellipsoid defined by a surface of constant probability density. The principal axes of the ellipsoid are derived from the anisotropic temperature factor coefficients, and the axes have lengths proportional to the rms components of displacement in these directions. If the factor of proportionality is set at 1.54 , there is a $50 \%$ probability that a random point in a thermal-motion distribution will fall inside the ellipsoid. ${ }^{1.12}$ This might be called the thermalmotion 50\%-probability ellipsoid.

A FORTRAN-coded Thermal Ellipsoid Plot program (OR TEP) which utilizes standard plotting subroutines has been written and is approaching its final stages of development. This program can be executed on either a CDC-1604A or an IBM 7090 computer. The plotting is done off-line on a digital $X-Y$ plotter such as that made by Calcomp or Benson Lehner.

A sample (Fig. 9.2) is shown of a structure refined recently by members of this group from threedimensional neutron diffraction data. The feature of particular interest is the thermal motion of the hydrogen atoms because such information is beyond the capabilities of $x$-ray diffraction. The figure is plotted as a stereoscopic pair so that correlations between the thermal-motion anisotropy and the molecular geometry and environment become more readily apparent to the viewer. Stereo viewing of the figure is best facilitated with a hand stereoscope, ${ }^{13}$ but may sometimes be realized with ocular gymnastics.

Systematic studies of thermal motion in closely related compounds would be a logical extension of the use of the program. For example, one might compare the torsional oscillation of the carboxyl groups in the numerous carboxylic acid structures which have been published.

\footnotetext{
${ }^{11}$ R. S. Burington and D. C. May, Handbook of Probo ability and Statistics with Tables, p. 107, Handbook Publishers, Sandusky, Ohio, 1953.

${ }^{12}$ D. B. Owen, Handbook of Statistical Tables, p. 203, Addis on-Wesley, Reading, Mass., 1962.

${ }^{13}$ For example, the Televiewer manufactured by the Keystone View Company, Meadville, Pa.
} 


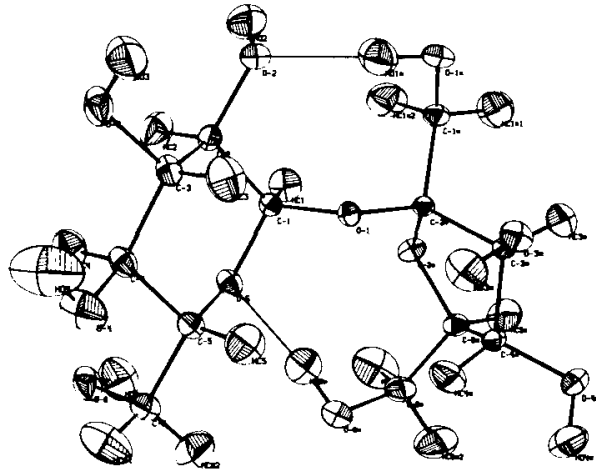

SUCROSE FROM NEUTRON DIFFRACTION
UNCLASSIFIED

ORNL DWG. $64 \cdot 6522$

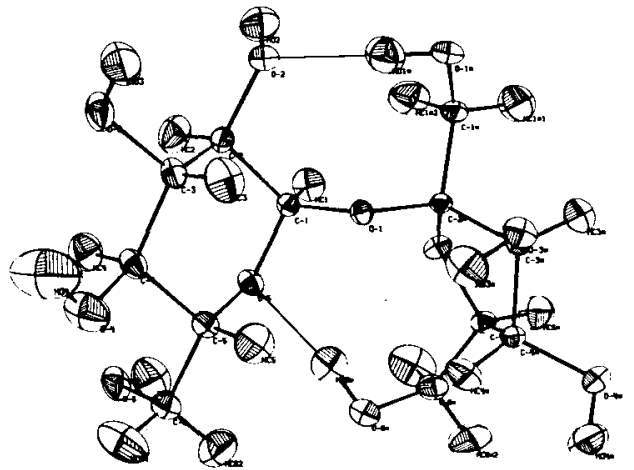

SUCROSE FROM NEUTRON DIFFRACTION

Fig. 9.2. A Stereoscopic Pair of Perspective Projections Showing the Sucrose Structure as Refined by G. M. Brown and H. A. Levy (Chem。Div。Ann. Progrr. Rept. June 20, 1964, ORNL-3488, pp. 108-11). The thermal-motion probability ellipsoids in the figure have axial dimensions 1.5 times the corresponding rms displacements.

\section{The Design of a Relatively Inexpensive Computer-Controlled Diffractometer}
W. R. Busing
R. D. Ellison
C. K. Johnson
H. A. Levy

The collection of three-dimensional singlecrystal $\mathrm{x}$-ray or neutron diffraction data is a procedure which is ideally suited for automation. The diffractometer shafts must be accurately set to precalculated angles, and the diffracted beam intensity must then be measured and recorded. The time for this operation is of the order of a few minutes, and several thousand measurements are often made for a given experiment.

A number of instruments have been constructed which read the precalculated angles from punched paper tape (or perhaps punched cards) and record the results on the same medium. ${ }^{14}$ The use of such "off-line" instruments requires access to a computer for preparation of the controlling tape and for processing the data output. An obvious modification of this procedure would be to eliminate the paper tape and to connect the diffractometer directly to the computer. A few such "on-line" systems have been completed or are under construction at the present time. ${ }^{15}$ To date, however, on-line diffractometers are in most

\footnotetext{
${ }^{14}$ For a review see S. C. Abrahams, Chem. Eng. News 41, 108 (1963).
}

cases considerably more costly than the corresponding off-line instruments, so that it is reasonable to ask whether they are correspondingly more useful.

Three years of experience with the Oak Ridge neutron diffractometer ${ }^{16}$ have convinced the authors that an off-line instrument is entirely satisfactory for routine data collection once the preliminary details of crystal orientation and cell-size determination have been performed. It is also clear, however, that a computer-controlled instrument which is capable of modifying its operations on the basis of the intensities which it measures would greatly assist these preliminary operations. Thus the advantages of on-line operation are to be found in the fringe benefits of feedback and flexibility - advantages which justify only a moderate increase in cost. Preliminary plans for an on-line diffractometer which meets this condition will now be described.

Two basic principles are to be followed. First, no attempt will be made to replace completely the auxiliary use of a large computer. Thus a relatively inexpensive computer will be used for

\footnotetext{
${ }^{15}$ See, for example, H. Cole, Y. Okaya, and F. W. Chambers, Congress of the IUCr, Rome, Italy, September 1963, paper $18(i) \cdot 21$, or K. F. Bowden et al., ibid., paper $\mathrm{S1} \cdot 32$.

${ }^{16}$ W. R. Busing and H. A. Levy, American Crystallographic Association Annual Meeting, July 1961, paper B-6.
} 
the instrument. The use of magnetic tape as a data medium is ruled out as prohibitively expensive. Second, the computer will be made to do as much work as possible, performing functions which would otherwise have to be done by means of expensive external hardware. This point will be illustrated by describing the two fundamental operations - shaft setting and counting.

The most common method of shaft setting involves the use of encoders or digitizers which sense the angular position in an absolute way. These encoders are costly and for computer control have the added disadvantage of requiring computer input devices for up to 18 bits of information per shaft. The system under consideration will set angles by means of pulse motors which move a fixed amount each time a signal is transmitted to them. The disadvantage of this technique for off-line operation would be that any pulses missed by the motor would cause cumulative errors. With the on-line instrument, however, it is planned that as a shaft rotates through a certain reference position a marker signal will be fed back so that the computer can correct small errors or take appropriate action in case of large ones. An external oscillator will control the rate of pulses to the motors by interrupting the computer periodically.

Conventional counting techniques involve the use of scalers, but these again have the disadvantage of requiring relatively complicated devices to transmit their information to the computer. Our plan calls for using the computer itself to count pulses, thus reducing the input to a single information line. Computers are available which will accept pulses at a rate of approximately $10^{5}$ counts/sec, and an external divider circuit will be provided to scale the input in cases for which higher rates are expected.

Several computers have been investigated, and one which appears quite suitable has 4096 12-bit words of random access memory and a memory cycle time of $6 \mu \mathrm{sec}^{17}$ It is estimated that 1000 words of program will be required for basic control of the diffractometer. Another 1000 words will be needed for standard arithmetic and inputoutput subroutines, leaving more than 2000 words available for programming various data collection schemes.

\footnotetext{
${ }^{17}$ The PDP-5 computer manufactured by Digital Equipment Corp., Maynard, Mass.
}

\section{Refinement of the Structure of $\alpha-D-G l u c o s e$ from Neutron Diffraction Data}
G. M. Brown
H. A. Levy

Because of the extraordinary biochemical importance of $\alpha$-D-glucose $\left(\mathrm{C}_{6} \mathrm{H}_{12} \mathrm{O}_{6}\right)$, we have undertaken the redetermination of its crystal and molecular structure by neutron analysis, continuing a program of study of sugar structures that was initiated by a redetermination of the structure of sucrose. ${ }^{18,19}$ The crystal structure of $a-D$-glucose was determined originally from two-dimensional $\mathrm{x}$-ray data by McDonald and Beevers. ${ }^{20,21}$ That determination was a significant contribution because it furnished confirmation of the stereochemical configuration of the molecule that had been deduced on purely chemical grounds. The precision attained was, however, far from that which can be reached today in crystal structure analysis. The aim of the present work is to furnish precise structural parameters, including those of the hydrogen atoms.

A preliminary note by Ferrier et al. ${ }^{22}$ describing a determination of the crystal structure of $a-D-$ glucose monohydrate by three-dimensional $\mathrm{x}$-ray methods promises that eventually the monohydrate structure will be reported with rather good precision. It will be of great interest to compare the fine details of structure of the sugar molecules in the two crystals and also to compare the details in the glucose molecules with those in the glucose moiety in sucrose. Comparisons with the structure of $\beta-\mathrm{D}-\mathrm{glucose}$, which Ferfier 23,24 has determined rather precisely, will also be appropriate.

$a-D-G l u c o s e$ crystals are orthorhombic, showing the symmetry of space group $P 22_{1} 2_{1} 2_{1}$, with four molecules per unit cell. In our work so far we

${ }^{18}$ G. M. Brown and H. A. Levy, Chem. Div. Ann. Progr. Rept. June 20, 1963 , ORNL-3488, p. 108.

${ }^{19} \mathrm{G}$. M. Brown and H. A. Levy, Science 141, 921 (1963).

${ }^{20}$ T. R. R. McDonald and C. A. Beevers, Acta Cryst. 3,394 (1950).

${ }^{21}$ T. R. R. McDonald and C. A. Beevers, Acta Cryst. 5, $654(1952)$.

${ }^{22}$ W. G. Ferrier, R. C. G. Killean, and D. W. Young, Acta Cryst. 15, 911 (1962).

${ }^{23}$ W. G. Ferrier, Acta Cryst. 13, 678 (1960).

${ }^{24}$ W. G. Ferrier, Acta Cryst. 16, 1023 (1962). 
have employed the unit-cell parameters of McDonald and Beevers, ${ }^{21} a=10.36 \pm 0.02 \mathrm{~A}, b=14.84 \pm$ $0.02 \mathrm{~A}$, and $\mathrm{c}=4.97 \pm 0.02 \mathrm{~A}$, though we intend eventually to establish the cell parameters more precisely.

Three-dimensional neutron intensity data were recorded with use of the automatic diffractometer from a carefully selected single crystal ${ }^{25}$ of $\alpha-D-$ glucose weighing $31.7 \mathrm{mg}$. Up to the limit of $\sin \theta$ of the instrument (0.824), 1677 independent reflections were recorded. The neutron wavelength was $1.078 \mathrm{~A}$. The intensities were converted to $F^{2}$ data by multiplication by absorption ${ }^{26}$ and Lorentz correction factors and by a scale factor derived from data from a standard crystal of $\mathrm{NaCl}$.

Least-squares refinement ${ }^{27}$ was started at once on the assumption that the parameters of McDonald and Beevers, including those postulated for hydrogen atoms, would converge to the correct ones. The assumption was justified, and the refinement is nearly finished. In the last three cycles, atomic coordinates and individual anisotropic thermal parameters of all 24 atoms and the single scale parameter were adjusted. As refinement progressed it became obvious that about 60 of the observations of highest intensity should be omitted from the data set because of extinction errors.

At the present stage of refinement the reliability index

$$
R_{F^{2}} \equiv \frac{\Sigma\left|F_{\text {obs }}^{2}-F_{\text {calcd }}^{2}\right|}{\Sigma F_{\text {obs }}^{2}}
$$

has the value 0.059 for the 1619 data included. The standard errors of the coordinates are about 0.001 to $0.002 \mathrm{~A}$ for the carbon and oxygen atoms and 0.002 to $0.005 \mathrm{~A}$ for the hydrogen atoms. The precision is essentially the same as that reached in the sucrose refinement.

\footnotetext{
${ }^{25}$ We thank Professor Andrew Van Hook of the College of the Holy Cross for growing crystals of glucose for us.

${ }^{26}$ D. J. Wehe, W. R. Busing, and H. A. Levy, OR ABS, a Fortran Program for Calculating Single Crystal Absorption Corrections, ORNL-TM-229 (1962).

${ }^{27}$ The computer program used was a version of the program of W. R. Busing, K. O. Martin, and H. A. Levy, OR FLS, a Fortran Crystallographic Least-Squares Program, ORNL-TM-305 (1962), as modified by W. Hamilton, J. Ibers, and C. K. Johns on.
}

All bond lengths and a selection of angles in the $\alpha-D$-glucose molecule are shown in Fig. 9.3. Redetermination of the unit-cell parameters may lead to small but significant changes from the values given. No corrections ${ }^{28,29}$ for the effects of thermal motion have yet been made. It seems obvious, however, from inspection of Fig. 9.4, which shows a stereoscopic view of the vibrational

\footnotetext{
${ }^{28}$ D. W. J. Cruickshank, Acta Cryst. 9, 757 (1956).

${ }^{29}$ W. R. Busing and H. A. Levy, Acta Cryst. 17, 142 (1964).
}
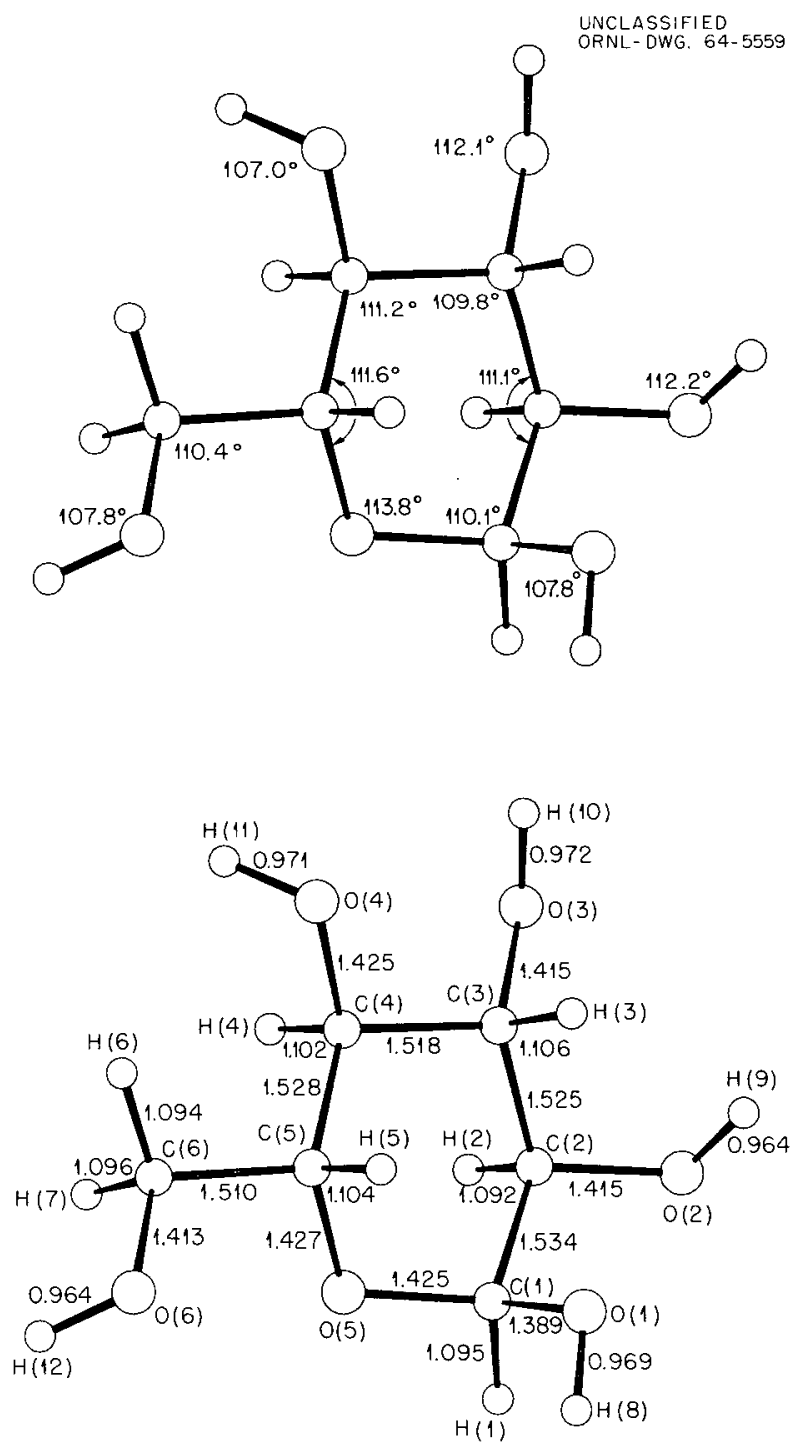

Fig. 9.3. Bond Lengths and Selected Bond Angles in the $\alpha$-D-Glucose Molecule. 
UNCLASSIFIED

ORNL DWG. 64.6523
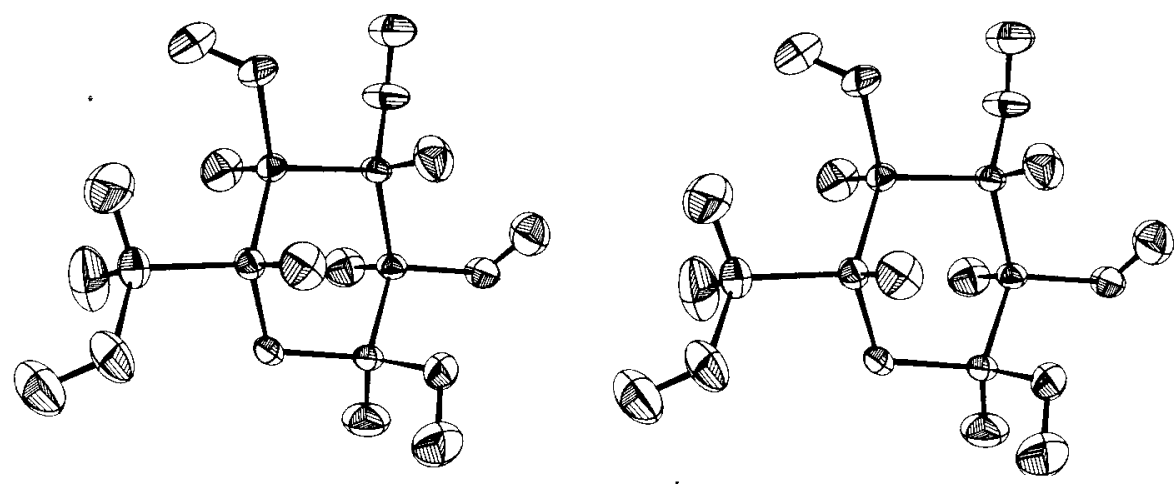

Fig. 9.4. Stereoscopic View of the a-D-Glucose Molecule Showing the Vibrational Ellipsoids. The ellipsoids are plotted on a scale 1.5 times that of the atomic separations. The atoms may be identified by referring to Fig. 9.3 .

ellipsoids ${ }^{30}$ of the molecule, that the $\mathrm{C}-\mathrm{H}$ and $\mathrm{O}-\mathrm{H}$ bond lengths are in need of correction. The uncorrected lengths may be short by a few hundredths of an angstrom. Other bonds may be short by smaller amounts. A detailed analysis of the thermal motion will be required to make the corrections, to the extent that they can be made.

In Table 9.4 a comparison is made of bond lengths, ring bond angles, and ring conformation angles $^{31}$ in $a-D$-glucose with the corresponding molecular parameters in the glucose moiety of sucrose. In general, the agreement in bond lengths is striking, most of the differences being of such small magnitude that they may well result only from errors in the cell parameters and from effects of thermal motion. The only marked differences are those in the chain of bonds $O(1)-C(1)$, $\mathrm{C}(1)-\mathrm{O}(5)$, and $\mathrm{O}(5)-\mathrm{C}(5)$. The pattern of bond lengths in this three-link chain is certainly different in the two sugars. We have previously pointed out the peculiar pattern of $\mathrm{C}-\mathrm{O}$ links in

\footnotetext{
${ }^{30} \mathrm{C}$. K. Johns on, Machine-Plotted Crystal Structure Diagrams with Thermal-Motion Probability Ellipsoids (this report).

${ }^{31}$ Consider four successive atoms around a ring, as $\mathrm{C}(1), \mathrm{C}(2), \mathrm{C}(3), \mathrm{C}(4)$. We define (see refs, 18 and 19) the ring conformation angle of the directed bond $\mathrm{C}(2) \rightarrow \mathrm{C}(3)$ as the angle, measured counterclockwise, that the projection of the bond $\mathrm{C}(2) \rightarrow \mathrm{C}(1)$ makes relative to the projection of bond $\mathrm{C}(3) \rightarrow \mathrm{C}(4)$ when one looks in the direction of bond $\mathrm{C}(2) \rightarrow \mathrm{C}(3)$.
}

this chain in the sucrose molecule, as well as the similar pattern in the furanose moiety. ${ }^{18,19}$ In $a-D$-glucose the $\mathrm{C}(1)-\mathrm{O}(1)$ bond of length $1.389 \mathrm{~A}$ is shorter than the average length, $1.420 \mathrm{~A}$, of the other $\mathrm{C}-\mathrm{O}$ bonds. A similar shortening of the $\mathrm{C}(1)-\mathrm{O}(1)$ bond relative to the other $\mathrm{C}-\mathrm{O}$ bonds has been observed in $\beta$-glucose, ${ }^{23} \beta$-arabinose, ${ }^{32} \alpha$-rhamnose monohydrate, ${ }^{33}$ and $a$-glucose monohydrate ${ }^{22}$ (not with a high level of significance in the latter two cases).

The ring bond angles are, on the whole, quite similar in $a$-D-glucose and in the corresponding moiety in sucrose. The differences, which correspond to small differences in energy, are reasonable, since the environment of the glucose group differs from one crystal to the other. The effects of the different environments show up more clearly on comparison of the ring conformation angles in the two crystals.

There are five different hydrogen bonds, located as described by McDonald and Beevers. ${ }^{20,21}$ The oxygen-oxygen separations are as follows, where in each case the oxygen atom of the donor $\mathrm{OH}$ group is given first: $\mathrm{O}(1)-\mathrm{O}(5), 2.847 \mathrm{~A}$; $\mathrm{O}(2)-\mathrm{O}(6), 2.776 \mathrm{~A} ; \mathrm{O}(3)-\mathrm{O}(2), 2.707 \mathrm{~A}, \mathrm{O}(4)-\mathrm{O}(4)$, $2.773 \mathrm{~A} ; \mathrm{O}(6)-\mathrm{O}(3), 2.711 \mathrm{~A}$.

\footnotetext{
${ }^{32}$ A. Hordvik, Acta Chem, Scand. 15, 16 (1961).

${ }^{33} \mathrm{H}$. McGeachin and C. A. Beevers, Acta Cryst. 10, 227 (1957).
} 
Table 9.4. Comparis on of Bond Lengths, Ring Bond Angles, and Ring Conformation Angles in $\alpha$-D-Glucose and in the Glucose Moiety of Sucrose

\begin{tabular}{|c|c|c|}
\hline & Glucose & Sucrose \\
\hline \multicolumn{3}{|l|}{ Bond } \\
\hline$C(1)-C(2)$ & $1.534 \mathrm{~A}$ & $1.534 \mathrm{~A}$ \\
\hline$C(2)-C(3)$ & $1.525 \mathrm{~A}$ & $1.520 \mathrm{~A}$ \\
\hline$C(3)-C(4)$ & $1.518 \mathrm{~A}$ & $1.524 \mathrm{~A}$ \\
\hline$C(4)-C(5)$ & $1.528 \mathrm{~A}$ & $1.523 \mathrm{~A}$ \\
\hline$C(5)-C(6)$ & $1.523 \mathrm{~A}$ & $1.510 \mathrm{~A}$ \\
\hline$C(1)-O(1)$ & $1.389 \mathrm{~A}$ & $1.420 \mathrm{~A}$ \\
\hline$C(1)-O(5)$ & $1.425 \mathrm{~A}$ & $1.408 \mathrm{~A}$ \\
\hline$C(2)-O(2)$ & $1.423 \mathrm{~A}$ & $1.415 \mathrm{~A}$ \\
\hline $\mathrm{C}(3)-\mathrm{O}(3)$ & $1.421 \mathrm{~A}$ & $1.415 \mathrm{~A}$ \\
\hline$C(4)-O(4)$ & $1.425 \mathrm{~A}$ & $1.413 \mathrm{~A}$ \\
\hline$C(5)-O(5)$ & $1.427 \mathrm{~A}$ & $1.436 \mathrm{~A}$ \\
\hline $\mathrm{C}(1)-\mathrm{H}(1)$ & $1.095 \mathrm{~A}$ & $1.105 \mathrm{~A}$ \\
\hline $\mathrm{C}(2)-\mathrm{H}(2)$ & $1.092 \mathrm{~A}$ & $1.105 \mathrm{~A}$ \\
\hline $\mathrm{C}(3)-\mathrm{H}(3)$ & $1.106 \mathrm{~A}$ & $1.100 \mathrm{~A}$ \\
\hline $\mathrm{C}(4)-\mathrm{H}(4)$ & $1.102 \mathrm{~A}$ & $1.100 \mathrm{~A}$ \\
\hline $\mathrm{C}(5)-\mathrm{H}(5)$ & $1.104 \mathrm{~A}$ & $1.105 \mathrm{~A}$ \\
\hline $\mathrm{C}(6)-\mathrm{H}(6)$ & $1.094 \mathrm{~A}$ & $1.087 \mathrm{~A}$ \\
\hline $\mathrm{C}(6)-\mathrm{H}(7)$ & $1.096 \mathrm{~A}$ & $1.092 \mathrm{~A}$ \\
\hline $\mathrm{O}(1)-\mathrm{H}(8)$ & $0.969 \mathrm{~A}$ & \\
\hline $\mathrm{O}(2)-\mathrm{H}(9)$ & $0.964 \mathrm{~A}$ & $0.968 \mathrm{~A}$ \\
\hline $\mathrm{O}(3)-\mathrm{H}(10)$ & $0.972 \mathrm{~A}$ & $0.962 \mathrm{~A}$ \\
\hline $\mathrm{O}(4)-\mathrm{H}(11)$ & $0.971 \mathrm{~A}$ & $0.971 \mathrm{~A}$ \\
\hline $\mathrm{O}(6)-\mathrm{H}(12)$ & $0.964 \mathrm{~A}$ & $0.951 \mathrm{~A}$ \\
\hline \multicolumn{3}{|l|}{ Ring Bond Angle } \\
\hline$C(1)-C(2)-C(3)$ & $111.1^{\circ}$ & $111.0^{\circ}$ \\
\hline$C(2)-C(3)-C(4)$ & $109.8^{\circ}$ & $108.1^{\circ}$ \\
\hline$C(3)-C(4)-C(5)$ & $111.2^{\circ}$ & $111.0^{\circ}$ \\
\hline$C(4)-C(5)-O(5)$ & $111.6^{\circ}$ & $110.6^{\circ}$ \\
\hline$C(5)-O(5)-C(1)$ & $113.8^{\circ}$ & $116.1^{\circ}$ \\
\hline$O(5)-C(1)-C(2)$ & $110.5^{\circ}$ & $110.9^{\circ}$ \\
\hline \multicolumn{3}{|l|}{ Conformation Angle } \\
\hline $\mathrm{C}(1) \rightarrow \mathrm{C}(2)$ & $54.1^{\circ}$ & $54.6^{\circ}$ \\
\hline $\mathrm{C}(2) \rightarrow \mathrm{C}(3)$ & $-51.3^{\circ}$ & $-55.1^{\circ}$ \\
\hline $\mathrm{C}(3) \rightarrow \mathrm{C}(4)$ & $53.3^{\circ}$ & $55.5^{\circ}$ \\
\hline $\mathrm{C}(4) \rightarrow \mathrm{C}(5)$ & $-57.5^{\circ}$ & $-54.5^{\circ}$ \\
\hline $\mathrm{C}(5) \rightarrow \mathrm{O}(5)$ & $62.3^{\circ}$ & $55.0^{\circ}$ \\
\hline $\mathrm{O}(5) \rightarrow \mathrm{C}(1)$ & $-60.9^{\circ}$ & $-54.8^{\circ}$ \\
\hline
\end{tabular}

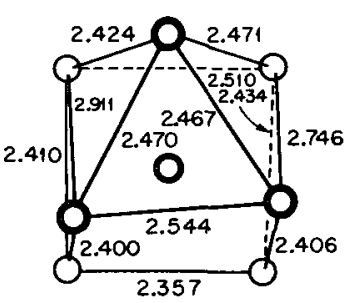

(a)

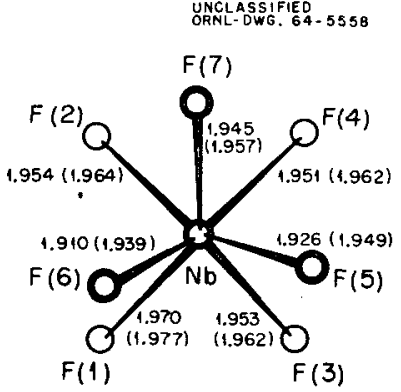

(b)
Fig. 9.5. Interatomic Distances (A) in the $\mathrm{NbF}_{7}{ }^{2-}$ lon. (a) Fluorine-fluorine distances. (b) Niobium-fluorine bond lengths. Values in parentheses are corrected for the effects of thermal motion (see text).

\section{Refinement of the Structure of $\mathrm{K}_{2} \mathrm{NbF}_{7}$ from Neutron Diffraction Data}
G. M. Brown
L. A. Walker ${ }^{34}$
H. A. Levy

In connection with recent work by $O$. L. Keller (Chemistry Division) on the Raman and infrared spectroscopy of complex ions of niobium(V) in hydrofluoric acid solutions, ${ }^{35}$ the crystal structure of $\mathrm{K}_{2} \mathrm{NbF}_{7}$ was redetermined ${ }^{36}$ from neutron diffraction data. The original structure determination by Hoard ${ }^{37}$ in 1939, from two-dimensional $x$-ray data, revealed an $\mathrm{NbF}_{7}^{2-}$ ion of rather peculiar shape (essentially that of Fig. 9.5). Apart from the strange shape of the ion, there was no particular reason to question the essential correctness of Hoard's structure; but it seemed desirable to confirm the structure and to refine it by a three-dimensional analysis of high precision. For $\mathrm{K}_{2} \mathrm{NbF}_{7}$ it is advantageous to employ neutron analysis, rather than $\mathrm{x}$-ray analysis, for two reasons. First, the similarity of the neutron scattering factors of potassium, niobium, and fluorine atoms ensures that the structural parameters of all atoms will be determined to about

\footnotetext{
${ }^{34}$ Research participant of the Oak Ridge Institute of Nuclear Studies, summer, 1963.

${ }^{35}$ O. L. Keller, Jr., J. Inorg. Chem. 2, 783 (1963).

${ }^{36}$ We thank O. L. Keller for suggesting this work.

${ }^{37}$ J. L. Hoard, J. Am. Chem. Soc. 61, 1252 (1939).
} 
the same precision. Second, the low neutron absorption coefficient $\left(0.24 \mathrm{~cm}^{-1}\right)$ of $\mathrm{K}_{2} \mathrm{NbF}_{7}$ makes it possible to obtain intensity data virtually free from absorption errors.

Unit-cell parameters were derived from $\mathrm{Cu} K a$ $x$-ray data obtained for a small crystal on a counter diffractometer: $a=5.846 \pm 0.003 \mathrm{~A}, b=12.693 \pm$ $0.006 \mathrm{~A}, c=8.515 \pm 0.004 \mathrm{~A}, \beta=90.0 \pm 0.1^{\circ}$. These parameters are close to those of Hoard, but more precisely determined. The space group is $P 2$ /c.

The automatic neutron diffractometer was employed to make 1754 observations of intensities (1358 independent) from an 18.5-mg crystal, sealed inside a thin-walled tube of quartz. Absorption correction factors, amounting at most to about 1.03 , were calculated ${ }^{38}$ and applied.

It became clear very quickly from least-squares calculations, ${ }^{39}$ beginning with Hoard's atomic coordinates, that the original $x$-ray structure is indeed basically correct. Refinement was straightforward. In the final refinement cycles atomic coordinates, individual anisotropic thermal parameters, the scale factor, and the scattering factors of niobium and potassium were adjusted. The scattering factor of fluorine was held fixed throughout at the value $0.55 \times 10^{-12} \mathrm{~cm}$. In the final cycles the 67 reflections of highest observed intensity were omitted from the set of observations because they appeared to show extinction errors. The value of the reliability index

$$
R_{F^{2}}=\frac{\Sigma\left|F_{\mathrm{obs}}^{2}-F_{\mathrm{calcd}}^{2}\right|}{\Sigma F_{\mathrm{obs}}^{2}}
$$

reached 0.089 .

The scale factor changed on refinement by only $0.06 \%$, much less than the standard error. The scattering factor of niobium changed from the initial value 0.69 to $0.696( \pm 0.005) \times 10^{-12} \mathrm{~cm}$. The scattering factor of potassium changed from 0.35 to $0.371( \pm 0.003) \times 10^{-12} \mathrm{~cm}$. (All values here are relative to the value $0.55 \times 10^{-12} \mathrm{~cm}$ for fluorine.)

\footnotetext{
${ }^{38}$ D. J. Wehe, W. R. Busing, and H. A. Levy, OR ABS, a Fortran Program for Calculating Single Crystal Absorption Corrections, ORNL-TM-229 (1962).

${ }^{39}$ Least-squares refinement was carried out by using the full-matrix least-squares program of W. R. Busing, K. O. Martin, and $\mathrm{H}$. A. Levy, OR FLS, a Fortran Crystallographic Least-Squares Program, ORNL-TM-305 (1962).
}

The fractional coordinates are as follows: ${ }^{40}$

$\begin{array}{lccc} & x & y & z \\ \mathrm{Nb} & 0.2717 & 0.1288 & 0.2228 \\ \mathrm{~K}(1) & 0.2396 & 0.4404 & 0.1833 \\ \mathrm{~K}(2) & 0.7623 & 0.2845 & 0.4447 \\ \mathrm{~F}(1) & 0.0464 & 0.2431 & 0.1994 \\ \mathrm{~F}(2) & 0.4573 & 0.2567 & 0.2114 \\ \mathrm{~F}(3) & 0.0448 & 0.1072 & 0.3880 \\ \mathrm{~F}(4) & 0.4598 & 0.1107 & 0.4102 \\ \mathrm{~F}(5) & 0.2166 & -0.0207 & 0.2159 \\ \mathrm{~F}(6) & 0.1875 & 0.1216 & 0.0064 \\ \mathrm{~F}(7) & 0.5571 & 0.0792 & 0.1317\end{array}$

The standard errors of these coordinates, converted into angstroms, are about $0.001_{1} \mathrm{~A}$ for the niobium atom, $0.001_{6}$ to $0.002_{5} \mathrm{~A}$ for the fluorine atoms, and $0.002_{5} \mathrm{~A}$ for the potassium ions. This set of parameters is significantly different from Hoard's set, even though the general description of the structure remains unchanged. The minimum, average, and maximum magnitudes of coordinate shifts resulting from the refinement are 0.001 , 0.032 , and $0.147 \mathrm{~A}$ respectively. Most of the coordinates shifted by amounts many times the standard deviations.

The $\mathrm{NbF}_{7}{ }^{2-}$ ion polyhedron is, in Hoard's own words, "conveniently visualized as derived from an $\mathrm{NbF}_{6}$ group in the form of a trigonal prism by the addition of a seventh fluorine atom through the center of one square face, followed by the appropriate distortion." The distortion is considerable, as can be seen by Fig. 9.5a, which shows the fluorine-fluorine distances along the edges of the polyhedron. These distances vary from 2.357 to $2.911 \mathrm{~A}$. Eviclently, electrostatic forces between the potassium ions and the fluorine atoms determine the fine details of shape of the $\mathrm{NbF}_{7}{ }^{2-}$ ion.

\footnotetext{
${ }^{40}$ When, as in this case, the angle $\beta$ of a monoclinic cell is indistinguishable from $90^{\circ}$, there is an ambiguity in the choice of positive directions of the crystal axes. The conventional basis of choice, that the interaxial angle between $a$ and $c$ be obtuse, becomes useless. Thus, for example, one could equally well choose $b$ and c to point in the opposite directions from those originally chosen, keeping the original a. In terms of the new coordinate axes the same structure will be described if the $x$ coordinates of our table are multiplied by -1 and the $y$ and $z$ coordinates are unchanged. Our choice of axes is consistent with that of Hoard. A sufficiently precise determination of $\beta$ might show it to be significantly different from $90^{\circ}$ and the ambiguity would be removed. Our choice might then be shown to be unconventional.
} 
The $\mathrm{Nb}-\mathrm{F}$ bond lengths are shown in Fig. 9.5b. The first value given for each bond is the value of the internuclear separation computed directly from the coordinates given above. The second value, in parentheses, has been corrected for the effects of thermal motion, assuming the so-called "riding" model. ${ }^{41}$ The range of the $\mathrm{Nb}-\mathrm{F}$ bond lengths after correction is 1.939 to $1.977 \mathrm{~A}$ (1.910 to $1.970 \mathrm{~A}$ before correction).

Use of the riding model is justified, because for every fluorine atom the principal axis of the vibration ellipsoid along which the root-meansquare vibrational amplitude is least lies within $10^{\circ}$ of the particular $\mathrm{Nb}-\mathrm{F}$ bond direction. Further, this least vibrational amplitude is in each case very close to that of the niobium atom, which vibrates nearly isotropically. The stereoscopic drawing ${ }^{42}$ of Fig. 9.6 shows the vibrational ellipsoids for the atoms of the $\mathrm{NbF}_{7}{ }^{2-}$ group and for the ten potassium ions which surround it. The lengths of the principal axes represent the root-mean-square vibrational amplitudes in the principal axis directions on a scale 2.25

${ }^{41}$ W. R. Busing and H. A. Levy, Acta Cryst. 17, 142 (1964).

${ }^{42}$ C. K. Johnson, Machine-Plotted Crystat Structure Diagrams with Thermal-Motion Probability Ellipsoids (this report). times that of the internuclear distances. The vibrational motion is, as shown in Fig. 9.6, greater for $F(5)$ and $F(6)$ than for the other fluorine atoms.

The internuclear separations $\mathrm{K}-\mathrm{F}$ (nine for each potassium) range from 2.64 to $2.93 \mathrm{~A}$. The shortest intermolecular $\mathrm{F}-\mathrm{F}$ distance is $3.07 \mathrm{~A}$.

\section{A Neutron Diffraction Study of the Structure of Potassium Hydrogen Chloromaleate}
R. D. Ellison
H. A. Levy

Maleic acid, the cis isomer of ethylene dicarboxylic acid, $\mathrm{HOOCCHCHCOOH}$, is constrained by valence forces to a configuration with an exceptionally short intramolecular $\mathrm{O} \ldots \mathrm{O}$ distance, about 2.4 to $2.5 \mathrm{~A}$. The singly ionized hydrogen maleate ion in the potassium salt has been shown by neutron and x-ray diffraction ${ }^{43}$ to involve a short internal hydrogen bond between these two oxygen atoms, with the hydrogen atom apparently situated at the center. In this crystal the hydrogen maleate ion possesses a plane of

${ }^{43}$ S. F. Darlow and W. Cochran, Acta Cryst. 14, 1250 (1961); also S. W. Peters on and H. A. Levy, J. Chem. Phys. 29, 948 (1958).
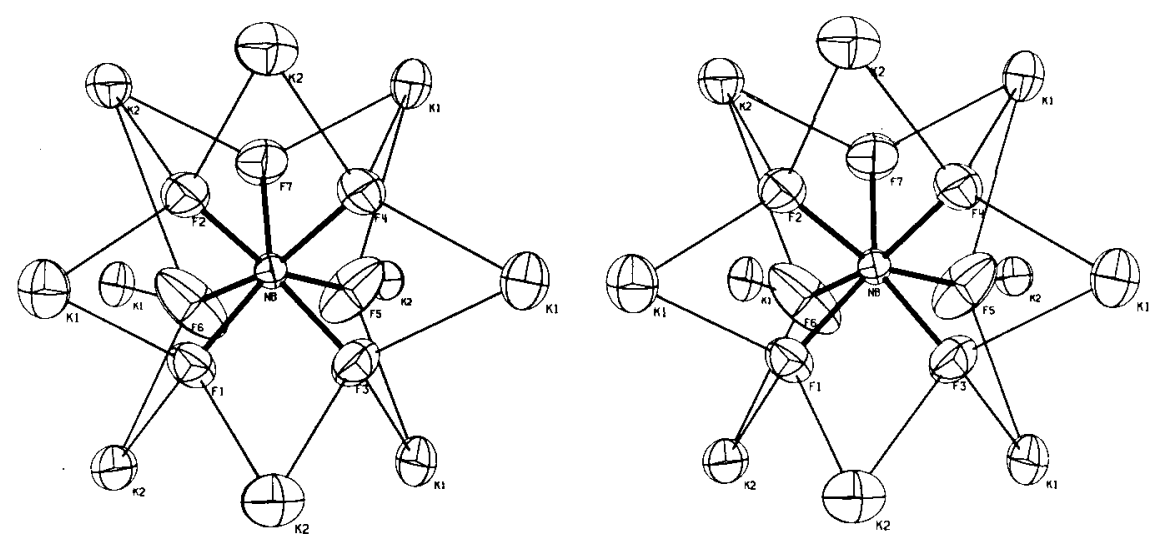

Fig. 9.6. Vibrational Ellipsoids of the Atoms of the $\mathrm{NbF}_{7}{ }^{2-}$ Group and of the Ten Potassium lons Which Surround It. The double lines indicate close potassium-fluorine contacts. 
mirror symmetry perpendicular to the $\mathrm{C}=\mathrm{C}$ bond, and the apparent hydrogen position is in this mirror plane.

The apparent centering of the hydrogen atom in the hydrogen bond can be given two interpretations: the hydrogen is truly localized at the center of the bond, or it is randomly situated in one or the other of two equivalent sites displaced perhaps as much as $0.1 \mathrm{~A}$ from the center:<smiles>OC1C=CC(O)O[CH]O1</smiles><smiles>OC1C=CC(O)OCO1</smiles>

The equivalence of the two carboxyl groups, as exemplified by the presence of a mirror plane in the crystal, makes the two alternatives indistinguishable. If this equivalence is removed, as by substitution for one of the ethylenic hydrogen atoms, the two noncentered configurations become nonequivalent, and there is a chance of observing the noncentered situation.

Accordingly, the crystal structure of the potassium salt of the chlorine-substituted acid has been studied. The crystal is orthorhombic with space group $P b c n$ and contains eight molecules in the cell whose parameters are $a=15.815 \mathrm{~A}, \quad b=$ $10.928 \mathrm{~A}$, and $\mathrm{c}=7.707 \mathrm{~A}$. The density is 1.881 $\mathrm{g} / \mathrm{cm}^{3}$, calculated; $1.868 \mathrm{~g} / \mathrm{cm}^{3}$, observed. A three-dimensional set of 1958 nonequivalent Bragg intensities, complete to $\sin \theta / \lambda$ of 0.698 , was collected on the Oak Ridge automatic neutron diffractometer.

The crystal structure was solved by analyzing a sharpened three-dimensional neutron Patterson function. Trial atomic positions were found from maxima of the minimum function

$$
\underset{i}{\operatorname{Min}}\left[w_{i} P\left(r-S_{i} r\right)\right],
$$

where $r$ is a vector ranging over the crystal cell, $S_{i}$ are the symmetry operations of the space group, and $w_{i}$ are weighting factors equal to the reciprocal of the number of operations $S_{i}$ that generate a given vector. Subsequently, multiple minimum functions

$$
\underset{i}{\operatorname{Min}}\left[P\left(r-S_{i} r_{0}\right)\right]
$$

were computed, where $r_{0}$ is a trial atomic position found from (1) and confirmed by a previously computed (2). Three such multiple minimum functions were constructed; the minimum of these three revealed all of the atoms except for hydrogen and potassium, and contained no extra peaks. A Fourier synthesis using signs determined by the atoms located in this way showed the complete structure. Five cycles of least-squares refinement yielded an $R$ factor (based on $F^{2}$ ) of 0.095 and a standard error of fit of 1.015. The atomic parameters are listed in Table 9.5.

The anion in this structure is very nearly planar. Its configuration and bond distances are shown in Fig. 9.7. The hydrogen atom of the internal hydrogen bond again appears very nearly at the center, and is thus subject to the same alternative interpretations as in the case of the unsubstituted maleate ion. However, as the two noncentered configurations are here chemically nonequivalent, the probability of the random arrangement is reduced.

Table 9.5. Atomic Position Parameters of Potassium Hydrogen Chloromaleate Expressed as Fractions of the Unit Cell Edges

\begin{tabular}{lccc}
\hline Atom & \multicolumn{3}{c}{ Parameter } \\
\cline { 2 - 4 } & $x$ & $y$ & $z$ \\
\hline Chiorine & 0.116 & -0.020 & -0.053 \\
Carbon 1 & 0.139 & 0.199 & 0.104 \\
Carbon 2 & 0.185 & 0.086 & 0.038 \\
Carbon 3 & 0.268 & 0.057 & 0.039 \\
Carbon 4 & 0.341 & 0.128 & 0.111 \\
Oxygen 1 & 0.064 & 0.210 & 0.073 \\
Oxygen 2 & 0.182 & 0.277 & 0.192 \\
Oxygen 3 & 0.329 & 0.223 & 0.204 \\
Oxygen 4 & 0.413 & 0.088 & 0.079 \\
Hydrogen 1 & 0.256 & 0.252 & 0.203 \\
Hydrogen 2 & 0.286 & -0.029 & -0.020 \\
Potassium 1 & 0.500 & -0.095 & 0.250 \\
Potassium 2 & 0.500 & 0.297 & 0.250 \\
\hline
\end{tabular}




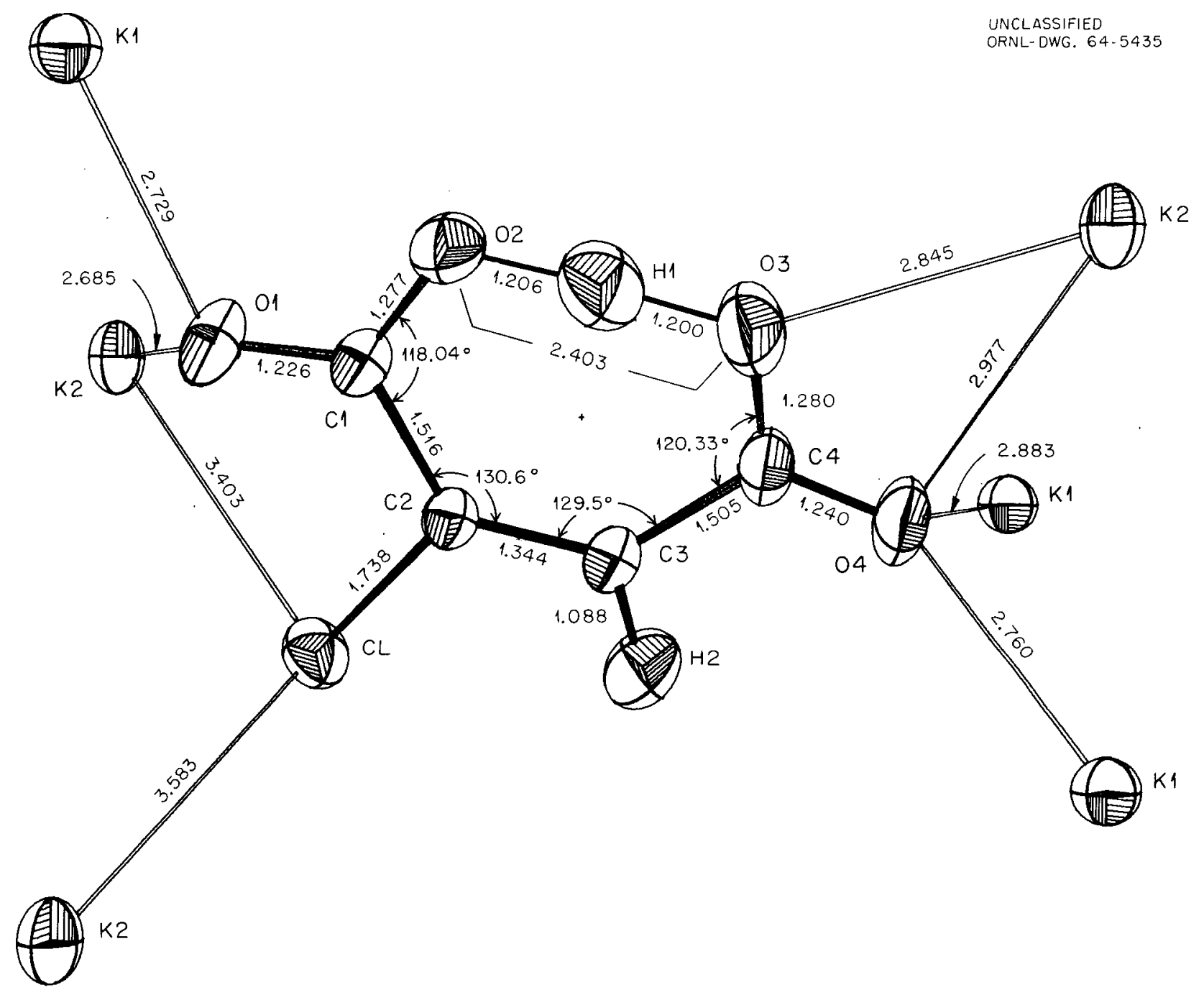

Fig. 9.7. Perspective Drawing of the Hydrogen Chloromaleate lon and Neighboring Potassium Atoms Made by Means of an Incremental $x-y$ Plotter Using a Computer Program Written by C. K. Johnson (Described Elsewhere in This Report). The atoms are represented by their probability ellipsoids of thermal displacement. Distances shown are in angstroms.

\section{An X-Ray Diffraction Study of a Crystalline Material Obtained from Xenon Hexafluoride}

\author{
P. A. Agron H. A. Levy
}

Several investigators ${ }^{44-48}$ have described the preparation and properties of the hexafluoride of xenon. In view of the great interest in xenon chemistry, knowledge of the molecular structure of the hexafluoride is highly desirable.

Small samples of $\mathrm{XeF}_{6}$ prepared by D. F. Smith (ORGDP) were sealed into portions of fluorothene tubing about 0.5 to $1.0 \mathrm{~mm}$ in inside diameter and
$0.08 \mathrm{~mm}$ in wall thickness. Crystals were found to grow by sublimation in a temperature gradient, and with care a single-crystal specimen could be isolated. The high vapor pressure of $\mathrm{XeF}_{6}$ at

${ }^{44}$ C. L. Chernick et al., p. 35 in Noble Gas Compounds, ed. by H. H. Hyman, University of Chicago Press, 1963.

${ }^{45}$ D. F. Smith, ibid., p. 39.

${ }^{46}$ B. Weinstock et al., ibid., p. 50.

${ }^{47}$ G. L. Gard et al., ibid., p. 61.

${ }^{48} \mathrm{~J}$. Slivnik et al., ibid., p. 64. 
room temperature, about $25 \mathrm{~mm},{ }^{44.45}$ makes it difficult to maintain a stable specimen. However, attempts to study the crystals at reduced temperatures invariably resulted in disruption of the specimen, presumably because of a structural transformation. Some specimens, especially small ones, were found to disappear in the $\mathrm{x}$-ray beam, and crystals of $\mathrm{XeF}_{4}$ were found to grow nearby.

Collecting $x$-ray data required, for each zone, a period of two days, during which the room temperature was controlled at $19 \pm 1^{\circ} \mathrm{C}$. Precession photographs obtained from several specimens were indexed on the basis of a monoclinic cell with $a=9.33 \mathrm{~A}, b=10.96 \mathrm{~A}$, and $\mathrm{c}=8.95 \mathrm{~A}$, all $\pm 0.01 \mathrm{~A}$ estimated deviation, and $\beta=91.9^{\circ} \pm 0.1$. A statistical analysis ${ }^{49}$ of the reduced data indicated the presence of a center of symmetry. In addition, the systematic absence of odd $0 k 0$ reflections showed the probable space group to be $P 2, / m$. The Patterson analysis, discussed below, indicated eight xenon atoms per unit cell, which corresponds to a reasonable calculated density, $3.6 \mathrm{~g} / \mathrm{cm}^{3}$, assuming the composition $\mathrm{XeF}_{6}$.

A three-dimensional set of 546 nonvanishing $x$-ray intensities was read from precession photographs made with unfiltered Mo $K$ radiation and was reduced to $F^{2}$ values with the aid of a computer program. ${ }^{50}$ No absorption corrections were considered feasible, because of the irregular crystal shape and the presence of the surrounding tube; the resulting errors are certainly significant.

A Patterson synthesis was made ${ }^{51}$ and was found to contain eight peaks of proper height to represent single xenon-xenon vectors and 24 peaks of about double this height, thus accounting for the expected number (56) of interactions among eight xenon atoms. Simple superpositions on the single peaks yielded the unique set of xenon positions given in Table 9.6, which conform to the symmetry of space group $P 2 / \mathrm{m}$. Two of these atoms, $\mathrm{Xe}(1)$ and $\mathrm{Xe}(2)$, lie in the mirror plane, while $\mathrm{Xe}(3)$ is in a general position. The resulting group of four atoms form a nearly regular tetrahedron with point-group symmetry $C_{s}-m$ and

${ }^{49}$ H. L. Yakel, ORSTAT, a Forttan Program for the Statistical Analysis of Diffraction data, ORNL-TM-750.

${ }^{50} \mathrm{D}$. K. Smith, Program for Data Reduction of X-Ray Intensities Obtained Using Precession Techniques, Livermore.

${ }^{51}$ R. D. Ellison and H. A. Levy, unpublished report for a modified version of "A Fourier Summation Program," by A. Zalkin (University of California, Berkeley).
Table 9.6. Xenon Porameters in Asymmetric Unit Cell

\begin{tabular}{lrrr}
\hline Xenon(1) & 0.07 & 0.250 & 0.28 \\
Xenon(2) & -0.19 & 0.250 & -0.11 \\
Xenon(3) & -0.31 & 0.445 & 0.275 \\
\hline
\end{tabular}

edge $4.19 \pm 0.02 \mathrm{~A}$; there are two tetrahedra per unit cell. The compound thus appears to be a tetramer. This is consistent with its relatively low vapor pressure when compared with $\mathrm{UF}_{6}(120$ $\mathrm{mm}$ at $25^{\circ} \mathrm{C}$ ).

Fourier syntheses ${ }^{51}$ based upon phases given by the above xenon positions have not yielded satisfactory positions for the fluorine atoms. However, indications have been obtained that fluorine atoms may be present in both bridging and nonbridging locations. Least-squares ${ }^{52}$ refinements of possible models give a discrepancy factor, $R=\Sigma\left|F_{\text {obs }}^{2}-F_{\text {calcd }}^{2}\right| / \Sigma F_{\text {obs }}^{2}$, of $35 \%$.

\section{MOLECULAR BEAM STUDIES}

\section{"Rainbow" Scattering in the Potassium- Xenon System}
Sheldon Datz
R. E. Minturn

For any intermolecular potential which has both an attractive and repulsive part a discontinuity should exist in a plot of the differential cross section vs scattering angle.

The origin of this effect (rainbow scattering) can be made plausible on a classical mechanical basis by first noting that in any central force field there is a unique scattering angle, $\chi$, for two colliding particles with a given relative velocity, $v_{r}$, and a given impact parameter, $b$. From elementary scattering theory for a given value of $v_{r}$, the differential cross section is given by

$$
\sigma(\chi)=-\frac{b}{\sin \chi} \frac{d b}{d \chi}
$$

or

$$
\sigma(\chi) \sin \chi=-b /\left(\frac{d \chi}{d b}\right)
$$

${ }^{52}$ W. R. Busing, K. O. Martin, and H. A. Levy, OR FLS, a Fortran Crystallographic Least Squares Program, ORNL-TM-305. 
The deflection function $\chi(b)$ is, of course, determined by standard classical mechanical orbit theory.

With a potential which gives a force field that changes from repulsive to attractive as the distance of separation is increased, the value of $d \chi / d b$ vanishes at the point where the attractive part of the potential gives its maximum contribution to the total scattering potential. Thus, at this point $\sigma(\chi) \sin \chi$ must become infinite. Semiclassical treatment of rainbow scattering retains the general conclusions of this simple argument.

Clearly, the experimental observation of rainbow scattering requires velocity selection (since $X$ is a function of both $b$ and $v_{r}$ ); the use of Maxwellian beams would integrate and obscure the effect. It also requires the use of very good angular resolution.

Rainbow scattering can provide direct information on intermolecular potentials by study of the rainbow angle as a function of collision energy. For example, with a potential of the exp- 6 type, that is,

$$
V(r)=\frac{\epsilon}{1-6 / \alpha}\left[\frac{6}{\alpha} e^{a\left(1-r / r_{m}\right)}-\left(\frac{r_{m}}{r}\right)^{6}\right]
$$

where $r_{m}$ is the distance of separation at the minimum of the potential, $\epsilon$ is the depth of the potential at $r=r_{m}$, and $a$ is a measure of the steepness of the repulsive portion of the potential, the rainbow angle is predicted to be sharply dependent on the quantity $E / \epsilon$, where $E$ is the collision kinetic energy in the center-of-mass coordinates, weakly dependent on $\alpha$, and independent of $r_{m}$. The study of location of the rainbow angle with $v_{r}$ therefore yields the potential well depth rather accurately and gives some indication of the value of $\alpha$ in this type of potential.

The distributions observed in the scattering of a velocity-selected potassium beam from xenon are shown in Fig. 9.8. The depth of the interatomic potential well obtained was $200 \mathrm{cal}$ or ca. $10 \%$ more than that determined for the potassiumkrypton system. ${ }^{53}$

\footnotetext{
${ }^{53}$ D. Beck, J. Chem. Phys. 37, 2884 (1962).
}

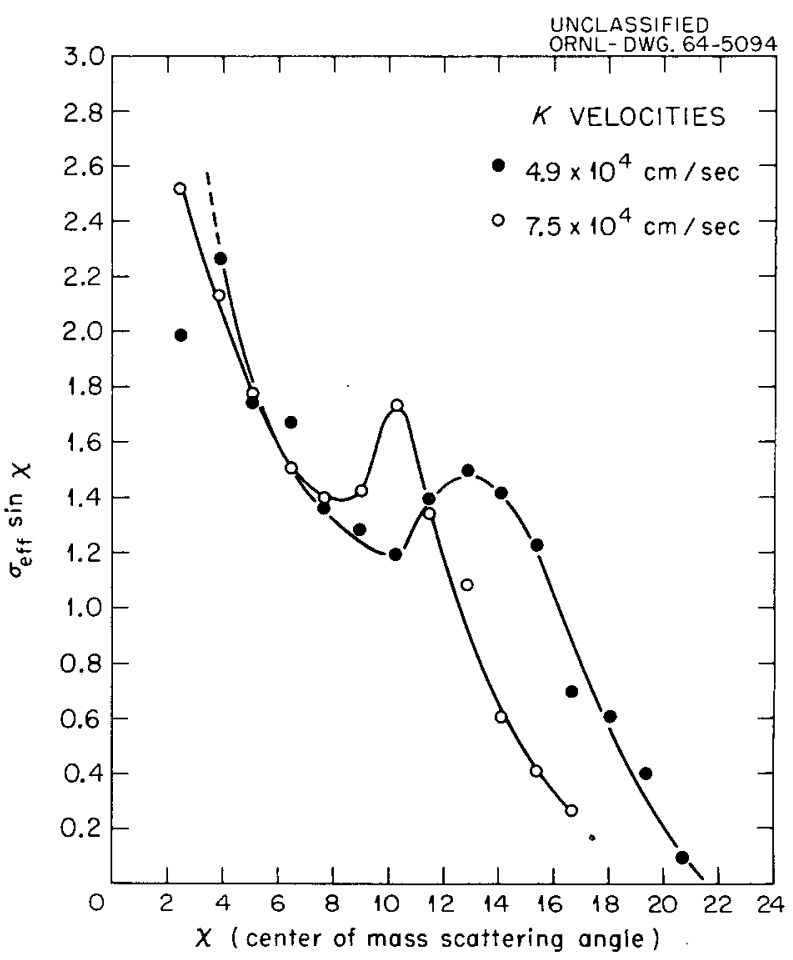

Fig. 9.8. The Elastic Differential Scattering Cross Section in Center-of-Mass Coordinates Multiplied by Sin $\chi$ vs Center-of-Mass Deflection Angle $\chi$ for the Potassium-Xenon System.

\section{Relative Total Scattering Cross Section of Potassium in Molecular and Atomic lodine}

\section{R. E. Minturn Sheldon Datz}

Information concerning long-range attractive intermolecular potentials can also be obtained from measurement of the total scattering cross section. For an attractive potential of the form $V=-C / r^{6}$ the total cross section $Q$ is given ${ }^{54}$ by

$$
Q=p\left(C / \hbar v_{r}\right)^{2 / 5},
$$

where $p$ is a numerical factor and $v_{r}$ is the relative velocity. For a simple mutual polarization interaction the constant $C$ for a given colliding pair can be computed from known values of the polarizabilities and ionization potentials by the London approximation. A calculation of this type showed

${ }^{54}$ H. S. W. Massey and C. B. O. Mohr, Proc. Roy. Soc. (London), Ser. A 144, 188 (1934). 
that the ratio of the cross sections for scattering of $\mathrm{K}$ by $\mathrm{I}_{2}$ and by $\mathrm{I}$ was

$$
\left(\frac{Q_{\mathrm{K}-\mathrm{I}_{2}}}{Q_{\mathrm{K}-\mathrm{I}}}\right)_{\text {London calc }}=1.42 .
$$

However, the existence of a long-range electronic exchange interaction between the potassium and atomic iodine would be expected to increase the effective value of $C$ for this pair. To determine if this effect would be observable by a beam experiment, a measurement was made of the relative total cross sections of scattering of $\mathrm{K}$ by $\mathrm{I}_{2}$ and I. (The atomic iodine beam was formed by thermal dissociation of $I_{2}$ at $1000^{\circ} \mathrm{K}$ and the cross-beam flux measured by a negative surface ionization gage.) The result was

$$
\left(\frac{Q_{\mathrm{K}-\mathrm{I}_{2}}}{Q_{\mathrm{K}-\mathrm{I}}}\right)_{\mathrm{exp}}=1.20,
$$

which indicated that the electronic exchange contribution was indeed observable. The significance of this effect is being evaluated.

\section{A Study of the Reactions of Cesium and Potassium with Bromine in Crossed Molecular Beams}
R. E. Minturn
Sheldon Datz

Crossed molecular beam techniques ${ }^{5,56}$ have been used to study the reaction of cesium with bromine. A monoenergetic beam of cesium atoms (obtained by passing a thermal beam through a six-disk mechanical velocity selector) ${ }^{57}$ collided at right angles with a molecular beam of $\mathrm{Br}_{2}$. The scattering was observed with a differential surface-ionization gage which contained a tungsten wire and a platinum alloy $(92 \% \mathrm{Pt}$ and $8 \% \mathrm{~W})$ wire, the latter being relatively insensitive to CsBr. This detector could be rotated through $90^{\circ}$ in the plane of the two beams.

\footnotetext{
${ }^{55}$ E. H. Taylor and Sheldon Datz, J. Chem. Phys. 23, 1711 (1955).

${ }^{56}$ Wade Fite and Sheldon Datz, Ann. Rev. Phys. Chem. 14, 61 (1963).

${ }^{57}$ F. A. Morse, R. B. Bernstein, and H. U. Hostettler, J. Chem. Phys. 36, 1947 (1962).
}

The elastic scattering pattern of cesium from $\mathrm{Br}_{2}$ displayed no rainbow scattering phenomena. Instead, the cesium distribution was sharply attenuated even at relatively low scattering angles. We interpret this decline to mean a large chemical reaction cross section.

The reactive scattering patterns for several cesium velocities are shown in Fig. 9.9 where the intensity of the $\mathrm{CsBr}$ is plotted against the laboratory angle $\theta$ (taken with respect to the original cesium beam direction). Product distributions were also measured with non-velocityselected cesium beams (not shown) but these were considerably more diffuse. ${ }^{58}$ Also plotted in Fig. 9.9 are two types of calculated centroid distributions. Curves $A$ are centroid distributions calculated in the usual way by folding the momentum of cesium into the distribution of $\mathrm{Br}_{2}$ momenta which arises from the thermal distribution of $\mathrm{Br}_{2}$ velocities $\left(T_{\mathrm{Br}_{2}}=407^{\circ} \mathrm{K}\right)$ and the angular spread $( \pm 2)$ in the $\mathrm{Br}_{2}{ }_{2}$ beam. The disagreement with experiment is obvious. Curves $B$ were obtained in a similar way, except that the cesium atom is assumed to interact with only one of the bromine atoms of the $\mathrm{Br}_{2}$ molecule and the interaction between the two bromine atoms is neglected during the collision (i.e., the impulse approximation). Thus, in curve $A$, for $90^{\circ}$ collisions, the centroid angle $\theta$ is given by

$$
\theta_{\mathrm{A}}=\tan ^{-1}\left[M_{\mathrm{Br}_{2}} v_{\mathrm{Br}_{2}} / M_{\mathrm{Cs}} v_{\mathrm{Cs}}\right],
$$

while in curve $B$,

$$
\theta=\tan ^{-1}\left[M_{\mathrm{Br}} v_{\mathrm{Br}_{2}} / M_{\mathrm{Cs}} v_{\mathrm{Cs}}\right] .
$$

The measured distributions appear to be well described by a broadened form of the $B$ distributions.

Since the actual distribution of $\mathrm{CsBr}$ is expected to be spread about the centroid direction by the recoil momentum, an estimate of the internal excitation of the $\mathrm{CsBr}$ can be made. The energy available for recoil is the sum of the zero-point energy difference $\left(\Delta D_{0}^{0}=44.5 \mathrm{kcal} / \mathrm{mole}\right)$, the initial relative kinetic energy $E_{r}=1$ to $2 \mathrm{kcal} / \mathrm{mole}$, and the internal energy of the $\mathrm{Br}_{2}(0.94 \mathrm{kcal} / \mathrm{mole}$ in rotation and $0.43 \mathrm{kcal} / \mathrm{mole}$ in vibration). The conversion of as little as $2.2 E_{t}$ into kinetic energy

\footnotetext{
${ }^{58}$ D. R. Herschbach has informed us that the Harvard University group has obtained similar results with non-velocity-selected beams.
} 


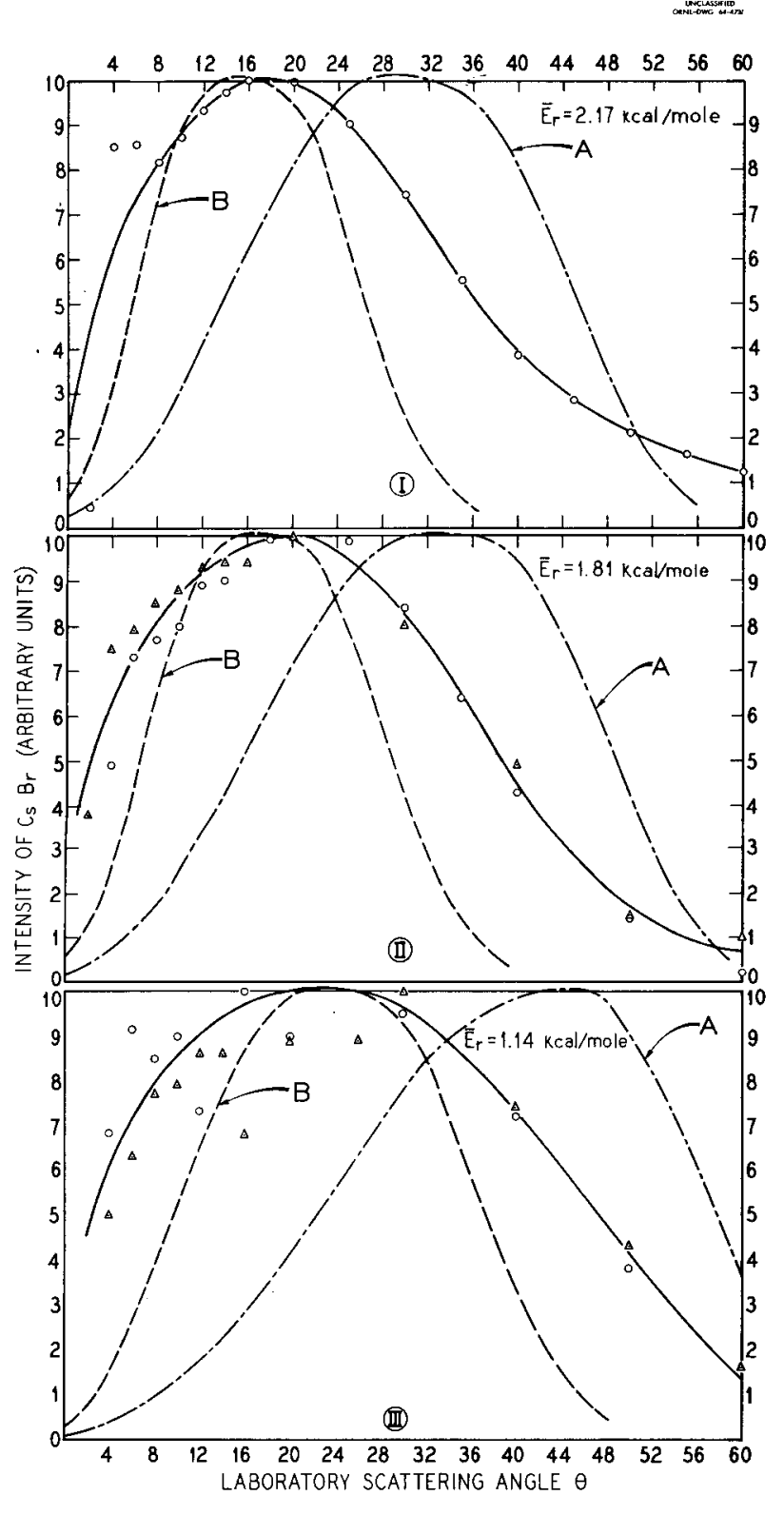

Fig. 9.9. The Angular Distributions of $\mathrm{CsBr}$ Obtained from Crossed Molecular Beams of $\mathrm{C}_{5}$ and $\mathrm{Br}_{2}$. The Cs atom beam velocities were 456, 408, and 298 $\mathrm{m} /$ sec for curves I, II, and III respectively. The $\mathrm{Br}_{2}$ beam had a thermal distribution at $407^{\circ} \mathrm{K}$ in all cases. The $\bar{E}_{r}$ values are those for the most probable $\mathrm{Br}_{2}$ velocity. The distributions labeled $A$ are calculated on the basis of an "activated complex" while those labeled $B$ are calculated on the basis of a "stripping" reaction. of the products would be sufficient to spread the distribution over $4 \pi$ steradians. Analysis of the observed distribution implies that approximately 0.5 to $1 \mathrm{kcal} / \mathrm{mole}$ has gone into translation (recoil), the remainder ( 99\%) having gone into internal excitation of the $\mathrm{CsBr}$.

The agreement of the distribution with type $B$, modified by the influences just discussed, suggests that this reaction proceeds by a "stripping" mechanism rather than through an activated complex. (These two types are well known in nuclear reactions.) The essential feature distinguishing the two is the timing of the movements of the individual particles. In stripping, the outgoing particles separate almost immediately after the two incident projectiles come within their range of interaction and the momentum of the $\mathrm{CsBr}$ product is just the sum of the initial momenta of the cesium and one of the bromine atoms. Thus, kinematically, the remaining bromine atom merely participates as a spectator to the reaction.

Observations made on the $\mathrm{K}+\mathrm{Br}_{2}$ system were also in accord with this mechanism. A broad peak was observed in the $\mathrm{KBr}$ distribution at an angle of ca. $20^{\circ}$ for $\mathrm{K}$ at $7.4 \times 10^{4} \mathrm{~cm} / \mathrm{sec}$ and $\mathrm{Br}_{2}$ at $407^{\circ} \mathrm{K}$. The extra broadening, in this case, was due to the relatively larger effect of the thermal distribution of $\mathrm{Br}_{2}$ velocities.

\section{A New Molecular Beam Scattering Apparatus}

\section{Sheldon Datz}

A new apparatus has been designed and constructed which will permit the extension of molecular beam techniques to the study of reactions in systems which do not involve alkali metals (e.g., hydrogen, free radicals, noncondensable gases). Two unique features of the new device are:

1. The scattering chamber was designed so that the source and detector are externally mounted and the detector may be rotated through an angle of $130^{\circ}$ without breaking the vacuum. This design permits great flexibility in the design of beam sources and detectors and permits the same apparatus to be modified for use in ion-molecule reaction studies and in beam-gas interaction studies. The chamber operates satisfactorily and a vacuum of $8 \times$ $10^{-8}$ torr has been attained. 
2. The detector is a four-pole mass filter with resolution $\Delta M / M=1 / 100$. The use of electronbombardment ionization permits detection of all molecular species. A detector section is bakeable and is separated from the scattering region by two stages of differential pumping. The ambient background in the ion source region is thereby reduced by a factor of $10^{4}$ giving a corresponding decrease in the noise level. This section is being assembled and calibrated.

\section{Differential Elastic Scattering of Low-Energy $\mathrm{Cs}^{+}$Ions $(2$ to $20 \mathrm{ev}$ ) from Noble Gases}

\section{G. Menendez Sheldon Datz}

At low energies it is expected that the elastic scattering of slow ions by neutral atoms will be strongly influenced by the attractive long-range polarization and dispersion forces. The potential should therefore contain at least three terms ${ }^{59}$ (i.e., an $r^{-6}$ attraction due to dispersion, an $r^{-4}$ attraction due to ion-neutral polarization, and an $\mathrm{r}^{-a}$ "hard core" repulsion term). Thus, for some conditions of relative collision energy "rainbow scattering" should be observed in the differential elastic scattering cross section.

This experiment is being done with the new rotating scattering chamber (see above). The beam of $\mathrm{Cs}^{+}$ions at from 2 to $20 \mathrm{ev}$ was formed in a source constructed from a commercial $6 \mathrm{~L} 6$ vacuum tube, and scattered from thermal cross beams of neon and argon. The angular distribution of the scattered $\mathrm{Cs}^{+}$ions was measured and compared with theoretically computed distributions. ${ }^{59}$ Preliminary results showed good agreement with the repulsive part of the theoretical potential, but some uncertainty remains about the attractive part and the predicted "rainbow scattering."

\section{Scattering Cross Sections of $H_{2}$ and $D_{2}$ in Helium}

\section{F. van der Valk G. E. Moore Sheldon Datz}

Work was begun on the determination of the relative scattering cross sections of $\mathrm{H}_{2}$ and $\mathrm{D}_{2}$ in helium. In this experiment a mixed $\mathrm{H}_{2}-\mathrm{D}_{2}$ modulated molecular beam was passed through a

\footnotetext{
${ }^{59}$ E. A. Mas on and J. T. Vandersilice, J. Chem. Phys. 31, 594 (1959).
}

scattering cell containing helium gas and into the mass spectrographic beam detector. The mass spectrometer was alternately focused on masses 2 and 4. A measurement of the mass 2 to mass 4 ratio with and without scattering gas yielded the relative scattering cross sections. This work was initiated because of the discrepancies which exist in transport properties of these gases. ${ }^{60}$

\section{Interactions of Gases and Surfaces}

\section{G. E. Moore Sheldon Datz E. H. Taylor}

In a continuation of the study of the reflection of modulated helium and molecular deuterium from platinum, refinements in the apparatus were completed that made possible more reliable determination of phase shifts of the modulated signal from the reflected beam relative to the incident beam. When 100 or $300^{\circ} \mathrm{K}$ helium or deuterium beams were reflected from an $\sim 1200^{\circ} \mathrm{K}$ platinum surface, a phase lead was observed corresponding to an increase in the velocity of the reflected beam. This increase corresponded to a thermal accommodation coefficient of 0.3 to 0.7 . Such an accommodation is more to be expected for a platinum surface contaminated with light atoms than for a pure platinum surface since the theoretical maximum energy exchange for collisions between particles of mass 4 and mass $\sim 200$ is only $8 \%$. This observation suggested a reexamination of the effect of oxygen on the reflection of helium from platinum, for although a layer of oxygen (present in the background gas of the vacuum system) on the platinum surface could account for relatively large accommodation coefficients, our earlier work $^{61}$ had implicated oxygen in a more complicated relationship than simple adsorption and desorption. The possibility that oxygen could oxidize, and thus remove, many likely contaminants (e.g., carbon) on the surface of the platinum was explored by exposing the hot platinum first to a relatively large amount of oxygen and then reducing the oxygen pressure and maintaining it at a much lower value during the

\footnotetext{
${ }^{60}$ See for example E. A. Mason, B. K. Annis, and M. Islam, IMP-AEC-30; Journal of Chemical Physics (in press).

${ }^{61}$ Sheldon Datz, G. E. Moore, and E. H. Taylor, p. 347 in Rarefied Gas Dynamics, vol. I, ed. by J. A. Laurmann, Academic, New York, 1963.
} 
study of the reflective behavior. This lower pressure was sufficient to continue removal of any new contaminants but low enough to prevent appreciable coverage of the surface by oxygen.

The polar plots of Fig. 9.10 summarize the results of the angular distribution of helium rereflected from a platinum surface. In Fig. 9.10A, curves I $\left(300^{\circ} \mathrm{K}\right.$ helium on $\sim 1300^{\circ} \mathrm{K}$ platinum) and II $\left(300^{\circ} \mathrm{K}\right.$ helium on $300^{\circ} \mathrm{K}$ platinum) show, respectively, the pseudospecular reflection of helium from hot platinum and the diffuse reflection from room-temperature platinum previously re-
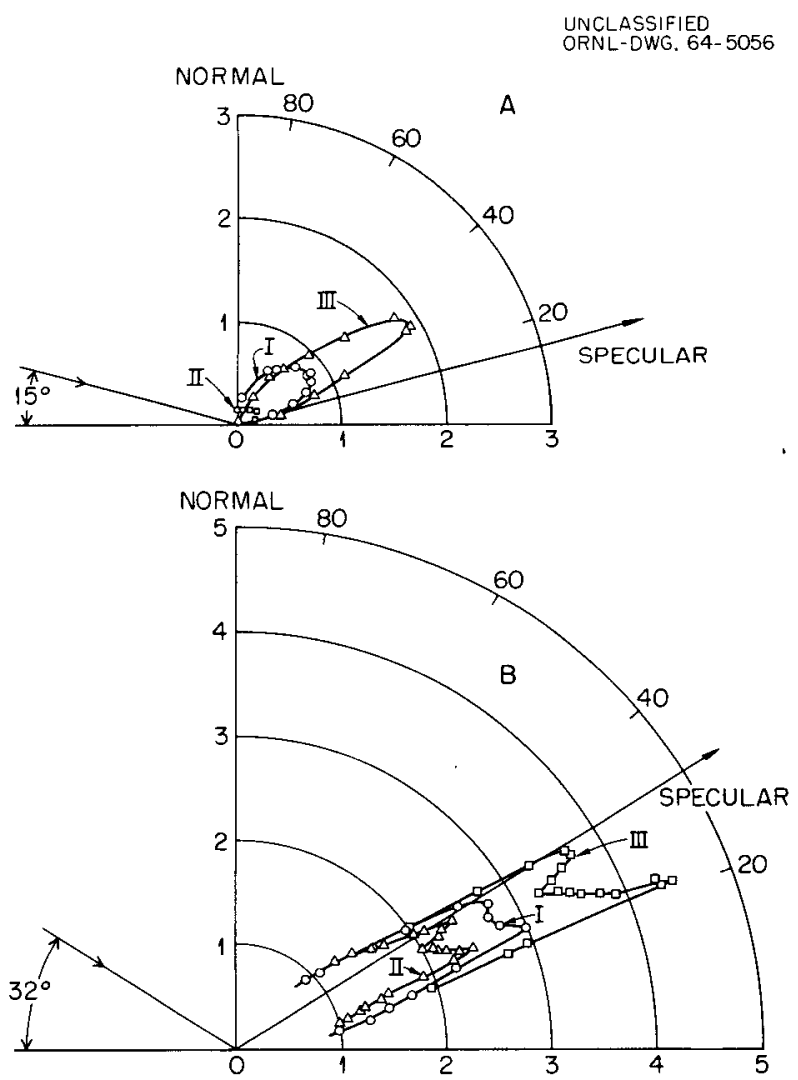

Fig. 9.10. Angular Distributions of Helium Reflected from Platinum.

\begin{tabular}{|c|c|c|c|c|}
\hline \multirow[b]{2}{*}{ Plot } & \multirow[b]{2}{*}{ Curve } & Temperature & Temperafure & \multirow[b]{2}{*}{ Ambient Atmosphere } \\
\hline & & $\begin{array}{l}\text { Helium } \\
\left({ }^{\circ} \mathrm{K}\right)\end{array}$ & $\begin{array}{c}\text { Platinum } \\
\left(\mathrm{O}^{\mathrm{O}}\right)\end{array}$ & \\
\hline \multirow[t]{3}{*}{$A$} & 1 & 300 & 1300 & Vacuum, $5.5 \times 10^{-7} \mathrm{~mm}$ \\
\hline & 11 & 300 & 300 & Vacuum, $5.5 \times 10^{-7} \mathrm{~mm}$ \\
\hline & III & 300 & 1300 & $5.4 \times 10^{-6} \mathrm{~mm} \mathrm{O}_{2}$ \\
\hline \multirow[t]{3}{*}{$B$} & I & 300 & 1300 & \multirow{3}{*}{$\begin{array}{l}\mathrm{O}_{2} \text { pretreat, } 1 \times 10^{-6} \mathrm{~mm} \mathrm{O}_{2} \\
\mathrm{O}_{2} \text { pretreat, } 2.0 \times 10^{-6} \mathrm{~mm} \mathrm{O}_{2} \\
\mathrm{O}_{2} \text { pretreat, } 1.3 \times 10^{-6} \mathrm{~mm} \mathrm{O}_{2}\end{array}$} \\
\hline & 11 & 100 & 1300 & \\
\hline & III & 300 & 900 & \\
\hline
\end{tabular}

ported. ${ }^{61}$ In the presence of oxygen (in an amount $\sim 10$ times greater than the background gas pressure) an increased intensity of the pseudospecularly reflective distribution was observed (curve III, Fig. 9.10A) which was still centered considerably toward the normal from the specular angle. The accommodation coefficient remained about 0.7 .

Treatment of the platinum while heated between 1000 and $1600^{\circ} \mathrm{K}$ with $1 \times 10^{-3} \mathrm{~mm} \mathrm{O}$ produced a surface which, at $1300^{\circ} \mathrm{K}$ and in a residual oxygen atmosphere of $\sim 1 \times 10^{-6} \mathrm{~mm}$, reflected specularly a room-temperature helium beam incident at a grazing angle of $20^{\circ}$. At incidence angles (measured from the surface) of from about 22 to $37^{\circ}$, a fine structure was observed in the reflected distribution of helium as shown in Fig. 9.10B. In these cases little $(\alpha<0.1)$ or no accommodation was detected. This fine structure was observed with helium but not with molecular deuterium, and its sharpness was enhanced with lower beam temperature (curve II, Fig. 9.10B) and with lower platinum temperature (curve III, Fig. 9.10B). This fine structure was not observed with an incident beam of higher temperature.

Such behavior suggests diffraction by a plane surface grating. X-ray diffraction patterns of the platinum surface revealed large single crystals with only very slight tilt to the planes, showing a (111) orientation fairly uniformly directed in the area of bombardment. However, to account for the observed reflected pattern on the basis of diffraction, the surface lattice spacing would have to be several times larger than normal.

Although it is not now possible to specify unequivocally the phenomenon giving rise to the fine structure, it seems likely, from the specularity of the reflection, its intensity (as high as $8 \%$ of the original beam), and the very small accommodation, that this reflection is from a predominantly uncontaminated platinum surface.

Introducing $\mathrm{CH}_{4}, \mathrm{CO}$, or $\mathrm{C}_{2} \mathrm{H}_{2}$ into the ambient atmosphere of the heated platinum caused significant changes in the reflection of a helium beam from the surface. Oxygen, under appropriate but not necessarily identical conditions for each contaminating gas, restored the original reflective pattern. Methane and $\mathrm{CO}$ yielded similar results which were quite different from the behavior caused by the presence of acetylene. 


\section{MASS SPECTROMETRY AND RELATED TECHNIQUES}

\section{Two-Stage Mass Spectrometer}

\author{
Russell Baldock L. E. Idom
}

The two-stage mass spectrometer has been in continuous use in support of the neutron crosssection measurement program of the Chemistry Division. Carefully shaped sample ovens formed from rhenium ribbons have been found to be entirely satisfactory for all of the isotopes listed below. By means of a die the rhenium ribbon is pressed into a deep canoe-like trough and is then baked for approximately $2 \mathrm{hr}$ at $2000^{\circ} \mathrm{C}$ in a high vacuum. The sample which is usually in the form of the nitrate is placed by means of a microliter syringe inside and in the center of the oven. The two sides are then drawn closely together by means of a pair of tweezers. This last step ensures that the positive ions from elements such as uranium and californium are more than $99 \%$ metal ions and the loss of sample by forming oxide ions is negligible.

All measurements for determining the neutron capture cross section of ${ }^{105} \mathrm{Rh}$ were completed. ${ }^{62}$ Most analyses were concerned with checking the yield of various chemical procedures. The isotope dilution technique employing enriched ${ }^{102} \mathrm{Pd}$ was used for this purpose and the same technique employing enriched ${ }^{108} \mathrm{Pd}$ was used to measure the ${ }^{105} \mathrm{Pd}$ and ${ }^{106} \mathrm{Pd}$ produced by irradiation of the starting material, enriched ${ }^{104} \mathrm{Ru}$. Isotopic analyses before irradiation and after one cycle in the ORR were completed on samples of enriched ${ }^{98} \mathrm{Ru}$, ${ }^{99} \mathrm{Ru}, \quad{ }^{100} \mathrm{Ru}$, and ${ }^{101} \mathrm{Ru}$ respectively. ${ }^{63}$ After irradiation the ${ }^{100} \mathrm{Ru}$ content of the enriched ${ }^{99} \mathrm{Ru}$ showed an approximate $9 \%$ increase, the ${ }^{101} \mathrm{Ru}$ content of the enriched ${ }^{100} \mathrm{Ru}$ showed an approximate $9 \%$ increase, and the ${ }^{102} \mathrm{Ru}$ content of the ${ }^{101} \mathrm{Ru}$ showed an approximate $2 \%$ increase. No change was observed in the ${ }^{99} \mathrm{Ru}$ content of the enriched ${ }^{98} \mathrm{Ru}$. Analyses were completed for the measurement of the thermal cross section and resonance integral for the reaction ${ }^{232} \mathrm{U}(n, \gamma){ }^{23} \mathrm{U}$

\footnotetext{
${ }^{62}$ See Resonance Integral and an Upper Limit for the Thermal Neutron Cross Section of ${ }^{105} \mathrm{Rh}$, chap. 1 (this report).

${ }^{63}$ See Neutron Cross Section Measurement of ${ }^{98} R u$, ${ }^{99} \mathrm{Ru},{ }^{100} \mathrm{Ru}$, and ${ }^{101} \mathrm{Ru}$, chap. 1 (this report).
}

(ref. 64). Using approximately $0.01 \mu \mathrm{g}$ of material the relative abundance of the isotopes of a sample of californium was determined. All exploratory analyses and isotopic abundances required prior to irradiation have been made for measuring the cross section of the reactions ${ }^{233} \mathrm{U}(n, 2 n)^{232} \mathrm{U}$, ${ }^{235} \mathrm{U}(n, 2 n){ }^{234} \mathrm{U},{ }^{92} \mathrm{Mo}(n, p){ }^{9} \mathrm{Nb}$, and the neutron capture cross sections for ${ }^{104} \mathrm{Pd},{ }^{105} \mathrm{Pd}$, and ${ }^{106} \mathrm{Pd}$ (ref. 65).

\section{CHARGE SPECTROMETRY}

\section{The Consequences of Inner-Shell Vacancies to Atoms and Molecules}

\section{T. A. Carlson M. O. Krause}

One of the principal areas of investigation for charge spectrometry has been the study of atomic readjustment to inner-shell vacancies and its subsequent effect on molecules. Earlier experiments ${ }^{56}$ were made with radioactive gases undergoing electron capture and internal conversion. The program has now been extended to investigations in which the initial vacancies are produced by $\mathrm{x}$ rays. Last year a charge spectrometer, equipped for use with $x$ rays, was put into operation. The spectrometer, which employs magnetic analysis, proved very successful, and charge distributions were obtained for initial holes in the $K$ shell of neon, $K$ and $L$ shells of argon, $K, L$, and $M$ shells of krypton, and $L$ and $M$ shells of xenon. Charge spectra of neon have also been measured as a function of the velocity of the photoelectron. Comparison with theory shows that though the gross spectra are consistent with the present ideas of Auger cascades and electron shake-off, there is more ionization following a $K$ hole in neon or an $L$ hole in argon than can be presently accounted for.

A code for calculating relativistic Hartree wave functions on the 1604 computer is near completion,

\footnotetext{
${ }^{64}$ See Thermal Neutron Cross Section and Resonance Integral of ${ }^{232} U$, chap. 1 (this report).

${ }^{65}$ See Thermal Neutron Cross Section and Resonance Integral of ${ }^{106} \mathrm{Pd}$, chap. 1 (this report).

${ }^{66}$ For example, A. H. Snell and F. Pleasonton, Phys. Rev. 100, 1396 (1955); T. A. Carls on and R. M. White, J. Chem. Phys。 38, 2930 (1963).
} 
and a program has been devised for also computing continuum wave functions and subsequently Auger transition rates. A number of electron shake-off probabilities have been calculated from $Z=10$ to $Z=36$.

Finally, some work has begun with molecular systems to ascertain the effect of the extensive decomposition that results when an inner-shell electron is removed.

Some of the details concerning our present research with $\mathrm{x}$ rays have been reported elsewhere. ${ }^{67}$

${ }^{67}$ T. A. Carls on and M. O. Krause, Phys. Div. Ann. Progr. Rept. Jan. 31, 1964, ORNL-3582, p. 24; M. O. Krause and T. A. Carlson, ibid., p. 30. 


\section{Water Research Program}
W. H. Baldwin
M. D. Danford
Sheldon Datz
C. E. Higgins
J. S. Johnson
K. A. Kraus
R. D. Lanier
M. H. Lietzke
A. E. Marcinkowsky
D. C. Michelson
Takashi Morozumi
H. O. Phillips

\author{
F. A. Posey \\ R. J. Raridon \\ George Scatchard ${ }^{1}$ \\ R. W. Stoughton
}

The Water Research Program at ORNL is under the sponsorship of the Office of Saline Water (OSW) and based on an agreement between the Department of the Interior and the U.S. Atomic Energy Commission. This agreement and its supplements specify that ORNL carry out fundamental research in a variety of fields including thermodynamic and transport properties of solutions, reactions and transport phenomena at surfaces, and study of separations processes including ion exchange and transport properties of inorganic and organic membranes. A substantial portion of this program is being carried out in the Chemistry Division and certain aspects of this work are summarized below. Since several of the individuals working on this program are doing so on a part-time basis, and since in several cases the work represents a cooperative program between personnel engaged in OSW and AEC activities, part of this work carries dual sponsorship by OSW and AEC.

\section{Hyperfiltration Studies of Membranes}

In hyperfiltration or reverse osmosis, salt is removed from aqueous solutions essentially by "pressure filtration" through suitable membranes. Studies in the Chemistry Division were principally concerned with (1) attempts to prepare new organic or inorganic membranes, (2) studies of a cellulose membrane to which polyacrylic acid is grafted, (3) development of equipment for rapidly evaluating membranes, and (4) examination of the transport relations in hyperfiltration. A brief discussion of most of these topics follows. There is little to report on new membrane development. While a considerable number of organic and inorganic systems has been studied, none were found which combined reasonable salt rejection with reasonable water transmission rates.

\section{Properties of a Cellophane-g-Polyacrylic-Acid Membrane}

Preliminary work with this cation exchange membrane, which is prepared by grafting polyacrylic acid to cellophane, was described in the previous annual report. ${ }^{2}$ Most of the work has been written up ("Preparation and Hyperfiltration Properties of a Polyacrylate-Cellophane Membrane" by W. H. Baldwin, D. L. Holcomb, and J. S. Johnson) and has been accepted for publication by the Journal of Polymer Science. A brief summary of the work follows:

The membrane shows reasonable salt rejection at permeation rates of the order of $0.005 \mathrm{~cm} \mathrm{hr}^{-1}$ atm $^{-1}$. With $\mathrm{NaCl}$, rejection, $R\left[R=\left(m_{\mathrm{feed}}\right.\right.$ - $\left.m_{\text {product }}\right) / m_{\text {feed }}$, where $m$ is concentration], increases with dilution qualitatively as one might expect from a "Donnan" exclusion mechanism applied to ion-exchange membranes. Variation of rejection with salt concentration is less pronounced with multivalent counter ions; with lanthanum nitrate, rejection was almost independent of concentration in the range 0.005 to $0.5 \mathrm{M}$. Rejection for

\footnotetext{
${ }^{1}$ Professor Emeritus, Massachusetts Institute of Technology; consultant, Oak Ridge National Laboratory.

${ }^{2}$ Chem. Div. Ann. Progr. Rept. June 20, 1963, ORNL. 3488 , p. 126 .
} 
sodium sulfate, a salt with a divalent co-ion, was higher than for $\mathrm{NaCl}$.

Permeation rates did not vary linearly with pressure as one might expect for an ideal membrane and rejection increased with increasing pressure. Presence of multivalent counter ions decreased permeation rates drastically, even in the presence of a large excess of $\mathrm{NaCl}$.

Temperature changes in the range $25-65^{\circ} \mathrm{C}$ did not affect rejection significantly but permeation rates increased with temperature approximately as expected from changes in viscosity of the solutions.

If salt rejection were due to a "Donnan" mechanism one predicts that at low salt concentrations the slope of a plot of $\log (1-R)$ vs logarithm of concentration of counter ions would approach 1 for $\mathrm{NaCl}$ and 2 for $\mathrm{Na}_{2} \mathrm{SO}_{4}$. Figure 10.1 illustrates that the variation of rejection with concentration is much less than predicted from this model. Glueckauf $^{3}$ in analogous experiments with ion exchange-electrodialysis membranes found similar though smaller departures from ideality which he attributed to inhomogeneities of the membrane.

Most of the rejection experiments were carried out with sodium chloride solutions of air-equilibrated $\mathrm{pH}$; this is not high enough for full neutralization of the polyacrylic acid and, hence, for full charge development. Some measurements were attempted as a function of $\mathrm{pH}(3$ to 11$)$. In general, rejection

${ }^{3}$ E. Glueckauf and R. E. Watts, Proc. Roy. Soc. (London) A268, 339 (1962); J. M. Crabtree and E. Glueckauf, Trans. Faraday Soc. 59, 2639 (1963).

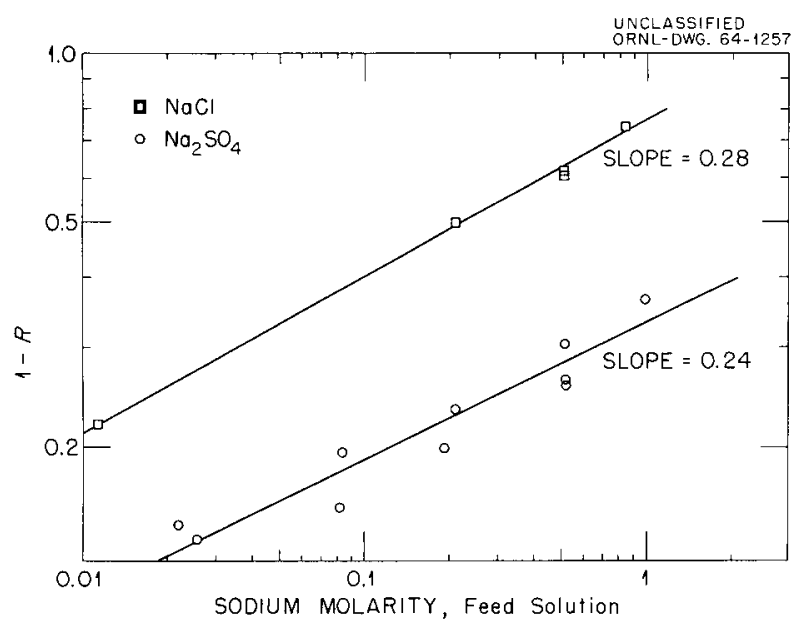

Fig. 10.1. Logarithmic Plot of Membrane Rejection. increased with $\mathrm{pH}$ as expected but the results were somewhat inconsistent and irreproducible, and at the higher $\mathrm{pH}$ there seemed to be irreversible changes in the membranes. Preliminary experiments have been carried out with membranes of varying ion exchange capacity ( 0.3 to 4.8 equivalents per $\mathrm{kg}$ dry film). A rough correlation of rejection with capacity was observed.

\section{Development of Equipment for Rapidly Evaluating Membranes}

There seems to be continuing need for the development of very rapid methods for the measurement of permeation and salt rejection characteristics of hyperfiltration membranes. A technique has been developed which seems suitable for rapid evaluation of these characteristics and adaptable to routine use. The equipment uses a modified tuberculin syringe as the pressure vessel and an adapter which securely holds a small sample of the membrane. The plunger of the syringe is driven by a piston of 40 times larger cross-sectional area; it in tum is driven by compressed air or nitrogen. With a well-fitting plunger and commercial syringes, experiments can be carried out routinely up to $100 \mathrm{~atm}$ pressure. Effluent from the syringe can be analyzed conductimetrically through a micro conductance cell built into the effluent tip.

Transmission rates can simply be determined from the time intervals between drops leaving the tip after separately determining the volume or weight per drop. Through analysis of the concentration profile of the effluent as a function of effluent volume (at constant flow velocity) the rejection properties of the membrane can be determined by matching observed curves with those calculated. The technique permits establishment of rejection properties with a given solution and membrane in usually less than $1 / 2 \mathrm{hr}$. A series of tests has been carried out with a Loeb-Sourirajan cellulose acetate membrane and a variety of salt solutions.

For computing rejection properties from the concentration profiles of the effluent we rely on the predictability of concentration polarization at the membrane-solution interface in an unstirred hyperfiltration system. As solvent (and lowconcentration solute) permeates the membrane the 
rejected salt builds up against the membrane interface. The rate of buildup increases with transmission rate $\left(v_{0}\right)$ of the membrane and time $(t)$ and decreases with the diffusion coefficient $(\mathbb{Q})$ of the salt in the solution phase. Different experiments may be correlated through the parameter $v_{0}^{2} t / D$. Theoretical transmission curves have been computed (by L. Dresner of the Neutron Physics Division) as a function of this parameter for a large number of values of percent rejection.

\section{Transport Relations in Hyperfiltration}

In phenomenological discussions of membrane behavior, rejection (or semipermeability) properties of membranes toward solutes of approximately the same molecular size as the solvent have been attributed by some to differences in diffusion rates of solutes and solvent in the membrane, and by others to differences in distribution of the two components between solution and membrane phases. To elucidate the contribution of these factors to observed properties, we have carried out an analysis for a model membrane with constant water content, constant activity coefficients of water and salt in the membrane, and the same distribution coefficients between solution and membrane at the two interfaces, that is, $D^{*}=m_{\alpha}^{*} / m_{\alpha}=m_{\omega}^{*} / m_{\omega}$, where $\alpha$ indicates the feed (high-pressure) interface; $\omega$ the low-pressure, or product, interface; * the membrane phase; and $m$ is the concentration of salt in moles per $\mathrm{kg}$ of $\mathrm{H}_{2} \mathrm{O}$. For illustration, we shall here use an approximate equation

$$
J_{2}=\beta J_{1} m^{*}-D_{2}^{*}\left(\mathrm{~d} m^{*} / \mathrm{d} x\right),
$$

where $J_{2}$ is salt flux (moles/cm $\left.{ }^{2}\right) ; J_{1}$ is water flux ( $\mathrm{kg} \mathrm{H}_{2} \mathrm{O} \mathrm{cm} \mathrm{cm}^{-2} \mathrm{sec}^{-1}$ ); $\mathbb{D}_{2}^{*}$ is the salt diffusion coefficient in appropriate units; and $\mathrm{x}$ is distance from the $\alpha$ interface. By continuity, $J_{2} / J_{1}=m_{\omega}$ The symbol $\beta$ is a coupling coefficient between solvent and solute flow in the membrane. We shall emphasize here the extreme case of complete coupling, $\beta=1$. This implies stronger interaction between membrane water and salt than between salt and membrane matrix, and we feel this is closer to the actual situation with most films than the opposite extreme, no coupling.
Equation (1) may be integrated to give a concentration profile of salt across the membrane. Concentration at the interfaces, distribution coefficient, and rejection are related by

$$
R=1-m_{\omega} / m_{a}=1-D^{*} /\left(m_{a}^{*} / m_{\omega}\right) .
$$

In Fig. 10.2, the ratio of salt molality in the membrane to that of the solution at the $\alpha$ interface, $\mathrm{m}^{*} / m_{\alpha}$, is plotted vs $x / l$, where $l$ is the thickness of the membrane; in this illustration, $D^{*}=0.1$. Curves are given for different values of the dimensionless variable $\sigma=J_{1} 1 / 1 \mathrm{Q}_{2}^{*}$; with a given membrane, $\sigma$ would be varied by changing the applied pressure and, in turn, $J_{1}$. For the limit of zero flow, it can be seen that, as one would expect at equilibrium, $m_{\alpha}=m_{\omega}$, and there is no rejection.

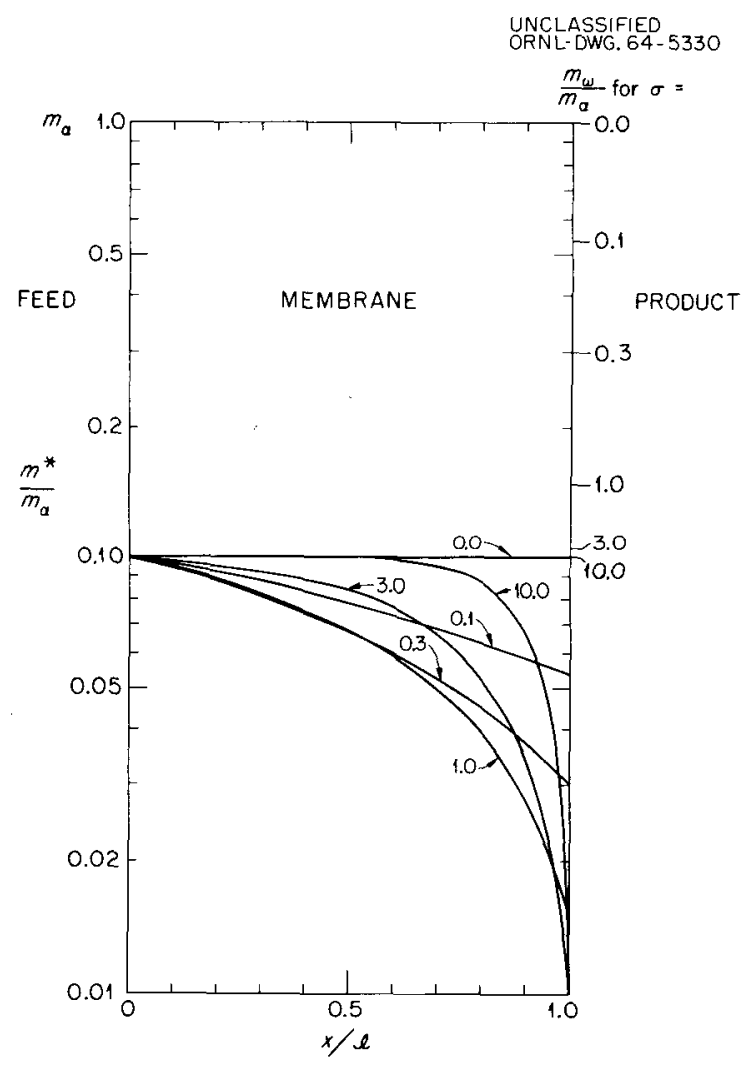

Fig. 10.2. Concentration Profiles Computed for Complete Coupling of Solvent and Solute Flow $(\beta=1)$. $D^{*}=0.1$ and values of $\sigma$ indicated on individual curves. 


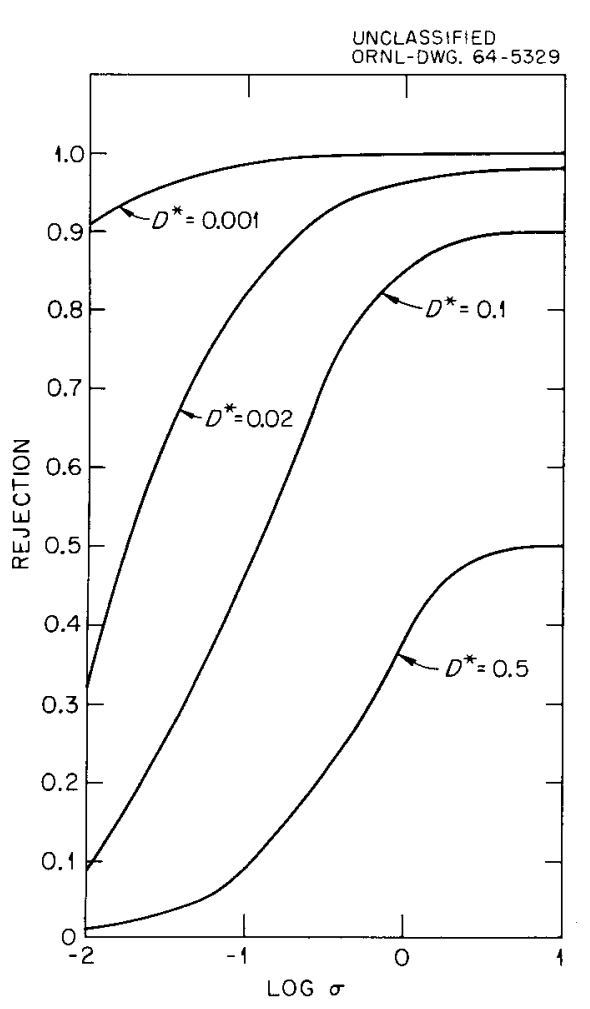

Fig. 10.3. Rejection of Membranes with Coupled Flow of Solvent and Solute $(\beta=1)$.

Increasing $J_{.1}$ results in a concentration gradient of salt through the membrane, since the effluent solution has a higher salt concentration than the membrane solution at the product interface, and consequently a contribution of diffusion to salt flow arises. As $\sigma$ becomes large, about 10, rejection reaches a limiting value, $1-D^{*}$. Here the distribution, or solubility, model of rejection is completely applicable, and measurements of the distribution coefficient between membrane and solution, or of an appropriate solution model of the membrane, should give rejection. Rejections of membranes vs $\log \sigma$ are given in Fig. 10.3 for different values of $D^{*}$. It is of interest that one obtains nearly the asymptotic values of rejection at values of $\sigma$ considerably less than 10 .

In the other extreme, no coupling $(\beta=0)$, rejection approaches unity as $\sigma$ increases. In this case also, however, before asymptotic rejection is reached, rejection is higher for lower values of $D^{*}$.

\section{The Effect of Dielectric Constant Difference on Hyperfiltration of Salt Solutions}

A number of papers in the literature have suggested that salt rejection by certain types of uncharged hyperfiltration membranes is related to the decrease in salt concentration at the interface between the salt solution and a medium of low dielectric constant; usually these conclusions are based on properties of the air-aqueous solution interface. In order to evaluate the importance of these considerations the equation of Onsager and Samaras for the equilibrium concentrations of an ion near a water-air interface was extended to interfaces between two phases with any dielectric constants, to the concentrations in the low dielectric constant phase, and to the minimum concentration in the membrane phase surrounded on both sides by an aqueous solution. The work has been summarized in a paper by George Scatchard entitled "The Effect of Dielectric Constant Difference on Hyperfiltration of Salt Solutions" which was published in Journal of Physical Chemistry 68, 1056 (1964). This paper also discusses hyperfiltration of sodium chloride solutions through uncharged membranes; it was shown that hyperfiltration depends largely on the equilibrium concentration within the membrane and almost not at all on the concentration very near the membrane surfaces.

\section{Diffusion Coefficients of Salts in Solutions}

Equipment has been assembled for determination of self-diffusion and tracer-diffusion coefficients in solutions. The measurements are carried out by a radiometric porous frit method which seems capable of yielding diffusion coefficients in a few minutes with a precision of a few percent.

In the method a thin slab of a porous material (e.g., porcelain) is saturated with a solution which contains a gamma-emitting radioisotope of the element of interest. Excess tracer solution is removed and the saturated frit is placed in a flow tube in front of a counter; solution of the same composition but not containing tracer is pumped past the frit. The counting rate of the frit is measured as a function of time. From these data diffusion coefficients, $\mathbb{D}$, may be obtained if the flow rate past the frit is sufficiently fast and if the frits have been calibrated with a tracer of 
known diffusion coefficient. The electronic equipment permits simultaneous measurement of diffusion coefficients of more than one tracer provided the tracers have significantly different gamma spectra.

The overall precision of the method has been checked with frits of various dimensions and diffusion coefficients have been measured for a number of systems where comparison with literature values was feasible. In addition, the diffusion coefficients of bromide ions have been determined in $\mathrm{NaBr}, \mathrm{KBr}$, and $\mathrm{HBr}$ solutions over wide concentration ranges. While for these systems $D$ varies significantly with electrolyte and its concentrations, the diffusion-viscosity product $\left(\mathbb{D}^{*}=\right.$ $\left.D \eta / \eta_{\mathrm{o}}\right)$ was found to be essentially independent of medium.

Diffusion coefficients of zinc have been determined in $\mathrm{HCl}$ and perchloric acid solutions, again over wide concentration ranges. The values of $1^{*}$ in $\mathrm{HCl}$ rise substantially more rapidly than those in $\mathrm{HClO}_{4}$ solutions at concentrations up to ca. $2 \mathrm{M}$. The difference clearly reflects the complexing reactions of $\mathrm{Zn}$ (II) with chloride ions. It appears that $D^{*}$ of the negatively charged complexes of $\mathrm{Zn}(\mathrm{II})$ are ca. $30 \%$ larger than those of $\mathrm{Zn}^{++}$.

\section{Activity Coefficients of Salts in Water Mixtures of Glycol, Glycerol, and Their Acetates}

An extensive study has been completed on the activity coefficients of $\mathrm{NaCl}, \mathrm{KCl}$, and $\mathrm{Ba}\left(\mathrm{NO}_{3}\right)_{2}$ at saturation in water mixtures of ethylene glycol and its mono- and diacetates, and in glycerol and its mono-, di-, and triacetates. The necessary solubilities were determined at $25^{\circ} \mathrm{C}$ by packedcolumn techniques. Radiometric methods for analysis were used where desirable. This work by K. A. Kraus, R. J. Raridon, and W. H. Baldwin has been written up ("Properties of Organic-Water Mixtures. I. Activity Coefficients of $\mathrm{NaCl}, \mathrm{KCl}$, and $\mathrm{Ba}\left(\mathrm{NO}_{3}\right)_{2}$ in Saturated Water Mixtures of Glycol, Glycerol, and Their Acetates. Model Solutions for Hyperfiltration Membranes") and accepted for publication by the Journal of the American Chemical Society.

Activity coefficients $\gamma_{ \pm_{(0)}}$ (computed by using the same reference states in the organic-water mixtures as for aqueous solutions and by expressing concentrations in moles per $\mathrm{kg}$ of water) for glycol and glycerol-water mixtures were usually less than for the two-component aqueous solutions. The activity coefficients increased with fraction of hydroxyl groups acetylated and were, for the fully acetylated compounds at low water content, more than 1000 times larger than for the two-component systems. The activity coefficients for $\mathrm{NaCl}, \mathrm{KCl}$, and $\mathrm{Ba}\left(\mathrm{NO}_{3}\right)_{2}$ were, at constant water content, approximately the same for glycol diacetate and glycerol triacetate.

\section{Effect of Salts on the Miscibility Gap in the Glycerol Triacetate-Water System}

Glycerol triacetate (GTA) and water are not completely miscible at room temperature. It was found that addition of $\mathrm{NaCl}, \mathrm{KCl}$, and $\mathrm{MgCl}_{2}$ reduces the mutual miscibility substantially; the decrease can be predicted by calculating the water activity of the water-rich phase and assuming that for the organic-rich phase the activity of water is a monotonic function (approaching Henry's law) of the mole fraction. Substantially the same curve applies to the organic-rich phase of the glycol diacetate system.

It was found that addition of certain other salts, for example, perchlorates, thiocyanates, iodides, and salicylates increases the mutual solubility of GTA and water to such an extent that complete miscibility eventually results.

For the anions listed, these "salting in" effects are in general insensitive to the cation used or its charge. Figure 10.4 shows a plot of moles of perchlorates required to produce miscibility vs weight percent GTA; a maximum occurs near $40 \%$ GTA. Complete miscibility at $40 \%$ GTA requires ca. 1 mole of perchlorate and salicylate ions per kilogram of solvent. For thiocyanates and iodides the corresponding anion concentrations are larger.

\section{Other Studies of Water-Organic Mixtures}

Activity coefficients of $\mathrm{NaCl}$ and $\mathrm{KCl}$ (in saturated solutions) were studied for a large variety of water-organic mixtures including various amides, alcohols, ethers, and sulfur-containing compounds. Activity coefficients of $\mathrm{KCl}$ are usually somewhat higher than those of $\mathrm{NaCl}$. In most cases the ratio of the two activity coefficients is of the order of 


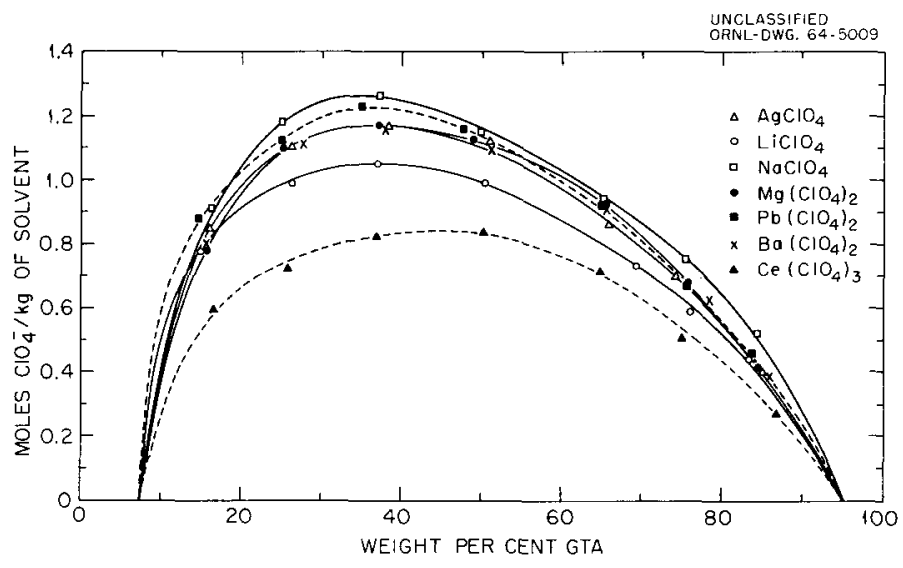

Fig. 10.4. Moles of Perchlorote Required to Produce Miscibility in the System Glycerol Triacetate-Water.

2 or less. In a few cases activity coefficient ratios as large as 6 have been observed.

The miscibility limits of the phenol-water system were established in the presence of $\mathrm{NaCl}, \mathrm{KCl}$, $\mathrm{RbCl}$, and $\mathrm{CsCl}$ at saturation with the salts. Solubility of the salts in the mixtures increases uniformly from sodium to cesium in the organicrich phases and the activity coefficient ratios $\Gamma=\gamma_{ \pm(0)} / \gamma_{ \pm}$correspondingly decrease by almost two orders of magnitude.

\section{Hydrates (Clathrates) of Oxygen and Nitrogen}

Brackman and Fite $^{4}$ have observed that water vapor condensing at liquid-nitrogen temperatures removes residual noncondensable gases from vacuum systems down to a pressure of $2 \times 10^{-5}$ torr. Although 50 water molecules were required to trap one nitrogen or oxygen molecule, it appeared that this effect might be related to clathrate formation. Existence of clathrates of oxygen and nitrogen was demonstrated by van Cleef and Diepen; ${ }^{5}$ their composition was not investigated. If the removal of noncondensable gases through addition of water at liquid-nitrogen temperatures were related to clathrate formation one would expect that, through proper control of the kinetics of condensation, the ratio of water to trapped gas

${ }^{4}$ R. T. Brackman and W. L. Fite, J. Chem. Phys. 34, 1572 (1961).

${ }^{5}$ A. van Cleef and G. A. M. Diepen, Rec. Trav. Chim. 79, 587 (1960). might be decreased from 50 to 1 , as given by Brackman and Fite, to the theoretical ratio of 5.8 to 1 .

This possibility was investigated by passing a stream of gas saturated with water vapor into a condenser cooled with liquid nitrogen. The solid condensate was melted and analyzed for permanent gas content. Preliminary experiments showed that if pure $\mathrm{O}_{2}$ or $\mathrm{N}_{2}$ was used in the gas stream, a mole ratio of water to gas of 20:1 to $30: 1$ was obtained. However, if carbon dioxide-free air was used, the ratio was $5: 1$ to $6: 1$, the trapped gas consisting mostly of $\mathrm{O}_{2}$. The solid did not decompose under vacuum at liquid-oxygen temperature but the gas was evolved at $-78^{\circ} \mathrm{C}$.

\section{Activity Coefficients of Salts by EMF Methods}

Evaluation of special glass electrodes for determination of free energies of salts in aqueous solutions and in mixed water-organic systems continued. Most of these studies so far have been with $\mathrm{NaCl}$. Measurements included activity coefficients of $\mathrm{NaCl}$ in a variety of water-organic mixtures as a function of salt concentration and water content and measurement of activity coefficients of $\mathrm{NaCl}$ in aqueous solutions in the presence of various alkalineearth chlorides.

For the aqueous two-component systems, the activity coefficients obtained from our glass electrode-silver-silver chloride cells were in good agreement with values available in the literature. 
Measurements of the activity coefficients of $\mathrm{NaCl}$ in water-methanol systems agreed well with literature data up to $50 \%$ methanol. Measurements have also been made in dioxane-water, dimethyl formamide-water, and Methyl Cellosolve-water mixtures.

Activity coefficients of $\mathrm{NaCl}$ in mixtures with alkaline-earth chlorides seem to follow Harned's rule reasonably well at constant ionic strength. For the $\mathrm{NaCl}-\mathrm{BaCl}_{2}$ system, they are in good agreement with unpublished data by $R$. A. Robinson (National Bureau of Standards).

\section{Calculation of Vapor Pressures of Sea Salt Solutions}

Vapor pressures of sea salt solutions and their concentrates were calculated by use of osmotic coefficient data for $\mathrm{NaCl}$ solutions and the calculated values compared with experimental measurements. Osmotic coefficients from the literature $^{6,7}$ in the range 25 to $100^{\circ} \mathrm{C}$ and 1 to $4 \mathrm{~m}$ $\mathrm{NaCl}$ were converted to values of $\phi_{\mathrm{p}}$, where

$$
\phi_{p} \equiv-\frac{1000}{2 m M_{W}} \ln \frac{p}{p_{0}} .
$$

Here $M_{W}$ is the molecular weight of water and $p$ and $p_{0}$ are the vapor pressures of $\mathrm{NaCl}$ solutions and (pure) water. Values of $\phi_{p}$ for 1 to $3 \mathrm{~m} \mathrm{NaCl}$ solutions and 125 to $270^{\circ} \mathrm{C}$ were taken from the work of Gardner, Jones, and de Nordwall. ${ }^{8}$ All $\phi_{p}$ values were fitted to an equation involving a Debye-Hückel expression plus a linear and quadratic term in total ionic concentration $\left(\sum_{i} m_{i}\right)$. The Debye-Hückel parameter $A$ was set equal to 1.5 at all temperatures. The linear and quadratic parameters were assumed to vary with absolute temperature $T$, according to the equations

${ }^{6}$ H. S. Harned and B. B. Owen, The Physical Chemistry of Electrolytic Solutions, 3d ed., pp. 415-92, Reinhold, New York, 1958.

${ }^{7}$ R. A. Robinson and R. H. Stokes, Electrolyte Solutions, Appendix 8.8, Academic Press, New York, 1955.

${ }^{8}$ E. R. Gardner, P. T. Jones, and H. J. de Nordwall, Trans. Faraday Soc. 59, 1994 (1963).

$$
\begin{aligned}
& B=\frac{B_{1}}{T}+B_{2}+B_{3} \ln T, \\
& C=\frac{C_{1}}{T}+C_{2}+C_{3} \ln T,
\end{aligned}
$$

whose functional form is consistent with a constant $\Delta C_{p}$. For sea salt mixtures the Debye-Hückel slope $\&$ in terms of that for a 1-1 electrolyte $\&_{1}$ becomes

$$
=\frac{\sum_{i} m_{i} Z_{i}{ }^{2}}{\sum_{i} m_{i}}
$$

where the sums are taken over all ions and where $m_{i}$ and $Z_{i}$ represent the molality and charge of the $i$ th ion. The relative ionic concentrations of sea salt solutions were taken from Spiegler's book. ${ }^{9}$

The vapor pressures of the sea salt mixtures were calculated by the use of Eq. (3) in which the denominator term $2 m$ was replaced by $\sum_{i} m_{i}$ for the mixture. The results are shown in Fig. 10.5. As seen in Fig. 10.5 the experimental data scatter badly about the calculated curves. It is interesting that in the concentration region where $\mathrm{NaCl}$ data exist ( $3 \mathrm{~m}$ and $4 \mathrm{~m}$ correspond approximately to 16 and $20 \mathrm{wt} \%$ total solids) the calculated curves are nearly straight lines with small negative slopes. It appears that, except perhaps for the extrapolated concentrations, the calculated values are at least as accurate as the existing experimental pressures. Hence if vapor pressures of sea salt solutions of greater accuracy than the calculated values are needed, much more accurate experimental measurements will have to be made.

The curvature of the calculated curves in the high concentration region is believed to be an artifact of the extrapolation; rather different (though self-consistent) sets of parameters can. represent osmotic coefficient data well over a limited concentration range, but these different sets can produce rather widely different values outside the range of fit.

\footnotetext{
${ }^{9}$ K. S. Spiegler, Salt Water Purification, Wiley, New York, 1962.
} 


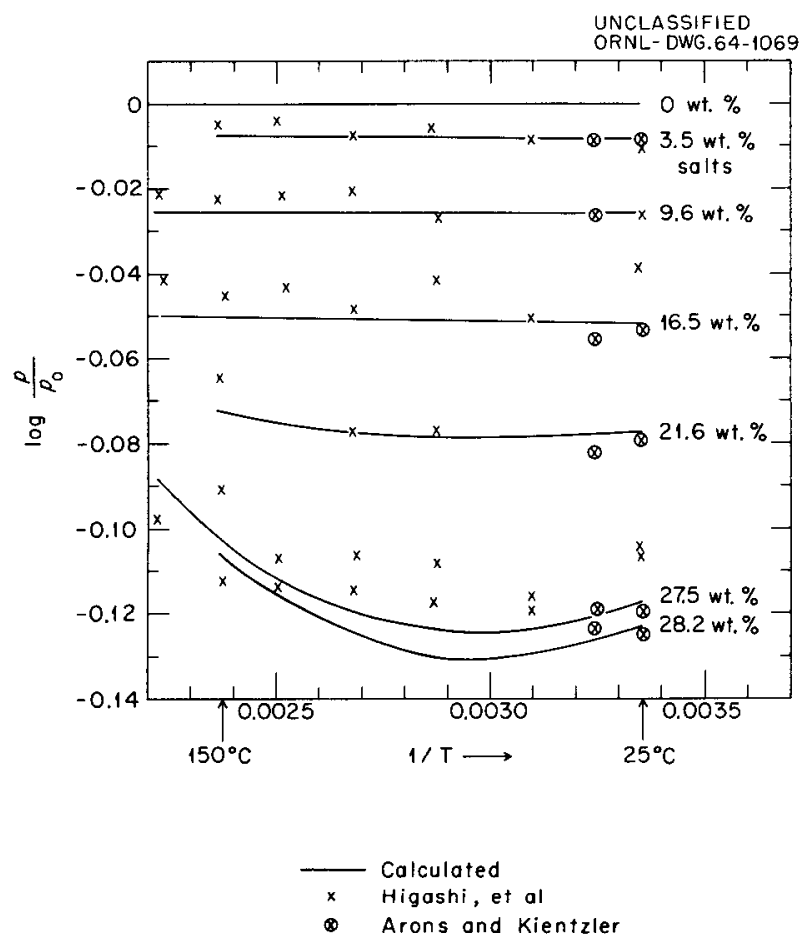

Fig. 10.5. Deviations of Vapor Pressures of Sea Salt Solutions from That of Water.

\section{Ion Exchange; Adsorption on Inorganic Materials}

Studies of the adsorption and ion exchange behavior of a variety of inorganic materials continued. This work was under sponsorship of OSW and AEC.

Principal emphasis was on (1) ion exchange and adsorption properties of oxides such as $\mathrm{MgO}$, $\mathrm{La}_{2} \mathrm{O}_{3}, \mathrm{Bi}_{2} \mathrm{O}_{3}$, which were expected to be only anion exchangers, that is, without significant cation adsorption region; (2) further examination of the exchange and adsorption properties of sulfides; and (3) adsorption properties of oxides with respect to sulfides.

Evaluation of the anion exchange properties of $\mathrm{Mg}(\mathrm{II}), \mathrm{La}(\mathrm{III})$, and $\mathrm{Bi}(\mathrm{III})$ is complicated by the fact that they have moderately high solubilities in acidic media; this is particularly true, of course, for $\mathrm{Mg}$ (II) for which experiments even in ammonium salt solutions are difficult.

When $\mathrm{Bi}(\mathrm{III})$ and $\mathrm{La}$ (III) were precipitated from $0.2 M$ solutions of the nitrates through addition of excess ammonia, large amounts of nitrates ( 1 to
$2 \frac{1}{2}$ moles $/ \mathrm{kg}$ ) were incorporated in the solid. These are removed (or exchanged) on addition of 0.5 to $1 M \mathrm{NaOH}$. Treatment of $\mathrm{Bi}_{2} \mathrm{O}_{3}$ with $0.1 M$ $\mathrm{HCl}$ in columns at flow rates of the order of 0.1 to $0.5 \mathrm{~cm} / \mathrm{min}$ causes adsorption of chlorides with uptakes of the order of 3 moles $/ \mathrm{kg}$. With $\mathrm{La}_{2} \mathrm{O}_{3}$ and $0.05 \mathrm{M} \mathrm{HCl}$, uptake was only of the order of $0.2 \mathrm{~mole} / \mathrm{kg}$. Magnesium oxide showed negligible chloride uptake at $97^{\circ} \mathrm{C}$ from $0.1 \mathrm{M} \mathrm{NH}_{4} \mathrm{Cl}$.

Chromate uptake by $\mathrm{Bi}_{2} \mathrm{O}_{3}$ and $\mathrm{La}_{2} \mathrm{O}_{3}$ was in excess of 1 mole $/ \mathrm{kg}$ when acidified chromate solutions were passed over small columns of these oxides at slow flow rates. Chromate uptake by $\mathrm{MgO}$ from $0.01 \mathrm{MK}_{2} \mathrm{CrO}_{4}$ at $97^{\circ} \mathrm{C}$ was very small at $\mathrm{pH} 7$.

All three oxides showed extensive phosphate adsorption. The rates of reaction seemed relatively slow. Elution of the adsorbed phosphate was difficult even with concentrated $\mathrm{NaOH}$ solutions.

The studies mentioned in the previous annual report $^{10}$ on exchange and adsorption of metal ions by sulfides has substantially been completed and submitted for publication to the Journal of Chromatography. The studies included the sulfides of $\mathrm{Ag}(\mathrm{I}), \mathrm{Fe}(\mathrm{II}), \mathrm{Cu}(\mathrm{II}), \mathrm{Zn}(\mathrm{II}), \mathrm{Pb}(\mathrm{II}), \mathrm{Cd}(\mathrm{II})$, $\mathrm{Hg}$ (II), and $\mathrm{As}$ (III). Most of these sulfides react extensively with ions which form more insoluble sulfides. Except in the case of $\mathrm{HgS}$, the reactions are principally metathetical, that is, approximately one equivalent of the metal of the sulfide is liberated per equivalent of metal adsorbed.

The reactions are usually rapid enough for chromatographic applications. In a few cases the reactions are only on the surface of the microcrystalline particles; in most cases, however, reaction is of the order of $50 \%$ of that predicted theoretically for complete metathesis and may approach $100 \%$ of theoretical.

A striking change in the crystallite size was observed during the conversion reactions. With initial materials having crystallite sizes of the order of 50 to $100 \mathrm{~A}$, as determined by x-ray diffraction techniques (carried out by R. L. Sherman of the ORNL Analytical Chemistry Division), the metathetical reactions seemed to cause a manyfold increase in apparent crystallite size. Reasons for this unusual behavior are not clear.

${ }^{10}$ Chem. Div. Ann. Progr. Rept. June 20, 1963, ORNL3488 , p. 87. 
Mercuric sulfide undergoes an interesting reaction with silver ions. Extensive adsorption of $\mathrm{Ag}^{+}$can occur without release of an equivalent amount of mercuric ions from the solid. Presumably the silver salt is adsorbed in a manner analogous to adsorption of mercuric salts by $\mathrm{HgS}$, a reaction which has been described in the literature. Extent of adsorption of silver salts by $\mathrm{HgS}$ may be as high as $4 \mathrm{moles} / \mathrm{kg}$ under suitable conditions. Only few eluting agents have been found effective.

A preliminary examination was carried out on the adsorption of sulfide ions $\left(\mathrm{Na}_{2} \mathrm{~S}\right)$ by oxides of metals which form insoluble sulfides. As expected, extensive reaction can occur although the rates of reaction were surprisingly different for the various oxides tested. Thus, $\mathrm{Ag}_{2} \mathrm{O}$ and $\mathrm{CdO}$ reacted extensively to form the sulfides; small $(1$ to $2 \mathrm{~cm}$ ) columns of these solids were more than $85 \%$ converted at solution flow rates of ca. $3 \mathrm{~cm} / \mathrm{min}$. Mercuric oxide, on the other hand, reacted only on the surface at a much slower flow rate $(0.1 \mathrm{~cm} / \mathrm{min})$.

\section{Methods for the Calculation of Polarization in Porous Electrodes}

The distribution of current and potential in porous electrodes is a problem of considerable potential interest to desalination and water treatment, as well as fuel cell and battery technology and chemical process industries. Because of their large surface to volume ratio, porous electrodes have potential applicability to redox processes, adsorption reactions of ionic and nonionic materials, and separations in flowing streams. A number of factors greatly complicate the calculation of reaction rates in porous electrodes as compared to planar electrodes. These factors include parameters pertaining to the physical structure of the electrode itself, such as porosity, specific surface area, and conductivity of the solid and electrolyte phases.

Solutions in closed form were derived for the distribution of current and potential in idealized, one-dimensional porous electrodes in the case of a simple oxidation-reduction reaction under pure activation control. Solutions were obtained for transfer coefficients of $1 / 3, \frac{1}{2}$, and $\frac{2}{3}$ for an electrode of finite length, while solutions for the semi-infinite electrode were derived for transfer coefficients of $1 / 4,1 / 3,1 / 2,2 / 3$, and $\frac{3}{4}$. Dimensionless parameters were used for economy of notation and ease in the comparison of solutions, which were developed in terms of Jacobian elliptic functions and integrals.

Although the general solutions, valid for both large and small values of polarization, are useful for calculations on the operation of porous electrodes in the special cases prescribed by the value of the transfer coefficient, the computations are tedious. An approximate method of calculation was developed which circumvents a great part of the arithmetical difficulty, but which provides approximate solutions which are in good agreement with the general solutions and which are valid for any value of the transfer coefficient. In the approximate method, a discontinuous rate law is assumed for the interfacial reaction which follows a linear polarization relation up to a certain value of polarization determined by the transfer coefficient, where a discontinuous transition occurs to an exponential rate law. The discontinuous rate law is a good approximation to the more exact rate law, and the effect of the discontinuity is averaged out to a considerable extent, so that potential distributions calculated in this manner are quite close to those found with the general solutions.

A family of calculated polarization curves for a porous electrode of finite length is shown in Fig. 10.6. The overvoltages (units of RT/F) of the front and back sides of the electrode $[\phi(0)$ and $\phi(1)$, respectively] are plotted against the logarithm of the reduced applied current ( $I=$ applied current/ total exchange current of the electrode) as a function of the resistance parameter, $\kappa$, which is essentially a ratio of solution impedance to interfacial impedance. The solid line represents the polarization curve of a porous electrode if the reaction were distributed uniformly throughout the electrode; it is identical to the polarization curve of a planar electrode of the same surface area. As the resistance parameter increases, the potential and current distributions become increasingly nonuniform, $\phi(0)$ becomes large compared to $\phi(1)$, and the Tafel slope $[d \phi(0) / d \log I]$ becomes twice that of a planar electrode. Fig. 10.7 shows a comparison of potential distributions in a semiinfinite porous electrode as a function of the transfer coefficient at constant applied current. Points in Fig. 10.7 were computed with both exact and approximate methods; the agreement between the methods is good. A paper by F. A. Posey entitled 


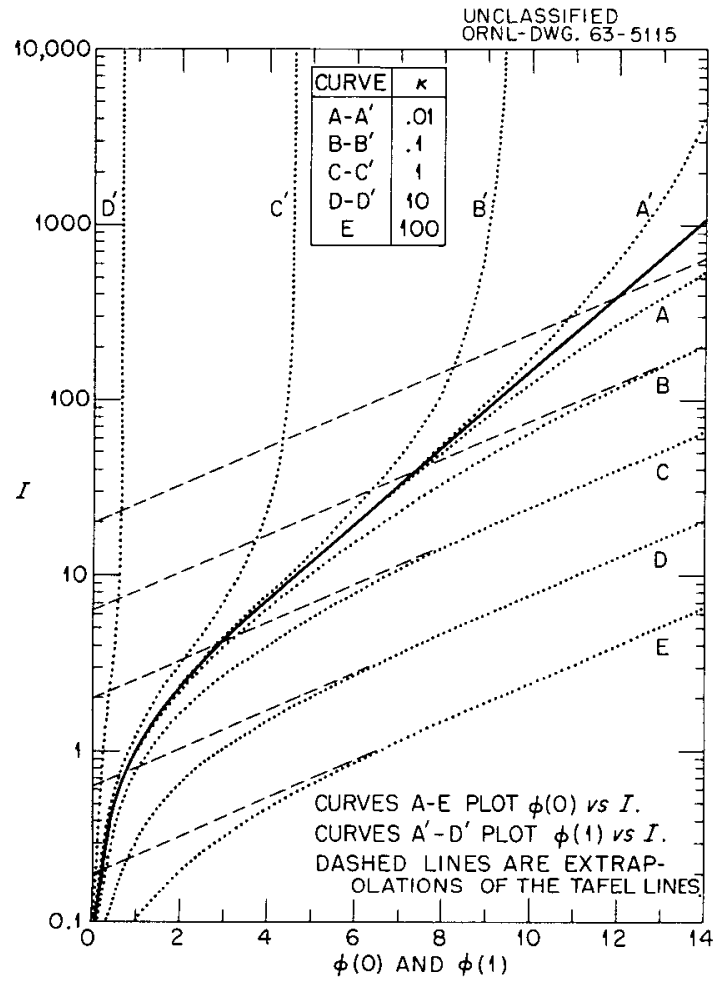

Fig. 10.6. Polarization Curves for the Finite Porous Electrode as a Function of the Resistance Parameter, $\kappa$, for the Case of the Symmetrical Rate Law $\left(\beta=\frac{1}{2}\right)$.

"Methods for the Calculation of Polarization in Porous Electrodes" summarizing this work has been accepted for publication in the Journal of the Electrochemical Society.

\section{Differential Capacity Measurements on Porous Electrodes}

Double-layer capacity measurements provide an important means for studying electrode systems. The capacity of the double layer is a function of the metal, electrode potential, temperature, and composition of the solution. Double-layer capacities reflect the presence of specifically adsorbed substances at the interface, and for this reason capacity measurements are useful for the study of processes occurring in porous electrodes of large surface area. The theory of potentiostatic and galvanostatic transients which occur during the charging of the double layer in porous electrodes of finite length was developed and verified

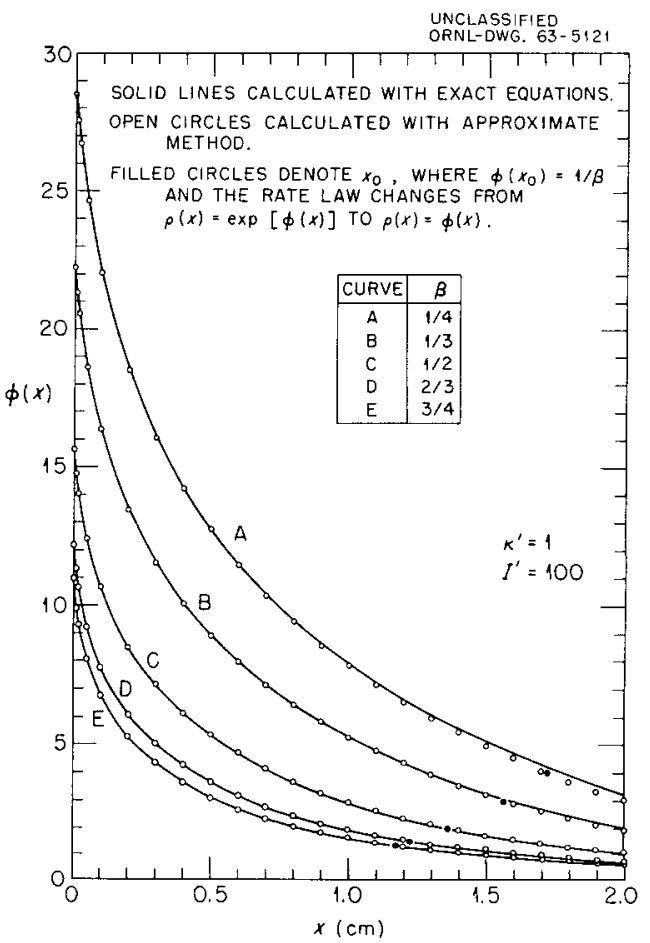

Fig. 10.7. Potential Distribution in the Semi-Infinite Porous Electrode as a Function of the Transfer Coefficient $(\beta)$ at Constant Current $\left(I^{\prime}\right)$.

on porous carbon electrodes in sodium chloride solutions.

In addition to the general theory of the charging processes in the interior of a porous electrode, other aspects of the measurements were treated. The effect of $I R$ drop which occurs in solution between the tip of the reference electrode capillary and the front surface of the porous electrode was calculated and observed experimentally. The effect of the external surface of the electrode on the observable charging transients was predicted and compared with observed transients; agreement was reasonable. Calculations are in progress on the effects of various types of pore size distributions on the shape of the transients.

The differential capacity of porous carbon electrodes was measured in $10^{-2}, 10^{-1}$, and $1 \mathrm{M} \mathrm{NaCl}$ solutions at $25^{\circ} \mathrm{C}$. The curves of capacity vs electrode potential compared favorably with similar capacity curves observed with pyrolytic graphite electrodes of known area in the same solutions. 


\section{Publications}

\section{NUCLEAR CHEMISTRY}

N. R. Johnson, E. Eichler, and G. D. O'Kelley, "Nuclear Chemistry," Technique of Inorganic Chemistry, vol. II, ed. by H. B. Jonassen, Wiley, New York, 1963.

R. L. Robinson, N. R. Johnson, and G. D. O'Kelley, "Gamma-Gamma Correlation in $\mathrm{V}^{51}$," Nucl. Phys. 47, 506 (1963).

G. D. O'Kelley, D. A. Bromley, and C. D. Goodman, "The Role of Multiparameter Pulse-Height Analyzers in Radioactivity Studies," pp. 49-58 in Proceedings of the Conference on Utilization of Multiparameter Analyzers in Nuclear Physics, ed. by L. J. Lidofsky, Columbia University Press, New York, 1963.

D. A. Bromley, C. D. Goodman, and G. D. O'Kelley, "Multiparameter Analysis in Accelerator Studies in Nuclear Physics," pp. 35-48 in Proceedings of the Conference on Utilization of Multiparameter Analyzers in Nuclear Physics, ed. by L. J. Lidofsky, Columbia University Press, New York, 1963.

C. D. Goodman, G. D. O'Kelley and D. A. Bromley, "Examining and Processing Data from the ORNL-Yale Analyzers," pp. 139-41 in Proceedings of the Conference on Utilization of Multiparameter Analyzers in Nuclear Physics, ed. by L. J. Lidofsky, Columbia University Press, New York, 1963.

D. E. Troutner, A. C. Wahl, and R. L. Ferguson, "Independent Fission Yield of $\mathrm{Sb}^{127}$," Phys. Rev. 134, B1027 (1964).

J. M. Chilton, R. A. Gilbert, R. E. Leuze, and W. S. Lyon, "A Redetermination of the Half-Life of Uranium-232," J. Inorg. Nucl. Chem. 26, 395 (1964).

P. M. Lantz, C. R. Baldock, and L. E. Idom, "Thermal Neutron Capture Cross Section and Resonance Capture Integral of $\mathrm{Ce}^{140}$ and Effective Capture Cross Section of Ce ${ }^{141}$,' Trans. Am. Nucl. Soc. 6(1), 44 (1963).

P. M. Lantz, C. R. Baldock, and L. E. Idom, "Thermal Neutron Capture Cross Section and Resonance Capture Integral of $\mathrm{Ce}^{140}$ and Effective Capture Cross Sections of $\mathrm{Ce}^{141}$," Nuclear Science and Engineering (in press).

J. Halperin, C. R. Baldock, R. E. Druschel, J. H. Oliver, and R. W. Stoughton, "Half-Life of ${ }^{208} \mathrm{Bi}$," J. Inorg. Nucl. Chem. 26, 391 (1964).

J. K. Dickens, F. G. Perey, R. J. Silva, and T. Tamura, "Proton Excitation of Two-Phonon Levels," Phys. Letters 6, 53 (1963).

J. K. Dickens, F. G. Perey, and R. J. Silva, "Level Structure of Ni ${ }^{64}$," Phys. Rev. 132, 1190 (1963).

J. K. Dickens, F. G. Perey, and R. J. Silva, "Fluctuations in the Excitation Function for Elastic and Inelastic Scattering of Protons from Ni ${ }^{62}$," Proceedings of the American Physical Society Conference on Compound Nuclear States, October 10-12, 1963, Gatlinburg, Tenn.

R. J. Silva and G. E. Gordon, "Nuclear Levels of $\mathrm{Cd}^{115}$ and $\mathrm{Cd}^{117}$ from (d,p)-Reaction Studies," Physical Review (in press). 


\section{NUCLEAR AND INORGANIC CHEMISTRY OF SPECIAL ELEMENTS}

O. L. Keller, Jr., "Characterization of Protactinium Species in Crystals and Solutions by Raman and Infrared Spectroscopy," Proceedings of the Protactinium Chemistry Symposium, Gatlinburg, Tennessee, Apr. 25-26, 1963, TID-7675.

R. H. Busey and O. L. Keller, Jr., "Structure of the Aqueous Pertechnetate Ion by Raman and Infrared

Spectroscopy. Raman and Infrared Spectra of Crystalline $\mathrm{KTCO}_{4}, \mathrm{KReO}_{4}, \mathrm{Na}_{2} \mathrm{MoO}_{4}, \mathrm{Na}_{2} \mathrm{WO}_{4}$, $\mathrm{Na}_{2} \mathrm{MoO}_{4} \cdot 2 \mathrm{H}_{2} \mathrm{O}$, and $\mathrm{Na}_{2} \mathrm{WO}_{4} \cdot 2 \mathrm{H}_{2} \mathrm{O}, " J$. Chem. Phys. 41, 215 (1964).

A. Chetham-Strode, "Comments on Electron Microscopy and Diffraction of Americium Oxides and Hydroxides," Proceedings of the Welch Foundation Conferences on Chemical Research, vol. VI, 1964 (in press).

\section{ISOTOPE CHEMISTRY}

G. M. Begun and W. H. Fletcher, "Vibrational Spectra of Aqueous Oxalate Ion," Spectrochim, Acta 19, 1343-49 (1963).

A. C. Rutenberg, A. A. Palko, and J. S. Drury, "Nuclear Magnetic Resonance Studies of BF ${ }_{3}$ Addition Compounds. I. The Exchange of $\mathrm{BF}_{3}$ between $\left(\mathrm{CH}_{3}\right)_{2} \mathrm{O} \cdot \mathrm{BF}_{3}$ and $\left(\mathrm{C}_{2} \mathrm{H}_{5}\right)_{2} \mathrm{O} \cdot \mathrm{BF}_{3}$, ' J. Am. Chem. Soc. 85, 2702 (1963).

A. A. Palko and J. S. Drury, "Separation of Boron Isotopes. VI. Ethyl Ether, Ethyl Sulfide, and Triethyl Amine-BF ${ }_{3}$ Systems," J. Chem. Phys. 40, 278 (1964).

D. A. Lee, "Anhydrous Lithium Thiocyanate," Inorg. Chem. 3, 289 (1964).

A. C. Rutenberg and J. S. Drury, "Some Isotope Fractionation Factors for Sulfur," J. Chem. Eng. Data 9, 43 (1964).

A. C. Rutenberg, A. A. Palko, and J. S. Drury, "NMR Studies of $\mathrm{BF}_{3}$ Addition Compounds. II. Exchange of $\mathrm{BF}_{3}$ between $\mathrm{C}_{6} \mathrm{H}_{5} \mathrm{OCH}_{3} \cdot \mathrm{BF}_{3}$ ", and $\left(\mathrm{C}_{2} \mathrm{H}_{5}\right)_{2} \mathrm{O} \cdot \mathrm{BF}_{3}, " J$. Phys. Chem. 68, 976 (1964).

\section{RADIATION CHEMISTRY}

C. J. Hochanadel, "Radiation Decomposition of Sodium Chlorate: Comparison of Yields and the PostIrradiation by $\gamma$-Rays and $\alpha$-Particles," J. Phys. Chem. 67, 2229 (1963).

G. L. Kochanny, Jr., A. Timnick, C. J. Hochanadel, and C. D. Goodman, "Radiation Chemistry Studies of Water as Related to the Initial Linear Energy Transfer of 11-Mev to 23-Mev Protons," Radiation Res. 19(3), 462 (1963).

T. J. Sworski, "Photochemical and Radiation Chemical Reduction of Ceric Ion in Aqueous Sulfuric Acid Solutions. Effect of Formic Acid," J. Phys, Chem. 67, 2858 (1963).

H. W. Kohn, "On the Hydrogen-Deuterium Exchange Activity of Silica Gel: Aluminum Impurity and Radiation Effect," J. Catalysis 2, 208 (1963).

P. S. Rudolph, "Radiation Effects on Glass," Proceedings, The Eighth Symposium on the Art of Glassblowing, 1963, pp. 114-22, Am. Sci. Glassblowers Soc., Wilmington, Del., 1963.

P. S. Rudolph and S. C. Lind, "Energy Transfer from Carbon Dioxide in the Radiation Induced Synthesis of Water," J. Chem. Phys. 40, 2601-7 (1964). 


\section{ORGANIC CHEMISTRY}

C. J. Collins and B. M. Benjamin, "A Quantitative Test for a Classical Carbonium Ion Mechanism," J. Am. Chem. Soc. 85, 2519 (1963).

V. F. Raaen, T. K. Dunham, Dorothy D. Thompson, and C. J. Collins, "Steric Origin of Some Seconddary Isotope Effects of Deuterium," J. Am. Chem. Soc. 85, 3497 (1963).

C. J. Collins, "Isotopes and Organic Reaction Mechanisms," pp. 1-91 in Advances in Physical Organic Chemistry, vol. 2, ed. by Victor Gold, Academic Press, London, 1964.

C. E. Higgins and W. H. Baldwin, "Separation of Butene Isomers and Butadiene by Gas Liquid Chromatography," Anal. Chem. 36, 473 (1964).

\section{CHEMISTRY OF AQUEOUS SYSTEMS}

*M. H. Lietzke and R. W. Stoughton, "Electromotive Force Studies in Aqueous Solutions at Elevated Temperatures. IV. The Activity Coefficients of $\mathrm{HBr}$ and $\mathrm{KBr}$ in $\mathrm{HBr}-\mathrm{KBr}$ Mixtures," J. Phys. Chem. 67, 2573 (1963).

*M. H. Lietzke and R. W. Stoughton, "The Activity Coefficients of Hydrochloric Acid and Sodium Chloride in Hydrochloric Acid-Sodium Chloride Mixtures," J. Tenn. Acad. Sci. 39, 30 (1964); also, ORNL-3471 (July 15, 1963).

E. W. Anacker, R. M. Rush, and J. S. Johnson, "Equilibrium Ultracentrifugation and Light Scattering of Sodium Lauryl Sulfate and Dodecyltrimethylammonium Bromide Solutions," J. Phys. Chem. 68, 81 (1964). (Joint with Department of Chemistry, Montana State College, Bozeman, Mont.).

J. Aveston, E. W. Anacker, and J. S. Johnson, "Hydrolysis of Molybdenum(VI). Ultracentrifugation, Acidity Measurements, and Raman Spectra of Polymolybdates," Inorg. Chem. 3, 735 (1964).

Fred Vaslow, "The Orientation of Water Molecules in the Field of an Alkali Ion," J. Phys. Chem. 67, 2773 (1963).

S. Lindenbaum and G. E. Boyd, "Spectrophotometric Investigation of the Extraction of Transition Metal Halo-Complex Ions by Amine Extractants," J. Phys. Chem. 67, 1238 (1963).

G. E. Boyd, F. Vaslow, and S. Lindenbaum, "Calorimetric Determinations of the Heats of Ion-Exchange Reactions. I. Heats of Exchange of the Alkali Metal Cations in Variously Cross-linked Polystyrene Sulfonates," J. Phys. Chem. 68, 590 (1964).

S. Lindenbaum and G. E. Boyd, "Osmotic and Activity Coefficients for the Symmetrical Tetra-n-Alkyl Ammonium Halides in Aqueous Solutions at 25", J. Phys. Chem. 68, 911 (1964).

F. Nelson, T. Murase, and K. A. Kraus, "Ion Exchange Procedures. I. Cation Exchange in Concentrated $\mathrm{HCl}$ and $\mathrm{HClO}_{4}$ Solutions," J. Chromatog. 13, 503 (1964).

J. H. Holloway and F. Nelson, "Ion Exchange Procedures. II. Separation of Zirconium, Neptunium and Niobium," J. Chromatog. 14, 255 (1964).

F. Nelson, D. C. Michelson, and J. H. Holloway, "Ion Exchange Procedures. III. Separation of Uranium, Neptunium and Plutonium," J. Chromatog. 14, 258 (1964).

T. Murase, E. L. Lind, and F. Nelson, "Ion Exchange Procedures. IV. Separation of $\mathrm{Th}^{234}\left(\mathrm{UX}_{1}\right)$ from Uranyl Nitrate Solutions." J. Chromatog. 14, 478 (1964).

F. Nelson, "Ion Exchange Procedures. V. Separation of Barium and Radium," Journal of Chromatography (in press).

F. Nelson, "Ion Exchange Procedures. VI. Cation Exchange of $\mathrm{Ac}(\mathrm{III})$ and $\mathrm{Fr}(\mathrm{I})$ in $\mathrm{HCl}$ and $\mathrm{HClO}_{4}$ Solutions; Isolation of ${ }^{227} \mathrm{Ac}$ from ${ }^{231} \mathrm{~Pa}$ and ${ }^{227} \mathrm{Ac}$ Daughters," Journal of Chromatography (in press). 


\section{ELECTROCHEMICAL KINETICS AND ITS APPLICATION TO CORROSION}

G. H. Cartledge, "Inhibition of Corrosion by the Pertechnetate Ion," Isotopes Radiation Technol. I, 125 (1964).

*F. A. Posey, T. Morozumi, and E. J. Kelly, "An Electrochemical pH-Stat and Its Application to Corrosion Studies," J. Electrochem. Soc. 110, 1183 (1963).

G. H. Cartledge, "Corrosion Inhibition by Pertechnetate Ion," pp. 280-82 in Encyclopedia of Electrochemistry (ed. by C. A. Hampel), Reinhold, New York, 1964.

G. H. Cartledge, "Flade Potential," pp. 601-2 in Encyclopedia of Electrochemistry (ed. by C. A. Hampel), Reinhold, New York, 1964.

E. J. Kelly, "Tafel Lines," pp. 1097-1100 in Encyclopedia of Electrochemistry (ed. by C. A. Hampe1), Reinhold, New York, 1964.

R. E. Meyer, "Gibbs-Helmholtz Equation," pp. 677-78 in Encyclopedia of Electrochemistry (ed. by C. A. Hampel), Reinhold, New York, 1964.

R. E. Meyer, "Coulomb's Law," pp. 301-3 in Encyclopedia of Electrochemistry (ed. by C. A. Hampel), Reinhold, New York, 1964.

R. E. Meyer, "Faraday's Laws," pp. 592-94 in Encyclopedia of Electrochemistry (ed. by C. A. Hampel), Reinhold, New York, 1964.

F. A. Posey, "Corrosion, Electrochemical Kinetics," pp. 263-67 in Encyclopedia of Electrochemistry (ed. by C. A. Hampe1), Reinhold, New York, 1964.

F. A. Posey, "Lippmann Potential," pp. 776-78 in Encyclopedia of Electrochemistry (ed. by C. A. Hampe1), Reinhold, New York, 1964.

F. A. Posey, "Billiter Potential," pp. 97-99 in Encyclopedia of Electrochemistry (ed. by C. A. Hampe1), Reinhold, New York, 1964.

\section{NONAQUEOUS SYSTEMS AT HIGH TEMPERATURES}

A. S. Dworkin and M. A. Bredig, "Heat Content and Entropy of Strontium Chloride from $298^{\circ}$ to $1200^{\circ} \mathrm{K}, " J$. Chem. Eng. Data 8, 416 (1963).

A. S. Dworkin and M. A. Bredig, "The Heats of Fusion of Some Rare Earth Metal Halides," J. Phys. Chem. 67, 2499 (1963).

A. S. Dworkin, H. R. Bronstein, and M. A. Bredig, "The Electrical Conductivity of Solutions of Metals in Their Molten Halides. VII. Rare Earth Metal Systems. Electron Exchange Between Adjacent Oxidation States," J. Phys. Chem. 67, 2715 (1963).

M. A. Bredig, "Mixtures of Metals with Molten Salts," in Molten Salt Chemistry, ed. by M. Blander, Interscience, New York, 1964; appeared also as ORNL-3391 (August, 1963). 


\section{CHEMICAL PHYSICS}

Henry Zeldes, "Paramagnetic Species in Irradiated $\mathrm{KNO}_{3}$," p. 764 in Proceedings of the First International Conference on Paramagnetic Resonance, Jerusalem, July 16-20, 1962, ed. by W. Low, Academic Press, New York, 1963.

J. H. Burns, R. D. Ellison, and H. A. Levy, "The Crystal Structure of the Molecular Addition Compound Xenon Difluoride-Xenon Tetrafluoride," J. Phys. Chem. 67, 1569 (1963).

W. R. Busing and H. A. Levy, "The Effect of Thermal Motion on the Estimation of Bond Lengths from Diffraction Measurements," Acta Cryst. 17, 142 (1964).

G. M. Brown and H. A. Levy, "Sucrose: Precise Determination of Crystal and Molecular Structure by Neutron Diffraction," Science 141, 921 (1963).

J. H. Burns, P. A. Agron, and H. A. Levy, "The Crystal and Molecular Structure of Xenon Tetrafluoride by Neutron Diffraction," pp. 211-20 in Noble-Gas Compounds, ed. by H. H. Hyman, University of Chicago Press, 1963.

H. A. Levy and P. A. Agron, "The Crystal and Molecular Structure of Xenon Difluoride by Neutron Diffraction," pp. 221-25 in Noble-Gas Compounds, ed. by H. H. Hyman, University of Chicago Press, 1963.

J. H. Burns, R. D. Ellison, and H. A. Levy, "The Crystal Structure of $\mathrm{XeF}_{2} \cdot \mathrm{XeF}_{4}$ by X-Ray Diffraction," pp. 226-28 in Noble-Gas Compounds, ed. by H. H. Hyman, University of Chicago Press, 1963.

P. A. Agron, G. M. Begun, H. A. Levy, A. A. Mason, C. G. Jones, and D. F. Smith, "Xenon Difluoride and the Nature of the Xenon-Fluorine Bond," Science 139, 3557 (1963).

H. A. Levy and M. D. Danford, "Diffraction Studies of the Structure of Molten Salts," pp. 109-25 in Molten Salt Chemistry, ed. by Milton Blander, Wiley, New York, 1964.

W. R. Busing, K. O. Martin, and H. A. Levy, "OR FFE, a Fortran Crystallographic Function and Error Program," ORNL-TM-306 (March, 1964).

Fred Vaslow, "A Simple Condensation Isotherm for a Hard Sphere Gas," J. Chem. Ed. 40, 485 (1963).

S. Datz, G. E. Moore, and E. H. Taylor, "The Reflection of Modulated Helium and Deuterium Molecular Beams from Platinum Surfaces," p. 347 in Proceedings of the Third Symposium on Rarefied Gas Dynamics, vol. I, Academic Press, New York, 1963.

W. L. Fite and S. Datz, "Chemical Research with Molecular Beams," Ann. Rev. Phys. Chem. 14, 61 (1963).

S. Datz and E. H. Taylor, "Atom Molecule Reaction of Hydrogen Studied by Molecular Beams," J. Chem. Phys. 39, 1896 (1963).

T. A. Carlson, "Recoil Energy Spectrum of the Sodium Ions Following the $\beta^{-}$Decay of $\mathrm{Ne}^{23}$," Phys. Rev. 132, 2239 (1963).

T. A. Carlson and R. M. White, "Formation of Fragment Ions from $\mathrm{CH}_{3} \mathrm{Te}^{125}$ and $\mathrm{C}_{2} \mathrm{H}_{5} \mathrm{Te}^{125}$ Following the Nuclear Decays of $\mathrm{CH}_{3} \mathrm{I}^{125}$ and $\mathrm{C}_{2} \mathrm{H}_{5} \mathrm{I}^{125}$," J. Chem. Phys. 38, 2930 (1963).

T. A. Carlson and R. M. White, "Fragmentation of the Excited Parent Ions, $\left[\mathrm{CH}_{3} \mathrm{Kr}^{82}\right]^{+}$and $\left[\mathrm{CH}_{3} \mathrm{O}^{18}\right]^{-}$, Following the $\beta^{-}$Decay of $\mathrm{CH}_{3} \mathrm{Br}^{82}$ and the $\beta^{+}$Decay of $\mathrm{CH}_{3} \mathrm{~F}^{18}, "$ J. Chem. Phys. 39, 1748 (1963).

T. A. Carlson, "Electron Shakeoff Following the $\beta^{-}$Decay of $\mathrm{Ar}^{41}$," Phys. Rev. 131, 676 (1963).

M. O. Krause, M. L. Vestal, W. H. Johnston, and T. A. Carlson, "Readjustment of the Neon Atom Ionized in the K Shell by X Rays," Phys. Rev. 133, A385 (1964).

O. L. Keller, Jr., Book Review: "Advances in Chemical Physics, Volume V, ed. by I. Prigogine," Nucl. Sci. Eng. 18, 149 (1964). 


\section{WATER RESEARCH PROGRAM}

*F. A. Posey, T. Morozumi, and E. J. Kelly, "An Electrochemical pH-Stat," J. Electrochem. Soc. 110, 1183 (1963).

F. A. Posey "Methods for the Calculation of Polarization in Porous Electrodes," Journal of the Electrochemical Society (in press).

F. Nelson, J. H. Holloway, and K. A. Kraus, "Cation Exchange Separation of Calcium and Magnesium at High Ionic Strength," J. Chromatog. 11, 258 (1963).

*M. H. Lietzke and R. W. Stoughton, "Electromotive Force Studies in Aqueous Solutions at Elevated Temperatures. IV. The Activity Coefficients of $\mathrm{HBr}$ in $\mathrm{HBr}-\mathrm{KBr}$ Mixtures," J. Phys. Chem. 67, 2573 (1963).

G. Scatchard, "The Effect of Dielectric Constant Difference on Hyperfiltration of Salt Solutions," J. Phys. Chem. 68, 1056 (1964).

*M. H. Lietzke and R. W. Stoughton, "The Activity Coefficients of Hydrochloric Acid and Sodium Chloride in Hydrochloric Acid-Sodium Chloride Mixtures," J. Tenn. Acad. Sci. 39, 30 (1964).

W. H. Baldwin, D. L. Holcomb, and J. S. Johnson, "Preparation and Hyperfiltration Properties of a Polyacrylate-Cellophane Membrane," Journal of Polymer Science (in press).

K. A. Kraus, R. J. Raridon, and W. H. Baldwin, "Properties of Organic-Water Mixtures. I. Activity Coefficients of $\mathrm{NaCl}, \mathrm{KCl}$ and $\mathrm{Ba}\left(\mathrm{NO}_{3}\right)_{2}$ in Saturated Water Mixtures of Glycol, Glycerol, and Their Acetates. Model Solutions for Hyperfiltration Membranes," J. Am. Chem. Soc. 86, 2571 (1964).

R. W. Stoughton, M. H. Lietzke, and R. J. White, "Calculation of Vapor Pressure of Sea Water Concentrates from Activity Coefficient Parameters of $\mathrm{NaCl}$ Solutions," Journal of the Tennessee Academy of Science (in press).

\footnotetext{
*Jointly supported by the ORNL Chemistry Division and the Water Research Program.
} 


\title{
Papers Presented at Scientific and Technical Meetings
}

\author{
NUCLEAR CHEMISTRY
}

A. Chetham-Strode and J. R. Tarrant, "Alpha Particle Spectroscopy - Instrumentation and Applications," Seventh Conference on Analytical Chemistry in Nuclear Technology, Gatlinburg, Tenn., October 1963.

\section{RADIATION CHEMISTRY}

J. F. Riley, "Ozone Yields for Irradiated Oxygen-Nitrogen Solutions as $77^{\circ} \mathrm{K}$," Gordon Research Conference on Radiation Chemistry, New Hampton, N.H., July 24, 1963.

T. J. Sworski, "Photochemical and Radiation Chemical Reduction of Ceric Ion in Aqueous Sulfuric Acid Solutions. Effect of Formic Acid," 145th National Meeting, American Chemical Society, New York, Sept. 8-13, 1963.

G. E. Boyd and Q. V. Larson, "Radiolysis of the Crystalline Alkali-Metal Bromates by Neutron Reactor Radiation," 146th National American Chemical Society Meeting, Denver, Colo., Jan. 19-24, 1964.

G. E. Boyd and T. G. Ward, Jr., "Radiolysis of Crystalline $\mathrm{LiBrO}_{3}$ by ${ }^{6} \mathrm{Li}$ Fission Recoil Particles," 146th National American Chemical Society Meeting, Denver, Colo., Jan. 19-24, 1964.

H. W. Kohn, "Radiation Induced Surface Oxidation of Hydrocarbons" (presented by N. H. Krohn of ORNL), 145th National Meeting of the American Chemical Society, New York, Sept. 12, 1963.

H. W. Kohn, "Radiation Chemistry of Surfaces," Research Conference, University of California College of Chemistry, Oct. 24, 1963.

H. W. Kohn, "Radiation Induced Surface Oxidation of Hydrocarbons," 56th Annual Meeting of American Institute of Chemical Engineers, Houston, Dec. 5, 1963.

\section{ORGANIC CHEMISTRY}

C. J. Collins, "The Mechanistic Implications of Some Secondary Isotope Effects of Deuterium and Carbon-14," XIXth International Congress of Pure and Applied Chemistry, London, July 10-17, 1963.

V. F. Raaen, "Steric Origin of Some Secondary Isotope Effects," Symposium on Isotope Mass Effects in Chemistry and Biology, Vienna, Dec. 9-13, 1963.

\section{CHEMISTRY OF AQUEOUS SYSTEMS}

M. H. Lietzke and R. W. Stoughton, "Recent EMF and Solubility Studies at Elevated Temperatures," American Chemical Society Meeting, New York, September 1963. 
J. Aveston, E. W. Anacker, and J. S. Johnson, "Hydrolysis of Molybdenum(VI). Ultracentrifugation, Acidity Measurements, and Raman Spectra of Polymolybdates," 146th National Meeting of the American Chemical Society, Denver, Colo., January 1964.

G. E. Boyd, "Thermal Effects in Ion Exchange Reactions," AAAS Gordon Research Conference on Ion Exchange, Meriden, N.H., Aug. 19-23, 1963.

S. Lindenbaum and G. E. Boyd, "Osmotic and Activity Coefficients of Some Quaternary Ammonium Halides in Aqueous Solution at 25\%," 145th National American Chemical Society Meeting, New York, Sept. 9-13, 1963.

F. Vaslow, "The Heats of Dilution of Polystyrene Sulfonic Acid and the Li, Na, K and Cs Salts," 145th National American Chemical Society Meeting, New York, Sept. 9-13, 1963.

G. E. Boyd, S. Lindenbaum, and Q. V. Larson, "The Absorption of Anionic Species by Strong-Acid Cation Exchangers: Identity of the Fe(III) Species Taken Up from Concentrated Aqueous Halide Solutions," 147th National American Chemical Society Meeting, Philadelphia, Apr. 6-10, 1964.

K. A. Kraus and F. Nelson, "Cation Exchange in Concentrated Electrolyte Solutions," Gordon Research Conference on Ion Exchange, Meriden, N.H., Aug. 18-23, 1963.

K. A. Kraus and F. Nelson, "Ion Exchange at High Ionic Strength," American Chemical Society Meeting, Philadelphia, April 1964.

\section{ELECTROCHEMICAL KINETICS AND ITS APPLICATION TO CORROSION}

E. J. Kelly, "Electrochemical Behavior of the Active Iron Electrode in Sulfate and Benzoate Solutions," 124th Meeting of the Electrochemical Society, New York, Sept. 29-Oct. 2, 1963.

R. E. Meyer, "The Electrochemistry of the Dissolution of Zirconium in Aqueous Solutions of Hydrofluoric Acid,"' 124th Meeting of the Electrochemical Society, New York, Sept. 29-Oct. 2, 1963.

F. A. Posey, T. Morozumi, and E. J. Kelly, "An Electrochemical pH-Stat," 124th Meeting of the Electrochemical Society, New York, Sept. 29-Oct. 2, 1963.

F. A. Posey, "Methods for the Calculation of Polarization in Porous Electrodes," 125th Meeting of the Electrochemical Society, Toronto, May 3-7, 1964.

\section{NONAQUEOUS SYSTEMS AT HIGH TEMPERATURES}

M. A. Bredig, "Electronic Conduction in Electropositive Metal Solutions," Gordon Research Conference on Fused Salts, Meriden, N.H., Aug. 28, 1963.

M. A. Bredig, "Electrical Conductance in Solutions of Metals in Molten Salts," Symposium on Fused Salts and Electrolytic Solutions, American Chemical Society National Meeting, New York, Sept. $10,1963$.

\section{CHEMICAL PHYSICS}

Ralph Livingston, "Paramagnetic Resonance in Hydrogen-Oxygen Systems," Sixth International Symposium on Free Radicals, Cambridge. England, July 4, 1963.

W. R. Busing and H. A. Levy, "Experience with the Oak Ridge Automatic Three-Circle Neutron Diffractometer,' International Colloquium of Neutron Diffusion and Neutron Diffraction, Grenoble, France, Sept. 3-5, 1963.

V. M. Padmanabhan, W. R. Busing, and H. A. Levy, "A Single-Crystal Neutron-Diffraction Study of $\mathrm{BaCl}_{2} \cdot 2 \mathrm{H}_{2} \mathrm{O}$," Sixth General Assembly International Congress and Symposia, International Union of Crystallography, Rome, Sept. 9-18, 1963. 
K. F. Bowden, W. R. Busing, D. B. G. Edwards, L. I. Hodgson, and O. S. Mills, "The System for Direct Computer Control of the Manchester Four-Circle Diffractometer," Sixth General Assembly International Congress and Symposia, International Union of Crystallography, Rome, Sept. 9-18, 1963.

H. A. Levy, "Automatic Single Crystal Diffractometers for Neutrons," Sixth General Assembly International Congress and Symposia, International Union of Crystallography, Rome, Sept. 9-18, 1963.

H. A. Levy, "Crystal Structures of the Xenon Fluorides by Neutron Diffraction," Sixth General Assembly International Congress and Symposia, International Union of Crystallography, Rome, Sept. 9-18, 1963.

H. A. Levy, "Neutron Diffraction in Chemical Research," Symposium on the Utilization of Research Reactors, Georgia Institute of Technology, Atlanta, Nov. 8, 1963.

H. A. Levy, "X-Ray Diffraction Studies of the Structure of Water," Debye 80th Birthday Symposium, Cornell University, Ithaca, N.Y., Apr. 15, 1964.

C. K. Johnson, "Machine-Drawn Atomic Crystal Structure Models," Summer Meeting of the Mid-Southeast Chapter of the Association for Computing Machinery, Gatlinburg, Tenn., June 19, 1964.

G. M. Brown, "Crystal Structure Determination by Neutron Diffraction," American Chemical Society, Lexington, Ky., Jan. 17, 1964.

G. M. Brown, "A Neutron-Diffraction Study of Sucrose $\left(\mathrm{C}_{12} \mathrm{H}_{22} \mathrm{O}_{11}\right)$," Sixth General Assembly International Congress and Symposia, International Union of Crystallography, Rome, Sept. 9-18, 1963.

G. M. Brown, "Recent Crystal Structure Determinations by Neutron Diffraction at Oak Ridge," International Colloquium of Neutron Diffusion and Diffraction, Grenoble, France, Sept. 3-5, 1963.

G. M. Brown, "Problems and Procedures in Collection of Three-Dimensional Data for Crystal Structure Determination," International Colloquium of Neutron Diffusion and Diffraction, Grenoble, France, Sept. 3-5, 1963.

R. B. Bevan, Jr., R. A. Gilbert, and R. H. Busey, "Low Temperature Heat Capacity of Rhenium Trichloride," Calorimetry Conference, Bartlesville, Okla., Oct. 16-18, 1963.

T. A. Carlson and M. O. Krause, "Atomic Readjustment Following the Formation of Inner Shell Vacancies," International Conference on Nuclear Spectroscopy (Devoted to the Role of Atomic Electrons in Nuclear Transformations), Warsaw, Sept. 24-28, 1963.

T. A. Carlson, "Atomic Readjustment to Inner Shell Vacancies," Southeastern Section Meeting, American Physical Society, Lexington, Ky., Nov. 7-9, 1963.

T. A. Carlson and M. O. Krause, "Atomic Readjustment to Inner Shell Vacancies in Neon and Argon," American Physical Society Meeting, N.Y., Jan. 22-25, 1964 [Bull. Am. Phys. Soc. 9, 51 (1964)].

M. O. Krause and T. A. Carlson, "Ionization of Krypton by X-Rays," American Physical Society Meeting, N.Y., Jan. 22-25, 1964 [Bull. Am. Phys. Soc. 9, 51 (1964)].

\section{WATER RESEARCH PROGRAM}

F. A. Posey, T. Morozumi, and E. J. Kelly, "An Electrochemical pH-Stat," 124th Meeting of the Electrochemical Society, New York, Sept. 29-Oct. 3, 1963.

R. J. Raridon and K. A. Kraus, "Activity Coefficients for $\mathrm{NaCl}, \mathrm{KCl}$ and $\mathrm{Ba}\left(\mathrm{NO}_{3}\right)_{2}$ in Saturated Organic-Water Mixtures," Southeastern Regional Meeting, American Chemical Society, Charlotte, N.C., Nov. 14-16, 1963.

R. J. Raridon, "Desalination," Meeting of the Tennessee Academy of Science, Apr. 11, 1964.

F. A. Posey, "Methods for the Calculation of Polarization in Porous Electrodes," 125th Meeting of the Electrochemical Society, Toronto, May 3-7, 1964. 


\section{Lectures}

\section{NUCLEAR CHEMISTRY}

A. Chetham-Strode, "Synthesis of the Transuranium Elements," Society of Sigma Xi, Texas Christian University, Fort Worth, Jan. 7, 1964.

A. Chetham-Strode, "Alpha Particle Spectroscopy," University of Kentucky, Lexington, Apr. 10, 1964.

G. D. O'Kelley, "Special Topics in Scintillation Counting," ORINS Radioisotope Training School, Oak Ridge, Tenn., Aug. 15 and Oct. 4, 1963, Jan. 22, Mar. 5, and May 20, 1964.

G. D. O'Kelley, "Some Experimental and Data-Handling Methods for the Study of Short-Lived Radionuclides," Joint Physics Colloquium of McMaster University and the University of Toronto, McMaster University, Hamilton, Ontario, Canada, Jan. 9, 1964.

N. R. Johnson, "Nuclear Properties of Some Medium-Weight Nuclei," Center for the Study of Nuclear Energy, Mol, Belgium, July 2, 1963; Institute for Nuclear Physics Research, Amsterdam, Netherlands, July 4, 1963.

\section{NUCLEAR AND INORGANIC CHEMISTRY OF SPECIAL ELEMENTS}

R. H. Busey, "Unusual Species of Rhenium in Sulfuric Acid Solutions," Auburn University, Auburn, Ala., May 13, 1964.

R. H. Busey, "Studies in the Chemistry of Rhenium and Technetium," Tuskegee Institute, Tuskegee, Ala., May 13, 1964.

\section{RADIATION CHEMISTRY}

J. F. Riley, "Radiation Chemistry," ORINS Radioisotope Technique Course, Aug. 21, 1963, and Jan. 24, Mar. 2, and May 12, 1964; ORINS Health Physics Course, Oct. 2, 1963.

H. W. Kohn, "Some Aspects of Chemonuclear Processing," Northern California Section of American Institute of Chemical Engineers, Berkeley, May 18, 1964.

\section{ORGANIC CHEMISTRY}

C. J. Collins, "Recent Work on the Pinacol Rearrangement," Marshall College, Huntington, W. Va., May 5, 1964. American Chemical Society Lecture Tour, Terre Haute, Ind., May 7, 1964.

C. J. Collins, "Use of Isotopes in Organic Chemistry," Monsanto Chemical Company, St. Louis, Nov. 20, 1963. 
C. J. Collins, "Isotope Effects of Deuterium," Kernreaktor, Karlsruhe, Germany, July 25, 1963. American Chemical Society Lecture Tour, Evansville, Ind., May 6, 1964.

C. J. Collins, "The Deamination Reaction," Technische Hochschule, Karlsruhe, Germany, July 27, 1963. American Chemical Society Lecture Tour, Ashland, Ky., May 5, 1964.

V. F. Raaen, "Secondary Carbon-14 and Deuterium Isotope Effects," Institute Rudjer Bosković, Zagreb, Yugoslavia, Dec. 6, 1963.

B. M. Benjamin, "A Study of Conformational Control of the Deamination Reaction by Nuclear Magnetic Resonance," University of Tennessee, Knoxville, Sept. 27, 1963.

W. H. Baldwin, "Radiocarbon Dating," Chattanooga Chapter of the Tennessee Archeological Society, Aug. 20, 1963; Berea College, Berea, Ky., Dec. 2, 1963; Chemistry Club, Oák Ridge High School, Jan. $30,1964$.

\section{CHEMISTRY OF AQUEOUS SYSTEMS}

K. A. Kraus, "Anion Exchange," ORINS Traveling Lecture at St. Mary's University, San Antonio, Tex., Apr. 17, 1964.

M. H. Lietzke, "The Calculation of the Second Dissociation Constants of Sulfuric and Deuteriosulfuric Acid from Solubility Data," Colgate University, Hamilton, N.Y., Nov. 6, 1963.

M. H. Lietzke, "Recent Thermodynamic Studies of Aqueous Solutions," University of Wisconsin, Madison; July 30, 1963.

\section{ELECTROCHEMICAL KINETICS AND ITS APPLICATION TO CORROSION}

G. H. Cartledge, "Electrochemical Surface Processes," University of Virginia, Charlottesville, Nov. 21, 1963.

G. H. Cartledge, "Use of Technetium in the Inhibition of Corrosion," King College, Bristol, Tenn., Apr. 27, 1964.

F. A. Posey, "Electrochemical Methods in the Study of Corrosion," University of Alabama, Tuscaloosa, Nov. 21, 1963.

F. A. Posey, "Electrochemical Methods in the Study of Corrosion," Tuskegee Institute, Ala., Feb. $10,1964$.

F. A. Posey, "Electrochemical Methods in the Study of Corrosion," Sigma Xi Lecture, Mississippi State University, State College, Feb. 11, 1964.

F. A. Posey, "Electrochemical Methods in the Study of Corrosion," University of Mississippi, University, Feb. 11, 1964.

\section{NONAQUEOUS SYSTEMS AT HIGH TEMPERATURES}

M. A. Bredig, "Solutions of Metals in Molten Salts," University of Pennsylvania, Philadelphia, Apr. $27,1964$. 


\section{CHEMICAL PHYSICS}

Ralph Livingston, "Paramagnetic Resonance Studies of Solids Containing Free Radicals," University of Arkansas, Fayetteville, Mar. 23, 1964.

Ralph Livingston, "Paramagnetic Resonance Studies of Solids Containing Free Radicals," Vanderbilt University, Nashville, Tenn., Mar. 25, 1964.

Ralph Livingston, "Paramagnetic Resonance Studies of Single Crystals Containing Free Radicals," University of Louisville, Louisville, Ky., May 5, 1964.

Ralph Livingston, "Radio-Frequency and Microwave Spectroscopy," Chemistry Study In-Service Institute (NSF sponsored), University of Louisville, Louisville, Ky., May 5, 1964.

G. M. Brown, "Current Research at ORNL in Crystal Structure Determination by Neutron Diffraction," ORINS Traveling Lecture Program, University of Oklahoma, Norman, Nov, 21, 1963, Oklahoma State University, Stillwater, Nov. 22, 1963, Emory University, Atlanta, Ga., Mar. 6, 1964, Tulane University, New Orleans, La., Apr. 13, 1964, and Texas A. \& M. University, College Station, Apr. 15, 1964.

G. M. Brown, "Determination of Structures of Organic Molecules by Neutron Diffraction," ORINS Traveling Lecture Program, University of Florida, Gainesville, Jan. 31, 1964, and University of Arkansas, Fayetteville, Apr. 17, 1964.

G. M. Brown, "Neutron Diffraction in the Study of Crystal and Molecular Structure," ORINS Traveling Lecture Program, Rice University, Houston, Apr. 14, 1964.

Russell Baldock, "Some Techniques and Problems in the Mass Spectrometry of Solids," Auburn University, Auburn, Ala., Nov. 1, 1963.

G. M. Begun, "Raman Spectra of the Xenon Fluorides," University of Tennessee, Knoxville, Mar. 5, 1964.

\section{WATER RESEARCH PROGRAM}

R. J. Raridon, "Desalination," Red Bank High School, Chattanooga, Tenn., Feb. 13, 1964.

R. J. Raridon, "Desalination," Converse College, Spartanburg, S.C., Nov. 10, 1963.

K. A. Kraus, "Desalination," State University of New York, Buffalo, New York, Mar. 11, 1964.

R. J. Raridon, "Desalination," Cosby High School, Cosby, Tenn., Mar. 19, 1964.

K. A. Kraus, "Desalination," Texas Woman's University, Denton, Tex., Apr. 16, 1964.

K. A. Kraus, "Desalination," Presbyterian College, Clinton, S.C., Apr. 27, 1964.

K. A. Kraus, "Desalination," North Carolina State College, Raleigh, Apr. 29, 1964. 
ORNL.3679

UC-4 - Chemistry

TID.4500 (32nd ed.)

INTERNAL DISTRIBUTION

1. Biology Library

2-4. Central Research Library

5. Laboratory Shift Supervisor

6. Reactor Division Library

7-8. ORNL - Y-12 Technical Library

Document Reference Section

9-43. Laboratory Records Department

44. Laboratory Records, ORNL R.C.

45. P. A. Agron

46. C. R. Baldock

47. W. H. Baldwin

48. D. S. Billington

49. F. F. Blankenship

50. E. G. Bohlmann

51. C. J. Borkowski

52-66. G. E. Boyd

67-74. M. A. Bredig

75. R. B. Briggs

76. H. R. Bronstein

77. A. R. Brosi

78. R. H. Busey

79. G. H. Cartledge

80. A. Chetham-Strode

81. C. J. Collins

82. D. R. Cuneo

83. F. L. Culler

84. M. D. Danford

85. S. Datz

86. J. S. Drury

87. A. S. Dworkin

88. E. Eichler

89. R. L. Ferguson

90. J. L. Gabbard

91. R. A. Gilbert

92. J. H. Gillette

93. W. R. Grimes

94. J. Halperin

95. C. J. Hochanadel

96. A. Hollaender

97. A. S. Householder

98. J. S. Johnson

99. N. R. John son

100. R. W. Johnson

101. W. H. Jordan

102. M. T. Kelley
103. B. H. Ketelle

104. K. A. Kraus

105. J. A. Lane

106. E. Lamb

107. C. E. Larson

108. H. A. Levy

109. M. H. Lietzke

110. T. A. Lincoin

111. S. C. Lind

112. S. Linden baum

113. R. Livingston

114. R. S. Livingston

115. R. N. Lyon

116. H. G. MacPherson

117. H. F. McDuffie

118. J. R. McNally, Jr.

119. K. Z. Morgan

120. M. L. Nelson

121. G. D. O'Kelley

122. G. W. Parker

123-124. R. B. Parker

125. J. J. Pinajian

126. F. A. Posey

127. S. A. Reynolds

128. P. S. Rudolph

129. H. E. Seagren

130. C. H. Secoy

131. E. D. Shipley

132. M. J. Skinner

133. A. H. Snell

134. R. W. Stoughton

135. C. D. Susano

136. J. A. Swartout

137-151. E. H. Taylor

152. R. E. Thoma

153. P. F. Thomason

154. F. Vaslow

155. G. M. Watson

156. A. M. Weinberg

157. G. C. Williams

158. T. E. Willmarth

159. T. H. Davies (consultant)

160. C. H. Hutchison (consultant)

161. I. Perlman (consultant)

162. G. Scatchard (consultant) 
163. H. Miller, Office of I sotope Development, AEC, Washington

164. R. W. McNamee, Union Carbide Corporation, New York

165. R. H. Schuler, Radiation Research Laboratories, Mellon Institute, 4400 Fifth Ave., Pittsburgh 13, Pa.

166. Division of Research and Development, AEC, Washington

167. Research and Development Division, AEC, ORO

168. Boeing Airplane Company

169. Union Carbide Corporation, Chemicals Division (South Charleston)

170. North American Aviation, Inc.

171. Masaharu Kondo, Professor of Chemistry, Radiation Chemistry Laboratory, Tokyo Metropolitan University, 1-950, Fukasawa-cho, Setagaya-ku, Tokyo, Japan

172. M. Daniels, Department of Chemistry, University College of West Indies, Kingston 7, Jamaica

173. J. P. W. Houtman, Reactor Institute Delft, Technische Hogeschool, Delft, The Netherlands

174. Technion, Israel Institute of Technology, Department of Nuclear Science, Haifa, Israel

175. W. T. Smith, Jr., Department of Chemi stry, University of Tennessee, Knoxville

176. J. H. Green, Department of Nuclear and Radiation Chemistry, The University of New South Wales, P.O. Box 1, Kensington, N.S.W., Australia

177. Ingmar Bergstrom, Nobel Institute of Physics, Stockholm 50, Sweden

178-821. Given distribution as shown in TID-4500 (32nd ed.) under Chemistry category (75 copies - OTS) 